U.S. Geological Survey National Water-Quality Assessment Program

\title{
Hydrogeology, Water Chemistry, and Transport Processes in the Zone of Contribution of a Public-Supply Well in Albuquerque, New Mexico, 2007-9
}

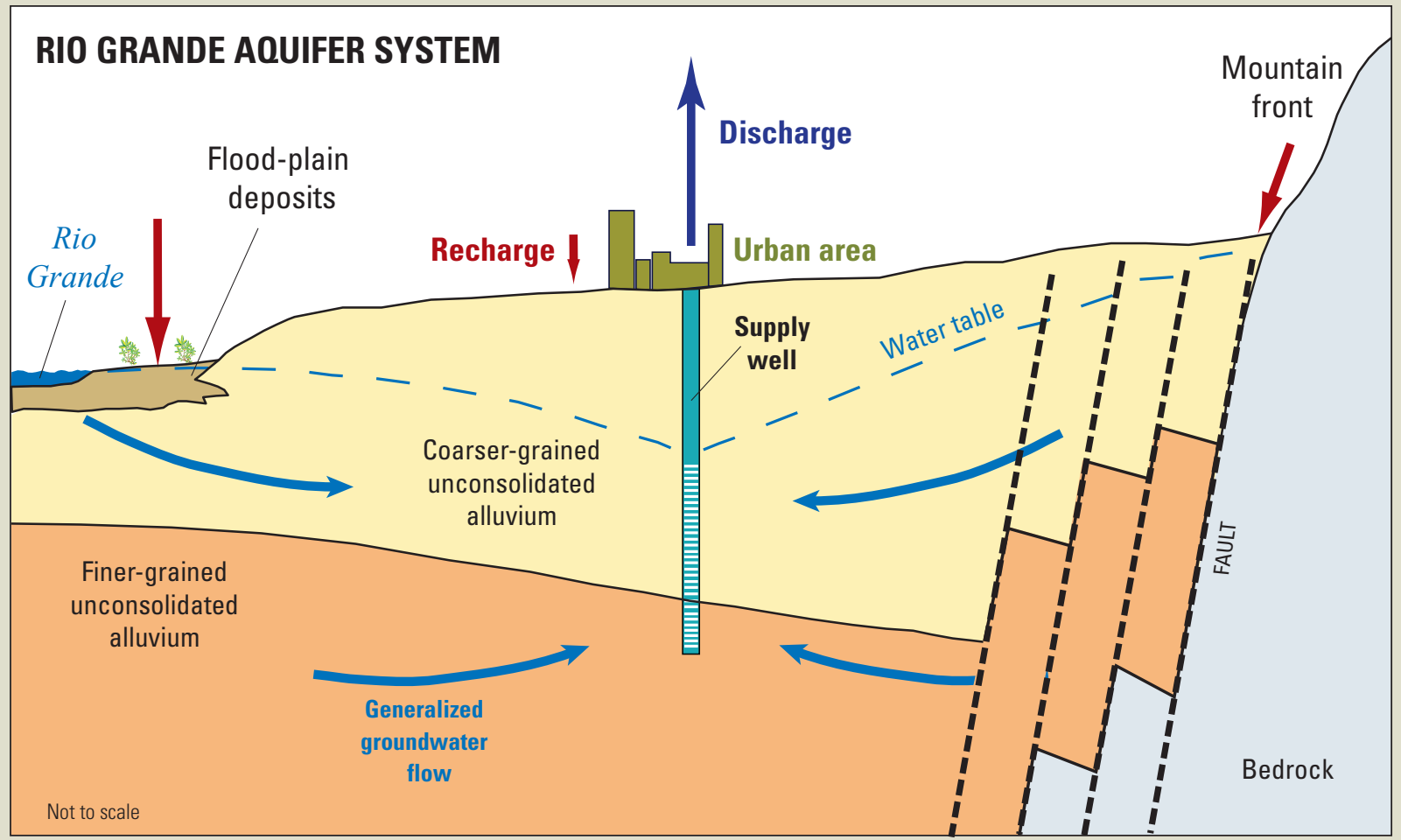

Scientific Investigations Report 2011-5182 



\section{Hydrogeology, Water Chemistry, and Transport Processes in the Zone of Contribution of a Public-Supply Well in Albuquerque, New Mexico, 2007-9}

By Laura M. Bexfield, Bryant C. Jurgens, Dianna M. Crilley, and Scott C. Christenson

U.S. Geological Survey National Water-Quality Assessment Program

Scientific Investigations Report 2011-5182 


\title{
U.S. Department of the Interior \\ KEN SALAZAR, Secretary \\ U.S. Geological Survey \\ Marcia K. McNutt, Director
}

\section{U.S. Geological Survey, Reston, Virginia: 2012}

\author{
This and other USGS information products are available at http://store.usgs.gov/ \\ U.S. Geological Survey \\ Box 25286, Denver Federal Center \\ Denver, CO 80225 \\ To learn about the USGS and its information products visit http://www.usgs.gov/ \\ 1-888-ASK-USGS
}

\author{
Any use of trade, product, or firm names is for descriptive purposes only and does not imply endorsement by the \\ U.S. Government. \\ Although this report is in the public domain, permission must be secured from the individual copyright owners to \\ reproduce any copyrighted materials contained within this report. \\ Suggested citation: \\ Bexfield, L.M., Jurgens, B.C., Crilley, D.M., and Christenson, S.C., 2012, Hydrogeology, water chemistry, and transport \\ processes in the zone of contribution of a public-supply well in Albuquerque, New Mexico, 2007-9: U.S. Geological \\ Survey Scientific Investigations Report 2011-5182, 114 p.
}




\section{Foreword}

The U.S. Geological Survey (USGS) is committed to providing the Nation with reliable scientific information that helps to enhance and protect the overall quality of life and that facilitates effective management of water, biological, energy, and mineral resources (http://www.usgs.gov/). Information on the Nation's water resources is critical to ensuring longterm availability of water that is safe for drinking and recreation and is suitable for industry, irrigation, and fish and wildlife. Population growth and increasing demands for water make the availability of that water, measured in terms of quantity and quality, even more essential to the long-term sustainability of our communities and ecosystems.

The USGS implemented the National Water-Quality Assessment (NAWQA) Program in 1991 to support national, regional, State, and local information needs and decisions related to water-quality management and policy (http://water.usgs.gov/nawqa). The NAWQA Program is designed to answer: What is the quality of our Nation's streams and groundwater? How are conditions changing over time? How do natural features and human activities affect the quality of streams and groundwater, and where are those effects most pronounced? By combining information on water chemistry, physical characteristics, stream habitat, and aquatic life, the NAWQA Program aims to provide science-based insights for current and emerging water issues and priorities. From 1991 to 2001, the NAWQA Program completed interdisciplinary assessments and established a baseline understanding of water-quality conditions in 51 of the Nation's river basins and aquifers, referred to as Study Units (http://water.usgs.gov/nawqa/ studies/study_units.html).

National and regional assessments are ongoing in the second decade (2001-12) of the NAWQA Program as 42 of the 51 Study Units are selectively reassessed. These assessments extend the findings in the Study Units by determining water-quality status and trends at sites that have been consistently monitored for more than a decade, and filling critical gaps in characterizing the quality of surface water and groundwater. For example, increased emphasis has been placed on assessing the quality of source water and finished water associated with many of the Nation's largest community water systems. During the second decade, NAWQA is addressing five national priority topics that build an understanding of how natural features and human activities affect water quality, and establish links between sources of contaminants, the transport of those contaminants through the hydrologic system, and the potential effects of contaminants on humans and aquatic ecosystems. Included are studies on the fate of agricultural chemicals, effects of urbanization on stream ecosystems, bioaccumulation of mercury in stream ecosystems, effects of nutrient enrichment on aquatic ecosystems, and transport of contaminants to public-supply wells. In addition, national syntheses of information on pesticides, volatile organic compounds (VOCs), nutrients, trace elements, and aquatic ecology are continuing.

The USGS aims to disseminate credible, timely, and relevant science information to address practical and effective water-resource management and strategies that protect and restore water quality. We hope this NAWQA publication will provide you with insights and information to meet your needs and will foster increased citizen awareness and involvement in the protection and restoration of our Nation's waters.

The USGS recognizes that a national assessment by a single program cannot address all water-resource issues of interest. External coordination at all levels is critical for cost-effective management, regulation, and conservation of our Nation's water resources. The NAWQA Program, therefore, depends on advice and information from other agencies-Federal, State, regional, interstate, Tribal, and local — as well as nongovernmental organizations, industry, academia, and other stakeholder groups. Your assistance and suggestions are greatly appreciated.

William H. Werkheiser

USGS Associate Director for Water 



\section{Contents}

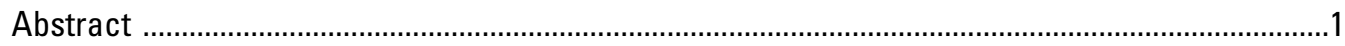

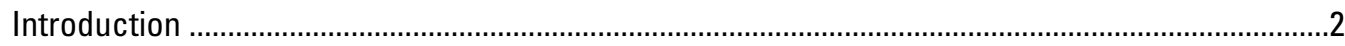

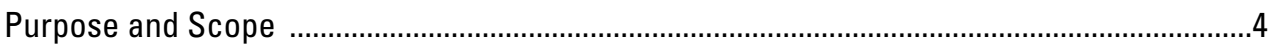

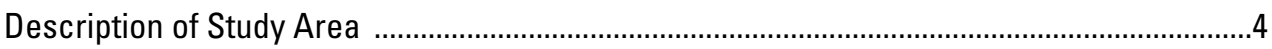

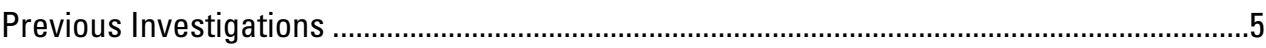

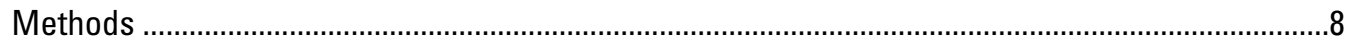

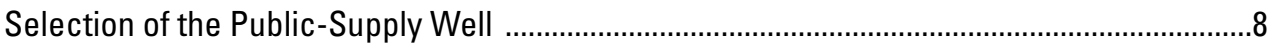

Design of Well Network ....................................................................................................

Drilling, Coring, Geophysical Logging, and Well Installation ..................................................10

Collection of Continuous Water-Level and Specific-Conductance Data ................................11

Collection and Analysis of Water Samples ......................................................................11

Collection of Depth-Dependent Flow and Chemistry Data ..................................................13

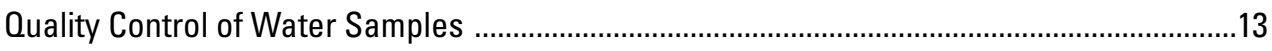

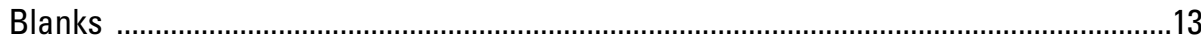

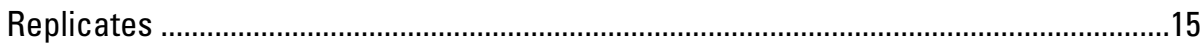

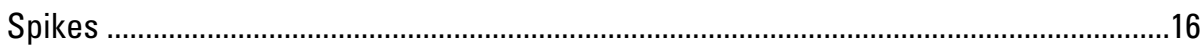

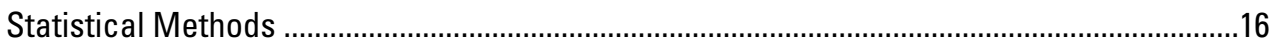

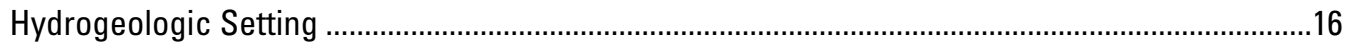

Geology, Mineralogy, and Sediment Chemistry ...................................................................16

Sediment Classification and Aquifer Hydraulic Properties .....................................................17

Groundwater Occurrence and Movement ............................................................................18

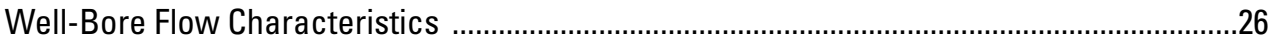

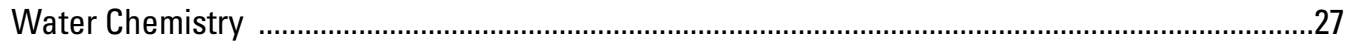

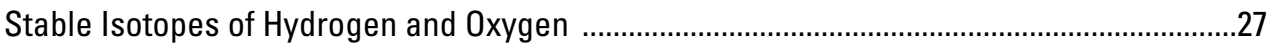

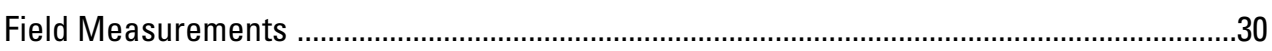

Reduction/Oxidation Conditions .....................................................................................

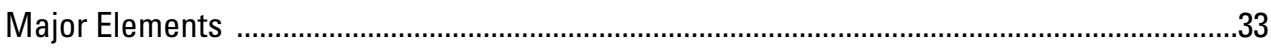

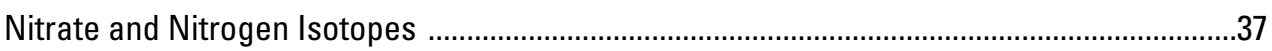

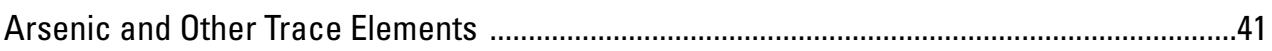

Volatile Organic Compounds .............................................................................................. 44

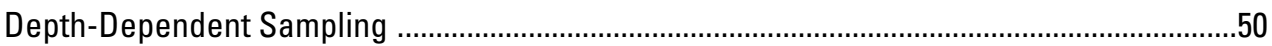

Temporal Variations in Groundwater Chemistry from the Studied Supply Well ......................52

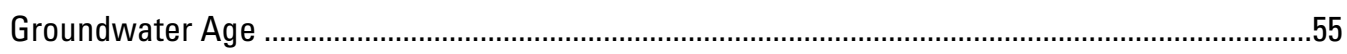

Recharge Temperature, Entrained Air, and Excess Nitrogen Gas .......................................55

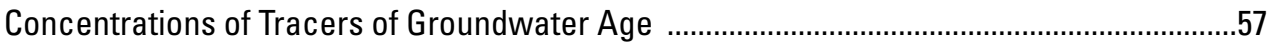

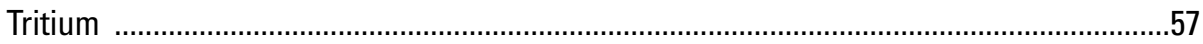

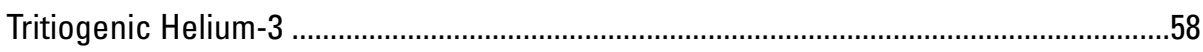

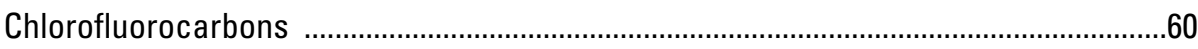

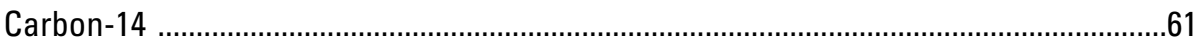

Inverse Geochemical Modeling ........................................................................61

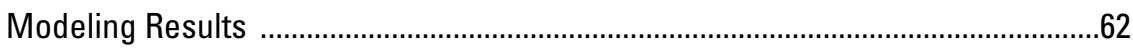

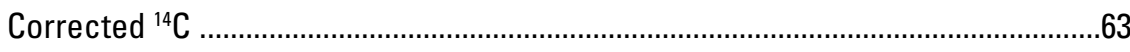

Radiocarbon and Calibrated ${ }^{14} \mathrm{C}$ Calendar Ages ..................................................64 


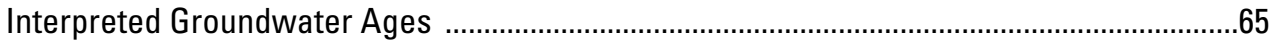

Tritium, CFC-113, and Carbon-14 Input History ……………........................................66

Unsaturated Zone Traveltime ...........................................................................................67

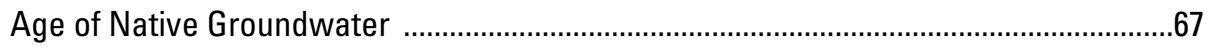

Age of Mixed Groundwater .......................................................................................

Age Distribution for the Studied Supply Well ................................................................70

Processes Affecting Transport of Anthropogenic and Natural Contaminants to the Public-

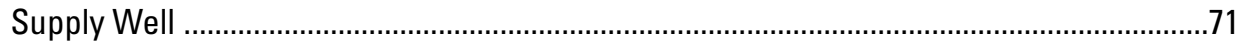

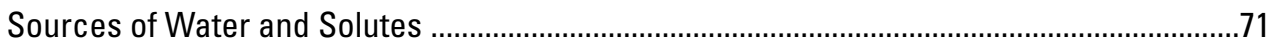

Movement of Water and Solutes to Supply Wells ……….................................................72

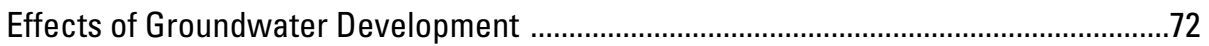

Effects of Geochemical Conditions and Attenuation Reactions .......................................73

Effects of Operation of the Studied Supply Well on Transport of Water and Solutes.............73

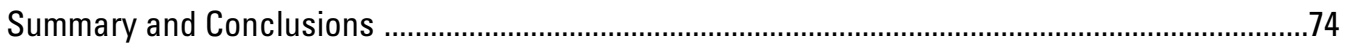

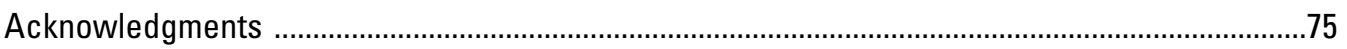

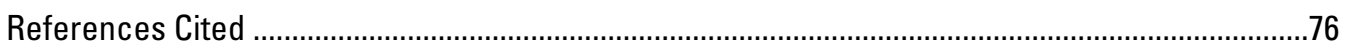

Appendixes

1. Mineralogy and Chemistry of Core Samples ………............................................112

2. Quality-Control Summary for Field Blanks .............................................................114

\section{Figures}

1. Map of features of the regional- and local-scale transport of anthropogenic and natural contaminants (TANC) study areas near Albuquerque in the Middle Rio Grande Basin, New Mexico

2. Map of particle pathlines representing 100-year zones of contribution (1905-2005) to the studied supply well, as simulated by the groundwater-flow model of the regional transport of anthropogenic and natural contaminants (TANC) study area, and locations of known releases of contaminants within the local-scale TANC study area in Albuquerque, New Mexico

3. Map of regional model simulation of hydraulic heads at the water table and production zone in August 2008, and locations of wells installed and sampled for the local-scale transport of anthropogenic and natural contaminants (TANC) study in Albuquerque, New Mexico

4. Diagram of geophysical logs and inferred lithology classes for selected monitoring and public-supply wells within the local-scale transport of anthropogenic and natural contaminants (TANC) study area in Albuquerque, New Mexico

5. Generalized diagrams of regional groundwater flow and of components of the groundwater budget near Albuquerque, New Mexico, under $A$, predevelopment conditions and $B$, modern conditions

6. Graphs of changes in water levels with time in the $A, \mathrm{FP} 1 ; B, \mathrm{FP} 2 ; C, \mathrm{FP} 3$; and $D$, FP4 monitoring well nests drilled for the local-scale transport of anthropogenic and natural contaminants (TANC) study in Albuquerque, New Mexico, October 2008 through September 2009

7. Graph of mean monthly groundwater withdrawals during 2000-7 from selected public-supply wells within the local-scale transport of anthropogenic and natural contaminants (TANC) study area in Albuquerque, New Mexico 
8. Diagram of approximate distribution of flow contributed from various depths of the aquifer to the studied supply well in Albuquerque, New Mexico under $A$, ambient conditions and $B$, pumping conditions

9. Graph of values for oxygen and hydrogen isotopes of groundwater from the localscale transport of anthropogenic and natural contaminants (TANC) study area in Albuquerque, New Mexico

10. Graphs of $A$, specific conductance and $B, \mathrm{pH}$ with depth below the water table in groundwater from the local-scale transport of anthropogenic and natural contaminants (TANC) study area in Albuquerque, New Mexico

11. Graph of dissolved oxygen with depth below the water table in groundwater from the local-scale transport of anthropogenic and natural contaminants (TANC) study area in Albuquerque, New Mexico

12. Piper diagram showing the general chemical composition of groundwater and surface water from the local-scale transport of anthropogenic and natural contaminants (TANC) study area in Albuquerque, New Mexico

13. Graph of chloride and chloride/bromide ratio in groundwater and in surface water from the local-scale transport of anthropogenic and natural contaminants (TANC) study area in Albuquerque, New Mexico

14. Graphs of relations of silica with $A$, depth below the water table, $B$, potassium, and $C$, chloride and of fluoride with $D$, depth below the water table and $E, \mathrm{pH}$ in groundwater from the local-scale transport of anthropogenic and natural contaminants (TANC) study area in Albuquerque, New Mexico

15. Graphs of relations of nitrate with $A$, depth below the water table and $B$, delta nitrogen-15 of nitrate and of $C$, delta oxygen-18 of nitrate with nitrogen-15 of nitrate in groundwater from the local-scale transport of anthropogenic and natural contaminants (TANC) study area in Albuquerque, New Mexico

16. Graphs of relations of delta nitrogen-15 of nitrogen gas with $A$, depth below the water table, $B$, the ratio of argon to nitrogen gas, and $C$, dissolved oxygen in groundwater from the local-scale transport of anthropogenic and natural contaminants (TANC) study area in Albuquerque, New Mexico

17. Graph of relation of estimated initial nitrogen- 15 of nitrate with estimated initial nitrate concentration in groundwater from the local-scale transport of anthropogenic and natural contaminants (TANC) study area in Albuquerque, New Mexico

18. Graphs of relations of arsenic with $A$, depth below the water table, $B, \mathrm{pH}$,

$C$, molybdenum, and $D$, vanadium in groundwater from the local-scale transport of anthropogenic and natural contaminants (TANC) study area in Albuquerque, New Mexico

19. Map showing concentrations of selected volatile organic compounds in groundwater from the local-scale transport of anthropogenic and natural contaminants (TANC) study area in Albuquerque, New Mexico

20. Diagram of concentrations of selected volatile organic compounds in groundwater along $A$, a northwest to southeast section and $B$, a southwest to northeast section in the local-scale transport of anthropogenic and natural contaminants (TANC) study area in Albuquerque, New Mexico

21. Diagram of $A$, vertical distribution of flow in the studied supply well (SSW) and $B$, results for selected constituents in groundwater samples from various depths in the SSW and in adjacent monitoring well nest FP1

22. Piper diagram showing the general chemical composition of multiple samples from the studied supply well (SSW) in the local-scale transport of anthropogenic and natural contaminants (TANC) study area in Albuquerque, New Mexico 
23. Graph of variation in concentrations of selected constituents in samples from the studied supply well (SSW) with duration of pumping

24. Graph of relation between excess nitrogen gas and delta nitrogen-15 of nitrogen gas for groundwater from the local-scale transport of anthropogenic and natural contaminants (TANC) study area in Albuquerque, New Mexico

25. Graph of recharge temperature with depth below the water table in groundwater from the local-scale transport of anthropogenic and natural contaminants (TANC) study area in Albuquerque, New Mexico

26. Graph of tritium with depth below the water table in groundwater from the localscale transport of anthropogenic and natural contaminants (TANC) study area in Albuquerque, New Mexico

27. Graph of recharge temperature, carbon-14 concentration, and tritium activity in samples collected from the studied supply well (SSW) during the month and year indicated

28. Graph of chlorofluorocarbon-113 (CFC-113) with depth below the water table in groundwater from the local-scale transport of anthropogenic and natural contaminants (TANC) study in Albuquerque, New Mexico

29. Graph of relation of carbon-14 concentration with delta carbon-13 in groundwater from the local-scale transport of anthropogenic and natural contaminants (TANC) study area in Albuquerque, New Mexico

30. Graph of carbon-14 content with depth below the water table in groundwater from the local-scale transport of anthropogenic and natural contaminants (TANC) study area in Albuquerque, New Mexico

31. Graph of relation between carbon- $14\left({ }^{14} \mathrm{C}\right)$ and tritium $\left({ }^{3} \mathrm{H}\right)$ in groundwater from the local-scale transport of anthropogenic and natural contaminants (TANC) study area in Albuquerque, New Mexico

32. Graph of input curves of carbon-14, chlorofluorocarbon-113 (CFC-113), and tritium used to interpret ages of groundwater from the local-scale transport of anthropogenic and natural contaminants (TANC) study area in Albuquerque, New Mexico

33. Graph of selected tracer output for dispersion models and binary mixing models, and measured tracers for groundwater from wells MNW4-D1 and SFMW-46 in the local-scale transport of anthropogenic and natural contaminants (TANC) study area in Albuquerque, New Mexico

34. Graph of tritium and carbon-14 output concentrations for three binary mixing models and tracer concentrations measured from the studied supply well (SSW) at different times

35. Graph of seasonal variability of the distribution of ages for two groundwater samples from the studied supply well (SSW) in the local-scale transport of anthropogenic and natural contaminants (TANC) study area in Albuquerque, New Mexico 


\section{Tables}

1. Well completion information, sampling dates, and the suites of analytes sampled for wells installed and (or) sampled for the local-scale transport of anthropogenic and natural contaminants (TANC) study near Albuquerque, New Mexico, 2007-9 .......84

2. Methods of analysis for water samples and suites of analytes sampled from wells for the local-scale transport of anthropogenic and natural contaminants (TANC) study near Albuquerque, New Mexico, 2007-9

3. Values of selected field measurements, inorganic constituents, and isotopes for groundwater samples collected for the local-scale transport of anthropogenic and natural contaminants (TANC) study in Albuquerque, New Mexico, 2007-9

4. Framework for classifying groundwater samples with respect to reduction/ oxidation (redox) conditions

5. Values of selected field measurements and concentrations of constituents used to classify reduction/oxidation (redox) conditions in groundwater samples collected for the local-scale transport of anthropogenic and natural contaminants (TANC) study in Albuquerque, New Mexico, 2007-9

6. Results for selected constituents, isotopes, and calculations related to the investigation of denitrification in groundwater samples collected for the localscale transport of anthropogenic and natural contaminants (TANC) study in Albuquerque, New Mexico, 2007-9

7. Concentrations of selected trace elements in groundwater samples collected for the local-scale transport of anthropogenic and natural contaminants (TANC) study in Albuquerque, New Mexico, 2007-9

8. Summary of results from the U.S. Geological Survey National Water Quality Laboratory (NWOL) for selected volatile organic compounds in groundwater samples collected for the local-scale transport of anthropogenic and natural contaminants (TANC) study in Albuquerque, New Mexic0, 2007-9

9. Results of low-level analysis at the U.S. Geological Survey Chlorofluorocarbon Laboratory for trichloroethylene (TCE) in groundwater from depth-dependent public-supply well samples, local-scale transport of anthropogenic and natural contaminants (TANC) study area, Albuquerque, New Mexico

10. Results for recharge temperature, entrained air, excess nitrogen gas, tritium/ helium-3 dating, chlorofluorocarbon dating, carbon-14 dating, and age classification for groundwater samples collected for the local-scale transport of anthropogenic and natural contaminants (TANC) study area in Albuquerque, New Mexico, 2007-9

11. Sources of recharge considered in inverse geochemical models for the localscale transport of anthropogenic and natural contaminants (TANC) study area in Albuquerque, New Mexico

12. Inverse geochemical modeling results for the local-scale transport of anthropogenic and natural contaminants (TANC) study area in Albuquerque, New Mexic0, 2007-9

13. Interpreted groundwater ages for the local-scale transport of anthropogenic and natural contaminants (TANC) study area in Albuquerque, New Mexico, 2007-9 


\section{Conversion Factors, Datums, and Water-Quality Units}

\section{SI to Inch/Pound}

\begin{tabular}{|c|c|c|}
\hline Multiply & By & To obtain \\
\hline \multicolumn{3}{|c|}{ Length } \\
\hline micrometer $(\mu \mathrm{m})$ & 0.00003937 & inch (in.) \\
\hline centimeter $(\mathrm{cm})$ & 0.3937 & inch (in.) \\
\hline meter (m) & 3.281 & foot $(\mathrm{ft})$ \\
\hline kilometer $(\mathrm{km})$ & 0.6214 & mile (mi) \\
\hline \multicolumn{3}{|c|}{ Area } \\
\hline square kilometer $\left(\mathrm{km}^{2}\right)$ & 247.1 & acre \\
\hline square kilometer $\left(\mathrm{km}^{2}\right)$ & 0.3861 & square mile $\left(\mathrm{mi}^{2}\right)$ \\
\hline \multicolumn{3}{|c|}{ Volume } \\
\hline liter (L) & 0.2642 & gallon (gal) \\
\hline cubic meter $\left(\mathrm{m}^{3}\right)$ & 264.2 & gallon (gal) \\
\hline liter (L) & 61.02 & cubic inch $\left(\mathrm{in}^{3}\right)$ \\
\hline cubic meter $\left(\mathrm{m}^{3}\right)$ & 35.31 & cubic foot $\left(\mathrm{ft}^{3}\right)$ \\
\hline cubic meter $\left(\mathrm{m}^{3}\right)$ & 0.0008107 & acre-foot (acre-ft) \\
\hline \multicolumn{3}{|c|}{ Flow rate } \\
\hline cubic meter per second $\left(\mathrm{m}^{3} / \mathrm{s}\right)$ & 70.07 & acre-foot per day (acre-ft/d) \\
\hline cubic meter per year $\left(\mathrm{m}^{3} / \mathrm{yr}\right)$ & 0.000811 & acre-foot per year (acre-ft/yr) \\
\hline meter per day $(\mathrm{m} / \mathrm{d})$ & 3.281 & foot per day $(\mathrm{ft} / \mathrm{d})$ \\
\hline cubic meter per second $\left(\mathrm{m}^{3} / \mathrm{s}\right)$ & 35.31 & cubic foot per second $\left(\mathrm{ft}^{3} / \mathrm{s}\right)$ \\
\hline liter per second $(\mathrm{L} / \mathrm{s})$ & 15.85 & gallon per minute (gal/min) \\
\hline cubic meter per second $\left(\mathrm{m}^{3} / \mathrm{s}\right)$ & 22.83 & million gallons per day (Mgal/d) \\
\hline \multicolumn{3}{|c|}{ Radioactivity } \\
\hline becquerel per liter $(\mathrm{Bq} / \mathrm{L})$ & 27.027 & picocurie per liter $(\mathrm{pCi} / \mathrm{L})$ \\
\hline \multicolumn{3}{|c|}{ Hydraulic conductivity } \\
\hline meter per day $(\mathrm{m} / \mathrm{d})$ & 3.281 & foot per day (ft/d) \\
\hline \multicolumn{3}{|c|}{ Hydraulic gradient } \\
\hline meter per kilometer $(\mathrm{m} / \mathrm{km})$ & 5.27983 & foot per mile (ft/mi) \\
\hline \multicolumn{3}{|c|}{ Transmissivity* } \\
\hline meter squared per day $\left(\mathrm{m}^{2} / \mathrm{d}\right)$ & 10.76 & foot squared per day $\left(\mathrm{ft}^{2} / \mathrm{d}\right)$ \\
\hline
\end{tabular}

Temperature in degrees Celsius $\left({ }^{\circ} \mathrm{C}\right)$ may be converted to degrees Fahrenheit $\left({ }^{\circ} \mathrm{F}\right)$ as follows:

$$
{ }^{\circ} \mathrm{F}=\left(1.8 \times^{\circ} \mathrm{C}\right)+32
$$

Temperature in degrees Fahrenheit $\left({ }^{\circ} \mathrm{F}\right)$ may be converted to degrees Celsius $\left({ }^{\circ} \mathrm{C}\right)$ as follows:

$$
{ }^{\circ} \mathrm{C}=\left({ }^{\circ} \mathrm{F}-32\right) / 1.8
$$

Vertical coordinate information is referenced to the North American Vertical Datum of 1988 (NAVD 88).

Horizontal coordinate information is referenced to the North American Datum of 1983 (NAD 83). 
Altitude, as used in this report, refers to distance above the vertical datum.

*Transmissivity: The standard unit for transmissivity is cubic foot per day per square foot times foot of aquifer thickness [( $\left.\left.\mathrm{ft}^{3} / \mathrm{d}\right) / \mathrm{ft}^{2}\right] \mathrm{ft}$. In this report, the mathematically reduced form, foot squared per day $\left(\mathrm{ft}^{2} / \mathrm{d}\right)$, is used for convenience.

Specific conductance is given in microsiemens per centimeter at 25 degrees Celsius $(\mu \mathrm{S} / \mathrm{cm}$ at $\left.25^{\circ} \mathrm{C}\right)$.

Concentrations of chemical constituents in water are given either in milligrams per liter (mg/L) or micrograms per liter $(\mu \mathrm{g} / \mathrm{L})$. 



\title{
Hydrogeology, Water Chemistry, and Transport Processes in the Zone of Contribution of a Public-Supply Well in Albuquerque, New Mexico, 2007-9
}

\author{
By Laura M. Bexfield, Bryant C. Jurgens, Dianna M. Crilley, and Scott C. Christenson
}

\section{Abstract}

The National Water-Quality Assessment Program (NAWQA) of the U.S. Geological Survey began a series of groundwater studies in 2001 in representative aquifers across the Nation in order to increase understanding of the factors that affect transport of anthropogenic and natural contaminants (TANC) to public-supply wells. One of 10 regional-scale TANC studies was conducted in the Middle Rio Grande Basin (MRGB) in New Mexico, where a more detailed local-scale study subsequently investigated the hydrogeology, water chemistry, and factors affecting the transport of contaminants in the zone of contribution of one 363-meter $(\mathrm{m})$ deep publicsupply well in Albuquerque. During 2007 through 2009, samples were collected for the local-scale study from 22 monitoring wells and 3 public-supply (supply) wells for analysis of major and trace elements, arsenic speciation, nutrients, dissolved organic carbon, volatile organic compounds (VOCs), dissolved gases, stable isotopes, and tracers of young and old water. To study groundwater chemistry and ages at various depths within the aquifer, the monitoring wells were divided into three categories: (1) each shallow well was screened across the water table or had a screen midpoint within $18.3 \mathrm{~m}$ of the water level in the well; (2) each intermediate well had a screen midpoint between about 27.1 and $79.6 \mathrm{~m}$ below the water level in the well; and (3) each deep well had a screen midpoint about $185 \mathrm{~m}$ or more below the water level in the well.

The 24- $\mathrm{km}^{2}$ study area surrounding the "studied supply well" (SSW), one of the three supply wells, consists of primarily urban land within the MRGB, a deep alluvial basin with an aquifer composed of unconsolidated to moderately consolidated deposits of sand, gravel, silt, and clay. Conditions generally are unconfined, but are semiconfined at depth. Groundwater withdrawals for public supply have substantially changed the primary direction of flow from northeast to southwest under predevelopment conditions, to west to east under modern conditions.

Analysis of age tracers indicates that groundwater from most sampled wells is dominated by old (pre-1950) water, ranging in mean age from about 4,000 years to more than
22,000 years, but includes a fraction of young (post-1950) recharge. Patterns in chemical and isotopic data are consistent with the conclusions that shallow groundwater in the area typically includes a fraction that evaporated prior to recharge and (or) flushed accumulated solutes out of the unsaturated zone during recharge, and that shallow groundwater has mixed to deeper parts of the aquifer, which receives recharge mainly by seepage from the Rio Grande.

Among shallow and intermediate wells that produced water with a fraction of young recharge, that fraction ranged between 1.5 and 46 percent. Samples from the two deep wells had groundwater ages exceeding 18,000 years, with no fraction of young recharge. Two supply wells (including the SSW) had a fraction of young recharge, which ranged between about 3 and 11 percent, despite mean groundwater ages exceeding 10,000 years. The fraction of young recharge to the SSW varied seasonally, probably because seasonal pumping patterns affected local hydraulic gradients and (or) because of flow through the well bore when the SSW is not pumping. Wellbore flow data collected during winter (low-pumping season) indicated that about 61 percent of the water pumped from the SSW entered the well from the intermediate part of the aquifer, and that the remaining 39 percent entered from the deep part of the aquifer.

Volatile organic compounds (VOCs) were detected in samples from most shallow and intermediate monitoring wells and from two of three supply wells, including the SSW. Detected VOCs were primarily chlorinated solvents or their degradation products. Many of the wells in which most of these VOCs were detected are located near known sites of solvent contamination that were targeted for sampling because trichloroethylene (TCE) and cis-1,2-dichloroethylene had been detected in the SSW, and several of these wells may have become contaminated at least partly because of enhanced vertical migration associated with the pumping of and (or) direct migration down deep well bores. Except for TCE in the sample from a shallow monitoring well, all detections of VOCs were at concentrations below Maximum Contaminant Levels (MCLs) set by the U.S. Environmental Protection Agency. Concentrations of all VOCs detected in the supply wells were less than one-tenth of the corresponding MCLs. However, the presence of VOCs in all but deep groundwater, 
Hydrogeology, Water Chemistry, and Transport Processes in the Zone of Contribution of a Public-Supply Well

including the detection of chloroform (a chlorination byproduct) in several shallow wells, indicates that groundwater in the study area commonly is affected by human activities, even to substantial depths.

The only natural contaminant detected at concentrations near or above its MCL was arsenic, which has been detected at elevated concentrations across broad areas of the MRGB. Concentrations of arsenic, present primarily as arsenate, exceeded the MCL of 10 micrograms per liter $(\mu \mathrm{g} / \mathrm{L})$ in water from the two deep wells (one of which had the highest concentration, $35 \mu \mathrm{g} / \mathrm{L}$ ), from one intermediate well, and from two supply wells, including the SSW. Water-quality and solidphase data from this study are consistent with elevated arsenic concentrations in groundwater being related to $\mathrm{pH}$-dependent desorption of arsenic from ferric oxyhydroxides in sediments in deep parts of the aquifer.

Concentrations of nitrate ranged between 1.3 and 5.4 milligrams per liter $(\mathrm{mg} / \mathrm{L})$ in water from shallow wells screened across the water table, but were less than $0.9 \mathrm{mg} / \mathrm{L}$ in water from all but one deeper well. Nitrogen isotopes and chloride/ bromide ratios for shallow wells were consistent with natural soil nitrogen. Nitrate concentrations and nitrogen isotopes indicated that denitrification is occurring at intermediate aquifer depths, and that the progress of the denitrification reaction typically is greatest for wells that include a fraction of groundwater associated with particular recharge sources or with known sites of contamination contributing organic compounds that can provide a carbon source for microbial respiration.

Overall, hydrologic and chemical data from the study area indicate that young recharge is reaching the aquifer across broad areas and is migrating from shallow to intermediate depths of the aquifer as a result of mixing that is associated with human development of groundwater. Consequently, groundwater that human activities in the urban study area have affected is present at depths that are within the screened intervals of public-supply wells, resulting in detections of VOCs and implying greater vulnerability to anthropogenic contamination than might be assumed based on the dominantly old age of the regional groundwater. However, the fractions of old groundwater that public-supply wells produce substantially dilute the anthropogenic contaminants, while contributing natural contaminants (primarily arsenic) to the wells. Based on data from the SSW, vulnerability of public-supply wells to natural and anthropogenic contaminants in the area changes through time, including with seasonal changes in pumping stresses that alter the fractions of young and old water being contributed to wells.

\section{Introduction}

Groundwater is an important source of public drinkingwater supplies across the United States, and particularly in the arid to semiarid Southwest, where the availability of surface-water supplies tends to be relatively limited. In 2000, public-supply withdrawals from basin-fill aquifers in southwestern States (primarily Arizona, California, Nevada, New Mexico, and Utah), including the Middle Rio Grande Basin (MRGB) of central New Mexico, totaled about 5 billion cubic meters $\left(\mathrm{m}^{3}\right)$, or about 23 percent of public-supply withdrawals from all aquifers in the United States (Maupin and Barber, 2005). Characteristics common to most southwestern alluvial basins, such as relatively low recharge rates, thick unsaturated zones, and long groundwater traveltimes, would appear to result in lower intrinsic susceptibility to most contaminants than in other areas of the United States. However, investigations of groundwater quality have commonly shown the presence of anthropogenic contaminants (such as volatile organic compounds (VOCs), pesticides, and elevated concentrations of dissolved solids and nitrate) in shallow groundwater of southwestern alluvial basins (Thiros and others, 2010). Also, natural contaminants such as arsenic have been documented at concentrations near or exceeding U.S. Environmental Protection Agency (USEPA) drinking-water standards in groundwater across broad areas of the Southwest, as a result of common regional factors including the composition of source rocks, long groundwater traveltimes that result in increased rockwater interaction, and the concentrating effects of evapotranspiration (Thiros and others, 2010).

In 2001, the U.S. Geological Survey (USGS) National Water-Quality Assessment (NAWQA) program began a series of groundwater studies in representative aquifers throughout the Nation, including southwestern basin-fill aquifers, in order to better understand the factors that affect transport of anthropogenic and natural contaminants (TANC) to public-supply wells (Eberts and others, 2005). For consistency of results, the TANC studies used the same methods to investigate the sources of contaminants to groundwater, the transport and fate of contaminants within aquifers, and the effects of contaminants on the quality of water produced by public-supply wells in various hydrogeologic settings. In 10 regional-scale TANC studies covering hundreds to thousands of square kilometers $\left(\mathrm{km}^{2}\right)$ (Paschke, 2007; Eberts, 2011), new or updated groundwater-flow models were used to help establish broad relations between various hydrogeologic and land-use variables and the quality of water observed in public-supply wells. A database was created to store values of the variables of interest for the contributing recharge area (CRA) and for the zone of contribution (ZOC) that groundwater-flow models simulated for selected public-supply wells. Paschke and others (2007) defined the CRA as the surface area on the three-dimensional boundary of the groundwater system that delineates the location of water entering the groundwater system that eventually flows to the well and discharges; the ZOC is the three-dimensional volumetric part of the aquifer through which groundwater flows to the discharging well from the CRA.

The hydrogeologic setting and simulation of groundwater flow for the regional-scale TANC study covering about the northern half of the MRGB (fig. 1) are described by Bexfield and others (2011). Of the 10 regional TANC study areas, 6 , including the one within the MRGB, were chosen for more 


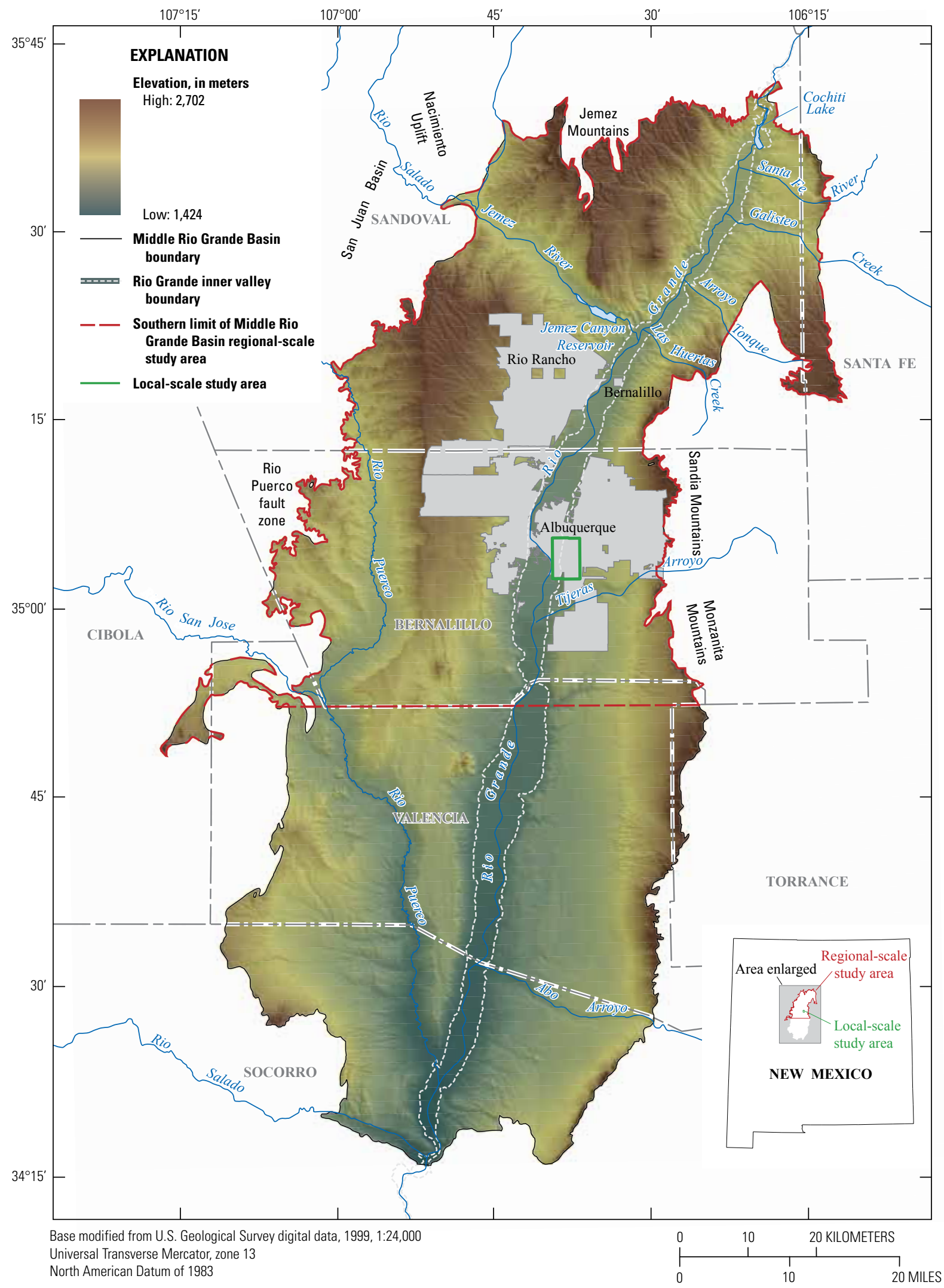

Figure 1. Features of the regional- and local-scale transport of anthropogenic and natural contaminants (TANC) study areas near Albuquerque in the Middle Rio Grande Basin, New Mexico. 
Hydrogeology, Water Chemistry, and Transport Processes in the Zone of Contribution of a Public-Supply Well

detailed, local-scale investigations that covered less than about $200 \mathrm{~km}^{2}$ and focused on specific physical and chemical processes affecting the vulnerability of public-supply wells to contamination.

The hydrogeologic properties, land-use characteristics, and water-quality issues of the Middle Rio Grande Basin are common among southwestern alluvial basins. Elevated concentrations of arsenic and detections of selected VOCs have each resulted in public-supply wells being removed from service in Albuquerque (CH2M Hill, 1991; U.S. Environmental Protection Agency, 2010b, 2010d), the most populous city in the MRGB, which relied on groundwater as its sole source of drinking-water supply through December 2008 (Albuquerque Bernalillo County Water Utility Authority, 2010). Groundwater continues to be a secondary source of public supply for Albuquerque, but a primary source of public supply for most other communities in the basin. An improved understanding of the transport of anthropogenic and natural contaminants to public-supply wells in the MRGB can aid in developing strategies for protecting the drinking-water resource in this basin and in similar southwestern alluvial systems having naturally long groundwater traveltimes, but also having recent contributions of young water associated with human activities and (or) having recent changes in directions of groundwater flow as a result of widespread withdrawals for public supply.

\section{Purpose and Scope}

This report describes the hydrogeology, water chemistry, and factors affecting the transport of selected anthropogenic and natural contaminants in the zone of contribution of a public-supply well in the local-scale TANC study area in Albuquerque, New Mexico. The report documents the design of a local-scale monitoring network and the methods used to collect hydrogeologic and water-quality data from installed and existing wells. The implications of data acquired through geophysical logging, sediment coring, and water-level measurements for hydrogeologic characteristics and groundwater-flow patterns within the study area also are described. This report discusses the use of isotopic and geochemical data to further refine concepts regarding the groundwater system (sources of groundwater recharge, directions of groundwater flow, and the extent of groundwater mixing) and to understand the sources, transport, and fate of contaminants of interest. Selected VOCs, arsenic, and nitrate concentrations from samples collected in 2007-9 are the focus of most discussions of the occurrence and distribution of contaminants. Implications of discrete flow measurements and geochemical data from the studied supply well with respect to the depths at which the aquifer contributes flow to the well are also presented. In addition, this report details the interpretive steps taken to estimate the ages of groundwater by using environmental tracers, and it subsequently presents the distribution of these interpreted ages of groundwater. This report is intended to serve as a foundation for future comparisons among TANC local-scale study areas.

\section{Description of Study Area}

The local-scale TANC study area in Albuquerque, New Mexico covers 24 square kilometers $\left(\mathrm{km}^{2}\right)$ toward the southern end of the 4,486- $\mathrm{km}^{2}$ regional-scale TANC study area, which encompasses about the northern half of the MRGB (fig. 1). In general, the hydrogeology and water quality of the local-scale study area are closely associated with, and determined by, characteristics of the larger regional-scale area, the following description of which is based largely on discussions in Bexfield and others (2011). The MRGB is one of a series of alluvial basins located along the Rio Grande Rift, a generally north-south trending area of Cenozoic crustal extension, and contains alluvial fill up to about 4,500 meters (m) thick. The regional study area is bounded by mountains on the north, northwest, and east, and by a fault zone and structural basin on the west (fig. 1). The land surface slopes downward from the basin margins to the Rio Grande floodplain (also known as the "inner valley"), which ranges to as much as $5.6 \mathrm{~km}$ in width. The alluvial fill of the MRGB is composed primarily of the unconsolidated to moderately consolidated Santa Fe Group deposits of late Oligocene to middle Pleistocene age that were deposited in fluvial, lacustrine, or piedmont-slope environments. These deposits, in combination with hydraulically connected post-Santa Fe Group valley and basin-fill deposits of Pleistocene to Holocene age, form the Santa Fe Group aquifer system of the basin (Thorn and others, 1993).

Most of the MRGB regional study area has a semiarid climate characterized by abundant sunshine, low humidity, and a high rate of evaporation that substantially exceeds the low rate of precipitation. Mean annual precipitation during 1914-2010 at Albuquerque was 22.1 centimeters $(\mathrm{cm}$ ) (Western Regional Climate Center, 2010a), with most precipitation falling July through October as localized, high-intensity thunderstorms of short duration. Annual potential evapotranspiration across the regional study area ranges from about 130 to more than 150 $\mathrm{cm}$ (Thorn and others, 1993). The mean monthly maximum temperature during $1914-2005$ at Albuquerque was $8.4^{\circ} \mathrm{C}$ in January and $33.2^{\circ} \mathrm{C}$ in July; the mean annual temperature was $13.7^{\circ} \mathrm{C}$ (Western Regional Climate Center, 2010b).

The Rio Grande is a perennial stream and is the primary surface-water feature of the regional study area, with a mean annual discharge at Albuquerque of about 37 cubic meters per second $\left(\mathrm{m}^{3} / \mathrm{s}\right)$ for $1974-2009$ (U.S. Geological Survey, Water Resources, 2010). Although the Rio Grande primarily loses water to the aquifer system as it flows from north to south through the regional study area, some northern river sections gain water (McAda and Barroll, 2002; Plummer and others, 2004a). A system of levees and jetty jacks (steel structures designed to trap sediment) directs the course of the Rio Grande, and an upstream series of dams affects the seasonal discharge patterns of the river. From May through October, substantial quantities of water are diverted north of Albuquerque into an extensive network of irrigation canals in the Rio Grande inner valley. Groundwater drains (riverside drains and interior agricultural drains) maintain the water table 
in the inner valley at a sufficient depth below land surface to allow sustained irrigated agriculture without damaging crops. Tributaries that contribute water to the Rio Grande within the regional study area include the Jemez River (fig. 1), which is perennial in most reaches, and several streams and arroyos that contribute ephemeral flow to the Rio Grande only during large storm events. The groundwater drain system and flooddiversion channels also contribute flow to the river.

Covering 83 percent of the regional study area, rangeland is the dominant land-use type, according to the National Land Cover Database (NLCD) dataset for 2001 (U.S. Geological Survey, 2003). Irrigated agriculture is practiced throughout the Rio Grande inner valley and makes up about 3.5 percent of the regional study area. Population growth since about 1940 has led to urbanization of former agricultural land and rangeland in the Albuquerque area of Bernalillo County, resulting in urban turf grass being the second most abundant crop (in terms of planted acreage) in the county in 1992 (Bartolino and Cole, 2002), with alfalfa being the most abundant crop type in the county based on planted acreage during the same year (Kinkel, 1995, app. 4). As of 2001, the NLCD dataset classified about 11 percent of land in the basin as urban. Population in the Albuquerque metropolitan area grew by more than 20 percent between 1990 and 2000, from about 589,000 to 713,000 (U.S. Census Bureau, 2001). In 2000, population density within the City of Albuquerque was about 960 persons $/ \mathrm{km}^{2}$ (U.S. Census Bureau, 2006).

Despite urbanization, water withdrawals during 2000 in the regional study area for irrigated agriculture were about 44 percent of total withdrawals, remaining nearly equal to withdrawals for public supply, which were about 45 percent of total surface-water and groundwater withdrawals (Wilson and others, 2003). Almost 97 percent of the water used for irrigated agriculture was surface water, primarily diverted from the Rio Grande and delivered to areas within the inner valley. Essentially all the water used for public supply in 2000 was groundwater, withdrawn primarily from the Santa Fe Group aquifer system. About 88 percent of groundwater used for public supply in 2000 was withdrawn by the City of Albuquerque (now the Albuquerque Bernalillo County Water Utility Authority), which began diverting surface water from the Rio Grande in 2008 with the intention of eventually meeting most demand with surface water. This change in water-supply strategy arose largely because of concerns about declining water levels in the aquifer (City of Albuquerque, 2003). The Albuquerque Bernalillo County Water Utility Authority plans to continue withdrawing groundwater to supplement supplies during drought and during times of peak demand in the summer (Albuquerque Bernalillo County Water Utility Authority, 2007).

Conditions within the Santa Fe Group aquifer system of the regional study area are generally unconfined, but they are semiconfined at depth. Under conditions preceding development in the area, the principal direction of groundwater flow was north to south through the center of MRGB, with greater components of east-to-west flow near the basin margins. This general flow pattern reflected not only sedimentation patterns in the basin but also the areal distribution of groundwater recharge and discharge. Shallow mountain-front processes and deep subsurface groundwater inflow contribute recharge along the northern and eastern margins of the basin; subsurface inflow also occurs along the western margin of the basin. Along most of its length, the Rio Grande leaks water to the aquifer system, as do some tributary streams and arroyos. Direct infiltration of precipitation across the landscape contributes little or no recharge to the aquifer system. Before the arrival of irrigated agriculture and a substantial population, most discharge occurred through evapotranspiration in riparian areas along the Rio Grande inner valley and the Jemez River (McAda and Barroll, 2002). Since development of irrigated agriculture and urbanized areas, water also recharges the aquifer system through seepage from irrigation canals, irrigated agricultural fields, and septic systems. Irrigated urban landscaping and leaky sewer and (or) water-distribution lines also likely contribute recharge in some areas. Water now also discharges from the system through groundwater drains and groundwater withdrawals for public supply. Large and extensive declines in water levels from sustained groundwater withdrawals in urbanized areas have substantially altered the direction of groundwater flow in the regional study area, particularly in and around Albuquerque, where groundwater now flows from all directions into major pumping centers both east and west of the Rio Grande. Lowered water levels in the aquifer have induced additional inflow from the surface-water system compared with predevelopment conditions.

The local-scale TANC study area (figs. 2 and 3) extends from the Rio Grande inner valley along its western boundary (minimum elevation about 1,505 $\mathrm{m}$ ) onto upland areas along its eastern boundary (maximum elevation about 1,625 m). Except for a small agricultural area in the far southwestern corner, all land in the local-scale study area is urban, including substantial areas of residential, commercial, and industrial land use, along with parks and recreation facilities, college and university grounds, vacant land, and transportation facilities (U.S. Geological Survey, 2003). Nearly all of the local-scale study area is within Albuquerque city limits and is on sewer systems, although currently (2010) and (or) recently unsewered areas are located adjacent to the study area to the south and west. Sites of known releases of contaminants that affect the subsurface within the local-scale study area include current or former facilities for manufacturing, dry-cleaning, and transportation with their leaky storage tanks or formerly improper storage and (or) disposal practices (fig. 2) (U.S. Environmental Protection Agency, 2010b, 2010c; Suzan Arfman, New Mexico Environment Department, Petroleum Storage Tank Bureau, written commun., 2009).

\section{Previous Investigations}

Results of the numerous investigations of the hydrogeology of the MRGB are summarized by Thorn and others (1993) and by Bartolino and Cole (2002); the findings of several studies of groundwater flow and chemistry also are summarized 


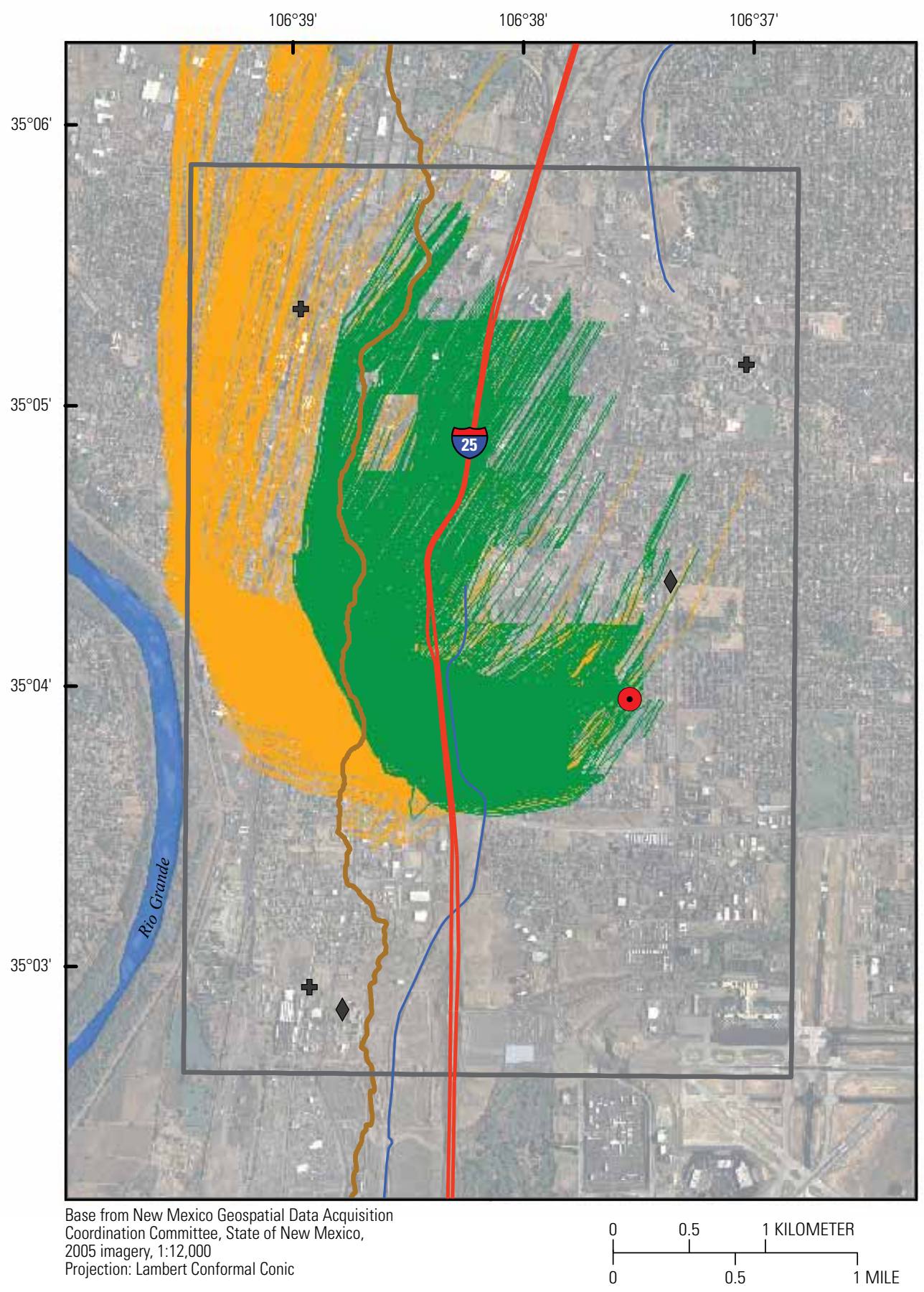

EXPLANATION

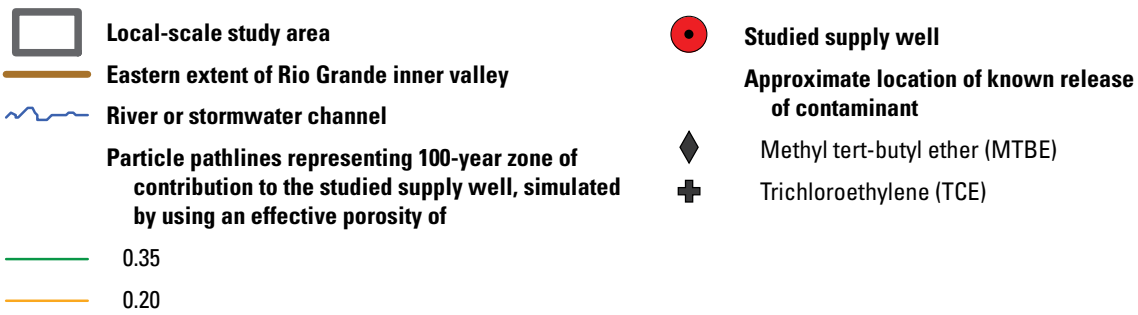

Figure 2. Particle pathlines representing 100-year zones of contribution (1905-2005) to the studied supply well, as simulated by the groundwater-flow model of the regional transport of anthropogenic and natural contaminants (TANC) study area, and locations of known releases of contaminants within the local-scale TANC study area in Albuquerque, New Mexico. 


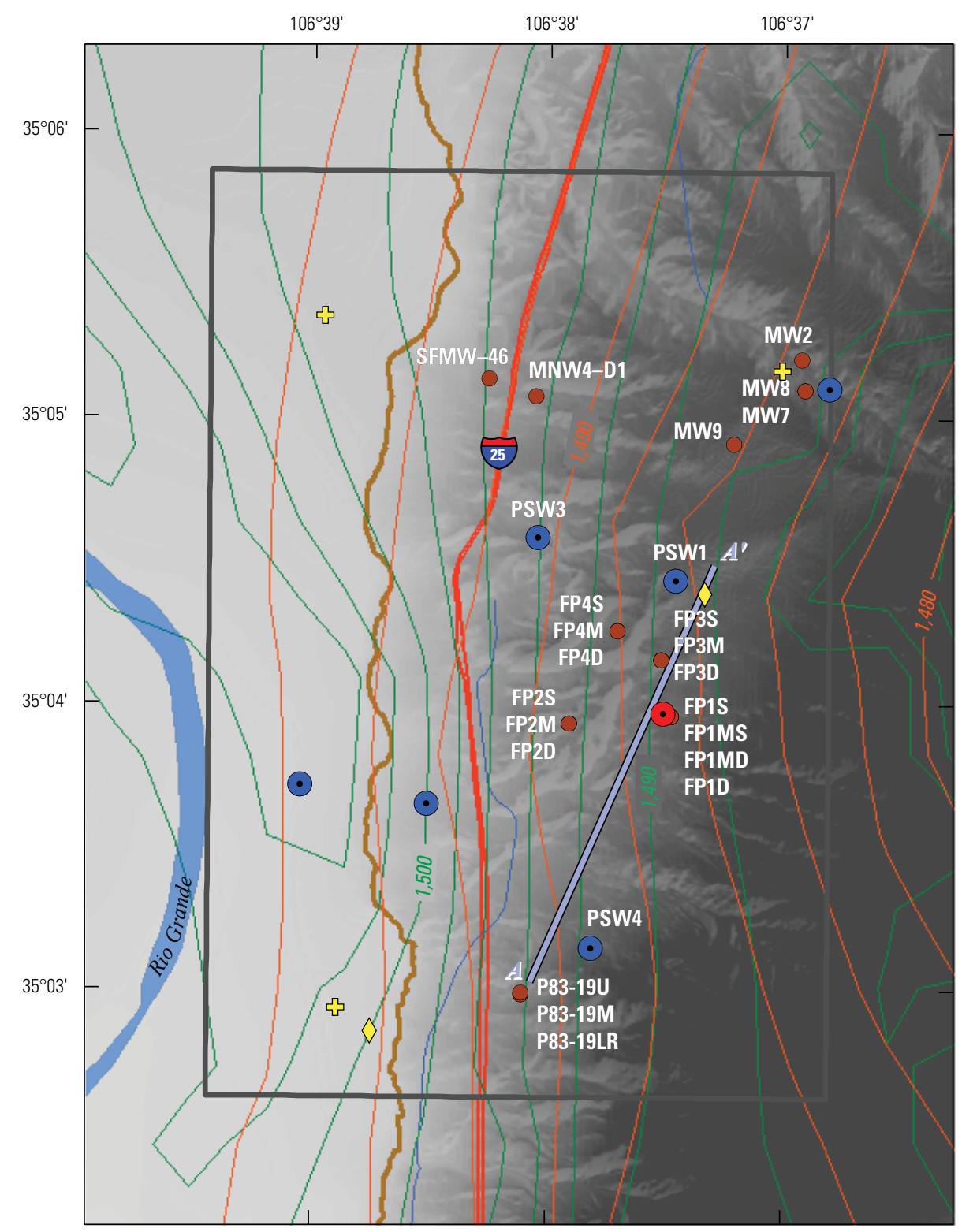

Base from U.S. Geological Survey National Elevation Dataset $1 / 3$ arc-second resolution Projection: Lambert Conformal Conic

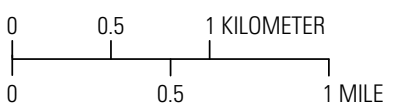

EXPLANATION
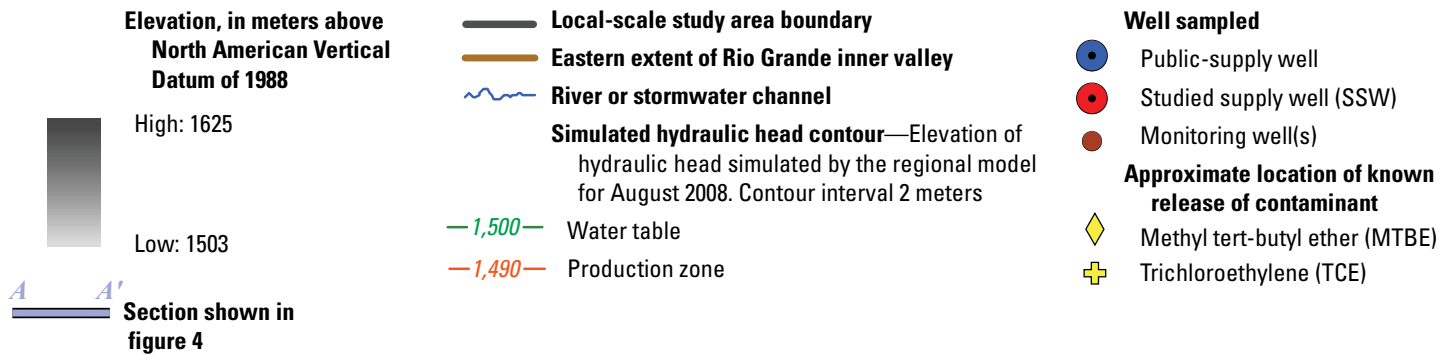

figure 4

Figure 3. Regional model simulation of hydraulic heads at the water table and production zone in August 2008, and locations of wells installed and sampled for the local-scale transport of anthropogenic and natural contaminants (TANC) study in Albuquerque, New Mexico. 
Hydrogeology, Water Chemistry, and Transport Processes in the Zone of Contribution of a Public-Supply Well

in Bexfield (2010) and Bexfield and others (2011). Therefore, only publications that are particularly relevant to the current study are specified here.

Hawley and Haase (1992), Hawley and others (1995), and Connell (2006) have described and (or) mapped characteristics of the sedimentary deposits that form the Santa Fe Group aquifer system in the Albuquerque area. Grauch and others (1999) used isostatic residual gravity to investigate basin structure and sediment thickness. Other than Thorn and others (1993), studies that have contributed to the conceptual model of groundwater flow and (or) the groundwater budget include the groundwater availability study by Bjorklund and Maxwell (1961); the groundwater-flow models of Kernodle and others (1995), McAda and Barroll (2002), and Sanford and others (2004a, 2004b); the water-level maps by Bexfield and Anderholm (2000, 2002a); the study of Rio Grande seepage by Bartolino and Niswonger (1999); the mountain-front recharge study by Anderholm (2001); and the groundwaterquality and age-dating investigation of Plummer and others (2004a, 2004b, 2004c).

Several investigations of groundwater chemistry within the MRGB have studied the implications of water chemistry not only for water use but also for recharge sources and groundwater flow. Basin-wide studies include those by Anderholm (1988) and by Plummer and others (2004a, 2004b, 2004c). The first of these Plummer and others studies delineated hydrochemical zones that generally correspond to various sources of groundwater recharge and used tracers of old (pre-1950) and young (post-1950) water to estimate groundwater recharge dates and traveltimes. Although traveltimes generally were estimated to be on the order of thousands of years, tracers of young water were present in samples from multiple wells in urban areas, indicating that human activities could potentially affect water quality. Investigations of groundwater chemistry that focused on the Albuquerque area include those by Logan (1990), Bexfield and others (1999), and Bexfield and Anderholm (2002b), the last of which included an analysis of temporal variability in groundwater chemistry from numerous public-supply wells, finding substantial variability and (or) statistically significant trends in the chemistry of water from wells in some areas of Albuquerque. Anderholm (1997), McQuillan and Keller (1988), and McQuillan and others (1989) focused on shallow groundwater quality and the likely effects of human activities, concluding that septic-system effluent had affected groundwater quality in some areas. The Anderholm (1997) study of groundwater quality in urban areas of the Rio Grande inner valley near Albuquerque detected pesticides and (or) VOCs at generally low concentrations in several shallow monitoring wells, indicating effects from human activities.

\section{Methods}

As part of the investigation of specific physical and chemical processes that affect the vulnerability of public-supply wells in the Albuquerque study area to contamination, a network of monitoring wells was installed in the vicinity of a single public-supply well selected for detailed study. Hydrogeologic data were collected for selected monitoring wells during their installation, and continuous water-level data were collected from all completed monitoring wells. Samples for analysis of groundwater chemistry were collected from the studied supply well (SSW; fig. 3), from the installed monitoring wells, and from selected other existing wells. The SSW was also sampled for data on depth-dependent flow and chemistry. This section describes the methods used during these various phases of study design and data collection.

\section{Selection of the Public-Supply Well}

The public-supply well selected as the focus of the local-scale TANC study (the SSW) is one of 39 wells sampled in 2005 for a wide range of analytes that are used to characterize groundwater quality across the regional-scale TANC study area (Eberts and others, 2011). The well was selected for study partly because it is among the few in the regionalscale study that produced water having concentrations of a natural contaminant approaching a U.S. Environmental Protection Agency Maximum Contaminant Level (MCL) for drinking water and detections of multiple anthropogenic compounds. This combination of contaminants allowed the study to explore factors relating to the sources and transport of both natural and anthropogenic contaminants. In particular, the arsenic concentration measured in groundwater from the well in 2005 was $9.3 \mu \mathrm{g} / \mathrm{L}$, only slightly lower than the MCL of $10 \mu \mathrm{g} / \mathrm{L}$ that went into effect in 2006 (U.S. Environmental Protection Agency, 2010a). The chlorinated solvents trichloroethylene (TCE) and cis-1,2-dichloroethylene (cis-1,2-DCE) were detected at low concentrations, about two to three orders of magnitude less than their respective MCLs; the gasoline oxygenate methyl tert-butyl ether (MTBE), for which no MCL has been established, was detected at a similar concentration. Although the concentrations at which these VOCs were detected are not near health-based standards for drinking water, the mere presence of these compounds indicates that the SSW is vulnerable to contamination associated with human activities.

The SSW was also selected for investigation because it was among the highest-producing wells in the area around the time of sampling in 2005. Another reason for selecting this well was that it has completion characteristics that are common to public-supply wells in the region. At a median annual groundwater withdrawal of nearly 1.7 million cubic meters $\left(\mathrm{m}^{3}\right)$, withdrawal from the selected well was among the top 25 percent of reported withdrawals for public-supply wells within the TANC regional study area during 1999-2003. Typical of the wells operated by local municipalities, the well (drilled in 1973) has a casing $41.4 \mathrm{~cm}$ in diameter and a nearly continuous screened interval that begins tens of meters below the water table and extends a couple hundred meters or more in depth. In particular, the SSW is cased to $363 \mathrm{~m}$ below land 
surface (mbls); the screened interval, which is surrounded by a gravel pack, extends from 107 to $359 \mathrm{mbls}$, or about 31 to $283 \mathrm{~m}$ below the static water level of $75.8 \mathrm{~m}$ that the USGS measured in 2007 (table 1 at end of report). Lastly, the well was selected for study because it was simulated by the groundwater-flow model of Bexfield and others (2011) to receive recharge from areas varying from relatively high to relatively low intrinsic susceptibility based on depth to water. Like most public-supply wells in the area, the SSW is located in an upland area generally believed to have low intrinsic susceptibility to groundwater contamination by human activities at the land surface because of the relatively large thickness of its unsaturated zone, typically exceeding $60 \mathrm{~m}$; however, the well also is located near the inner valley, where the unsaturated zone is substantially thinner.

The groundwater-flow model documented by Bexfield and others (2011) for the regional TANC study area was used to simulate particle pathlines representing a ZOC to the SSW during the 100 years prior to 2005 (fig. 2). When an assumed effective porosity of 0.35 was used to model the aquifer of the MRGB, based on published values for sand aquifers and on laboratory analysis of local aquifer sediments (as described in the following "Geology, Mineralogy, and Sediment Chemistry" section), the model provided a reasonable representation of the groundwater velocity of most flow paths, given available age-tracer data (Bexfield and others, 2011). The resulting ZOC to the SSW within the past 100 years (1905-2005) includes both inner-valley and upland areas (fig. 2). Land use in much of this 100 -year ZOC has been urban since as early as 1935 (Hester, 2006) and likely was previously a mixture of agricultural land in the inner valley and undeveloped rangeland in upland areas. The use of effective porosity values lower than 0.35 , which probably are more representative of the upper range of groundwater velocities that result from local heterogeneity of the sedimentary deposits (Bexfield and others, 2011), leads to simulated 100 -year ZOCs that have larger areas located within the inner valley; see, for example, the ZOC for an effective porosity of 0.20 (fig. 2). Such ZOCs as are shown in figure 2 represent only the three-dimensional volumetric part of the aquifer through which groundwater flows to the discharging well; they do not identify the specific areas on the land surface at which recharge may have occurred during the simulated time period.

\section{Design of Well Network}

The network of wells from which data were collected as part of the local-scale TANC study included both newly installed and existing wells (fig. 3; table 1). Locations for newly installed monitoring wells fall within the simulated 100 -year ZOC of the SSW for an effective porosity of 0.35 (figs. 2 and 3). The selected locations were intended to allow collection of data on groundwater levels and on chemistry along likely paths of groundwater flow to the supply well. These paths included those existing before and after groundwater withdrawals had substantially altered flow directions in the production zone of the aquifer (depths across which most public-supply wells are screened) from primarily northeastto-southwest to primarily west-to-east. Given the dense urban development in parts of the local-scale study area and the space that drilling equipment capable of reaching the depths necessary for installing the monitoring wells required, factors such as drilling permission and physical access also partly dictated the locations of the wells.

Monitoring wells were installed in two phases. During the first phase, 10 wells were installed at three flow-path (FP) locations during February through April 2007. At each location, three to four individual monitoring wells were nested in a single borehole. The FP1 nest (fig. 3), consisting of 1 well screened across the water table and 3 wells screened within the open interval of the SSW, was installed about 33 m east of the SSW. This placement allowed measurement of hydraulic heads and groundwater chemistry from relatively discrete aquifer intervals so that the data could be compared with data from the SSW, which are integrated over a large aquifer interval. The FP2 nest, consisting of 1 well screened across the water table and 2 wells screened near the top of the open interval of the SSW, was installed about $625 \mathrm{~m}$ west of the SSW, with the intent of intersecting a flow path representing recent directions of regional groundwater flow toward the SSW. The FP3 nest, also consisting of 1 well screened across the water table and 2 wells screened near the top of the open interval of the SSW, was installed about $360 \mathrm{~m}$ north of the SSW, with the intent of intersecting a flow path representing predevelopment directions of regional groundwater flow toward the SSW.

During the second phase of installing the monitoring wells, 3 wells were installed at a single site in September 2008. This FP4 nest, consisting of 1 well screened across the water table and 2 wells screened near the top of the open interval of the SSW, was installed about $625 \mathrm{~m}$ northwest of the SSW (fig. 3). The location of this nest was selected in an attempt to intersect a likely path of groundwater flow to the SSW that was tentatively identified primarily from groundwater chemistry obtained during June 2007 through February 2008 from the 10 previously installed monitoring wells (nests FP1-3) and from 9 monitoring wells that existed before the TANC study began (existing monitoring wells). The 9 existing monitoring wells (MW2, MW7, MW8, MW9, SFMW-46, MNW4-D1, P83-19U, P83-19M, and P83-19LR) (fig. 3), considered part of the local-scale TANC well network, were selected to enable the study to characterize the chemistry of groundwater moving in the general direction of the SSW from three known sites of groundwater contaminated with chlorinated solvents, including TCE, which was detected in a groundwater sample collected from the SSW in July 2005. When the FP4 monitoring wells were sampled for groundwater chemistry in November 2008, samples also were collected from 2 public-supply wells along the same general flow path. Therefore, the final network of 25 wells sampled for the localscale TANC study consisted of the SSW, 2 other public-supply wells, 9 existing monitoring wells at 8 locations, and 13 newly installed monitoring wells at 4 locations (nests FP1-4) (fig. 3). 
To facilitate interpretation and discussion of groundwater data, the study grouped the wells included in the final network into four categories based on well type (monitoring or public supply) and the depths of the aquifer across which they are screened. The shallow wells are monitoring wells screened across the water table (6 wells, further identified as shallow (water-table) wells) or having a screened interval that, although not intersecting the water table, has a midpoint within about $18.3 \mathrm{~m}$ of the water level in the well ( 1 well). The 13 intermediate wells are monitoring wells having a screened interval with a midpoint between about 27.1 and $79.5 \mathrm{~m}$ below the water level in the well. The 2 deep wells are monitoring wells having a screened interval with a midpoint about $185 \mathrm{~m}$ or more below the water level in the well. The 3 supply wells are the public-supply wells (including the SSW), which have screened intervals spanning depths that include at least the categories of intermediate and of deep wells. The screened intervals of the supply wells are at least $190 \mathrm{~m}$ in length, whereas the saturated screened intervals of the monitoring wells are all less than about $21.3 \mathrm{~m}$ in length, and generally no more than about $12.2 \mathrm{~m}$ in length.

\section{Drilling, Coring, Geophysical Logging, and Well Installation}

The USGS Rocky Mountain Drilling Unit (Denver, Colorado) performed all drilling and installation of wells. Boreholes were as much as $29.2 \mathrm{~cm}$ in diameter and were drilled by using the mud-rotary method, which employs circulation of a water-bentonite mix to remove drill cuttings and to help maintain borehole stability. All drilling equipment was steamcleaned between drill sites to prevent cross-contamination. Borehole depths were selected to focus on the upper 75-80 $\mathrm{m}$ of the aquifer, where anthropogenic contaminants originating at or near the land surface were most likely to be present. Based on earlier studies of arsenic occurrence (by Bexfield and Plummer [2003] and Plummer and others [2004a]) and on cost considerations, only one borehole was drilled to depths greater than $80 \mathrm{~m}$ that would most likely contribute groundwater with high arsenic concentrations to the SSW.

The three or four monitoring wells installed in the borehole at each flow-path site were constructed of $5.1-\mathrm{cm}-$ diameter schedule 80 polyvinyl chloride blank casing with $5.1-\mathrm{cm}$-diameter stainless steel screens (slot size, $0.025 \mathrm{~cm}$ ) and sumps. Screened intervals were selected to span either the water table or the thickness of a selected deposit of relatively coarse-grained sediments, as determined primarily from geophysical logs of the boreholes. Screened intervals (including unsaturated intervals in wells screened across the water table) ranged from 9.1 to $30.5 \mathrm{~m}$ in length, depending on the thickness of the targeted coarse-grained deposit and, for water-table wells, depending on the potential for fluctuation and (or) decline of the water-table. A sand pack was installed adjacent to each screened interval, extending from as much as $5 \mathrm{~m}$ below the bottom of the screen to generally about $10 \mathrm{~m}$ or less above the top of the screen. Individual monitoring wells within each borehole were hydraulically isolated from one another by sealing the annular space with bentonite at least $6 \mathrm{~m}$ in thickness. The well nests were sealed by filling the borehole from above the uppermost sand pack to the land surface with bentonite. When possible, the individual monitoring wells were developed (procedure to ensure connection with the aquifer) by air injection; when not possible (in wells screened relatively close to the water table), bailing was used instead. After development, locking caps were installed on each individual monitoring well and a locking steel protective cover was placed over each nest; concrete pads were installed around each protective cover and were sloped to direct precipitation and (or) irrigation water away from the well nest.

Although driller's logs were recorded and drill cuttings were collected at 3-m intervals and archived to aid in determining lithology, geophysical logs (particularly shortnormal resistivity logs) collected by a private contractor in each borehole were used as the primary guide for identifying and selecting relatively coarse-grained deposits at which well screens would be placed. The resistivity logs were also used to correlate sedimentary deposits across boreholes so that the same coarse-grained deposit could be screened in multiple locations when desired. In addition to resistivity logs, the geophysical logs collected at all sites were caliper, natural gamma, and spontaneous potential logs (log types are described in Keys [1990]); these logs were collected by using a probe that measures differences in electric potential (resistivity and spontaneous potential $\operatorname{logs}$ ), and a probe that measures natural gamma radiation (natural gamma log) and borehole diameter (caliper $\log$ ). Density, fluid resistivity, neutron, and sonic logs were collected at only some sites; these logs were collected by using a probe with a gamma radiation source and detector (density log), a probe that measures differences in electric potential (fluid resistivity log), a probe with a neutron source and detector (neutron log), and a probe that transmits and receives acoustic waves (sonic log). Where available, the sonic $\log$ was used to aid in identifying the water table. A laboratory description of the drill cuttings from the nearly $368-\mathrm{m}$ FP1 borehole was used in combination with the resistivity logs to establish textural categories, which have been used in a groundwater-flow model for the local-scale TANC study area (Charles Heywood, U.S. Geological Survey, written commun., 2010).

Core samples were collected from the FP1 and FP3 boreholes in March 2007 to characterize the mineralogy, chemistry, and physical properties of the sedimentary deposits at various depths between the water table and the bottom of the SSW. Depths for core collection generally were targeted to range within the intervals at which monitoring well screens were likely to be placed, based on existing geophysical logs, but two samples from the FP1 borehole were collected from depths that were almost entirely below the corresponding screened intervals. The boreholes and depths from which core samples were obtained are listed in appendix 1, table 1-1. Samples were collected by using a wire-line split-barrel 
sampler 3.0- to 4.6- $\mathrm{m}$ in length with an inside diameter of about $7.9 \mathrm{~cm}$. Immediately after core sections were retrieved from the borehole, they were transferred to a nitrogen-filled sampling chamber, where subsamples were sealed in glass jars to minimize exposure to the atmosphere before being sent for laboratory analysis. General physical characteristics of the core samples (including grain size, sorting, and color of sediments) were recorded on site. Laboratory analysis of core samples included determination of moisture content, mineralogy (by X-ray diffraction), and carbon content. Acid extractions were used to quantify the abundance of selected major and trace elements and to determine iron speciation in grain coatings or other mineral phases, as well as to quantify the presence of acid-volatile sulfides and pyritic sulfur. In addition, experiments were conducted to determine the availability of arsenic through desorption from aquifer sediments. Laboratory methods and results of sample analysis are presented in appendix 1 .

\section{Collection of Continuous Water-Level and Specific-Conductance Data}

Continuous water-level monitors were installed in all 13 FP monitoring wells shortly after well completion to evaluate changes in hydraulic heads and in vertical hydraulic gradients as a result of daily and seasonal stresses on the aquifer resulting from the pumping of public-supply wells in the local-scale TANC study area. Hourly water-level, watertemperature, and specific-conductance data were recorded in the shallow (water-table) wells at the FP1, FP2, and FP3 sites from January or March 2008 through September 2010 by using In-Situ Aqua TROLL ${ }^{\circledR} 200$ instruments consisting of a vented pressure transducer, conductivity sensor, temperature sensor, and data logger. In-Situ Level TROLL ${ }^{\circledR} 500$ instruments consisting of a vented pressure transducer, temperature sensor, and data logger were used to measure and record hourly water-level and water-temperature data in the seven intermediate or deep monitoring wells at the FP1, FP2, and FP3 sites from January or March 2008 through September 2010, and in all three monitoring wells at the FP4 site from January 2009 through September 2010. Differences in contemporaneous water-level data among individual monitoring wells confirmed that the well-installation methods had been effective in isolating each well completion from others at the same FP site.

The continuous water-level and water-quality instruments in the FP monitoring wells were serviced quarterly and checked for sensor function, fouling, and calibration according to USGS quality-assurance and quality-control protocols (Wagner and others, 2006). The silicon strain gage pressure sensors (full pressure range 0 to 206.84 kilopascal) used to measure continuous water levels were corrected for instrument drift using contemporaneous independent waterlevel measurements made manually at each visit by using a calibrated Solinst ${ }^{@} 101$ water-level meter. A three-point temperature calibration check was performed annually on all temperature sensors, with readings checked against a calibration thermometer certified by the National Institute of Standards and Technology. A two-point specific-conductance calibration check was performed during each site visit on the 4-electrode-cell conductivity sensors, with readings checked against calibration standard solutions appropriate to the range of specific conductance observed for each well. Recalibration of a conductivity sensor was performed only if the sensor reading was more than 3 percent greater than the concentration of the standard solution. The variability of specific conductance and temperature with depth was measured within the saturated screened interval of each shallow (water-table) well during multiple site visits; the data were collected at intervals of 0.6 to 1.5 meters by using a calibrated Solinst ${ }^{\circledR} 107$ TLC meter. Data downloaded from the continuous water-level and water-quality instruments were processed, reviewed, and loaded into the USGS National Water Information System (NWIS) database (http://waterdata.usgs.gov/nm/nwis/), where independent water-level measurements recorded during each site visit were also stored.

\section{Collection and Analysis of Water Samples}

Water samples were collected from the local-scale TANC study well network during June 2007 through May 2009, with most wells being sampled only once (table 1 ). With a few exceptions, every analyte listed in table 2 (at end of report) was included in the first sampling of an individual well, which occurred in June 2007, December 2007 to February 2008, or November 2008 (table 1). This standard suite of analytes included field measurements, major and trace elements, arsenic speciation, low-level perchlorate, nutrients, ultraviolet absorbance, dissolved organic carbon (DOC), VOCs (including low-level analysis), radon, radium, dissolved gases, stable isotopes, and tracers of young and old water. In some cases, radon was not collected because of logistical considerations related to sample holding time. Analysis of tritium/helium-3 $\left({ }^{3} \mathrm{H} /{ }^{3} \mathrm{He}\right)$ for age-dating purposes was not conducted for some wells at which the helium content was too high to allow for age dating by this method. Selected monitoring wells were sampled a second time in November 2008 by using an abbreviated suite of analytes (tables 1 and 2) to evaluate potential temporal changes in groundwater chemistry and (or) to replace samples that had not been successfully collected and analyzed during the original sampling event.

For the local-scale TANC study, water samples were collected from the SSW during five sampling events by using four differing suites of analytes (tables 1 and 2). In June 2007, the well was sampled for the standard suite of analytes. In December 2007, depth-dependent samples were collected for the same suite of analytes by methods detailed in the following section. In February 2008, eight sample sets were collected for an abbreviated suite of analytes during a 10-hour period for a time-dependent sampling event to investigate short-term 
temporal changes in the chemistry of groundwater produced by the SSW. In November 2008, the well was sampled for a different abbreviated suite of analytes to investigate longer term temporal changes (relative to previously collected samples). Yet another abbreviated suite of analytes was included in a May 2009 time-dependent sampling event during which six sample sets were collected over a 64-hour period.

Groundwater samples were collected in accordance with procedures described in Koterba and others (1995) and in the USGS National Field Manual (U.S. Geological Survey, variously dated). With the exception of depth-dependent samples, samples from supply wells were collected by using the dedicated turbine pump; sample lines made of polytetrafluoroethylene (PTFE, hereafter referred to as Teflon $\left[{ }^{\odot}\right.$ DuPont $\left.^{\mathrm{TM}}\right]$ ) and nylon were attached to an existing tap located on the discharge line from the wellhead, prior to any water treatment. Samples from monitoring wells were collected by using a submersible pump that was lowered into the well and connected directly to Teflon and nylon lines. Three different types of submersible pumps were used over the course of sampling (three individual Bennett pumps, a Grundfos Rediflo 2, and a Proactive SS MegaMonsoon); the choice of pump (table 1) for an individual monitoring well depended partly on the depth to water and on the well diameter. For both public-supply and monitoring wells, at least three casing volumes of water were purged from the well before sampling. Water samples were collected after field measurements of water temperature, specific conductance (SC), $\mathrm{pH}$, dissolved oxygen (DO), and turbidity had stabilized.

For the collection of most samples, water was routed through only Teflon lines to a sample chamber inside a mobile laboratory, where the samples were filtered (if required), bottled, and preserved (if required). Samples collected for analysis of alkalinity, major and trace elements, arsenic speciation, low-level perchlorate, nutrients, ultraviolet absorbance, DOC, radium, nitrogen and oxygen isotopes in dissolved nitrate, and carbon isotopes were filtered with a 0.45 -micrometer capsule filter. Major- and trace-element and radium samples were preserved with nitric acid; arsenic-speciation samples were preserved with ethylenediaminetetraacetic acid; DOC samples were preserved with sulfuric acid; VOC samples were preserved with hydrochloric acid; and samples for nitrogen and oxygen isotopes in dissolved nitrate were preserved with sodium hydroxide. Radon-222 samples were collected outside the mobile laboratory, before contact with the atmosphere, in a syringe used to inject the sample into a mineraloil-based scintillation solution in a 20-milliliter glass vial. For the collection of samples analyzed for ${ }^{3} \mathrm{H} /{ }^{3} \mathrm{He}$, nitrogen isotopes of nitrogen gas, dissolved gases, low-level VOCs, and chlorofluorocarbons (CFCs), water was routed through only nylon lines to a sample location outside the mobile laboratory, where the samples were bottled or $\left(\right.$ for $\left.{ }^{3} \mathrm{H} /{ }^{3} \mathrm{He}\right)$ sealed in copper tubes before contact with the atmosphere. Samples for nitrogen isotopes of nitrogen gas were preserved with sodium hydroxide. After sample collection at each well was completed, all sample equipment was cleaned according to standard NAWQA procedures that include the use of phosphate-free liquid soap, deionized water, and methanol, although methanol was not used in cleaning of the nylon sample line.

Laboratory results for every type of analyte except lowlevel VOCs were entered into the USGS NWIS database. For each type of analyte, table 2 lists the analyzing laboratory and the references that describe the laboratory methods. For most analytes, the laboratory reports a chemical concentration in water in milligrams per liter $(\mathrm{mg} / \mathrm{L})$ or micrograms per liter $(\mu \mathrm{g} / \mathrm{L})$. Radon, radium, and tritium $\left({ }^{3} \mathrm{H}\right)$ results are reported by the laboratory in picocuries per liter $(\mathrm{pCi} / \mathrm{L})$. For this study, ${ }^{3} \mathrm{H}$ values reported by the laboratory were converted to tritium units (TU). Results for stable isotopes of hydrogen, oxygen, nitrogen, and carbon are reported as the ratio of the heavy to the light isotope (designated by " $\delta$ " [delta]) in units of per mil (\% or per thousand) relative to a defined isotopic standard. For delta deuterium $(\delta D)$ and delta oxygen-18 $\left(\delta^{18} \mathrm{O}\right)$, values are reported relative to Vienna Standard Mean Ocean Water (VSMOW). For delta nitrogen-15 $\left(\delta^{15} \mathrm{~N}\right)$, values are reported relative to nitrogen gas in air. For delta carbon- $13\left(\delta^{13} \mathrm{C}\right)$, values are reported relative to the Vienna Pee Dee belemnite (VPDB) standard. Laboratory values for carbon-14 $\left({ }^{14} \mathrm{C}\right)$ are normalized to a common $\delta^{13} \mathrm{C}$ value of -25 per mil (VPDB) and reported as percent modern (PM). For this study, the reported ${ }^{14} \mathrm{C}$ concentrations were converted to nonnormalized values in units of percent of modern carbon (pmC) by using the equation provided in Plummer and others (2004a). Details on the laboratory units and applications of the analytes used in estimation of the ages of groundwater are provided in the section of this report entitled "Groundwater Age".

The USGS National Water Quality Laboratory (NWQL) reports concentrations in water as quantitative, estimated (semiquantitative), or censored (nonquantitative), as described in detail in Childress and others (1999). Quantitative results are reported with no accompanying remark and are equal to or greater than the laboratory reporting level (LRL). The LRL is defined as two times the long-term method detection level (LT-MDL), where the LT-MDL is set to limit the chance of reporting a false positive (a reported detection for a sample when the analyte of interest is not actually present) to no greater than 1 percent. In general, when an analyte is not detected or is detected at a concentration less than the LT-MDL, the laboratory reports the analyte as less than (remark code of " $<$ ") the LRL, which limits the chance of a false negative result (not detecting the analyte when it is actually present in the sample) to no greater than 1 percent. Results for analytes that are detected at concentrations between the LT-MDL and the LRL are reported as estimated (remark code of "E"). For laboratory methods classified by the NWQL as "information-rich," estimated concentrations are reported even for analytes that are detected at concentrations below the LT-MDL. Such laboratory methods include the method used in this study for the analysis of VOCs.

For the radiological analytes radon-222, radium-226, radium-228, and ${ }^{3} \mathrm{H}$, laboratory reporting methods are 
described by McCurdy and others (2008). These reporting methods apply to all three laboratories that measured values of these analytes (table 2). Tables in this report that include the laboratory results for these analytes also include laboratory measures of the uncertainty of those results.

\section{Collection of Depth-Dependent Flow and Chemistry Data}

Depth-dependent flow data were collected in the SSW under both ambient (nonpumping) and pumping conditions in order to determine the depths at which groundwater was entering or leaving the well screen and at what rate. Flow direction and velocity were measured at $6.1-\mathrm{m}$ intervals throughout the length of screened interval (except below about $352 \mathrm{~m}$ in depth because of debris collection toward the bottom of the well) by using an electromagnetic flowmeter (EMFM), which also recorded temperature and fluid resistivity (Gregory Stanton, U.S. Geological Survey, written commun., 2007). An EMFM measures the voltage induced by groundwater flowing at a right angle through a magnetic field generated by the tool. The resulting voltage is used to calculate a groundwater velocity, which is used to calculate a volumetric flow rate. Because the dedicated turbine pump typically present in the SSW was close to the well casing, there was insufficient space for inserting the EMFM or other equipment for collecting depthdependent flow and chemistry data. Therefore, the dedicated turbine pump was removed and a submersible pump of smaller diameter was temporarily installed in the well for well-bore flow measurements under pumping conditions. The intake of the submersible pump was set at the top of the screened interval, about $6.1 \mathrm{~m}$ above the typical setting of the turbine pump intake. The submersible pump produced about 2,460 to 2,840 liters per minute (L/min) (650 to 750 gallons per minute [gal/ $\mathrm{min}]$ ), which was substantially less than the typical production of about $11,660 \mathrm{~L} / \mathrm{min}(3,080 \mathrm{gal} / \mathrm{min})$ by using the turbine pump. Although the total flow rate during the collection of depth-dependent flow and chemistry data under pumping conditions was lower than the rate during typical operation of the SSW, the results of the sampling effort are believed to provide useful information about relative flow and groundwater chemistry from different depths of the aquifer.

Based on the flow profile under pumping conditions, five depths were selected for collecting depth-dependent groundwater samples in order to investigate changes in chemistry across depth intervals at which fairly large flow increases were observed. Because nearly 60 percent of the flow came from about the upper $68.6 \mathrm{~m}$ of the well screen, four of the five depth-dependent samples were collected across this interval. The samples were collected from about 115, 133, 151, 176, and 241 meters below land surface (mbls). Each of these samples represents the chemistry of all groundwater entering the screened interval below the depth of sampling, which was assumed to be thoroughly mixed. The depth-dependent samples were collected by using a Bennett sample pump lowered to the depths of interest while the SSW was being pumped at about $2,460 \mathrm{~L} / \mathrm{min}(650 \mathrm{gal} / \mathrm{min})$. A groundwater sample also was collected at the wellhead (by using typical procedures for sampling of public-supply wells) to characterize the chemistry of water entering the well across its entire screened interval. Because of the amount of time required for sampling and for the movement of equipment between depths, not all samples could be collected in a single day. The upper four depth-dependent samples were collected successively, from top to bottom, on December 4, 2007. The lowest depthdependent sample and the wellhead sample were collected the following day. Because of the extensive time required to move the groundwater sample equipment between land surface and the sampling depths, because of the possibility of snagging the sample equipment on pump-related equipment in the well, and particularly because several centimeters of food-grade mineral oil (used for lubricating the turbine pump) covered the top of the water table, the sample equipment was not cleaned between samplings. The volume of water flowing past the outside of the sample equipment and pumped through the tubing was assumed to be sufficient to remove any contaminants encountered at the previously sampled depth; chemical results from the depth-dependent sampling indicate that this assumption was valid.

\section{Quality Control of Water Samples}

Quality-control samples were collected to assess whether laboratory results for environmental samples were truly representative of the composition of the groundwater being studied. In particular, field blanks, source-solution blanks, replicates, and spikes were collected for selected analytes; summary data for field blanks are listed in appendix 2, table $2-1$. These samples were used to evaluate variability in results from environmental samples and to ascertain any evidence of bias resulting from methods of sample collection, processing, or transport, or from laboratory analysis.

\section{Blanks}

Field blanks were collected for selected analytes at several sites to determine whether samples might become contaminated (biased) during sample collection, processing, transport, or analysis. All field blanks were collected by using blank water that was certified by the NWQL to be appropriate for the analytes of interest. In particular, inorganic blank water was used for analyses of nutrients, major ions, trace elements, and radium, and nitrogen-purged volatile pesticidegrade blank water was used for analyses of VOCs, DOC, and ultraviolet absorbance. Field blanks were processed by using the same procedures and equipment as those used for the environmental samples. Five individual sample pumps (three of which had dedicated sample tubing) were used for collecting of environmental samples from monitoring wells. At least one set of field blanks for VOCs, metals, and nutrients was 
collected from each combined set of sample pump, tubing, and fittings. One set of field blanks for the same analytes was also collected from the tubing and fittings used to collect samples from public-supply wells having dedicated turbine pumps. Ten field blanks were collected for VOCs, eight for metals, and six for nutrients. One to three field blanks was collected for each of the following: major ions, iodide, arsenic speciation, radium, DOC, and ultraviolet absorbance. Meaningful field blanks cannot reasonably be collected for the other analytes listed in table 2.

Source-solution blanks were collected to verify that the blank water used for corresponding field blanks had no detectable concentrations of the analytes of interest. Source-solution blanks were analyzed in association with all field blanks for VOCs and with selected field blanks for metals and nutrients. The source-solution blanks were collected by pouring blank water (source solution) directly into sample bottles that were stored, shipped, and analyzed in the same manner as that used for the field blanks and the environmental samples. One VOC, acetone, was detected at similar concentrations in one field blank and its corresponding source-solution blank; in this case, the source solution was assumed to be the origin of acetone in the field blank. One other VOC, toluene, was detected in three field blanks and in their corresponding source-solution blanks; however, toluene was detected in two of these three field blanks at concentrations substantially greater than the concentrations in the source-solution blanks and was detected in three additional field blanks (but not in the corresponding source-solution blanks). As a result, toluene in the field blanks was assumed to have a source other than the source-solution blanks.

Sample bias was evaluated and managed by following the general procedure detailed by Landon and others (2008), restated here with slight modifications. Sample bias was considered to be of potential concern with regard to a particular analyte if (1) the analyte was detected in one or more field blanks and environmental samples, (2) the concentration detected in the field blank was greater than the concentration detected in the associated source-solution blank, and (3) the minimum concentration detected in environmental samples was less than the sum of the maximum concentration detected in field blanks and half the LRL (this sum is subsequently referred to as "the censoring threshold"). Analytes meeting these criteria were examined for chronological patterns in their detection in field blanks and in environmental samples. If an analyte was detected in at least one field blank and in closely associated environmental samples (collected shortly before or after the field blank), detections in the environmental samples at concentrations below the censoring threshold were flagged in the NWIS database as being potentially biased during sample collection, processing, transport, or analysis (censored) and generally were removed from the interpretative dataset used for this study. When an analyte was detected in half or more of all field blanks, detections at concentrations below the censoring threshold in environmental samples collected at any time (not just shortly before or after the field blank) were censored because of the possibility that systematic bias was introduced during sample collection and analysis. When an analyte was detected in fewer than half of all field blanks, detections of the analyte in environmental samples that were not closely associated with those field blanks were not censored.

For VOCs, all detections of five analytes and some detections of three analytes in environmental samples were censored. Four compounds (or compound pairs) that are components of gasoline were detected in three to six field blanks and in at least one environmental sample: benzene, toluene, ethylbenzene, and $\mathrm{m}$ - and $\mathrm{p}$-xylene. All detections of these compounds in environmental samples were at concentrations less than the maximum concentration in an associated field blank, and all were censored. Contamination of samples with these compounds was attributed to the need to run most of the submersible sample pumps by using a gasoline-powered generator or air compressor. Although the gasoline-powered equipment was kept as far away from the sample site and the mobile laboratory as possible when in use, in some cases this equipment was mounted on the same trailer as the sample tubing. Whether the four gasolinerelated compounds entered the water samples as a result of direct contact of airborne gasoline exhaust with the sample vials or of contact of the water with sample tubing that had absorbed the compounds from airborne gasoline exhaust was not determined. There was no evidence from other data sources that any of the four censored gasoline-related compounds should have been present in the sampled groundwater. The fifth compound for which detections were censored for all samples in which it was detected was chlorobenzene, which was present in half of the field blanks. The source of chlorobenzene, which is used as a solvent and degreaser, was not determined.

The three VOCs for which detections were censored in some samples were dichloromethane, bromodichloromethane, and trichloromethane (chloroform). Dichloromethane was detected in two field blanks and was censored in one associated environmental sample, where its concentration was less than the concentrations detected in the field blanks. The source of dichloromethane, which is used as a solvent, was not determined. Bromodichloromethane was detected in one field blank and was censored in one associated environmental sample, where its concentration was less than the concentration detected in the field blank. Chloroform was detected in four field blanks and was censored in several associated environmental samples having concentrations below the appropriate censoring threshold. Bromodichloromethane and chloroform are chlorination byproducts that might have been present in field blanks as a result of incomplete flushing of the tap water used during cleaning of the sample tubing with subsequent rinses using deionized water, methanol, and blank water. In this case, environmental samples collected after the sample tubing had been flushed with copious quantities of groundwater would be unlikely to have been biased with respect to these two compounds. However, because 
incomplete flushing of the tubing could not be definitively pinpointed as the source of contamination to the field blanks, the decision was made to censor data for bromodichloromethane and chloroform according to the procedure detailed earlier in this section.

Several other VOCs were detected in at least one field blank (see app. 2), but no environmental data for these compounds were censored. Censoring was not required because there were no detections of these compounds in associated environmental samples, the compounds were detected in fewer than half of field blanks, and (or) the concentrations detected in field blanks were substantially lower than the concentrations in associated environmental samples for which the same sampling equipment was used. In some cases, these compounds appeared to be present in a field blank as a result of carryover from an environmental sample combined with the difficulty of thoroughly flushing about $300 \mathrm{~m}$ of sample tubing with the solutions used for cleaning.

Some or all detections of six different metals needed to be censored: chromium, copper, lead, manganese, nickel, and zinc. All six metals were detected in at least half of field blanks, but in no corresponding source-solution blanks. For each of the six metals, at least 10 detections in environmental samples were at concentrations below the censoring threshold. For copper and lead, all detections in environmental samples were at concentrations below the censoring threshold. With the exception of manganese, these six metals were of little interpretative interest for this study and their censoring had no effect on study conclusions. Although manganese was included in interpretations related to assessments of redox conditions in the aquifer, the censoring of relatively low concentrations (less than $0.78 \mu \mathrm{g} / \mathrm{L}$ ) had no adverse effect on these assessments. The source(s) of bias in results for these six metals were not definitively determined, but they might have been related to the use of stainless steel sample pumps or of metal fittings required to attach the sample tubing to pumps and other equipment.

Despite detections of DOC in two of three field blanks, no data for DOC detections were censored. The detections of DOC in the field blanks were attributed to the use of capsule filters that were later found to be inappropriate for collecting DOC field blanks (U.S. Geological Survey Office of Water Quality Water-Quality Information Note 2008.13). These filters could introduce detectable, and even quite large, concentrations of DOC to water samples if the samples were collected after rinsing of the filter with about 1 liter or less of sample water, which is common during the collection of field blanks because of costs associated with volatile pesticidegrade blank water. This contamination issue is not thought to have affected environmental samples because DOC samples were always collected last, after several liters of water had passed through the filter. DOC data were used only minimally in data interpretation for this study, and only in support of conclusions drawn from interpretation of other analytes. With respect to nutrients, total nitrogen was detected at a low concentration in one field blank. All but one environmental sample had concentrations well above the level of detection in the field blank. The total nitrogen value for the one environmental sample with a low concentration was not censored because the environmental sample was collected with different equipment and was not closely associated in time with the field blank.

\section{Replicates}

Replicate samples were collected to evaluate variability resulting from sample collection and analysis. Replicate samples were sequential, with each replicate sample set collected immediately after the environmental sample set for an individual type of analysis. During the course of the study, at least three replicate sample sets were collected for VOCs, major ions, metals, and nutrients. At least one replicate sample set was collected for most other analytes, except selected age tracers $\left({ }^{14} \mathrm{C}\right.$ and $\left.{ }^{3} \mathrm{H} /{ }^{3} \mathrm{He}\right)$. For dissolved gas and $\mathrm{CFC}$ analyses, the laboratory routinely analyzed replicate samples for each sample site. Relative standard deviation (RSD) was used as a measure of variability between replicate pairs. RSD was calculated by using unrounded laboratory results by dividing the absolute value of the standard deviation by the mean concentration for each replicate pair and multiplying the result by 100 . If the result for one sample (either environmental or replicate) was reported as a nondetect and the result for the other sample in the pair was reported as a concentration below the LRL, the RSD was set to zero because the results are analytically identical. If the result for one sample (either environmental or replicate) was reported as a nondetect and the result for the other sample in the pair was reported as a concentration greater than the LRL, the nondetect result was set equal to one-quarter of the LRL for the purpose of calculating the RSD. RSD values of 20 percent or less were considered acceptable for this study.

Results for the replicate samples indicated that the mean RSD for nearly all analytes was less than 5 percent. All analytes that exceeded 5 percent with respect to mean RSD also exceeded 20 percent. These analytes were radium-226, radium-228, hydrogen from the CFC laboratory, CFC-11, CFC-12, and CFC-113. Of these analytes, only the individual CFCs were included in interpretation for this study, and only in combination with other age tracers or with respect to indicating the mere presence or absence of a component of young water. Variability in the $\mathrm{CFC}$ results is believed to represent actual variability in the concentrations of CFCs in individual sample bottles. Many of the wells sampled for this study either had only relatively small components of young water (resulting in very small CFC concentrations) or had been drilled only recently (likely resulting in small, sporadic contributions of residual drilling fluid to groundwater captured by the sample pumps). Under either circumstance, the sensitivity of the laboratory method to even very small changes in the fraction of young water in the sample could result in the level of variability observed in the data. 


\section{Spikes}

Two types of spikes-laboratory matrix spikes and surrogates - were used to examine bias and to evaluate the possible presence of interference from the chemistry of the environmental samples (matrix interference) during laboratory analysis. Laboratory matrix spikes were prepared by adding solutions containing known concentrations of target analytes to replicate environmental samples after their arrival at the laboratory. The laboratory matrix spikes contained all compounds included in the particular analyte group being evaluated. Three laboratory matrix spikes were collected for VOCs and one was collected for arsenic speciation. Surrogates were added to all environmental samples that were collected and analyzed for VOCs. Surrogate VOC compounds, which are added to samples at the laboratory just before analysis, are compounds that behave like the analytes of interest but are not normally present in the environment. The three surrogate compounds used by the laboratory were 1,2-dichloroethane-d4, 1-bromo-4-fluorobenzene, and toluene-d8.

Recoveries were examined for each type of spike. For laboratory matrix spikes, recoveries were calculated as the percent of the expected concentration of the spike that was reported in the spiked environmental sample (after subtracting any detected concentration of the compound in the corresponding unspiked environmental sample). For surrogates, recoveries were reported by the laboratory. Spike recoveries ranging from 70 to 130 percent were considered acceptable for this study (Connor and others, 1998).

Spike recoveries were within the acceptable range for most of the compounds evaluated. Among the three field matrix spikes for VOCs, the mean recoveries for individual compounds ranged from 77.6 to 121.4 percent; the only recoveries that fell outside the acceptable range were for tetrahydrofuran in one spike sample (136.4 percent) and carbon disulfide in the same sample (69.2 percent). Tetrahydrofuran was not detected in any environmental samples during this study. Carbon disulfide was detected in one environmental sample; recoveries below 100 percent (but still within the acceptable range for 2 of 3 laboratory matrix spikes) indicate that the concentration reported for that sample could be biased low. The recoveries for arsenate ( 89.1 percent) and for arsenite (78.1 percent) in the one arsenic speciation laboratory matrix spike were both within acceptable limits. Among the three VOC surrogate compounds added to samples at the laboratory, the mean recoveries were 86.2 percent (standard deviation 9.7 percent) for 1-bromo-4-fluorobenzene; 99.8 percent (standard deviation 4.7 percent) for toluene-d8; and 126.1 percent (standard deviation 15.4 percent) for 1,2-dichloroethane-d4. From 50 environmental samples, recoveries of 1,2-dichloroethane-d4 exceeded 130 percent in 16 samples (indicating that concentrations of 1,2-dichloroethane in several environmental samples could be biased high), and recoveries of 1-bromo-4-fluorobenzene fell below 70 percent in 3 samples.

\section{Statistical Methods}

Statistical methods were used to identify and characterize significant correlations between potential explanatory variables and concentrations of constituents of particular interest. Spearman's rho ( $\rho$ ), a rank-order correlation coefficient (Helsel and Hirsch, 1995), was used in most cases. Values of this nonparametric measure of correlation range from +1.0 (perfect positive correlation), through 0.0 (no correlation), to -1.0 (perfect negative correlation). For this report, a correlation was considered statistically significant if the calculated p-value was less than 0.05 . In selected cases when the relation between two variables appeared linear and an estimate of the equation describing that relation was desired, the least-squares fit was determined by using linear regression.

\section{Hydrogeologic Setting}

An understanding of the sources, transport, and fate of groundwater contaminants in the area of the SSW requires knowledge of the physical and chemical characteristics of the local aquifer sediments, as well as knowledge of groundwater occurrence and movement. Data collected by the TANC study on lithology, solid-phase chemistry, groundwater levels, aquifer properties, and wellbore flows were used to enhance previous knowledge of the hydrogeologic setting of the study area.

\section{Geology, Mineralogy, and Sediment Chemistry}

The local-scale TANC study area extends from the nearly flat surface of the Rio Grande inner valley on the west to the Rio Grande terraces of moderate relief on the east. It is likely that all the currently saturated sediments in the study area belong to the Santa Fe Group, although overlying Rio Grande alluvium of Quaternary age might have been saturated in the inner valley before local water levels declined because of groundwater withdrawals. East of the inner valley, fluvial sediments of the Sierra Ladrones Formation (part of the Santa Fe Group) that the ancestral Rio Grande deposited in the study area are present beneath the Quaternary alluvium, but the sediments are relatively thin and probably are generally above the water table (Connell, 2006). Therefore, the wells sampled for the local-scale TANC study, along with other public-supply wells within the study area, are screened almost entirely within the Ceja Formation of the Santa Fe Group. This formation directly underlies the Quaternary alluvium within the inner valley and the Sierra Ladrones Formation elsewhere (Connell, 2006; Connell, 2008).

The Ceja Formation consists of fluvial deposits (sand, gravel, and mud) of Pliocene age that were derived from the western and northwestern parts of the MRGB and deposited by southeast-flowing tributary streams and rivers (Connell and others, 1999; Connell, 2006; Connell, 2008). The formation 
generally thickens and dips down to the east. The lower interval of the Ceja Formation, known as the Atrisco member, is described by Connell (2008) as a succession of generally brownish, fine-grained, poorly sorted, massive to laminated, silty to clayey sandstone and mudstone. Within the study area, the Ceja Formation coarsens upward from the Atrisco member into the Rio Puerco member, which is named for a major tributary to the Rio Grande. The Rio Puerco member is described by Connell (2008) as containing "planar to trough cross-stratified pebble to cobble gravel and pebbly to cobbly sand and fine-to coarse-grained sand, with scattered boulders and large cobbles," and as having "abundant volcanic gravel with subordinate chert, red granitic, and sedimentary (mostly sandstone) gravel" (p. 27). Supplemental digital data released with the Connell (2006) publication indicate that the screened intervals of the public-supply wells sampled for the local-scale TANC study do not extend beyond the Rio Puerco member of the Ceja Formation. The screened intervals of public-supply wells that were not sampled as part of the investigation, but that are located in the western part of the local-scale study area, extend into the Atrisco member.

Detailed descriptions of cuttings that were available for the FP1 borehole between about 55 and $171 \mathrm{mbls}$ are consistent with driller's logs in indicating that the lithology of the sediments is primarily very fine to very coarse sand, with varying fractions of silt or gravel. The cuttings indicate that zones dominated by very coarse sand or granules (sometimes accompanied by pebbles) are relatively common between about 70 and $107 \mathrm{~m}$, with zones dominated by silty sand becoming more common below about $130 \mathrm{~m}$. Sediments in the cuttings were determined to vary from very poorly sorted to well sorted, with moderate sorting being most common. Detailed descriptions of core samples from six intervals in the FP1 and FP3 boreholes (see app. 1 for core intervals) appear consistent with descriptions of the cuttings with respect to lithology, sorting, and the increasing presence of finer sediments with depth. Carbonate cementation was clearly observed in some core intervals, and the application of hydrochloric acid to both the cuttings and core samples indicated that the presence of calcite was common. Optical mineralogy of the cuttings and X-ray diffraction of the core samples (see table 1-1 in app. 1 for X-ray diffraction results) were consistent in indicating the presence of quartz, feldspar (orthoclase and plagioclase), calcite, and clay minerals (mainly smectite, with lesser to trace amounts of illite, kaolinite, and chlorite). The presence of basalt was noted in the cuttings in several samples throughout the described interval. Detailed descriptions were not conducted for cuttings from the other three FP boreholes because comparison of geophysical logs collected in all four boreholes indicated similarly irregular sequences of mostly sandy sediments with general characteristics like those of the sediments from the FP1 borehole.

Laboratory analyses were conducted on core samples to characterize the chemical composition of the aquifer sediments (app. 1, tables 1-1 to 1-3). Analysis of total carbon content yielded results ranging from 1.9 to 5.0 grams per kilogram $(\mathrm{g} / \mathrm{kg})$. In 5 of 6 samples, the reported inorganic carbon content was within $0.1 \mathrm{~g} / \mathrm{kg}$ of the total carbon content, reflecting the minimal presence of organic carbon and the presence of most carbon in the likely form of calcite. The remaining sample, from the 86- to 89-m interval of the FP1 borehole, was the only one with a detectable organic carbon content, reported as $0.23 \mathrm{~g} / \mathrm{kg}$. Laboratory analysis of all core samples for acid volatile sulfides plus pyritic sulfur yielded the presence of only minor amounts ranging from 0.3 to $2.5 \mu \mathrm{g} / \mathrm{kg}$. Sequential extractions that use hydrochloric and nitric acid to target ferric oxyhydroxides and their associated trace elements, but likely also extract various amounts of other oxides in addition to clay and carbonate minerals, yielded median concentrations for individual sample intervals of iron (hydrochloric acid extraction) ranging from 270 to $640 \mathrm{mg} /$ $\mathrm{kg}$; of manganese (hydrochloric acid extraction) ranging from 51 to $133 \mathrm{mg} / \mathrm{kg}$; of arsenic (nitric acid extraction) ranging from 0.15 to $0.54 \mathrm{mg} / \mathrm{kg}$; and of uranium (nitric acid extraction) ranging from 0.10 to $1.24 \mathrm{mg} / \mathrm{kg}$. These extractions probably overestimate the fraction of these elements that groundwater could mobilize from the sediments, but the magnitudes of the results indicate that the concentrations of these elements in groundwater are not limited by their abundance in sediments. All the highest iron, arsenic, and uranium contents were from a clayey core sample collected from the 365- to $368-\mathrm{m}$ sample depth in the FP1 borehole. This same core sample yielded the largest amounts of arsenic to solution $(0.106 \mu \mathrm{g}$ of arsenic per $\mathrm{g}$ of wet sediment, and $0.134 \mu \mathrm{g}$ of arsenic per $\mathrm{g}$ of dry sediment) during laboratory desorption experiments that targeted arsenic, although the experiments indicated that all the core samples contained some arsenic that was readily desorbed.

Laboratory analysis was also conducted to estimate the total porosity of the aquifer sediments. The mostly sandy, fully saturated core samples that were submitted for analysis yielded moisture contents ranging from 27 to 35 percent. These values should closely approximate the total porosity of the samples that were analyzed; however, porosity values of the gravelly, poorly sorted sediments that were not analyzed would likely be lower.

\section{Sediment Classification and Aquifer Hydraulic Properties}

Sediments in boreholes that were located in the localscale TANC study area and had available geophysical logs (specifically, short-normal resistivity logs) were grouped into general lithology classes to aid the development of a spatial correlation model of hydraulic conductivity used for selected depths of a groundwater-flow model of the area (Charles Heywood, U.S. Geological Survey, written commun., 2010). A broad overview of the process is provided here.

The lithology of sediments encountered in the saturated section of the FP1 borehole, as consistently characterized by driller's logs, descriptions of cuttings, and descriptions of core 
samples from selected depths, consisted primarily of very fine to very coarse sand, with varying fractions of silt or gravel; zones dominated by gravel or clay were rare and relatively thin. Nevertheless, short-normal resistivity logs, which were available for the four TANC boreholes and the six boreholes previously drilled for public-supply wells within the study area (plus five other boreholes previously drilled for publicsupply wells just east of the study area), showed variability with depth that indicated distinct differences in grain size and probably in hydraulic conductivity (fig. 4). Individual patterns in the variability of resistivity-log responses were similar among boreholes spread across more than $2.5 \mathrm{~km}$ along an approximate north-south axis, indicating that certain sedimentary deposits extended across broad areas along that axis.

Depths within the FP1 borehole at which resistivitylog responses indicated larger grain size correlated reasonably well with depths at which cuttings from that borehole indicated a greater proportion of coarse sand and gravel. Likewise, depths at which the resistivity-log responses indicated smaller grain size correlated reasonably well with depths at which cuttings indicated a greater proportion of fine sand and silt or silty clay. Correlations of the resistivity$\log$ responses with the descriptions of cuttings from the FP1 borehole were used to divide the log responses into high, medium, and low resistivity values that represented coarse, medium, and fine sedimentary deposits, respectively. Resistivity data for the various boreholes were collected by using different individual geophysical tools, not all of which were calibrated to provide the same response to materials of identical lithology. However, similarities in the patterns of resistivity could be used to correlate individual sedimentary deposits among boreholes and consequently to determine resistivity values for other boreholes that corresponded with the resistivity values used to delineate the lithology categories in the FP1 borehole. Once the resistivity values appropriate for categorization were determined for each borehole, inferred lithology classes of coarse, medium, or fine lithology were assigned at $3-\mathrm{m}$ intervals for depths corresponding with about 55 to $171 \mathrm{mbls}$ at the location of FP1 (fig. 4). In the spatial correlation model of hydraulic conductivity created for these depths within the groundwater-flow model, 3-m intervals classified as "coarse" were assigned the highest value for hydraulic conductivity, intervals classified as "fine" were assigned the lowest value, and intervals classified as "medium" were assigned an intermediate value. The exact value assigned to each class was determined based on hydraulic conductivity estimated from the water-level response in selected monitoring wells to pumping of the SSW, from hydraulic-conductivity estimates cited in the literature (summarized in McAda and Barroll [2002]), and from the results of model calibration (Charles Heywood, U.S. Geological Survey, written commun., 2011). Previous estimates of hydraulic conductivity based on aquifer tests that used public-supply wells in the vicinity of the SSW were about $6.1 \mathrm{~m} / \mathrm{d}$ (Thorn and others, 1993).

\section{Groundwater Occurrence and Movement}

Conditions within the aquifer in the local-scale TANC study area are generally unconfined, but are considered semiconfined at depth because interbedded fine-grained layers result in a poor hydraulic connection with depths near the water table. No thick, laterally extensive fine-grained deposits effectively acting as confining layers have been identified at locations or depths included in this study. Water-level contours representing predevelopment conditions (that is, conditions before extensive development of groundwater) in the upper few hundred feet of the Santa Fe Group aquifer (Bexfield and Anderholm, 2000) indicate that groundwater once flowed through the study area from the northeast toward the southwest, moving in the general direction of the Rio Grande, which is located just beyond the western extent of the study area. The conceptual model of regional groundwater recharge and discharge under predevelopment conditions (fig. $5 \mathrm{~A}$ ) would imply that groundwater in the area was sourced along upgradient reaches of the Rio Grande and (or) along the eastern mountain front and was flowing toward the riparian area along the Rio Grande to be discharged through evapotranspiration. The general chemistry and isotopic composition of groundwater sampled by Plummer and others (2004a) in and near the local-scale TANC study area indicated that groundwater within the study area had recharged along the Rio Grande, typically thousands of years ago, and that the westward extent of groundwater that had recharged along the eastern mountain front was located about 4 to $5 \mathrm{~km}$ east of the study area.

The transient nature of the groundwater system in the local-scale TANC study area is illustrated by maps of water levels in the area at different periods of time. The regional water-level contours of Bjorklund and Maxwell (1961) for data collected during 1953 through 1960 show that directions of groundwater flow within the local-scale TANC study area at that time had already been noticeably altered as a result of groundwater withdrawals from public-supply wells located in the downtown area of Albuquerque, causing groundwater to flow into the study area from the west, north, and east. The water-table contours of Summers (1992) for data collected during the winter of 1988-89 in the Albuquerque area indicate that shallow groundwater flow within the TANC study area had substantially changed direction relative to predevelopment conditions. By $1988-89$, groundwater was moving primarily from west to east as a result of large groundwater withdrawals centered in the eastern part of Albuquerque. Similar patterns of flow can be inferred from water-level data representing winter conditions in the production zone of the aquifer in the Albuquerque area during 1999-2002 (Bexfield and Anderholm, 2002a) and from hydraulic heads simulated by the regional TANC groundwater-flow model of Bexfield and others (2011) for the water table and production zone (model layer 5) during August 2008 (fig. 3). The conceptual model of regional groundwater recharge and discharge under modern conditions (fig. $5 B$ ) is consistent with seepage of water from 


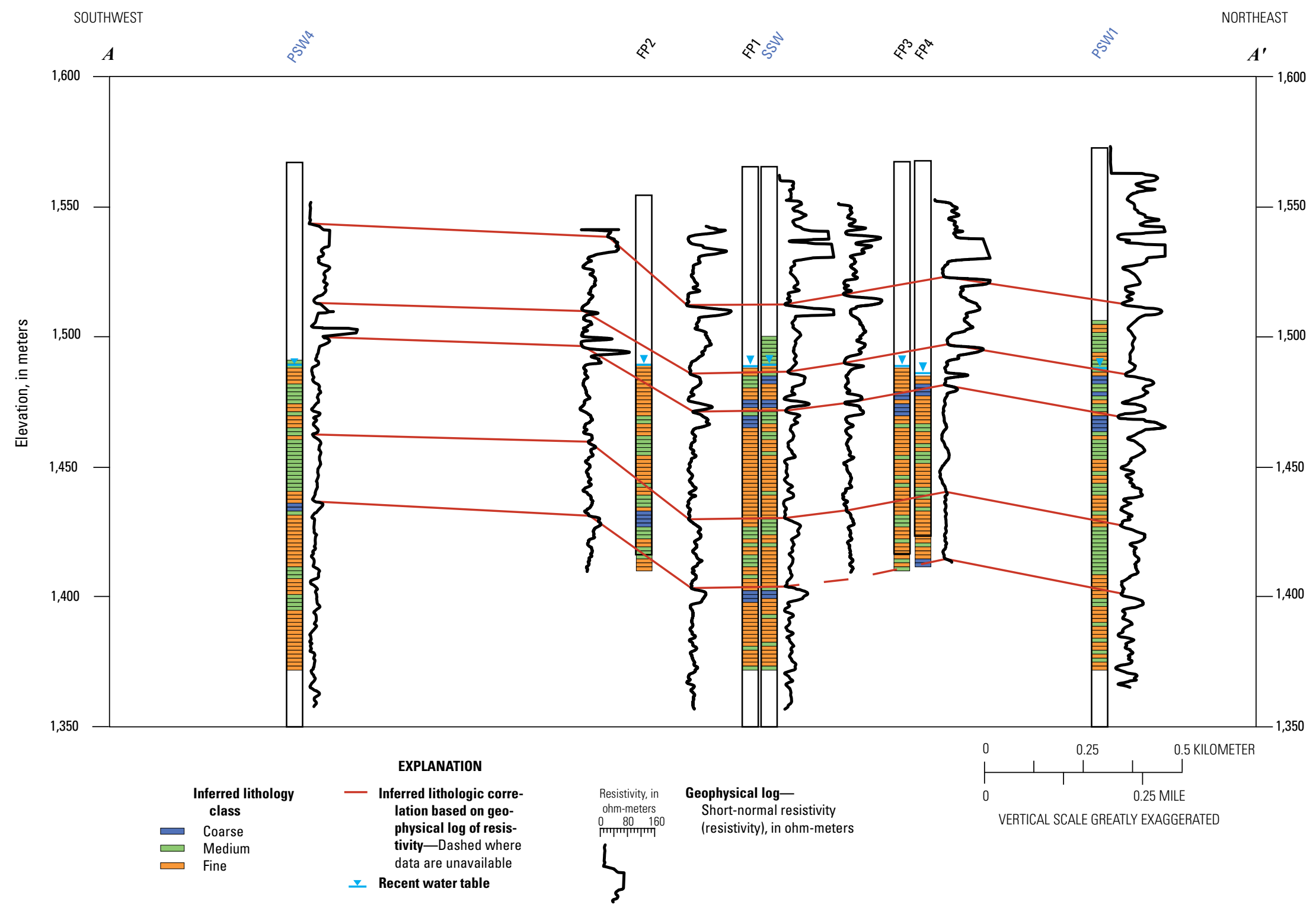

Figure 4. Geophysical logs and inferred lithology classes for selected monitoring and public-supply wells within the local-scale transport of anthropogenic and natural contaminants (TANC) study area in Albuquerque, New Mexico. Location of section shown on figure 3. 
A. Predevelopment conditions

Total flux, 160 million cubic meters

per year

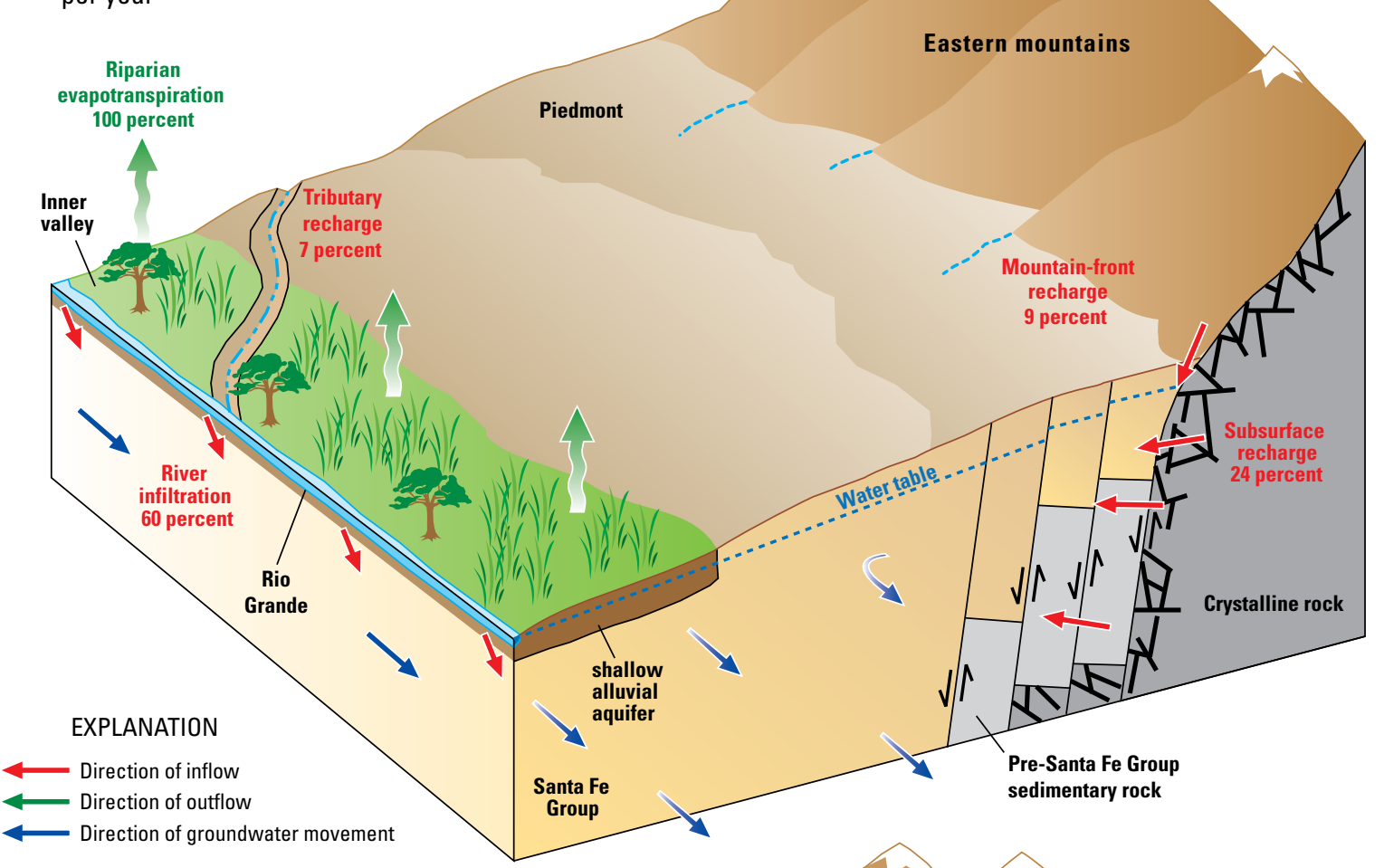

\section{B. Modern conditions}

Total flux, 708 million cubic meters per year

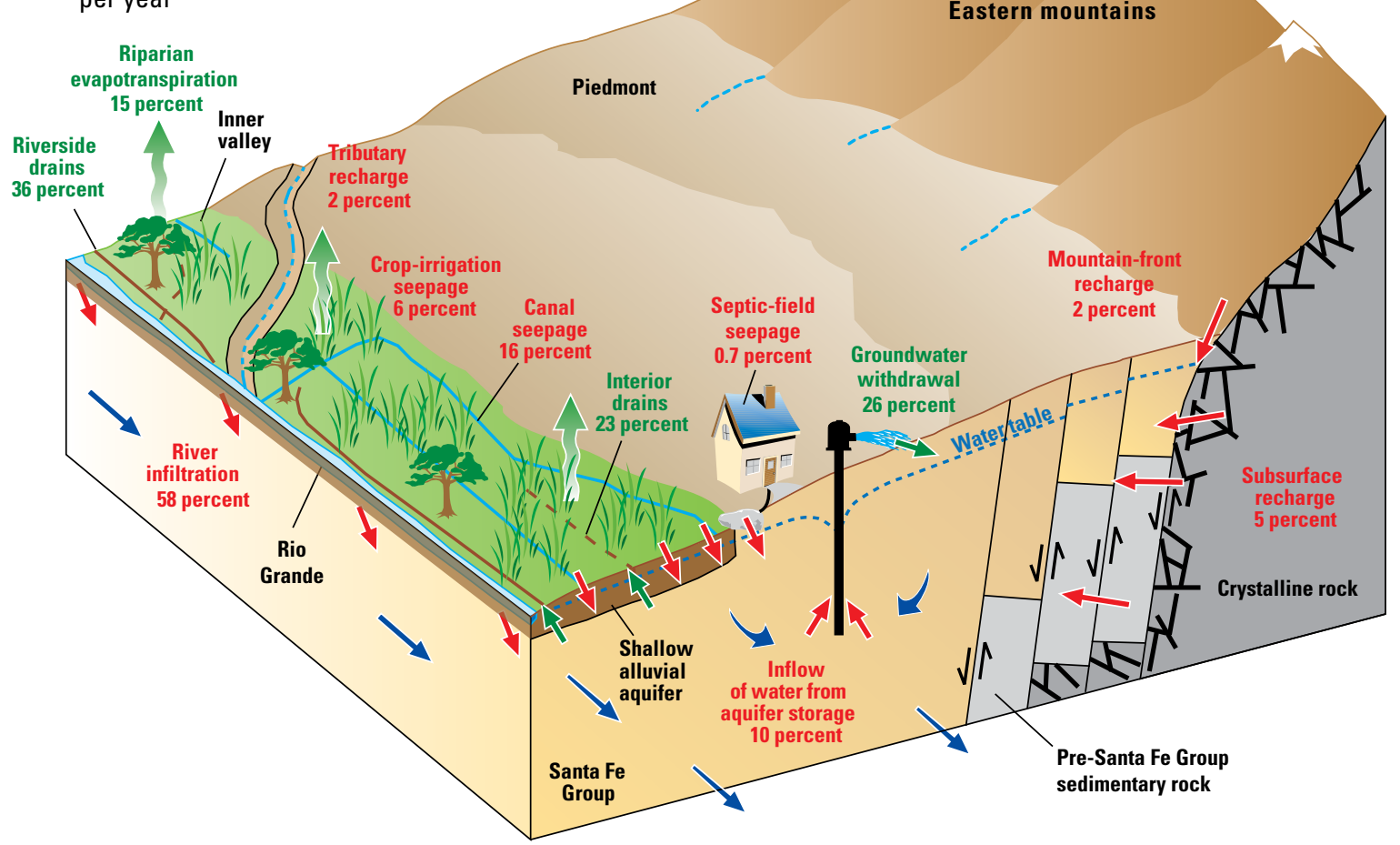

Figure 5. Regional groundwater flow and of components of the groundwater budget near Albuquerque, New Mexico, under $A$, predevelopment conditions and $B$, modern conditions. 
the Rio Grande (enhanced by modern hydraulic gradients) being the primary source of modern recharge to groundwater in the local-scale TANC study area, and with groundwater withdrawals for public supply being the primary mechanism of discharge. Given the prevalence of urban land use in the area, irrigated urban landscaping and leaky sewer and (or) waterdistribution lines also would be expected to contribute some recharge to the aquifer, as would unlined stormwater channels (fig. 2) designed to capture urban runoff for transport to the Rio Grande.

Available data indicate that recent depths to water in the local-scale TANC study area are as little as $10.5 \mathrm{~m}$ in the Rio Grande inner valley along the western margin of the study area and as much as $92 \mathrm{~m}$ in upland areas along the eastern margin. Based on the map of Bexfield and Anderholm (2000), water-level declines from predevelopment through 1999-2002 probably ranged from about 6 to $24 \mathrm{~m}$ across the study area, with the smaller declines occurring closer to the Rio Grande. Water-level contours from the same map indicate that a typical horizontal hydraulic gradient across the study area in the winters during 1999-2002 was about 0.004 .

Daily to seasonal patterns in groundwater withdrawals by public-supply wells within the study area, each of which is operated on its own individual pumping schedule, result in temporal variability in both the direction and the magnitude of local horizontal and vertical hydraulic gradients. Continuous water-level data from the FP monitoring wells (figs. $6 A-6 D$ ) clearly illustrate that water levels vary on a daily and seasonal basis by as much as several meters, depending on the depth of the monitoring well and its proximity to a public-supply well. The smallest water-level fluctuations generally are observed in the wells completed across the water table because they are farthest from the pumping stresses that are being applied to deeper parts of the aquifer and because the dewatering of sediments releases more water from storage per unit change in hydraulic head. When the SSW is being pumped on a daily cycle, the water level recorded in FP1S, the shallow (watertable) well of FP1 ( $33 \mathrm{~m}$ from the SSW), can vary by as much as $1 \mathrm{~m}$ during a day. When the SSW has not been pumped for several days, water levels in the shallow (water-table) well of FP1 (FP1S) still show a daily fluctuation (as do water levels in all monitoring wells in the FP nests), but only of about 0.12 $\mathrm{m}$ or less; these fluctuations presumably result from the daily pumping cycles of other public-supply wells within the study area. Seasonal fluctuations in the highest daily water level for the water-table wells of all four FP nests indicate that water levels typically are highest near the end of March or the beginning of April and lowest during September. These observations are consistent with historic data indicating that groundwater withdrawals from public-supply wells within the study area generally are greatest during the months of April through September (fig. 7). The magnitudes of observed seasonal waterlevel fluctuations in the shallow (water-table) wells vary from less than $1 \mathrm{~m}$ to more than $2.3 \mathrm{~m}$, depending on the location of the well and on the individual years the seasons for which are being compared.
Within each FP well nest, the largest water-level fluctuations are observed in wells categorized as intermediate with respect to their screened depths: FP1MS, FP2D, FP3D, and FP4D. These wells presumably have the largest fluctuations because they are screened closest to the depths of the aquifer at which the greatest pumping stresses are applied. Daily pumping cycles of the SSW can result in water-level fluctuations in FP1MS that approach $10 \mathrm{~m}$ in magnitude. Daily water-level fluctuations associated with operation of the SSW can exceed $3 \mathrm{~m}$ in FP3D (360 $\mathrm{m}$ from the SSW) and $1 \mathrm{~m}$ in FP2D (625 $\mathrm{m}$ from the SSW). Daily water-level fluctuations in FP4D, which is located $625 \mathrm{~m}$ from the SSW but also only about $475 \mathrm{~m}$ from another public-supply well, can approach $2 \mathrm{~m}$. Fluctuations in the highest daily water levels of these four wells show the same seasonal timing of highest and lowest water levels as does the timing observed in the shallow (water-table) wells, but the magnitudes of the fluctuations are greater, ranging from about $2.7 \mathrm{~m}$ to $4.8 \mathrm{~m}$, depending on the location of the well and on the individual years the seasons for which are being compared.

Vertical hydraulic gradients in many parts of the localscale TANC study area change in direction and magnitude as water levels respond to supply-well pumping. As would be expected, the largest changes in gradients among the FP well nests are observed closest to the SSW. The gradient between the shallow (water-table) (S) and intermediate (MS) wells at FP1 is generally downward when the SSW is pumping and upward when it is not; however, during high-pumping season (typically May through October), the gradient can remain downward even when the SSW is not pumping (fig. $6 A$ ). When the SSW has remained idle for relatively long periods, the magnitude of the upward gradient between FP1S and FP1MS is about 0.05 ; when the SSW has been pumping frequently, the magnitude of the downward gradient is about 0.16 . The gradient between the intermediate well, FP1MS, and the upper deep well, FP1MD, is generally upward, with a magnitude ranging from about 0.01 (SSW off) to 0.05 (SSW on). The gradient between the two deep wells, FP1MD and FP1D, appears to be consistently upward, with a magnitude ranging from about 0.01 (SSW off) to 0.08 (SSW on). Data from the FP2 and FP4 well nests, located farthest from the SSW and having three wells each, indicate that vertical gradients typically are upward during low-pumping seasons, but can be downward between either the upper two or lower two wells during high-pumping seasons. Data from the FP3 nest of three wells indicate that the gradient between the shallow (water-table) well, FP3S, and the upper intermediate well, FP3M, generally is upward when the SSW has remained idle for relatively long periods (magnitude of about 0.07 ) and downward when the SSW is pumping or has been pumping frequently (magnitude of about 0.08 ). The gradient between the upper and lower intermediate wells, FP3M and FP3D, generally is upward whether or not the SSW is pumping (magnitude of about 0.09), but can be downward when the SSW has been pumping frequently (magnitude of about $0.03)$. 


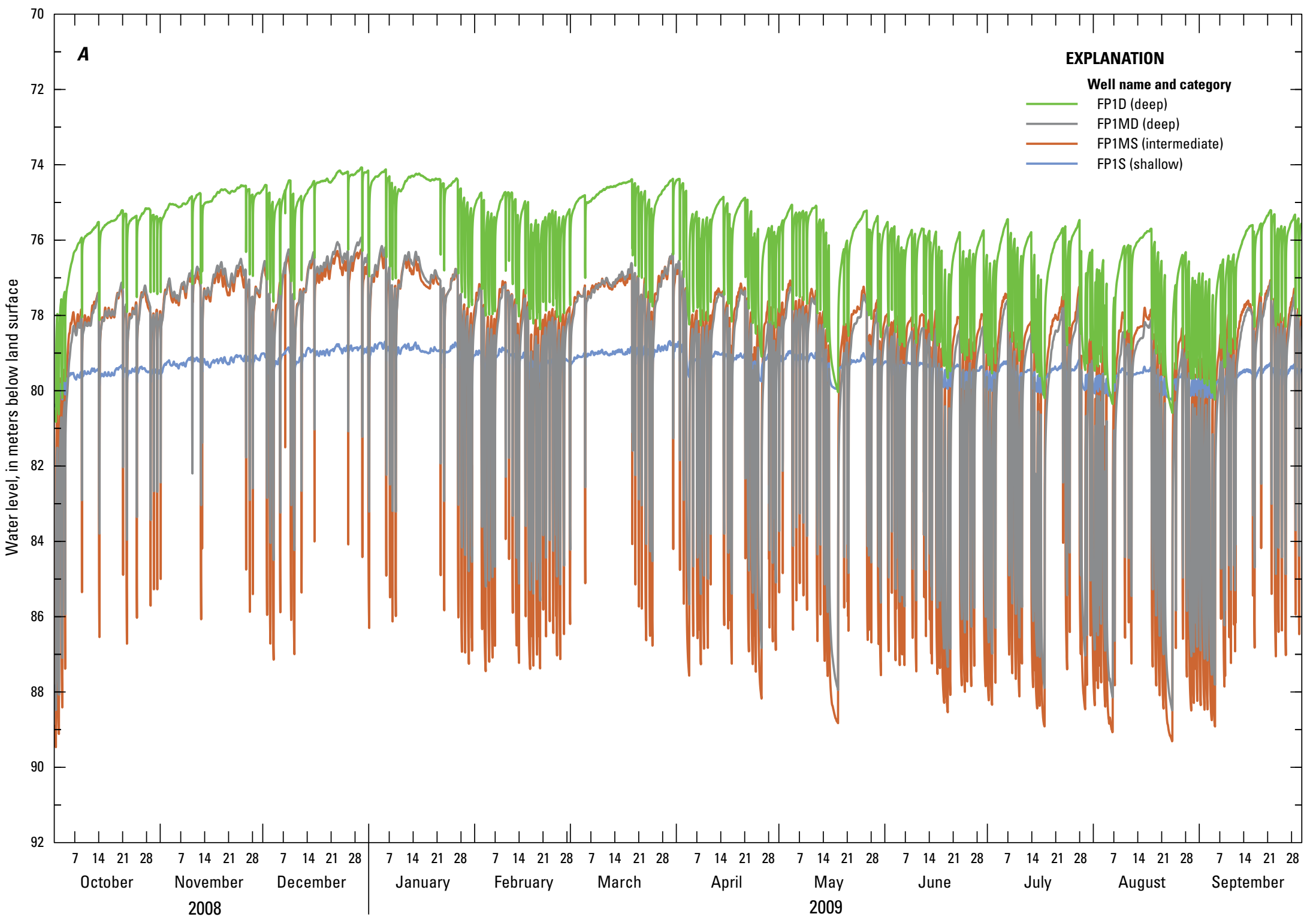

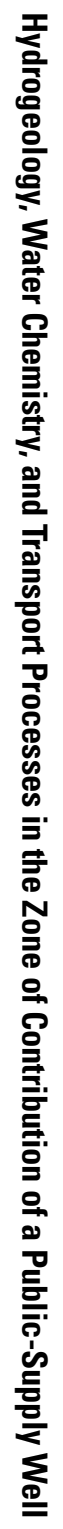

Figure 6. Changes in water levels with time in the $A, F P 1 ; B, F P 2 ; C, F P 3$; and $D$, FP4 monitoring well nests drilled for the local-scale transport of anthropogenic and natural contaminants (TANC) study in Albuquerque, New Mexico, October 2008 through September 2009. Well completion information is listed in table 1. 


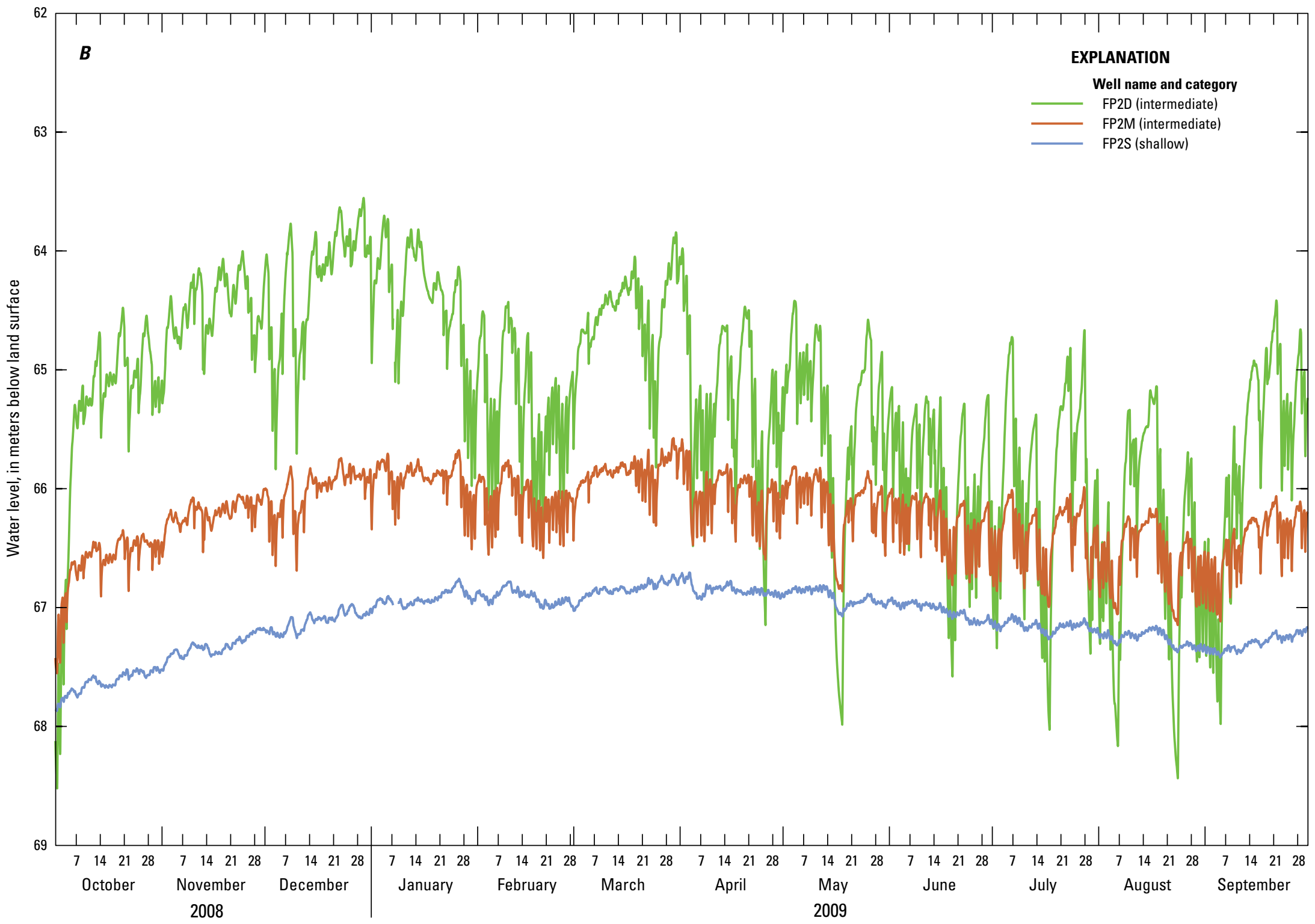

Figure 6. Changes in water levels with time in the $A, \mathrm{FP} 1 ; B, \mathrm{FP} 2 ; C, \mathrm{FP} 3$; and $D$, FP4 monitoring well nests drilled for the local-scale transport of anthropogenic and natural contaminants (TANC) study in Albuquerque, New Mexico, October 2008 through September 2009. Well completion information is listed in table 1.-Continued 


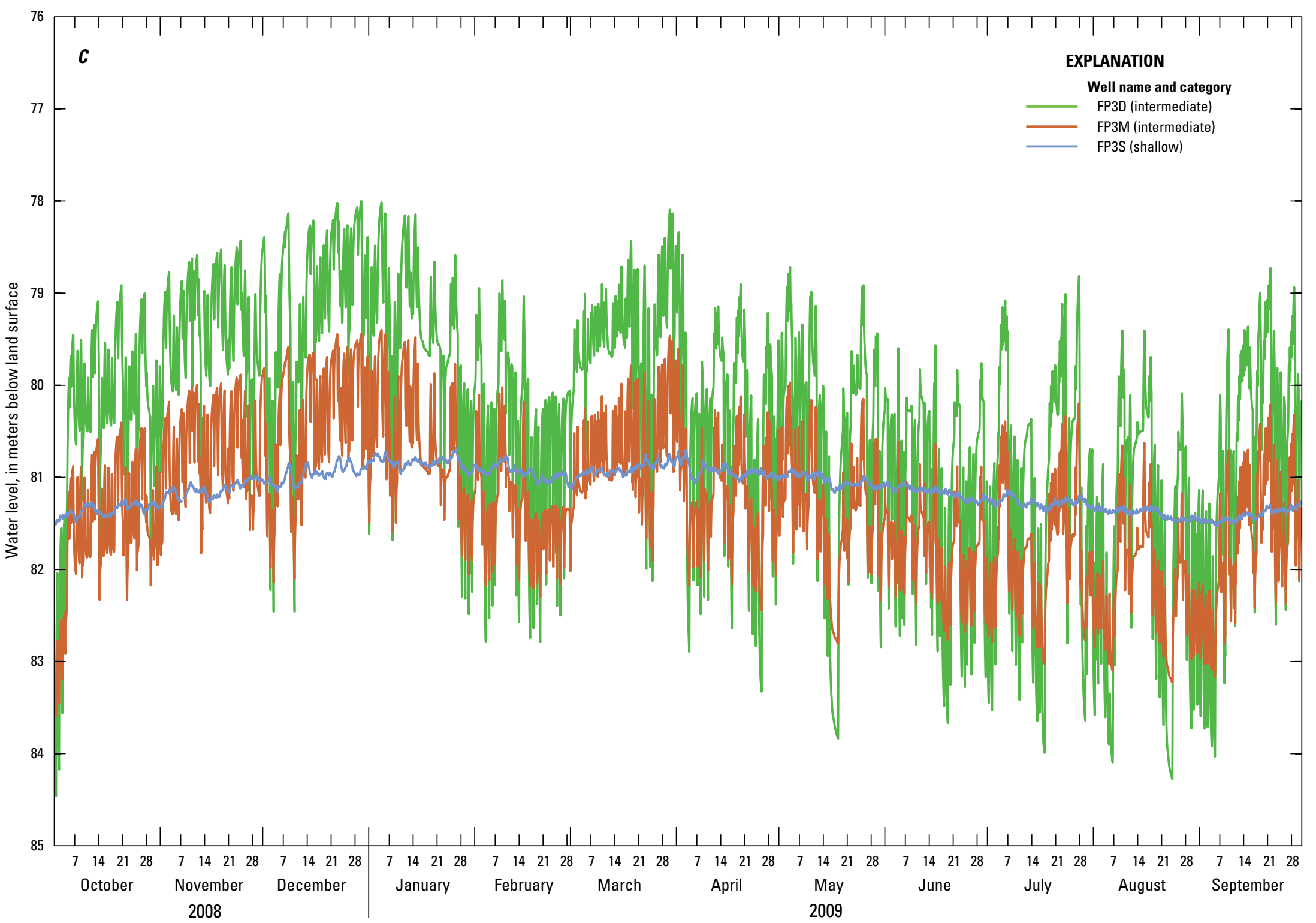

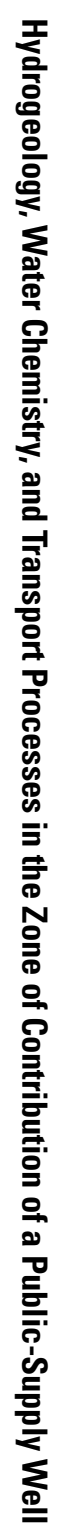

Figure 6. Changes in water levels with time in the $A, F P 1 ; B, F P 2 ; C, F P 3$; and $D$, FP4 monitoring well nests drilled for the local-scale transport of anthropogenic and natural contaminants (TANC) study in Albuquerque, New Mexico, October 2008 through September 2009. Well completion information is listed in table 1.-Continued 


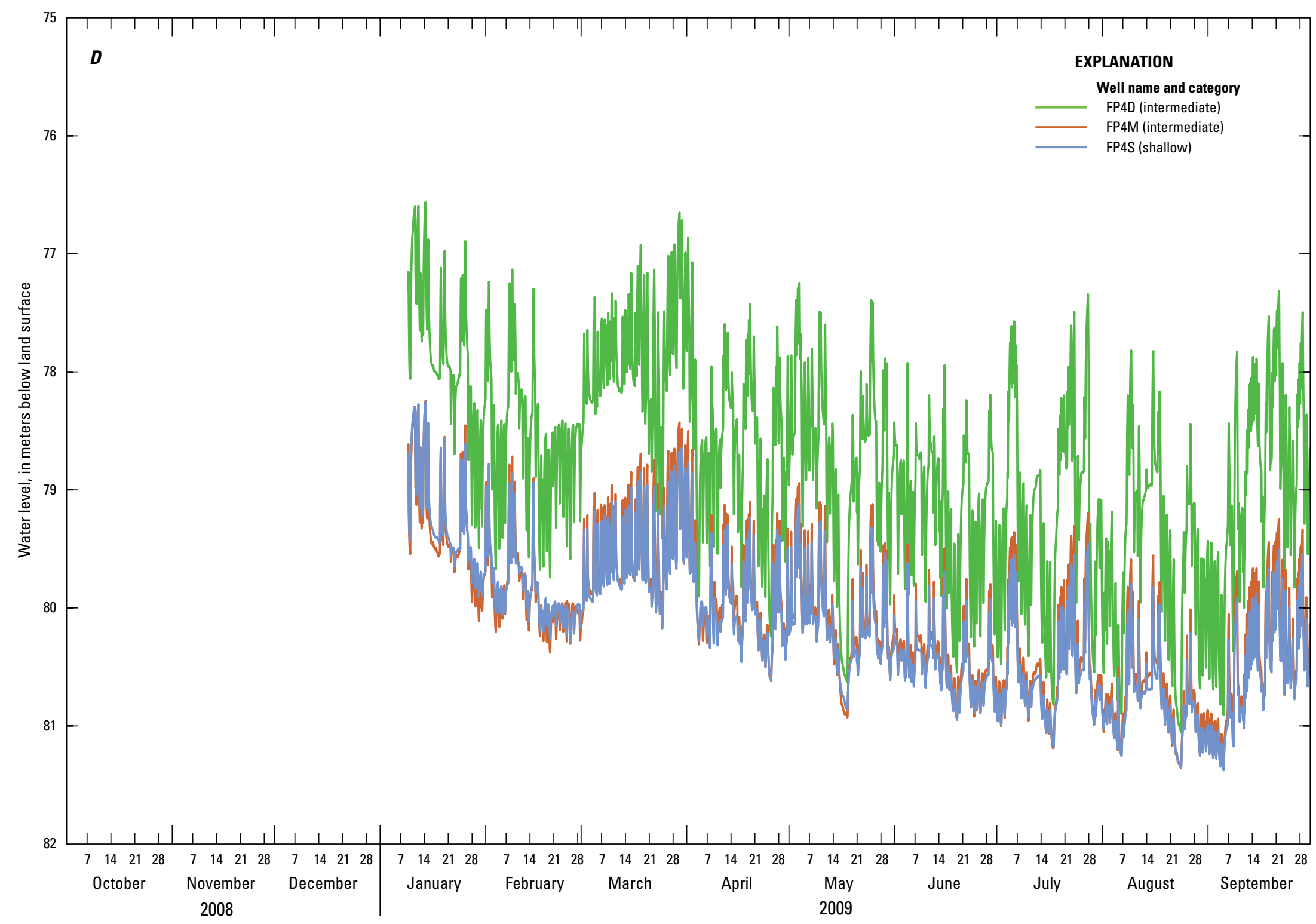

Figure 6. Changes in water levels with time in the $A, \mathrm{FP} 1 ; B, \mathrm{FP} 2 ; C$, FP3; and $D, \mathrm{FP} 4$ monitoring well nests drilled for the local-scale transport of anthropogenic and natural contaminants (TANC) study in Albuquerque, New Mexico, 0ctober 2008 through September 2009. Well completion information is listed in table 1.-Continued 


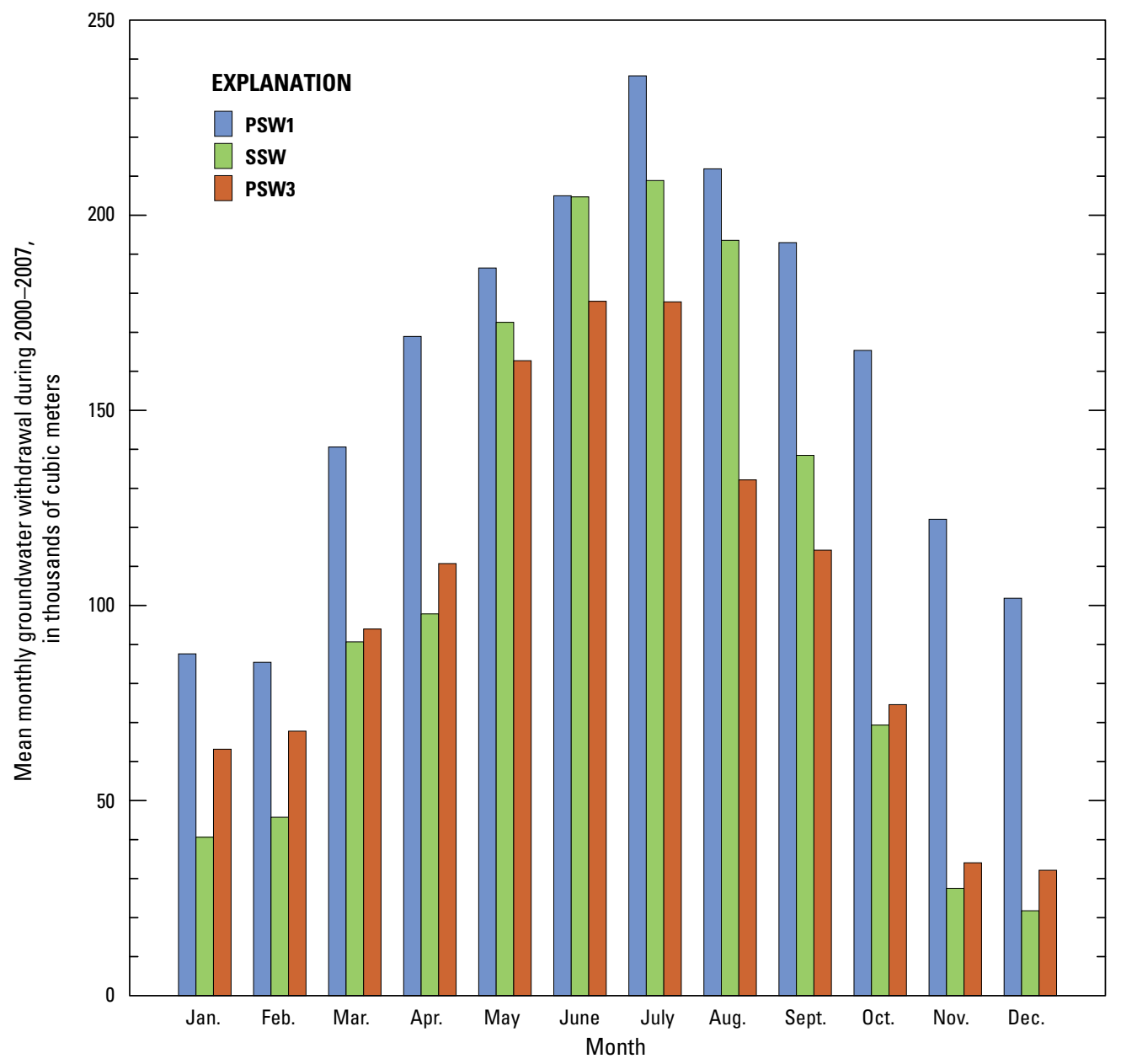

Figure 7. Mean monthly groundwater withdrawals during 2000-7 from selected public-supply wells within the local-scale transport of anthropogenic and natural contaminants (TANC) study area in Albuquerque, New Mexico. Well completion information is listed in table 1.

Data from the FP well nests indicate that daily and seasonal patterns in supply-well pumping cause substantial water-level fluctuations that vary in magnitude with location and depth, thereby complicating efforts to estimate meaningful water-level contours and corresponding groundwater-flow directions (horizontal and vertical) across the local-scale TANC study area. In essence, hydraulic heads and gradients at any given time in many parts of the study area are determined by which public-supply wells are pumping and (or) have recently been pumping most frequently. The distribution of monitoring wells with continuous water-level recorders is insufficient for accurately characterizing hydraulic heads and gradients across large parts of the study area at any given time. With the exception of data from the FP wells, information on vertical gradients across the study area in particular is lacking. Some water-level data are available for monitoring wells installed at different depths in the vicinity of known sites of groundwater contamination shown in figure 2 . However, these data are limited with respect to temporal variability and (or) with respect to indications of the effects of operating local pump-and-treat systems on local hydraulic gradients, although Landin (1999) characterized vertical gradients near the site located northwest of the SSW as "generally downward" during initial investigation of the site. Because of the paucity of data available to conduct detailed spatial and temporal characterization of hydraulic gradients across the study area, the best estimates of "typical" hydraulic heads and groundwater-flow directions are provided by groundwater-flow models of the area. Hydraulic heads simulated by the regional TANC model (Bexfield and others, 2011) during August 2008 (highpumping season) indicate that groundwater is flowing generally eastward and downward from the water table toward the production zone (fig. 3).

\section{Well-Bore Flow Characteristics}

According to measurements of well-bore flow made by using the EMFM, substantial quantities of groundwater move through the SSW under ambient conditions. The highest rate of flow measured by the EMFM was about $772 \mathrm{~L} / \mathrm{min}$ 
(204 gal/min), which was recorded at approximately $200 \mathrm{mbls}$ (fig. $8 \mathrm{~A}$ ). The direction of flow was consistently upward throughout all but about the upper and lower 12 to $14 \mathrm{~m}$ of the 244-m interval of screen that could be tested. However, flow measurements indicated that groundwater was alternately entering the well bore across one or more $6.1-\mathrm{m}$ measurement intervals and leaving the well bore across the adjacent interval(s) (fig. 8A). Overall, the well bore primarily gained water from the aquifer below about $261 \mathrm{mbls}$ and primarily lost water to the aquifer above about 157 mbls.

Under pumping conditions, measurements made by using the EMFM indicated that well-bore flow was consistently upward above the lowest measurement interval. However, similar to behavior observed under ambient conditions, groundwater was alternately entering the well bore across one or more $6.1-\mathrm{m}$ measurement intervals and leaving the well bore across the adjacent interval(s) (fig. $8 B$ ). This behavior might not have occurred in the SSW under normal pumping conditions when using the dedicated turbine pump, which typically produces water at a rate at least four times higher than the rate that the submersible test pump could achieve (ranging from about 2,770 to $2,880 \mathrm{~L} / \mathrm{min}$, or about 732 to $762 \mathrm{gal} / \mathrm{min}$, during measurements of flow). Nevertheless, overall patterns of aquifer depths contributing the most water to the well are likely to be similar under higher and lower pumping rates. The EMFM measurements indicate that about 35 percent of the flow was from about the bottom $150 \mathrm{~m}$ of screens (below about $212 \mathrm{mbls}$ ), that only about 4 percent was from about the next $40 \mathrm{~m}$ of screens, and that about 61 percent was from about the upper $60 \mathrm{~m}$ of screens (above about 169 mbls). The interval of the aquifer that produced 61 percent of the flow to the SSW is roughly equivalent to the interval sampled by the intermediate monitoring wells. Aquifer depths contributing the largest gains in flow to the SSW generally corresponded with relatively coarse sediments, as indicated by depths with higher resistivity on the short-normal resistivity log for the SSW (fig. 8). A visual log of the well bore achieved with a down-hole camera, which was conducted a few days before logging ambient flow, indicated that the well screen was encrusted with mineral deposits to varying degrees. Encrustation appeared fairly minor in the upper section of the screens, with mineral deposits becoming more evident below about 190 mbls. Below about 215 mbls, encrustation appeared sufficient to possibly affect the connection between the well bore and the aquifer. As discussed in the later "Major Elements" and "Carbon-14" sections of this report, calcite is likely to be precipitating from groundwater in the study area, which probably explains the origin and primary composition of the mineral deposits.

\section{Water Chemistry}

The chemical composition of groundwater in the localscale TANC study area is determined by the chemistry of the primary recharge source, the chemistry and mixing fractions of additional recharge sources, the chemical reactions occurring with sediment along a groundwater-flow path, and the biological processes occurring along a groundwater-flow path. The following discussion builds on the conclusions of previous regional investigations of recharge sources and chemical processes that affect groundwater chemistry in the MRGB, especially on the investigation by Plummer and others (2004a), which also discusses groundwater traveltimes, generally estimated to be on the order of thousands of years. The current study focuses on the chemical and isotopic characteristics of groundwater in the study area that are most useful in understanding the recharge sources, mixing fractions, and chemical and biological processes that affect the water quality of the SSW. The sources and transport processes that affect natural and anthropogenic contaminants that have been detected in groundwater from the SSW and from nearby public-supply and monitoring wells are particularly emphasized. The use of chemical and isotopic data in interpreting groundwater ages is discussed in the "Groundwater Age" section of this report.

\section{Stable Isotopes of Hydrogen and Oxygen}

Previous investigations, including those by Yapp (1985) and Plummer and others (2004a), demonstrated that stable isotopes of hydrogen and oxygen in groundwater in the Albuquerque area were helpful in determining the primary sources of recharge to the aquifer. The stable isotopic composition of groundwater sampled at various locations around Albuquerque was found to closely reflect the composition of water recharging primarily along the Rio Grande, along the mountain front of the eastern MRGB, or along the mountain front of the northern MRGB, which in turn reflects the typical elevation at which precipitation associated with each of those sources occurs. Plummer and others (2004a) determined that groundwater derived from mountain-front recharge processes along the east side of Albuquerque typically had $\delta \mathrm{D}$ values between -80 and -85 per mil, whereas groundwater derived from seepage along the Rio Grande typically had $\delta \mathrm{D}$ values between -90 and -100 per mil, reflecting the large contribution that snowmelt runoff from high elevations in southern Colorado and northern New Mexico makes to river flow. Groundwater derived from recharge occurring along the northern margin of the MRGB, which includes inflow of deep groundwater that likely recharged outside the basin at high elevations and (or) under cooler climatic conditions, typically had $\delta \mathrm{D}$ values similar to or lighter than values for recharge derived from the Rio Grande.

Groundwater from wells sampled for the local-scale TANC study generally had $\delta \mathrm{D}$ values between about -90 and -98 per mil (fig. 9; table 3 at end of report). These values are consistent with data collected by Plummer and others (2004a), which indicated that groundwater within the study area had recharged along the Rio Grande. As a group, the deep and the supply wells (including the SSW) in the TANC network produced water with the lightest $\delta \mathrm{D}$ values, generally between -94 and -98 per mil (fig. 9). However, samples from several 

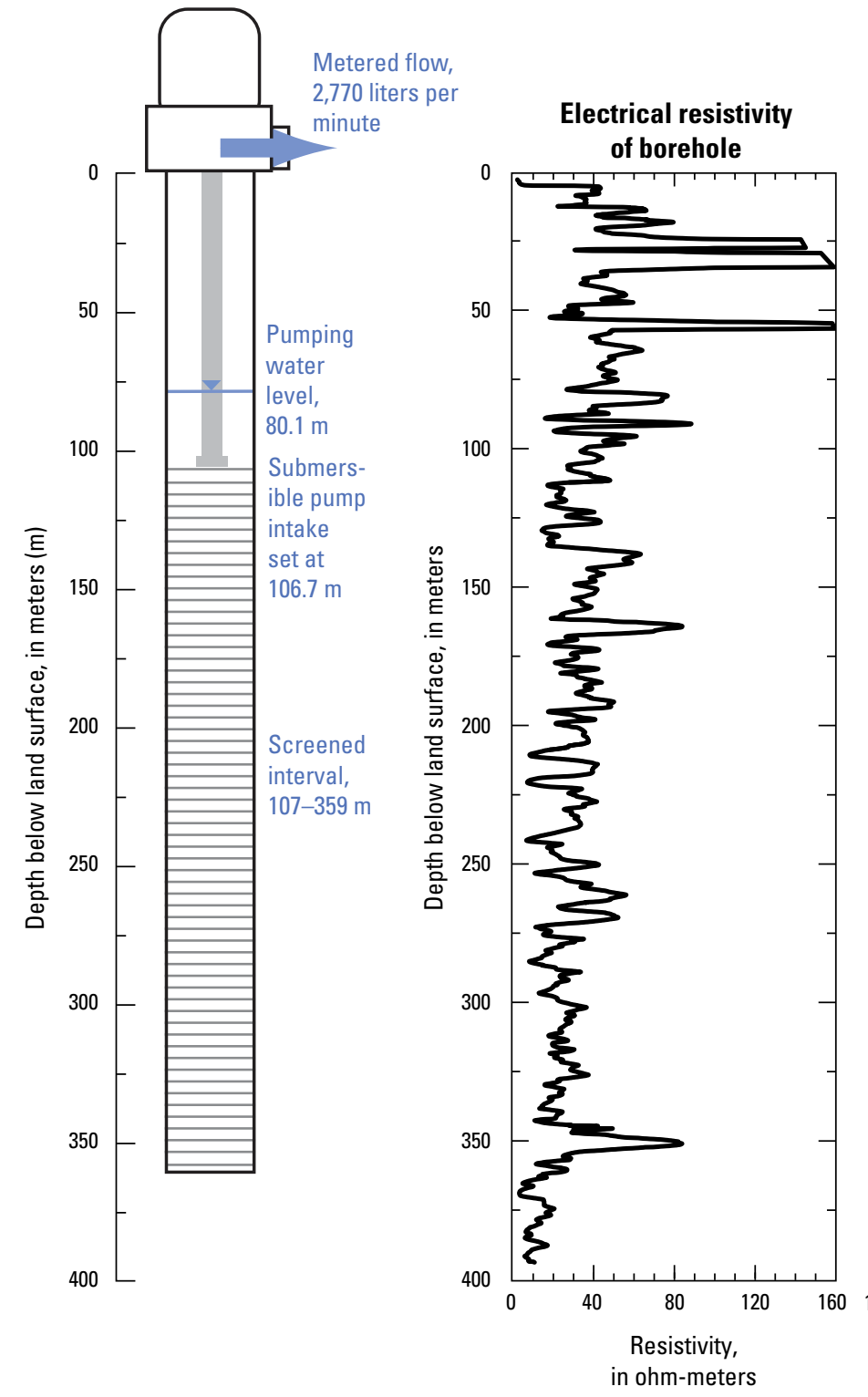

A. Ambient flow

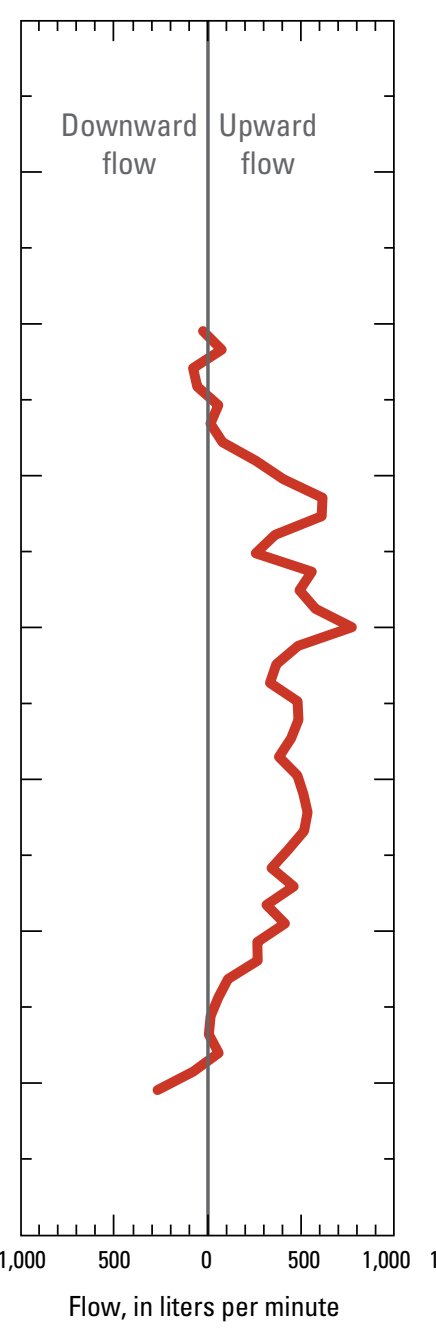

B. Pumping flow

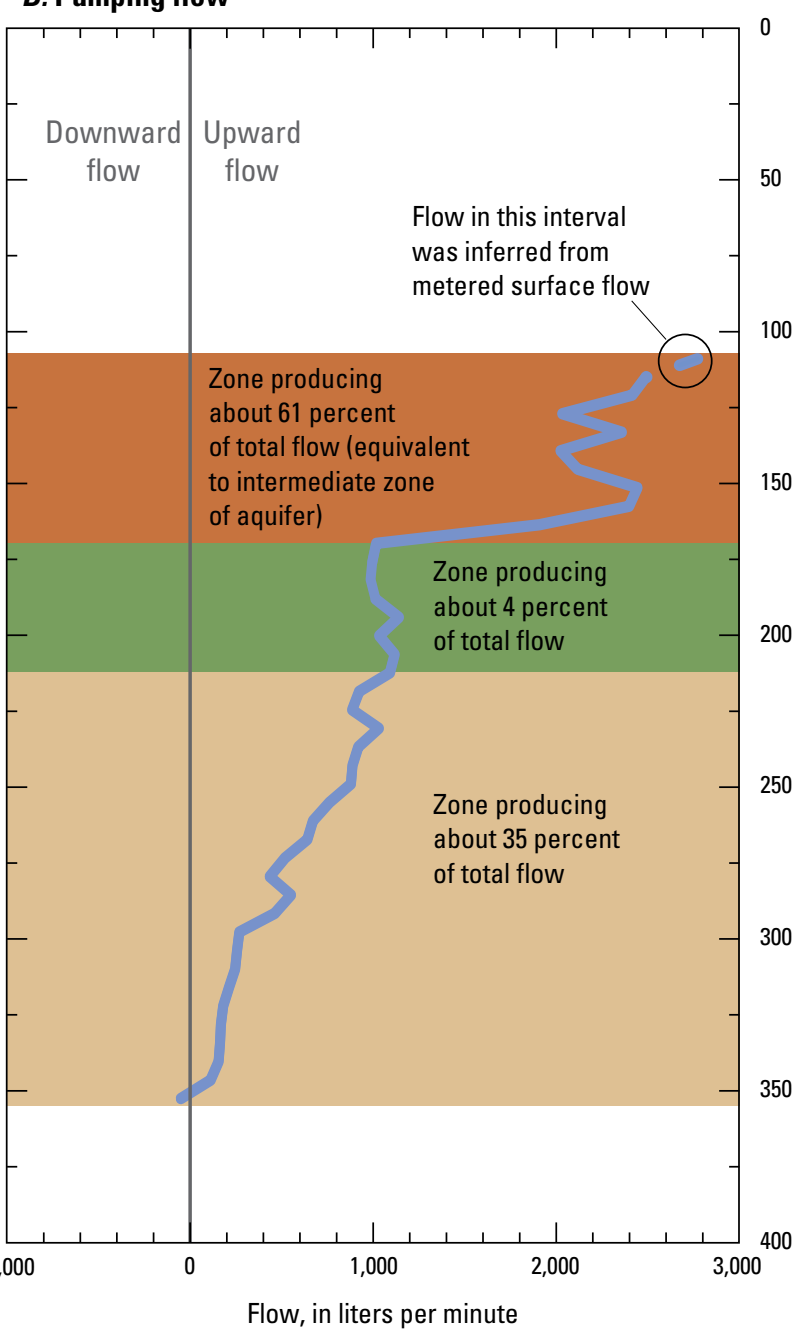

Figure 8. Approximate distribution of flow contributed from various depths of the aquifer to the studied supply well in Albuquerque, New Mexico under $A$, ambient conditions and $B$, pumping conditions. 


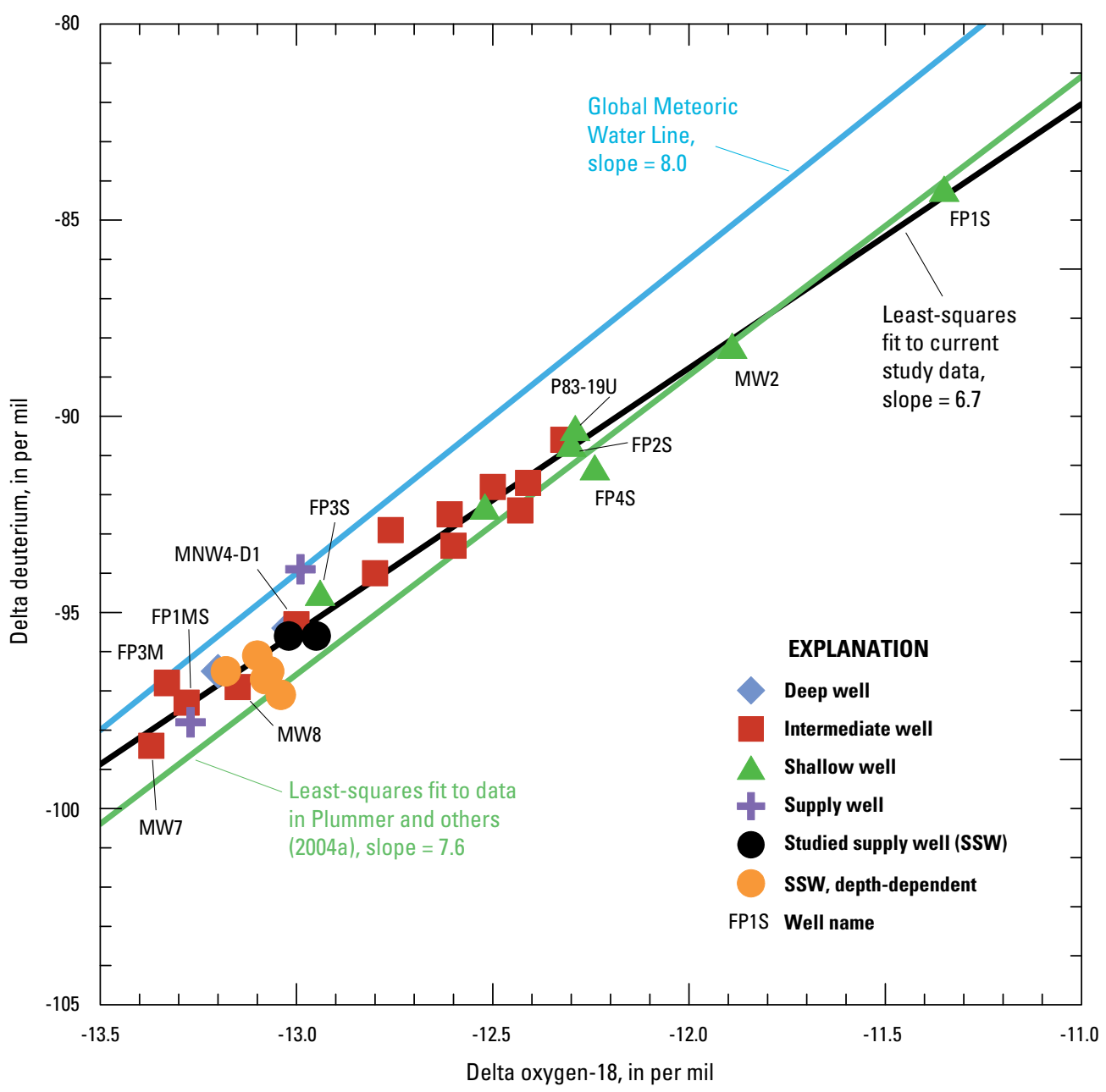

Figure 9. Values for oxygen and hydrogen isotopes of groundwater from the local-scale transport of anthropogenic and natural contaminants (TANC) study area in Albuquerque, New Mexico.

intermediate wells were also among samples with the lightest $\delta \mathrm{D}$ values (FP1MS, FP3M, MNW4-D1, MW7, and MW8), as was a sample from a shallow well (FP3S). As discussed in detail in the "Groundwater Age" section of this report, groundwater samples with the lightest $\delta \mathrm{D}$ values generally were interpreted as having the largest fractions of old recharge (on the order of thousands of years), sourced primarily from the Rio Grande, and the smallest fractions of young recharge.

Most shallow and intermediate wells produced groundwater with $\delta D$ values heavier than -94 per mil (fig. 9). Five of the six heaviest $\delta \mathrm{D}$ values were for groundwater from shallow wells (FP1S, FP2S, FP4S, MW2, and P83-19U), implying that the $\delta \mathrm{D}$ values for groundwater from intermediate wells could represent mixing between shallow and deeper groundwater. The two heaviest $\delta \mathrm{D}$ values were -84.2 per mil from FP1S and -88.2 per mil from MW2, which fall outside the range of values identified by Plummer and others (2004a) as being typical for recharge from the Rio Grande. The pattern of heavier $\delta \mathrm{D}$ values in groundwater sampled at or near the water table indicates that shallow groundwater in the area typically has a fraction of recharge that either did not originate as seepage from the Rio Grande (originating instead as precipitation within or along the margins of the MRGB) or that became fractionated during recharge as a result of evaporation. Fractionation associated with evaporation is indicated when a line through data plotted on a graph of $\delta \mathrm{D}$ values in relation to $\delta^{18} \mathrm{O}$ values has a lower slope than the Global Meteoric Water Line (GMWL), which defines the relation between $\delta \mathrm{D}$ and $\delta^{18} \mathrm{O}$ in worldwide fresh surface waters (as determined by Rozanski and others, 1993). The slope of a line with the best least-squares fit to the groundwater samples from the TANC well network is about 6.7, whereas the slope for the GMWL is 8.0 (fig. 9), indicating that evaporation has likely affected the stable isotopic composition of a fraction of water recharging the aquifer in the study area. Because the depth to water in most or all of the study area is too large for evaporation to occur directly from the water table, it is likely that evaporation of water that ultimately recharged the aquifer occurred at the land surface or during infiltration through the upper unsaturated zone. 


\section{Field Measurements}

Specific conductance, which is related to the concentration of dissolved solids in a water sample, was between about 365 and 600 microsiemens per centimeter $(\mu \mathrm{S} / \mathrm{cm})$ for groundwater samples collected from most wells in the localscale TANC study area (fig. 10A; table 3). For these wells, specific conductance did not show a continuous pattern with depth, although higher values generally were measured for water from wells completed at shallower depths $(\rho=-0.62$, $\mathrm{p}$-value $<0.001$ ). Samples from 4 intermediate wells (FP1MS, FP3M, MW7, and MW8) had specific conductance lower than $365 \mu \mathrm{S} / \mathrm{cm}$; all four of these wells also had light $\delta \mathrm{D}$ values and were interpreted to contain relatively small fractions of young water.

Samples from seven wells had specific conductance of about $600 \mu \mathrm{S} / \mathrm{cm}$ or higher (fig. 10A; table 3). Five of these wells are shallow (water-table) wells (FP1S, FP2S, FP4S, MW2, and MW9), which had specific conductance up to $1,314 \mu \mathrm{S} / \mathrm{cm}$. The pattern of higher specific conductance in groundwater at or near the water table implies that shallow groundwater in the area typically obtained a fraction of recharge from a source that had elevated specific conductance, that was evaporated before recharge, and (or) that flushed accumulated solutes out of the unsaturated zone during recharge. Solutes can build up over time in the unsaturated zone in basins such as the MRGB, where relatively low rates of precipitation relative to evapotranspiration result in little recharge from precipitation across broad areas (Plummer and others, 2004a). In such areas, any water that does result in recharge after infiltration through the unsaturated zone will tend to have relatively high concentrations of solutes. The five shallow (water-table) wells with relatively high specific conductance also have relatively heavy $\delta \mathrm{D}$ values, an outcome consistent with the conclusion that groundwater from these wells includes a fraction of water that evaporated before recharge. This fraction could include water that migrated relatively quickly through the unsaturated zone after evaporation at or near the land surface and (or) water that was flushed out of the soil zone after residing there for a relatively long period. The two intermediate wells with relatively high specific conductance (MNW4-D1 and SFMW-46) were both associated with the known groundwater contamination site located northwest of the SSW, implying that relatively high specific conductance might be characteristic of that source of contamination and (or) that groundwater migrated to these wells from the water table.

For groundwater samples from most wells, field measurements of $\mathrm{pH}$ ranged between about 7.4 and 8.1, and showed no clear pattern with depth (fig. 10B; table 3). Monitoring wells producing groundwater with relatively high $\mathrm{pH}$ values (about 7.8 or higher) included the two deep wells, four shallow (water-table) wells (FP1S, FP2S, FP3S, and FP4S), and four intermediate wells (FP1MS, FP3M, FP3D, and MW8). Samples from the 4 shallow wells also had relatively low partial pressures of carbon dioxide gas $\left(\mathrm{pCO}_{2}(\mathrm{~g})\right)$, in some cases approaching the atmospheric value of $10^{-3.5}$, and generally their alkalinity values were the lowest measured among all wells (table 3). Biological activity in the upper unsaturated zone, such as plant root respiration and microbial respiration from the decomposition of organic matter, generally substantially increases $\mathrm{pCO}_{2}(\mathrm{~g})$, adding to the acidity of the water and correspondingly lowering $\mathrm{pH}$ values as the carbon dioxide gas dissolves. This process tends to enhance dissolution of calcite and other minerals, also increasing bicarbonate concentrations and alkalinity values, as observed in MW9 (fig. 10B; table 3). The high-pH shallow groundwater samples appear not to have been substantially affected by biological activity within the unsaturated zone or aquifer, possibly as a result of low levels of organic matter and (or) of short residence times in the parts of the unsaturated zone that water encounters when recharging these wells, together with naturally low levels of organic matter in the aquifer.

Of the intermediate wells with high-pH groundwater samples, three (FP1MS, FP3M, and MW8) produced samples with relatively low $\mathrm{pCO}_{2}(\mathrm{~g})$ values, similar to samples from the high-pH shallow wells, and relatively low alkalinity values, although generally slightly higher than the alkalinity values from the high-pH shallow wells. Samples from these three high-pH intermediate wells also had light $\delta \mathrm{D}$ values and were interpreted to consist primarily of old groundwater with ages on the order of thousands of years. Groundwater that has been in contact with silicate aquifer sediments and isolated from the atmosphere for this extended period of time tends to decrease in $\mathrm{pCO}_{2}(\mathrm{~g})$ and to increase in $\mathrm{pH}$ as a result of mineral dissolution (Langmuir, 1997). This geochemical evolution of groundwater probably explains the low $\mathrm{pCO}_{2}(\mathrm{~g})$ and the high $\mathrm{pH}$ values observed in samples from deep wells, as well as the geochemical similarities observed in samples from most of the high-pH intermediate wells.

The sample from one intermediate well (SFMW-46) had an anomalously low $\mathrm{pH}$ value (fig. $10 B$; table 3 ). Similar to well MW9, groundwater from this well also had the high $\mathrm{pCO}_{2}$ (g) and high alkalinity that would be expected in the presence of biological activity. SFMW-46 is associated with the known groundwater contamination site located northwest of the SSW, where the source of VOCs to the aquifer likely has made additional organic carbon available for microbial respiration.

\section{Reduction/0xidation Conditions}

Reduction/oxidation (redox) conditions influence the occurrence and fate of many common groundwater contaminants, including arsenic, nitrate, and VOCs, through processes that affect the mobilization and (or) degradation of contaminants (Chapelle and others, 1995; McMahon and Chapelle, 2008). Various electron acceptors are present in groundwater, and, where sufficient electron donors - typically, dissolved or particulate organic carbon - are available, subsurface microorganisms will utilize electron acceptors in order of their efficiency. As a result, groundwater chemistry evolves through these microbial processes. The most efficient electron 

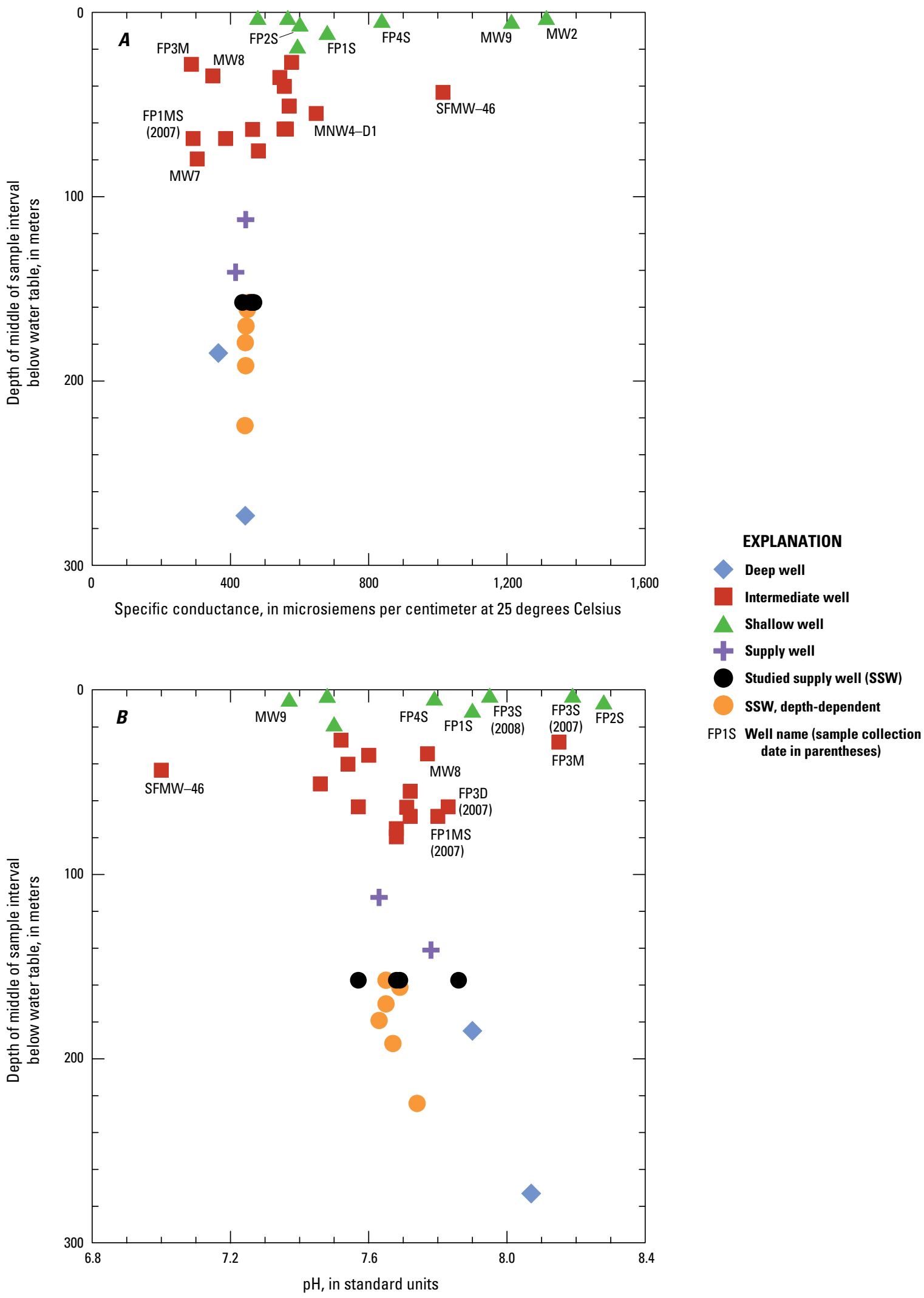

date in parentheses)

Figure 10. A, specific conductance and $B, \mathrm{pH}$ with depth below the water table in groundwater from the local-scale transport of anthropogenic and natural contaminants (TANC) study area in Albuquerque, New Mexico. 
acceptor, dissolved oxygen (DO), will be utilized first, followed by nitrate, manganese, iron, sulfate, and carbon dioxide. McMahon and Chapelle (2008) devised a framework for classifying groundwater samples with respect to redox conditions by using field measurements of DO and laboratory measurements of nitrate, manganese, iron, and sulfate (table 4 at end of report). Groundwater samples collected for the local-scale TANC study were classified according to this framework, which was incorporated into a Microsoft ${ }^{\circledR}$ Excel $^{\circledR}$ workbook described by Jurgens and others (2009); the resulting classifications are shown in table 5 (at end of report).

Groundwater samples from most local-scale TANC wells had DO concentrations higher than $0.5 \mathrm{mg} / \mathrm{L}$ and were classified as oxic (table 5). Similar to findings for other alluvial aquifers in the western United States, these generally persistent oxic conditions are consistent with the minimal presence of organic carbon in aquifer sediments (McMahon and Chapelle, 2008). The full range of measured DO concentrations is 0.05 to $8.2 \mathrm{mg} / \mathrm{L}$, with the highest concentrations being measured in samples from shallow (water-table) wells (FP1S, FP2S, FP4S, MW2, and MW9) (fig. 11; table 5). All but 2 of the 17 samples collected from the SSW by using the dedicated turbine pump (regular samples) had DO concentrations higher than $0.5 \mathrm{mg} / \mathrm{L}$; for the 2 samples with DO lower than $0.5 \mathrm{mg} / \mathrm{L}$, results for the other analytes used in redox classification indicated the presence of suboxic (rather than anoxic) or unknown, but likely suboxic, conditions.

All other samples with DO concentrations less than $0.5 \mathrm{mg} / \mathrm{L}$ were from intermediate wells. Samples collected in 2007 from FP1MS and FP3D were classified as suboxic or mixed, partly because of DO concentrations less than 0.5 $\mathrm{mg} / \mathrm{L}$; samples from these same wells in 2008, however, had DO concentrations higher than $0.5 \mathrm{mg} / \mathrm{L}$ (table 5). Although samples from FP3D had manganese and iron concentrations below the thresholds that would cause the samples to be classified as anoxic, these samples did have small concentrations of methane, which caused them to be classified as mixed; in the case of the 2008 sample, an odor of hydrogen sulfide also was present, further indicating that a fraction of water that had encountered anoxic conditions was present. Samples from FP2D and FP2M were classified as anoxic, and specifically as manganese reducing. The MNW4-D1 sample also had evidence of manganese-reducing conditions, but the sample was classified as mixed because it included detectable methane. None of the samples observed to have DO concentrations less than $0.5 \mathrm{mg} / \mathrm{L}$ had nitrate concentrations of $0.5 \mathrm{mg} / \mathrm{L}$ or above, indicating either that nitrate concentrations in the recharge water were low or that nitrate reduction had taken place.

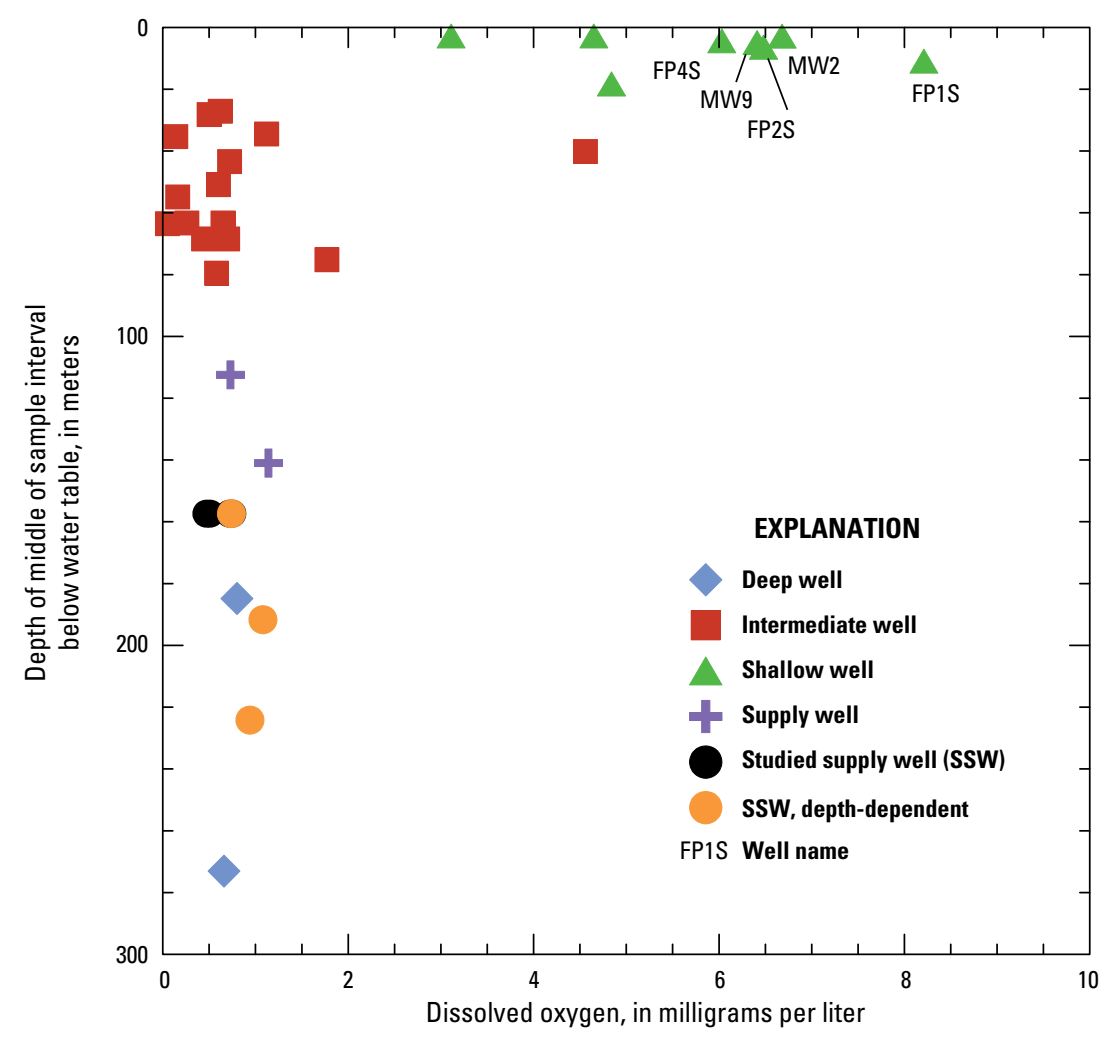

Figure 11. Dissolved oxygen with depth below the water table in groundwater from the local-scale transport of anthropogenic and natural contaminants (TANC) study area in Albuquerque, New Mexico. 
Samples from FP2S and FP4M were classified as mixed because their DO concentrations were higher than $0.5 \mathrm{mg} / \mathrm{L}$, and their manganese concentrations were higher than $50 \mu \mathrm{g} / \mathrm{L}$. The FP2S sample also had an odor of hydrogen sulfide. FP2S is located near a stormwater conveyance channel that usually contains standing water and vegetation (characteristics conducive to anoxic conditions) and that might contribute recharge to FP2S, particularly during precipitation events. Although the sample from SFMW-46 (associated with the known groundwater contamination site located northwest of the SSW) had a DO concentration higher than $0.5 \mathrm{mg} / \mathrm{L}$, the sample was classified as mixed because of detectable methane; a low (estimated) concentration of nitrate also indicated the presence of a fraction of water that had encountered anoxic conditions.

\section{Major Elements}

The major-element chemistry of groundwater in the local-scale TANC study area reflects the chemical composition of recharge sources and the chemical reactions occurring along a groundwater-flow path. This section focuses on relations among major elements that are useful in determining water types, solute sources, and major geochemical processes. Water types can be inferred from a trilinear (or Piper) diagram (Hem, 1992) that illustrates the relative proportion of major cations and anions in milliequivalents per liter (meq/L) (fig. 12).

Most groundwater samples had a composition that was not dominated by any single cation (fig. 12; table 3). Magnesium was consistently only a small proportion (generally between 10 and 20 percent) of total cations. Calcium and sodium each typically ranged between about 20 and 60 percent of total cations. On the Piper diagram shown in figure 12, samples cluster closely along a line between about 80 percent calcium plus magnesium with 20 percent sodium plus potassium at one end, and about 30 percent calcium plus magnesium with 70 percent sodium plus potassium at the other end. Samples from most shallow and intermediate wells tend to cluster toward the higher calcium-plus-magnesium end of the line, near the cation composition of a representative sample of surface water from the Rio Grande. Samples from supply wells had cation compositions falling between those of intermediate and those of deep wells. The sample from FP1D had the highest proportion of sodium plus potassium, likely representing the most extensive reaction of groundwater with sediments along a flow path through such processes as cation exchange and plagioclase feldspar weathering, as discussed by Plummer and others (2004a). Similar to the findings of Plummer and others (2004a), groundwater samples from the local-scale TANC study area generally were just below to just above saturation with respect to calcite, based on analysis of sample results using the geochemical software PHREEQC, version 2.17.1 (Parkhurst and Appelo, 1999). Geochemical calculations presented in the "Carbon-14" section of this report indicate the common precipitation of small quantities of calcite that would cause minor decreases in calcium concentrations.
The groundwater samples from the local-scale TANC study area were relatively variable with respect to anion compositions (fig. 12; table 3). Of the anions listed on the axis, "Chloride, Fluoride, Nitrate," of the Piper diagram in figure 12, chloride was the dominant anion in all samples; therefore, the other, minor anions are disregarded for this discussion. In samples from all shallow (water-table) wells, chloride was greater than 20 percent of total anions, possibly reflecting a fraction of recharge that flushed accumulated solutes out of the unsaturated zone. Sulfate in samples from five of the six shallow (water-table) wells constituted about 40 percent or more of total anions, unlike samples from deeper wells, which generally had smaller proportions of sulfate. Two of the three intermediate wells that had proportions of chloride (MNW4-D1 and SFMW-46) greater than 20 percent of total anions are both associated with the known groundwater contamination site located northwest of the SSW, implying that relatively high chloride might be characteristic of that source of contamination and (or) that groundwater migrated to these wells from the water table. The proportion of chloride was also relatively high in samples from deep wells, perhaps reflecting a fraction of relatively mineralized groundwater from a deep source, as described by Plummer and others (2004a).

Samples from supply wells (including regular samples from the SSW) had proportions of chloride falling between those of intermediate wells, which typically have chloride as less than 20 percent of total anions, and those of deep wells. Samples from most intermediate wells fall closely along a line between about 70 percent bicarbonate plus carbonate with 30 percent sulfate plus chloride at one end and about 40 percent bicarbonate plus carbonate with 60 percent sulfate plus chloride at the other end (fig. 12). The anion composition of a representative sample of surface water from the Rio Grande falls slightly toward the higher bicarbonate plus carbonate end of this line. Therefore, groundwater samples with higher proportions of sulfate and (or) chloride probably include a fraction of water from a recharge source other than the Rio Grande, or they have been affected by reactions with aquifer sediments. Because the minerals described in cuttings and core samples from the study area do not have sulfate or chloride as major components, and because the mass of calcite precipitation that would be required to substantially reduce the proportion of bicarbonate is high, fractions of recharge from other sources appear to be the most likely cause of increased proportions of sulfate and (or) chloride in groundwater samples from the study area.

The relation between chloride and bromide, which commonly is investigated for information about solute sources, further indicates that sources of water and solutes besides the Rio Grande have affected the chemical composition of groundwater in the study area. Although historical bromide data for the Rio Grande at Albuquerque were not available in the USGS NWIS database, bromide data were collected by Plummer and others (2004a) at a location about $4.2 \mathrm{~km}$ upstream. These samples from the Rio Grande at Campbell 


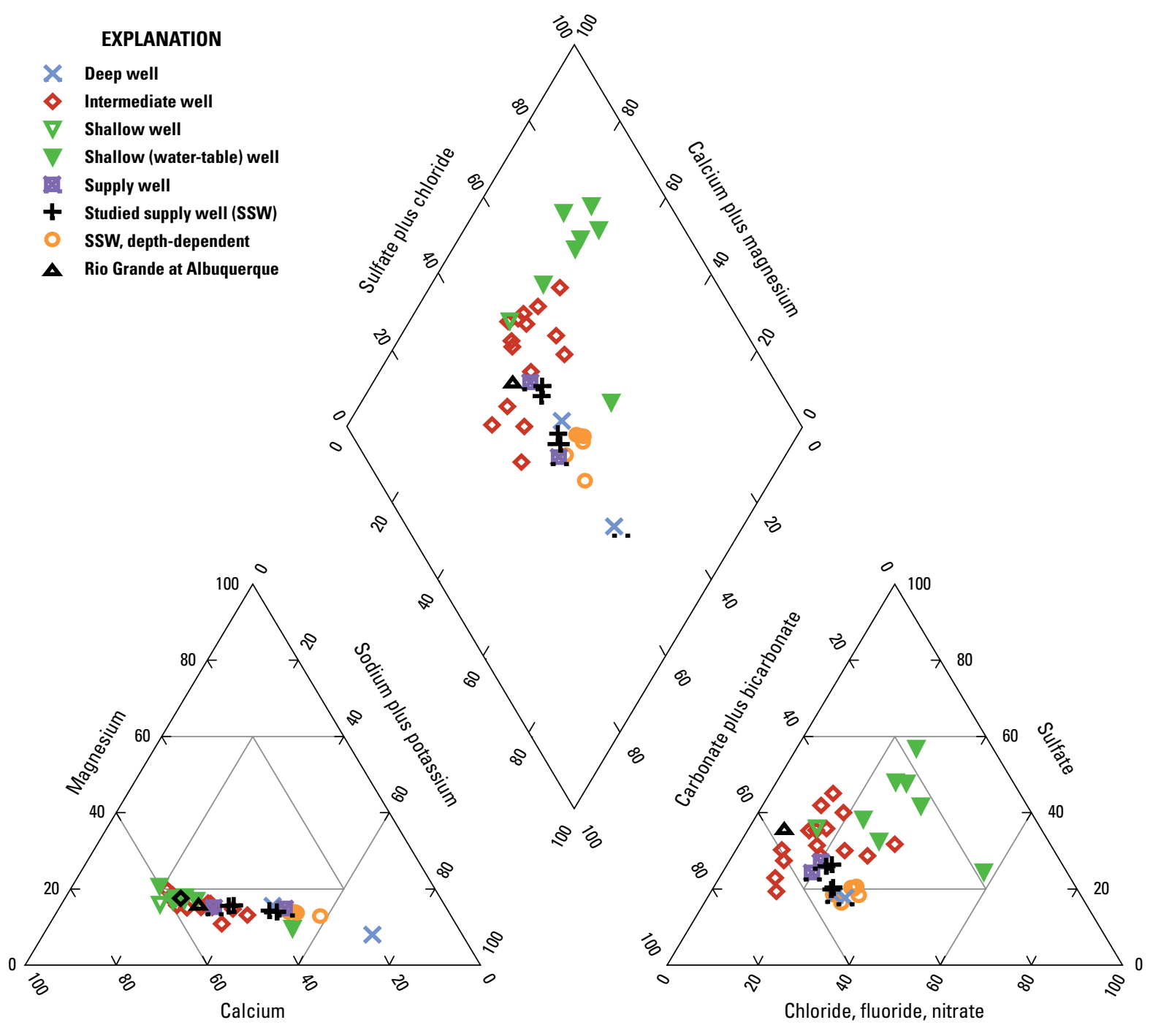

PERCENTAGE OF TOTAL IONS, IN MILLIEQUIVALENTS PER LITER

Figure 12. General chemical composition of groundwater and surface water from the local-scale transport of anthropogenic and natural contaminants (TANC) study area in Albuquerque, New Mexico.

Road in Albuquerque (Rio Grande at Campbell) that have detectable bromide concentrations are plotted against compositions of groundwater samples from the local-scale TANC study area on the graph of the chloride/bromide ratio in relation to chloride concentration in figure 13.

The Rio Grande samples generally plot closest to three of the groundwater samples (from wells FP1MS, FP3M, and MW7; fig. 13) that have the lightest $\delta \mathrm{D}$ values and were interpreted to consist primarily of old recharge sourced from the Rio Grande. These surface-water and groundwater samples have chloride concentrations between about 12 and $23 \mathrm{mg} / \mathrm{L}$ and chloride/bromide ratios between about 150 and 300. Groundwater samples from shallow (water-table) wells (FP1S, FP2S, FP3S, FP4S, MW2, and MW9) typically have substantially higher chloride concentrations (above $45 \mathrm{mg} / \mathrm{L}$ ) and lower chloride/bromide ratios (120 or below) than samples from other wells, again possibly reflecting a fraction of recharge that flushed accumulated solutes out of the unsaturated zone to the water table. The two intermediate wells associated with the known groundwater contamination site located northwest of the SSW (MNW4-D1 and SFMW-46) also have high chloride concentrations (above $65 \mathrm{mg} / \mathrm{L}$ ), but their accompanying chloride/bromide ratios are high (above 325), perhaps being characteristic of that source of contamination. Groundwater samples from the deep wells, and particularly from FP1D, also have relatively high chloride concentrations and chloride/bromide ratios, again perhaps reflecting a fraction of relatively mineralized groundwater from a deep 


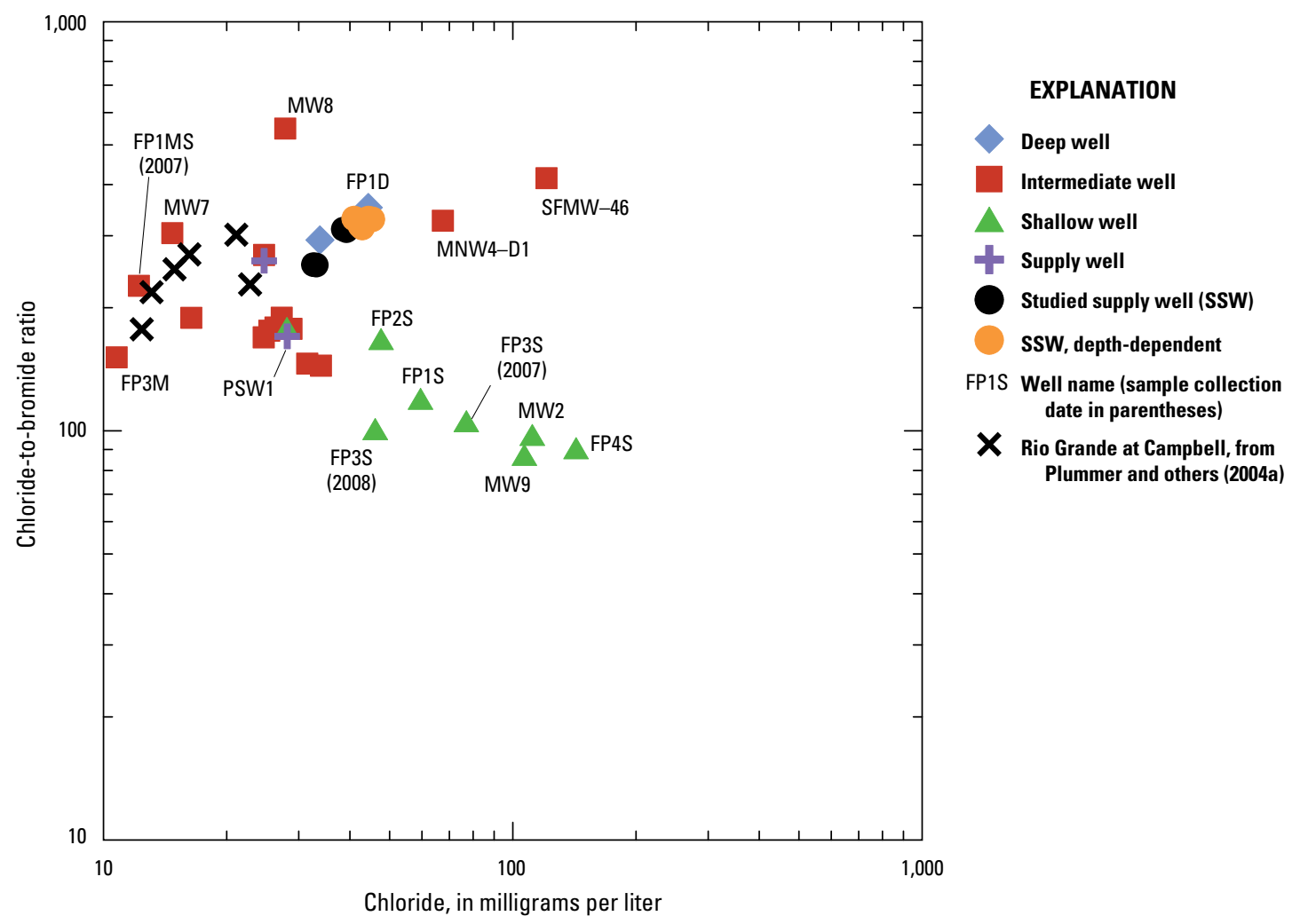

Figure 13. Chloride and chloride/bromide ratio in groundwater and in surface water from the local-scale transport of anthropogenic and natural contaminants (TANC) study area in Albuquerque, New Mexico.

source. The groundwater sample from MW8 has the highest chloride/bromide ratio (548) of any groundwater sample in the study, but with only a moderate chloride concentration. The reason for the relative lack of bromide in this sample is not known. Groundwater samples from several intermediate wells cluster in a group as having moderate chloride concentrations of about 25 to $30 \mathrm{mg} / \mathrm{L}$ and chloride/bromide ratios of about 145 to 190 . Samples from the supply wells mostly plot as having values between those of the cluster of intermediate wells and those of the deep wells, although the sample from PSW1 plots between those of the cluster of intermediate wells and those of the shallow wells, potentially indicating a greater component of shallow groundwater in the sample from PSW1.

Certain constituents in groundwater samples show relations with one another and with depth that appear to indicate reactions with aquifer sediments. In particular, fairly consistent increases in concentration were observed with depth below the water table for silica $(\rho=0.91$, p-value $<0.001)$ and fluoride $(\rho=0.80$, p-value $<0.001)$ (fig. $14 A)$. Silica and potassium concentrations tend to increase in tandem ( $\rho=0.78$, p-value $<0.001$ ) (fig. $14 B)$, consistent with the weathering of silicate minerals, including potassium feldspar and volcanic glass, as discussed by Plummer and others (2004a) for the MRGB. The general increase in silica concentrations with depth is probably a result of increased mineral weathering with longer groundwater traveltimes. A graph of silica with chloride (fig. 14C) illustrates that groundwater samples from shallow (water-table) wells (FP1S, FP2S, FP3S, FP4S, MW2, and MW9) and from the two intermediate wells associated with the known groundwater contamination site located northwest of the SSW (MNW4-D1 and SFMW46) have relatively small concentrations of silica despite having large chloride concentrations, perhaps reflecting substantial fractions of young recharge that have had insufficient contact time to weather silicate minerals. In addition, increases in fluoride concentrations with increasing depth and $\mathrm{pH}(\rho=0.41$, p-value $=0.01)$ (figs. $14 D$ and $E)$ are consistent with weathering of silicic volcanic rocks along groundwater flow paths. However, the relation with $\mathrm{pH}$ also could indicate $\mathrm{pH}$-dependent exchange and sorption reactions (Robertson, 1991; Plummer and others, 2004). Such pH-dependent reactions probably explain the relatively high fluoride concentrations in some shallow (water-table) wells (FP1S, FP2S, and FP3S) that have relatively short residence times but relatively high $\mathrm{pH}$ values (fig. 14E). None of the groundwater samples 

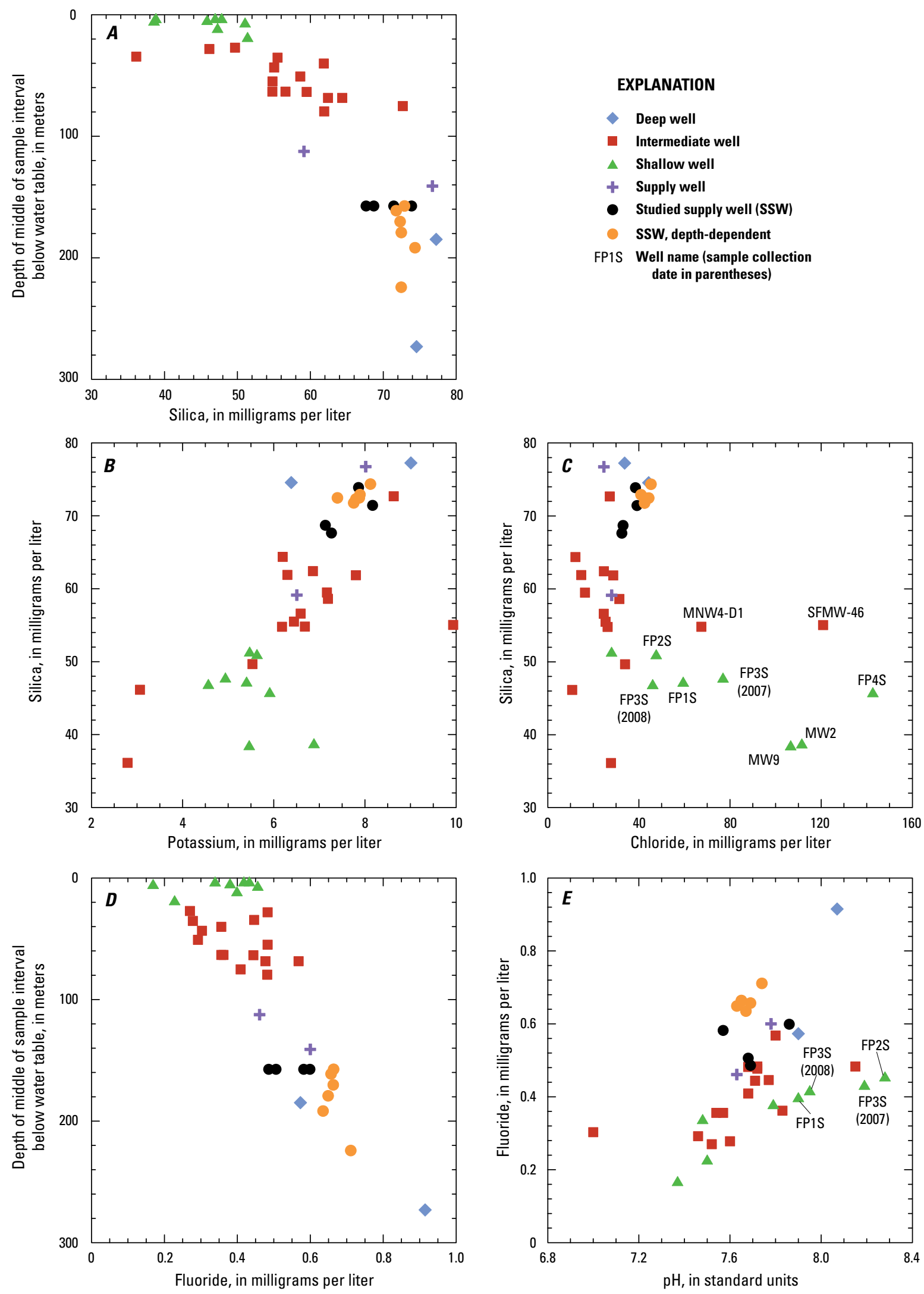

Figure 14. Relations of silica with $A$, depth below the water table, $B$, potassium, and $C$, chloride and of fluoride with $D$, depth below the water table and $E, \mathrm{pH}$ in groundwater from the local-scale transport of anthropogenic and natural contaminants (TANC) study area in Albuquerque, New Mexico. 
collected for the local-scale TANC study had fluoride concentrations exceeding the USEPA MCL of $4 \mathrm{mg} / \mathrm{L}$ (U.S. Environmental Protection Agency, 2010a).

\section{Nitrate and Nitrogen Isotopes}

Nitrite plus nitrate was detected in groundwater samples from all but one well (FP2D) within the study area. Concentrations of nitrite plus nitrate in these samples ranged from an estimated value of $0.03 \mathrm{mg} / \mathrm{L}$ to $5.43 \mathrm{mg} / \mathrm{L}$ as nitrogen (N) (table 6 at end of report). Nitrite was detected in wells from all depth categories, but at concentrations that were less than $0.15 \mathrm{mg} / \mathrm{L}$ and less than 6 percent of the total nitrite-plus-nitrate concentration; therefore, nitrite plus nitrate, which is expressed in concentrations as $\mathrm{N}$, is discussed simply as "nitrate" throughout this report. Concentrations of ammonia were below detection or below the LRL in groundwater samples from all but one well (FP1MS), further indicating that nitrogen in groundwater of the local-scale TANC study area is present primarily in the form of nitrate.

Concentrations of nitrate were highest in groundwater samples from shallow (water-table) wells (FP1S, FP2S, FP3S, FP4S, MW2, and MW9) and from the intermediate well MW8, all of which had concentrations of $1.3 \mathrm{mg} / \mathrm{L}$ or higher (fig. 15A; table 6). None of the concentrations, however, exceeded the USEPA maximum contaminant level (MCL) of $10 \mathrm{mg} / \mathrm{L}$ (U.S. Environmental Protection Agency, 2010a).
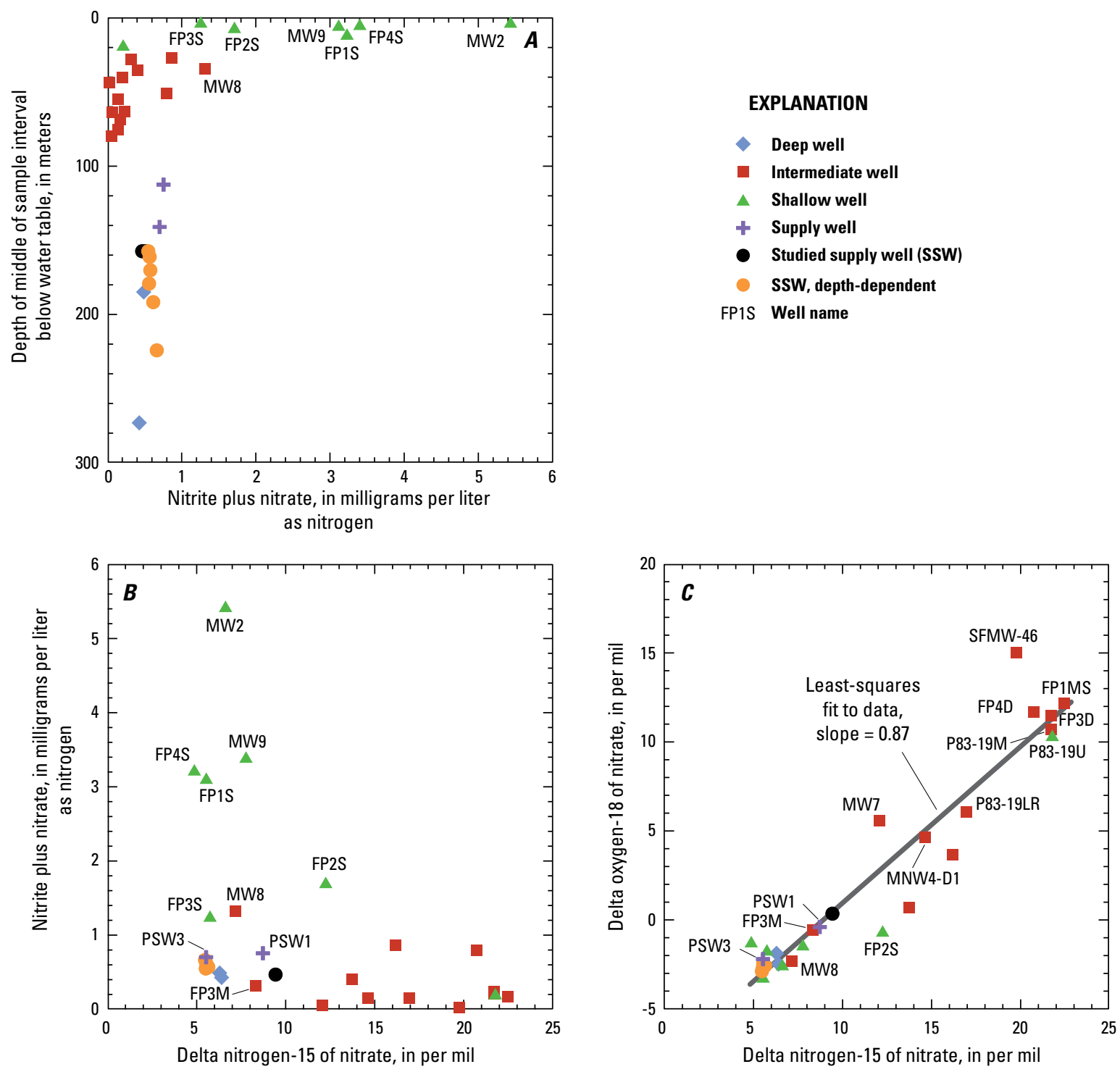

Figure 15. Relations of nitrate with $A$, depth below the water table and $B$, delta nitrogen-15 of nitrate and of $C$, delta oxygen-18 of nitrate with nitrogen- 15 of nitrate in groundwater from the local-scale transport of anthropogenic and natural contaminants (TANC) study area in Albuquerque, New Mexico. 
Concentrations of nitrate generally were lowest in samples from intermediate wells, most of which had concentrations below $0.4 \mathrm{mg} / \mathrm{L}$; the median concentration from these wells was $0.2 \mathrm{mg} / \mathrm{L}$. Samples from deep wells had slightly higher concentrations of nitrate, between 0.4 and $0.5 \mathrm{mg} / \mathrm{L}$. Along with concentrations of dissolved oxygen above $0.5 \mathrm{mg} / \mathrm{L}$, the presence of higher concentrations of nitrate in samples from deep wells when compared to those from most intermediate wells appears to indicate that groundwater traveltime is not the only factor controlling transitions in redox conditions from oxic to suboxic or anoxic. Because substantial denitrification has likely not occurred in deep wells (as discussed in the following paragraphs), concentrations of nitrate from these wells could be representative of background concentrations of nitrate for older groundwater in the study area. Modern values of nitrate observed near Albuquerque by Plummer and others (2004a) for the Rio Grande, believed to be the primary source of recharge to groundwater in the study area, rarely exceeded $0.25 \mathrm{mg} / \mathrm{L}$.

Values of certain isotopes, $\delta^{15} \mathrm{~N}$ of nitrate $\left(\delta^{15} \mathrm{~N}-\mathrm{NO}_{3}\right)$, $\delta^{18} \mathrm{O}$ of nitrate $\left(\delta^{18} \mathrm{O}-\mathrm{NO}_{3}\right)$, and $\delta^{15} \mathrm{~N}$ of nitrogen gas $\left(\delta^{15} \mathrm{~N}-\mathrm{N}_{2}\right)$, can be useful in identifying and quantifying denitrification, as well as in identifying likely sources of nitrate to groundwater (Kendall and Aravena, 2000; McMahon and others, 2008). Isotopic fractionation that occurs during the denitrification of nitrate to nitrogen gas results in enrichment (that is, increasing values) of $\delta^{15} \mathrm{~N}$ and $\delta^{18} \mathrm{O}$ in the residual nitrate. As the reaction progresses, the $\delta^{15} \mathrm{~N}$ of the resulting nitrogen gas also increases. Measured values of $\delta^{15} \mathrm{~N}-\mathrm{NO}_{3}$ in groundwater samples from the local-scale TANC study area ranged from about 4.9 to 22.5 per mil, values of $\delta^{18} \mathrm{O}-\mathrm{NO}_{3}$ ranged from about -3.2 to 15.0 per mil, and values of $\delta_{15} \mathrm{~N}-\mathrm{N}_{2}$ ranged from about 0.5 to 2.4 per mil (table 6).

Groundwater samples with the lightest values of $\delta^{15} \mathrm{~N}-\mathrm{NO}_{3}$ (below 8 per mil) and of $\delta^{18} \mathrm{O}-\mathrm{NO}_{3}$ (below -1 per mil) were from five of the six shallow (water-table) wells (FP1S, FP3S, FP4S, MW2, and MW9), the two deep wells, the supply well PSW3, and the intermediate well MW8 (figs. 15B and $C$ ). It is likely that these samples represent groundwater where minimal denitrification has occurred, either because of a substantial component of young, oxic recharge (near the water table), or because little organic carbon is present along a groundwater flow path (in the deeper aquifer). The values of $\delta^{15} \mathrm{~N}-\mathrm{NO}_{3}$ and of $\delta^{18} \mathrm{O}-\mathrm{NO}_{3}$ in these samples are consistent with nitrate derived from natural soil nitrogen (Kendall and Aravena, 2000). Three other samples with relatively light $\delta^{15} \mathrm{~N}_{-} \mathrm{NO}_{3}$ (below 10 per mil) and $\delta^{18} \mathrm{O}-\mathrm{NO}_{3}$ (below 1 per mil) are from the supply wells SSW and PSW1 and the intermediate well FP3M. As with the deep and the supply wells, the intermediate wells MW8 and FP3M were interpreted to have large fractions of old groundwater, with little recent recharge. One shallow (water-table) well, FP2S, has a relatively light value of $\delta^{18} \mathrm{O}-\mathrm{NO}_{3}\left(-0.6\right.$ per mil), but a $\delta^{15} \mathrm{~N}-\mathrm{NO}_{3}$ value of 12.2 per mil. The sample from $\mathrm{FP} 2 \mathrm{~S}$, which might receive recharge from a nearby stormwater conveyance channel, was classified as being of mixed redox conditions. The starting isotopic composition of nitrate in recharge from the conveyance channel might not be typical of other recharge sources in the study area, and the usual presence of standing water and vegetation in the channel could allow denitrification to occur before recharge.

A graph of the relation of $\delta^{18} \mathrm{O}-\mathrm{NO}_{3}$ with $\delta^{15} \mathrm{~N}-\mathrm{NO}_{3}$ (fig. $15 C$ ) shows that groundwater samples from most wells fall along a least-squares regression line with a slope of 0.87 $\left(r^{2}=0.91\right)$. This slope falls near the high end of ranges of about 0.48 to 0.83 reported in the literature for denitrification (Böttcher and others, 1990; Aravena and Robertson, 1998; Mengis and others, 1999; Fukada and others, 2003; Sigman and others, 2005; McMahon and others, 2008). Groundwater samples with the heaviest values of $\delta^{15} \mathrm{~N}-\mathrm{NO}_{3}$ (above 19 per mil) and of $\delta^{18} \mathrm{O}-\mathrm{NO}_{3}$ (above 10 per mil), likely indicating the greatest progress of the denitrification reaction, are mostly from intermediate wells. These six wells include one intermediate well associated with the known groundwater contamination site located northwest of the SSW (SFMW-46), one shallow and one intermediate well associated with the known groundwater contamination site located southwest of the SSW (P83-19U and P83-19M), and the intermediate wells FP1MS, FP3D, and FP4D. As subsequently discussed in the "Volatile Organic Compounds" section, groundwater sampled from FP3D and FP4D appears to include a fraction of VOCcontaminated groundwater associated with the site located northwest of the SSW. This means that, except for FP1MS, all the wells with relatively heavy isotopes of nitrate include groundwater associated with known sites of contamination with organic compounds that can provide a carbon source for microbial respiration. Groundwater from these five wells had concentrations of DOC ranging from about 0.6 to $2.1 \mathrm{mg} / \mathrm{L}$ (table 6).

Measured values of $\delta^{15} \mathrm{~N}-\mathrm{N}_{2}$ in groundwater samples from the local-scale TANC study area were also consistent with the occurrence of denitrification, particularly in intermediate wells (fig. 16A; table 6). Values of $\delta^{15} \mathrm{~N}-\mathrm{N}_{2}$ were generally consistent with those of $\delta^{15} \mathrm{~N}-\mathrm{NO}_{3}$ and $\delta^{18} \mathrm{O}-\mathrm{NO}_{3}$ in that samples from the shallow (water-table) wells and the intermediate wells FP3M and MW8 had values that were among the lightest, indicating minimal denitrification, and that samples from the intermediate wells SFMW-46, FP3D, and FP4D had values among the heaviest, indicating greater denitrification. Unlike the nitrate isotopes, the value of $\delta^{15} \mathrm{~N}-\mathrm{N}_{2}$ for the groundwater sample from MNW4-D1, the second intermediate well associated with the groundwater contamination site located northwest of the SSW, was also quite heavy. Sample results for $\delta^{15} \mathrm{~N}-\mathrm{N}_{2}$ were relatively light (although heavier than for shallow wells) in deep wells and in supply wells, similar to results for nitrate isotopes. Unlike the nitrate isotopes, values of $\delta^{15} \mathrm{~N}-\mathrm{N}_{2}$ also were relatively light (below 1 per mil) in samples from FP1MS, MW7, and the P83-19 wells associated with the groundwater contamination site located southwest of the SSW. The reason for the disagreement in results for FP1MS and MW7 is unclear; however, the disagreement in results for the P83-19 wells is likely associated with the stripping of 


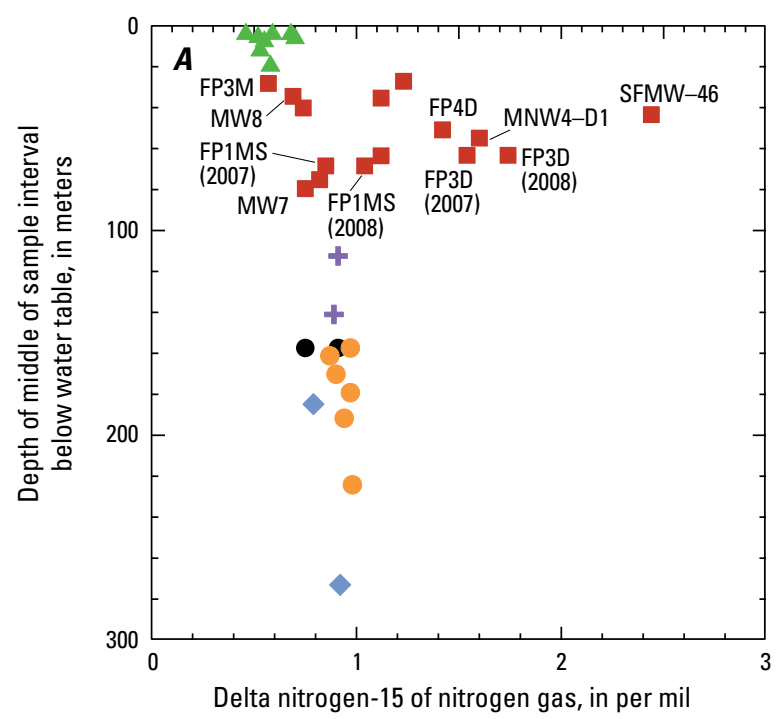

EXPLANATION

- Deep well

- Intermediate well

$\Delta$ Shallow well

+ Supply well

- Studied supply well (SSW)

SSW, depth-dependent

FP3M Well name (sample collection date in parentheses)
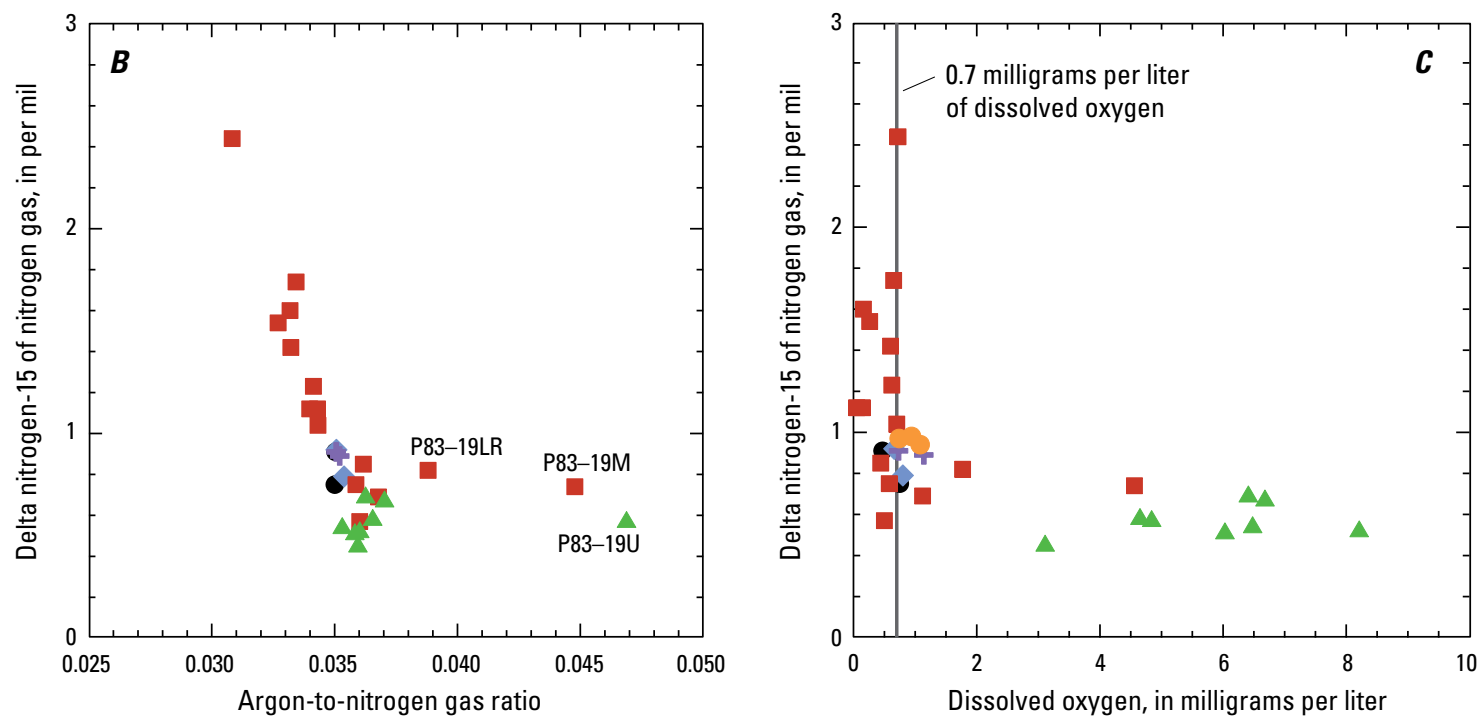

Figure 16. Relations of delta nitrogen-15 of nitrogen gas with $A$, depth below the water table, $B$, the ratio of argon to nitrogen gas, and $C$, dissolved oxygen in groundwater from the local-scale transport of anthropogenic and natural contaminants (TANC) study area in Albuquerque, New Mexico.

dissolved gases from groundwater as a result of operation of a pump-and-treat facility at that contamination site (Harding Lawson Associates, 2000). This conclusion is consistent with comments noted by the laboratory that analyzed the dissolvedgas samples and with the high ratio of argon to nitrogen in the dissolved-gas results for the P83-19 wells (fig. 16B). It would appear that much of the nitrogen gas produced by denitrification occurring in groundwater in the area of the contamination site (and therefore having relatively heavy values of $\delta^{15} \mathrm{~N}-\mathrm{N}_{2}$ ) was stripped from the groundwater prior to sampling for the TANC study. A pump-and-treat facility has also been operating at the groundwater contamination site located northwest of the SSW, but any effects of this facility on associated TANC groundwater samples have not been clearly evident in laboratory results.

Excluding the P83-19 wells, a graph of $\delta^{15} \mathrm{~N}-\mathrm{N}_{2}$ with the ratio of argon to nitrogen gas (fig. 16B) shows a clear relation between them $(\rho=-0.79$, $p$-value $<0.001)$, indicating that the values of $\delta^{15} \mathrm{~N}-\mathrm{N}_{2}$ are closely representative of denitrification reaction progress, as measured by the quantity of "excess" nitrogen gas added to the quantity already present in a sample through equilibrium with the atmosphere under recharge conditions. (The concept of excess nitrogen gas and its importance in the calculation of recharge temperatures and groundwater ages is discussed in the later "Recharge Temperature, Entrained Air, and Excess Nitrogen Gas" section 
of this report.) A graph of the relation between $\delta^{15} \mathrm{~N}-\mathrm{N}_{2}$ and dissolved-oxygen concentrations in groundwater samples from the study area (fig. 16C) implies that substantial denitrification, as measured by $\delta^{15} \mathrm{~N}-\mathrm{N}_{2}$ values above 1 per mil, has occurred in groundwater with observed dissolved-oxygen concentrations as high as $0.7 \mathrm{mg} / \mathrm{L}$. Samples from all wells having $\delta^{15} \mathrm{~N}-\mathrm{N}_{2}$ values above 1 per mil have manganese concentrations exceeding $9 \mu \mathrm{g} / \mathrm{L}$, and most have manganese concentrations exceeding $30 \mu \mathrm{g} / \mathrm{L}$, which is consistent with the presence of a fraction of water that has encountered anoxic conditions.

For a groundwater sample affected by denitrification, the initial concentration of nitrate and the initial $\delta^{15} \mathrm{~N}$ value of nitrate (prior to denitrification) can be estimated by using the method described in McMahon and others (2008). This method incorporates the measured concentrations of dissolved nitrate and nitrogen gas, the measured values of $\delta^{15} \mathrm{~N}^{-\mathrm{NO}_{3}}$ and $\delta^{15} \mathrm{~N}-\mathrm{N}_{2}$, and the estimated concentration of excess nitrogen gas from denitrification. For groundwater samples from the local-scale TANC study area, estimation of the concentration of excess nitrogen gas from denitrification by using estimates of recharge temperature and entrained air is subsequently described in the "Recharge Temperature, Entrained Air, and Excess Nitrogen Gas" section of this report. The initial concentration of nitrate is then equal to the sum of the measured concentration of nitrate and the estimated concentration of excess nitrogen gas (all concentrations as $\mathrm{N}$ ). The initial $\delta^{15} \mathrm{~N}$ of nitrate is calculated as

$$
\begin{gathered}
\delta^{15} \mathrm{~N}\left[\mathrm{NO}_{3}\right]_{\text {init }}=\left\{\left[\mathrm{NO}_{3}-\mathrm{N}\right]_{\text {meas }} \times \delta^{15} \mathrm{~N}\left[\mathrm{NO}_{3}\right]_{\text {meas }}+\right. \\
\left.\left[\text { excess } \mathrm{N}_{2}-\mathrm{N}\right] \times \delta^{15} \mathrm{~N}\left[\operatorname{excess} \mathrm{N}_{2}-\mathrm{N}\right]\right\} /\left[\mathrm{NO}_{3}-\mathrm{N}\right]_{\text {init }}
\end{gathered}
$$

where

$\delta^{15} \mathrm{~N}\left[\mathrm{NO}_{3}\right]_{\text {init }}$ is the initial $\delta^{15} \mathrm{~N}$ of nitrate,

$\left[\mathrm{NO}_{3}-\mathrm{N}\right]_{\text {meas }}$ is the measured concentration of nitrate, $\delta^{15} \mathrm{~N}\left[\mathrm{NO}_{3}\right]_{\text {meas }}$ is the measured $\delta^{15} \mathrm{~N}$ of nitrate,

[excess $\mathrm{N}_{2}-\mathrm{N}$ ] is the estimated concentration of excess nitrogen gas from denitrification,

$\delta^{15} \mathrm{~N}\left[\right.$ excess $\left.\mathrm{N}_{2}-\mathrm{N}\right]$ is the estimated $\delta^{15} \mathrm{~N}$ value of the excess nitrogen gas from denitrification, and

$\left[\mathrm{NO}_{3}-\mathrm{N}\right]_{\text {init }}$ is the initial concentration of nitrate.

The $\delta^{15} \mathrm{~N}$ value of the excess nitrogen gas from denitrification is estimated as follows:

$$
\begin{gathered}
\delta^{15} \mathrm{~N}\left[\text { excess } \mathrm{N}_{2}-\mathrm{N}\right]=\left\{\left[\mathrm{N}_{2}-\mathrm{N}\right]_{\text {meas }} \times \delta^{15} \mathrm{~N}\left[\mathrm{~N}_{2}-\mathrm{N}\right]_{\text {meas }}-\right. \\
\left(\left[\mathrm{N}_{2}-\mathrm{N}\right]_{\text {meas }}-\left[\mathrm{N}_{2}-\mathrm{N}\right]_{\text {ea }}-\left[\text { excess N } \mathrm{N}_{2}-\mathrm{N}\right]\right) \times \delta^{15} \mathrm{~N}\left[\mathrm{~N}_{2}-\mathrm{N}\right]_{\text {asw }} \\
\left.-\left[\mathrm{N}_{2}-\mathrm{N}\right]_{\text {ea }} \times \delta^{15} \mathrm{~N}\left[\mathrm{~N}_{2}-\mathrm{N}\right]_{\mathrm{ea}}\right\} /\left[\text { excess } \mathrm{N}_{2}-\mathrm{N}\right]
\end{gathered}
$$

where

$\left[\mathrm{N}_{2}-\mathrm{N}\right]_{\text {meas }}$ is the measured concentration of nitrogen gas, $\delta^{15} \mathrm{~N}\left[\mathrm{~N}_{2}-\mathrm{N}\right]_{\text {meas }}$ is the measured $\delta^{15} \mathrm{~N}$ of nitrogen gas,

$\left[\mathrm{N}_{2}-\mathrm{N}\right]_{\mathrm{ea}}$ is the estimated concentration of nitrogen gas from entrained air,

$\delta^{15} \mathrm{~N}\left[\mathrm{~N}_{2}-\mathrm{N}\right]_{\text {asw }}$ is the $\delta^{15} \mathrm{~N}$ of nitrogen gas in air-saturated water (equal to about 0.7 per mil at room

\author{
temperature [Klots and Benson (1963)]), \\ and \\ $\delta^{15} \mathrm{~N}\left[\mathrm{~N}_{2}-\mathrm{N}\right]_{\mathrm{ea}}$ is the $\delta^{15} \mathrm{~N}$ of nitrogen gas from entrained air \\ (defined to be 0 ).
}

Lastly, denitrification reaction progress can be estimated as 1 minus the ratio of measured to initial concentrations of nitrate.

Estimates of the initial concentration of nitrate and initial $\delta^{15} \mathrm{~N}$ value of nitrate for groundwater samples from the local-scale TANC study area (fig. 17; table 6) indicate some variability in sources and processes affecting nitrate concentrations. Calculated enrichment factors for $\delta^{15} \mathrm{~N}$ as nitrate that was denitrified to nitrogen gas in the study area generally were about -15 to -1 per mil, which is fairly consistent with factors of -10 to -2 per mil calculated by McMahon and others (2008) for studies in a variety of hydrogeologic settings. For groundwater samples that do not appear to have been affected by denitrification (table 6 ), the laboratory-reported values are graphed in figure 17; the P83-19 wells are not included because of issues with the concentrations of nitrogen gas for these samples. Estimated initial concentrations of nitrate range from about 0.2 to $5.4 \mathrm{mg} / \mathrm{L}$. Groundwater samples with the lowest estimated initial concentrations of nitrate were from the two deep wells and three intermediate wells, FP1MS, FP3M and MW7, which have been identified as consisting of primarily old groundwater. The highest estimated initial concentrations (above $3 \mathrm{mg} / \mathrm{L}$ ) were for samples from four shallow (water-table) wells (FP1S, FP4S, MW2, and MW9). All the estimated initial $\delta^{15} \mathrm{~N}$ values of nitrate for samples from these four wells were below 8 per mil, which is consistent with nitrate sourced from natural soil nitrogen (Kendall and Aravena, 2000), perhaps representing flushing of accumulated nitrate from the unsaturated zone as recent recharge migrates to the water table in areas where recharge previously was negligible. Although the initial $\delta^{15} \mathrm{~N}$ values samples from these four wells do not clearly rule out a contribution of nitrate from fertilizer, only two of the four wells are located relatively closely to urban turf areas.

Samples from one shallow (water-table) well (FP2S) and six intermediate wells (SFMW-46, MNW4-D1, FP2M, FP3D, FP4M, and FP4D) have estimated initial concentrations of nitrate exceeding $1 \mathrm{mg} / \mathrm{L}$ and estimated initial $\delta^{15} \mathrm{~N}$ values of nitrate exceeding 10 per mil (fig. 17). These relatively high initial $\delta^{15} \mathrm{~N}$ values of nitrate are consistent with a nitrate source from septic systems and perhaps from leaking sanitary sewer lines (Kendall and Aravena, 2000; McMahon and others, 2008). It is not known whether these initial $\delta^{15} \mathrm{~N}$ values of nitrate would also be consistent with the presence of animal waste in urban runoff, such as the stormwater runoff believed to contribute some recharge to wells at the FP2 location. It also is not known whether the source of nitrate associated with the groundwater contamination site located northwest of the SSW is related to sewer/septic waste, urban runoff, or some other source that is characteristic of the contamination at that site. For groundwater samples from the local-scale TANC study area where denitrification appears to have occurred, 


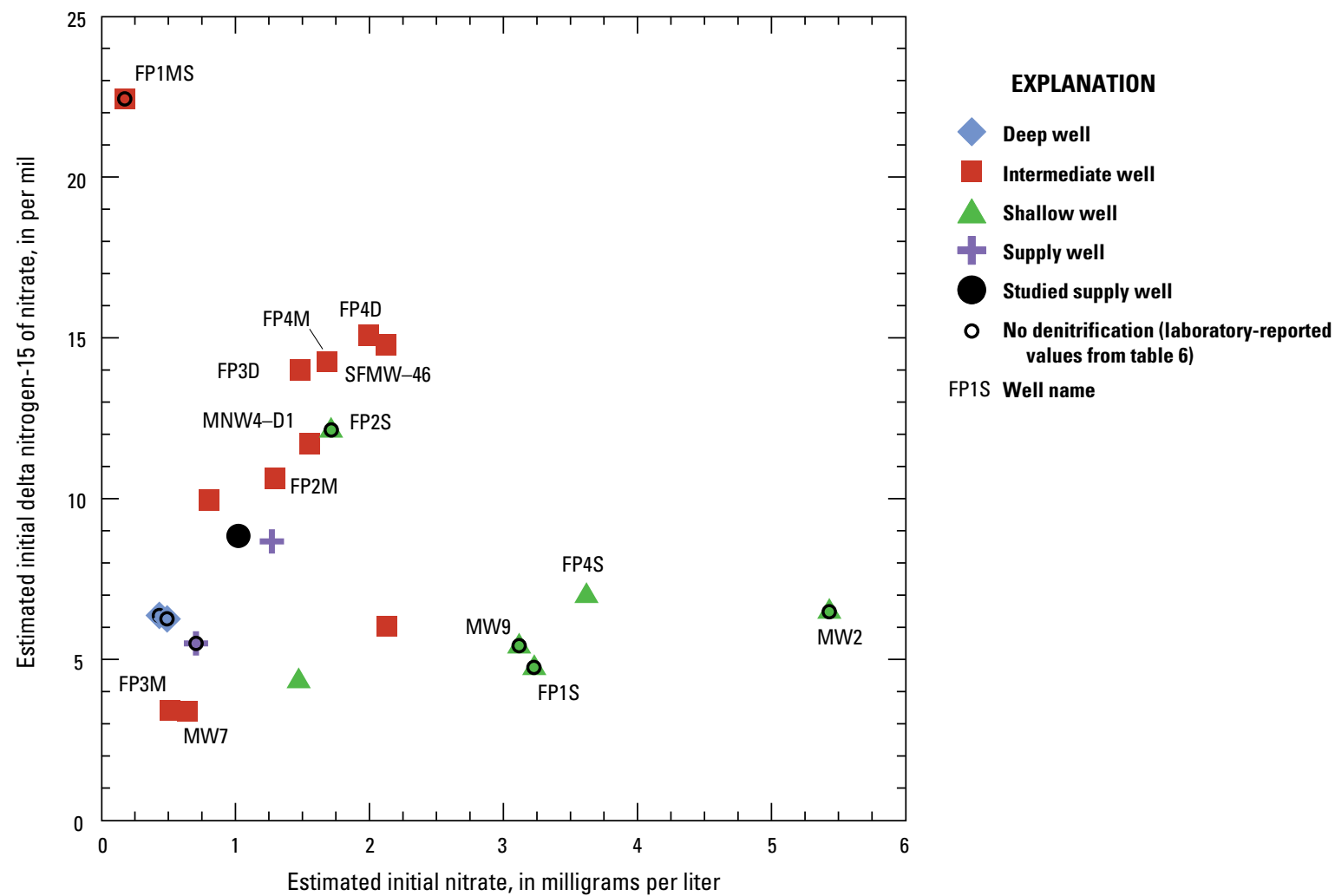

Figure 17. Relation of estimated initial nitrogen-15 of nitrate with estimated initial nitrate concentration in groundwater from the localscale transport of anthropogenic and natural contaminants (TANC) study area in Albuquerque, New Mexico.

estimated reaction progress ranged from 0.03 in FP4S to 0.99 in SFMW-46 (table 6).

\section{Arsenic and Other Trace Elements}

The USEPA established MCLs for several trace elements (U.S. Environmental Protection Agency, 2010a) that can be present in elevated concentrations in groundwater as a result of natural processes and (or) human activities. Previous investigations showed that arsenic occurs naturally in aquifer sediments of the MRGB (Stanton and others, 2001a, 2001b), and that groundwater concentrations exceed the USEPA MCL of $10 \mu \mathrm{g} / \mathrm{L}$ across broad areas, including in and near Albuquerque (Bexfield and Plummer, 2003; Plummer and others, 2004). Elevated arsenic concentrations were measured even in areas of the basin where groundwater recharge originated at the Rio Grande, which generally has arsenic concentrations near Albuquerque less than $4 \mu \mathrm{g} / \mathrm{L}$, with a median value around $3 \mu \mathrm{g} / \mathrm{L}$ (Bexfield and Plummer, 2003; Plummer and others, 2004a). As the only trace element that was detected at concentrations near or above the MCL in groundwater during the local-scale TANC study, arsenic is the focus of the trace-element discussion in this report. However, other trace elements are discussed briefly for the insight that they provide about particular recharge sources and (or) geochemical processes.
Concentrations of arsenic in groundwater samples from the local-scale TANC study area ranged from 1.7 to $35 \mu \mathrm{g} / \mathrm{L}$ and generally increased with depth below the water table ( $\rho=0.80$, p-value $<0.001)$ (fig. 18 ; table 7 at end of report). Concentrations were below $5.1 \mu \mathrm{g} / \mathrm{L}$ in all shallow wells and in all but two intermediate wells (SFMW-46 and MNW4-D1), both of which are associated with the groundwater contamination site located northwest of the SSW. Concentrations exceeded $10 \mu \mathrm{g} / \mathrm{L}$ in samples from the two deep wells, from one intermediate well (MNW4-D1), from PSW3, and from the SSW. Laboratory analysis for arsenic speciation indicated that the more oxidized form of arsenic, arsenate $\left(\mathrm{HAsO}_{4}^{2-}\right.$ in the $\mathrm{pH}$ range 6.9 to 11.5), was dominant in groundwater samples from the study area. The reduced form of arsenic, arsenite $\left(\mathrm{H}_{3} \mathrm{AsO}_{3}{ }^{0}\right.$ up to $\mathrm{pH}$ 9.2), was below detection in groundwater samples from all but one well (FP2D), where redox conditions were classified as anoxic, and arsenite was just under half of the total dissolved arsenic.

It should be noted that the drinking water delivered to customers by the water utility was in compliance with USEPA drinking-water standards during the time period that the concentration of arsenic in groundwater samples collected by the TANC study from individual supply wells exceeded 10 $\mu \mathrm{g} / \mathrm{L}$ (Albuquerque Bernalillo County Water Utility Authority, written commun., 2010). The water utility generally blends 

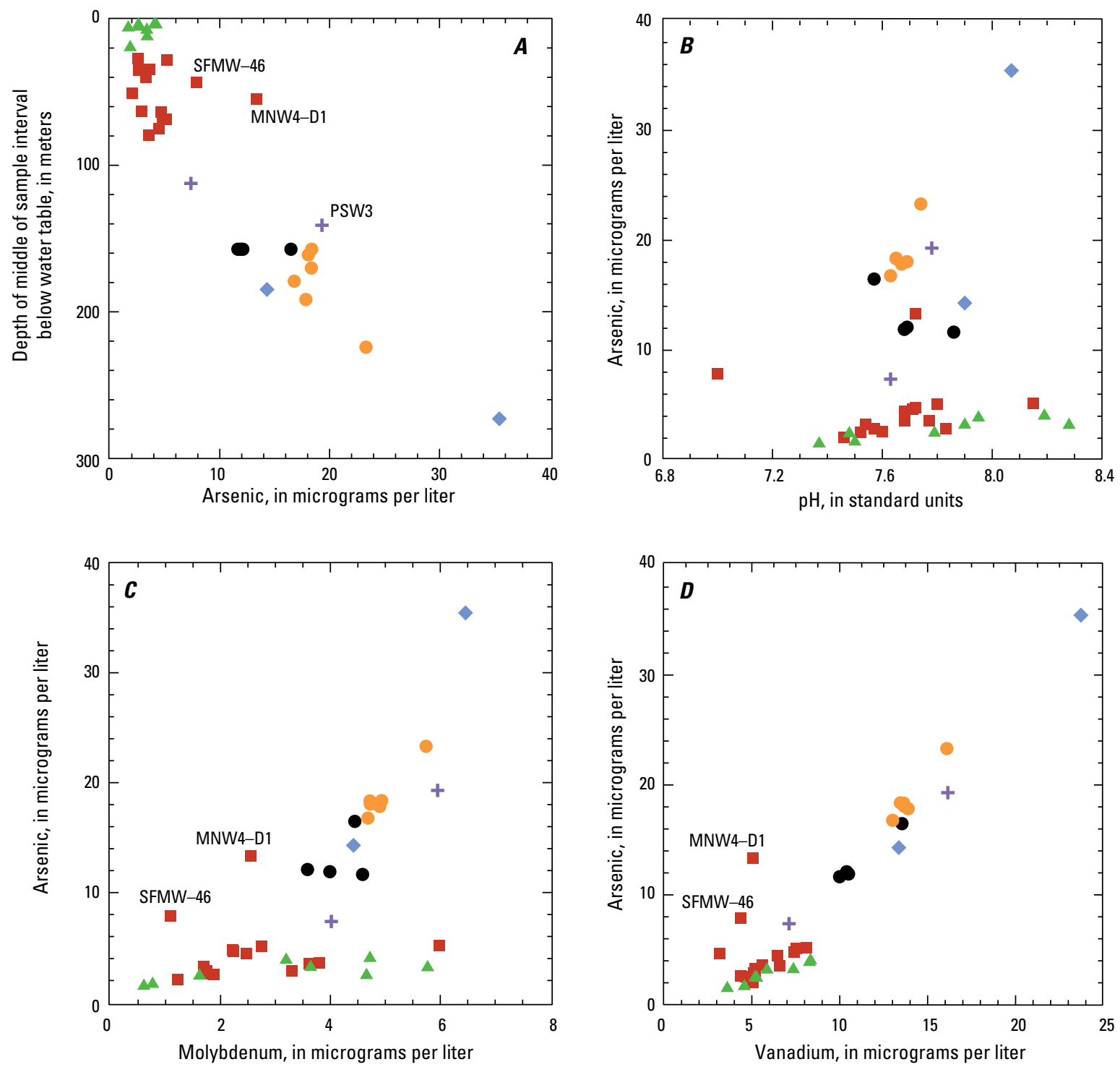

\section{EXPLANATION}

- Deep well

- Intermediate well

- Shallow well

+ Supply well

- Studied supply well (SSW)

- SSW, depth-dependent

FP1S Well name

Figure 18. Relations of arsenic with $A$, depth below the water table, $B, \mathrm{pH}, C$, molybdenum, and $D$, vanadium in groundwater from the local-scale transport of anthropogenic and natural contaminants (TANC) study area in Albuquerque, New Mexico. 
water from multiple sources prior to delivery to customers and had been given extended deadline (the end of 2008) to comply with the USEPA MCL of $10 \mu \mathrm{g} / \mathrm{L}$ (EBSCO Industries, Inc., 2008, written commun., 2010), which represented a substantial reduction from the previous MCL of $50 \mu \mathrm{g} / \mathrm{L}$.

Investigations by Bexfield and Plummer (2003) and Plummer and others (2004a) found that elevated concentrations of arsenic in groundwater of the MRGB were controlled by a combination of factors, including $\mathrm{pH}$-dependent sorption reactions. Adsorption of arsenic also depends on the properties of the solid (mineral) surfaces, arsenic speciation, and the concentrations of arsenic and other ions that compete for sorption sites (Stollenwerk, 2003). In general, arsenate adsorbs to a greater extent than arsenite at $\mathrm{pH}$ values below 7. However, adsorption of arsenate decreases substantially above a $\mathrm{pH}$ of about 7 as a result of the increasing negative charge of the solid surface and the aqueous arsenate, whereas adsorption of arsenite increases with increasing $\mathrm{pH}$, reaching a maximum as it approaches a pH of 8 or 9 (Stollenwerk, 2003).

Water-quality and solid-phase data from the local-scale TANC study area are consistent with the investigations of Stanton and others (2001a, 2001b), Bexfield and Plummer (2003), and Plummer and others (2004a) in indicating the importance of $\mathrm{pH}$-dependent sorption reactions. Stanton and others (2001a, 2001b) conducted sequential extractions on Santa Fe Group sediments from a borehole in the western part of Albuquerque completed primarily in the Atrisco member of the Ceja Formation and older sediments, and found that most arsenic was contained in mixed-metal (primarily iron) oxides and could be mobilized by desorption under relatively high $\mathrm{pH}$ and (or) anoxic conditions. Sequential extractions targeting ferric oxyhydroxides and their associated trace elements in core samples from the TANC study area found that both the highest iron and the highest arsenic contents were in a clayey core sample collected from the 365- to 368-m depth in the FP1 borehole; a sandy core sample from this same depth also had relatively high iron and arsenic contents (app. 1, table 1-3). Desorption experiments on wet sediments showed that, although shallower core samples contained some arsenic that was readily desorbed, the amounts of arsenic yielded to solution by the deepest core samples were as much as 10 times higher.

In groundwater samples from the local-scale TANC study area, relations of arsenic with $\mathrm{pH}$ and selected other trace elements appear to show the importance of both groundwater $\mathrm{pH}$ and arsenic availability on sediments in determining aqueous arsenic concentrations. Although arsenic concentrations do not show a clear correlation with $\mathrm{pH}$ values for all groundwater samples collected for the TANC study $(\rho=0.28$, $p$-value $=$ 0.09 ), arsenic concentrations in samples from the 22 monitoring wells generally increase with increasing $\mathrm{pH}(\rho=0.52$, $\mathrm{p}$-value $=0.01)($ fig. $18 B)$. Samples from the two deep wells, which have the highest arsenic concentrations, have relatively high $\mathrm{pH}$ values of 7.9 and 8.1, indicating the likely importance of desorption from iron oxides in the deeper part of the aquifer. Arsenic concentrations from the monitoring wells increase with increasing $\mathrm{pH}$ values up to about 7.8, excepting the samples from the wells associated with the groundwater contamination site located northwest of the SSW, which have relatively high arsenic concentrations, given their $\mathrm{pH}$ values, Groundwater samples from the shallow and the intermediate wells that have $\mathrm{pH}$ values higher than about 7.8 do not have higher arsenic concentrations than samples with lower $\mathrm{pH}$ values. The absence of arsenic concentrations greater than $5 \mu \mathrm{g} / \mathrm{L}$ in samples from shallow and intermediate wells that have relatively high $\mathrm{pH}$ values could indicate that the amount of arsenic available for desorption from aquifer sediments at these shallower depths is insufficient to raise the aqueous arsenic concentration above $5 \mu \mathrm{g} / \mathrm{L}$.

The likely occurrence of $\mathrm{pH}$-dependent desorption of arsenic from aquifer sediments is supported by the relations of arsenic in all groundwater samples with molybdenum ( $\rho=$ 0.71 , p-value $<0.001)$ and with vanadium $(\rho=0.83$, p-value $<0.001$ ) (figs. $18 C$ and $D$ ), two other elements that form oxyanions with $\mathrm{pH}$-dependent sorption on mineral surfaces (Goldberg and others, 1996; Brinton and O'Connor, 2003; Wright and Belitz, 2010). Arsenic and molybdenum concentrations generally increase together in groundwater samples from the 22 monitoring wells. However, the shallow and the intermediate wells that have relatively high $\mathrm{pH}$ values plot off this trend with relatively high molybdenum values, which could indicate that sufficient molybdenum (but not arsenic) is available for desorption to allow continuing increases in concentration as $\mathrm{pH}$ increases. Similar patterns are observed between arsenic and vanadium. The possible reductive dissolution of metal oxides containing arsenic, which would provide an alternate mechanism for release of arsenic into solution, appears unlikely because of the generally oxic conditions in the aquifer and the absence of increasing concentrations of iron or manganese with increasing concentrations of arsenic.

The two wells (SFMW-46 and MNW4-D1) associated with the groundwater contamination site located northwest of the SSW have unusually high concentrations of arsenic compared to those of molybdenum and vanadium (figs. $18 \mathrm{C}$ and $D$ ). These relatively high concentrations of arsenic might be characteristic of the contamination source, especially given that the concentrations of certain other trace elements, particularly boron, lithium, strontium, and uranium are also unusually high in SFMW-46 and MNW4-D1 compared to other intermediate wells (table 7). However, another possible explanation for the relatively high concentrations of arsenic relates to redox conditions. The groundwater samples from MNW4D1 and SFMW-46 were classified as mixed, indicating the presence of a fraction of water that had encountered anoxic conditions. The presence of anoxic conditions in the area of these wells might have allowed the temporary formation of arsenite, which is less easily sorbed than arsenate under certain conditions, although arsenite was not detected in groundwater samples from these wells.

The origin of the arsenic sorbed to deeper sediments within the local-scale TANC study area is unclear. 
Investigations by Bexfield and Plummer (2003) and by Plummer and others (2004a) found that sources of elevated concentrations of arsenic in groundwater of the MRGB included inflow of high-arsenic groundwater related to silicic volcanism in the Jemez Mountains north of the basin, and upwelling of mineralized water of deep origin along major structural features across the basin. Plummer and others (2004a) stated that groundwater that originated as subsurface inflow from the Jemez Mountains was probably present at depth within the local-scale TANC study area; this conclusion is perhaps supported by the interpretation of Connell (2006) that sediments of the Atrisco member extend from the western part of the MRGB into the study area at a depth near the bottom of the SSW. However, certain characteristics of groundwater samples from the deep wells, including relatively high concentrations of chloride, boron, fluoride, lithium, and molybdenum (table 7), also appear consistent with the observations of Bexfield and Plummer (2003) in areas they identified as having high concentrations of arsenic as a result of upwelling of mineralized water of deep origin. Grauch and others (1999) indicated the likely presence of a structural high only a few miles south of the local-scale TANC study area, which could contribute to upward movement of groundwater in this area. Observed upward hydraulic gradients in the TANC well network also could help explain the relatively high concentration of arsenic in groundwater from FP1MD, which is completed at a depth at which results of experiments on core samples did not indicate particularly high amounts of arsenic sorbed to sediments.

Results of sequential extractions on core samples from the local-scale TANC study area indicated the presence of relatively high amounts of uranium in sediments from the 365- to 368-m depth in the FP1 borehole (app. 1, table 1-3). Although desorption experiments were not conducted for uranium, most of the uranium present in these core samples was presumed to be adsorbed to mineral surfaces, given the tendency for uranium (VI), the form most commonly present under $\mathrm{pH}$ and redox conditions observed in the study area, to adsorb to ferric oxyhydroxides (Langmuir, 1997). Uranium concentrations in groundwater samples (table 7) generally were less than $5.0 \mu \mathrm{g} / \mathrm{L}$ and were less than $7.5 \mu \mathrm{g} / \mathrm{L}$ from all but 1 well (SFMW-46), as compared to the USEPA MCL of $30 \mu \mathrm{g} / \mathrm{L}$ (U.S. Environmental Protection Agency, 2010a). The sample from FP1D (at a depth similar to the core sample with high uranium content) had a concentration of only 2.1 $\mu \mathrm{g} / \mathrm{L}$, indicating that conditions are probably not conducive to substantial desorption of uranium from aquifer sediments. The concentration of uranium in the sample from SFMW-46 was $21.8 \mu \mathrm{g} / \mathrm{L}$, which might signify a characteristic of the groundwater contamination source at the site located northwest of the SSW. However, the relatively high alkalinity of groundwater from SFMW-46 could contribute to its relatively high concentration of uranium because the formation of carbonate complexes reduces the ability of uranium to sorb to sediments (Langmuir, 1997).

\section{Volatile Organic Compounds}

VOCs were detected by the NWQL in at least one groundwater sample from 18 of the 25 wells sampled for the local-scale TANC study (table 8 at end of report). At least one VOC was detected in samples from all 7 shallow wells, 9 of 13 intermediate wells, and 2 of 3 supply wells, including the SSW. VOCs were not detected in samples from the 2 deep wells. Of the 22 monitoring wells sampled, it should be noted that 3 shallow wells and 6 intermediate wells were targeted for sampling specifically because they were known to intercept previously identified plumes of groundwater contamination or were known to be located in proximity to those plumes. In addition, the monitoring well nests installed as part of the TANC study were intentionally located in areas where knowledge of the hydrogeologic system indicated that groundwater contamination associated with one or more previously identified plumes might be intercepted at some depth. Therefore, samples from the monitoring wells do not constitute a random dataset that is representative of the frequency with which VOCs would be detected in the aquifer beneath urban land use across the Albuquerque area. Nevertheless, the results from this study do show that VOCs are commonly present in shallow groundwater in the study area, even at considerable distances from known contamination sites, indicating that some fraction of shallow groundwater across broad areas has been affected by urban land use. The results also indicate that it is not uncommon for VOCs to migrate to intermediate aquifer depths, including depths at which public-supply wells are generally screened, and to be transported considerable distances from their sources.

Twenty different VOCs were detected among all of the analyzed groundwater samples (table 8). Of the 9 VOCs detected in samples from 5 or more wells, 6 are solvents or their degradation products, listed here in order of detection frequency, from the most (14) to the fewest (6) wells: TCE; cis-1,2-DCE; tetrachloroethylene (PCE); 1,2-dichloroethane; 1,1-dichloroethane; and trans-1,2-dichloroethylene (trans1,2-DCE). The relatively high frequency of detection of chlorinated solvents and their degradation products is expected because areas near documented sources of groundwater contamination with TCE were targeted for sampling after having detected TCE along with its degradation product, cis-1,2-DCE, in the SSW during the regional-scale TANC study. Most of the detections of solvents or their degradation products appear to be associated with the previously identified point sources of groundwater contamination with TCE (fig. 2), which likely resulted from leaking storage tanks and (or) improper chemical disposal (U.S. Environmental Protection Agency, 2001; Harding Lawson Associates, 2000; Bart Faris, New Mexico Environment Department, Ground Water Quality Bureau, oral commun., 2006). The organic synthesis compound 1,1-dichloroethylene was detected in samples from seven wells, all of which are directly associated with or appear to have been affected by known sites of groundwater contamination located northwest and southwest of the SSW, indicating the likelihood 
that this VOC also came from these known point sources of solvents.

The gasoline oxygenate MTBE was detected in groundwater samples from two supply wells (PSW1 and the SSW) and from three monitoring wells associated with a known site of groundwater contamination with MTBE and other gasolinerelated VOCs located southwest of the SSW. Another known site of groundwater contamination with MTBE is located close to PSW1 (fig. 2), although the MTBE at this site has not been documented to have migrated past a relatively shallow zone of perched groundwater that is not believed to be connected to the regional aquifer system (Bruce Furst, New Mexico Environment Department, Ground Water Quality Bureau, written commun., 2006).

Chloroform (also known as trichloromethane), a byproduct of the chlorination of drinking water, as well as a laboratory solvent and an industrial product, was detected in groundwater samples from four shallow (water-table) wells, one intermediate well, and one supply well. (The NWQL also reported detections in samples from six additional wells, including the two other shallow (water-table) wells, that were judged to have possibly been affected by contamination of sampling equipment, based on results from field blanks.) Detections of chloroform in samples from two shallow (water-table) wells were accompanied by detections of bromodichloromethane and (or) dibromochloromethane, which are also chlorination byproducts. Based on groundwater data from across the United States, Zogorski and others (2006) concluded that chloroform and other chlorination byproducts typically reach groundwater as a result of one or more potential sources of chlorinated water: irrigation of urban turf areas, leaking distribution and (or) sewer lines, and septic-tank effluent. Zogorski and others (2006) also noted that relative frequencies of detection and magnitudes of concentrations among chlorination byproducts usually decrease with increasing bromine concentrations, thus accounting for why chloroform generally is detected most frequently and at the highest concentrations. The detection of chloroform in at least four of six shallow (water-table) wells within the study area (FP1S, FP2S, MW2, and MW9) implies that chlorinated municipalsupply water is reaching the aquifer across broad areas and is migrating locally to intermediate depths. Because only two of these four wells are located relatively closely to urban turf areas, infiltration of irrigation water appears to be an unlikely explanation of the detections of chloroform in all four wells. Leaking distribution and (or) sewer lines in this area of Albuquerque, which has been urbanized since at least the 1930s, would seem to be likely sources of chloroform in groundwater. The sample from FP2S might receive recharge from a nearby stormwater conveyance channel, which carries urban runoff that could contain some chloroform, if it were not completely volatilized.

Except for the TCE concentration of $14.0 \mu \mathrm{g} / \mathrm{L}$ in the groundwater sample from the shallow (water-table) monitoring well MW2, which is not used for drinking-water supply, all detections of VOCs were at concentrations that were below the corresponding USEPA MCLs. For the VOCs detected in the sample from supply well PSW1 (chloroform; cis-1,2-DCE; trans-1,2,-DCE; MTBE; PCE; and TCE), concentrations of all compounds were less than one-tenth of the corresponding USEPA MCL, and concentrations of all but TCE were less than one-hundredth of the corresponding USEPA MCL. For the VOCs detected in various samples collected for the localscale TANC study from the SSW (cis-1,2-DCE, MTBE, TCE), concentrations of all compounds were less than one-hundredth of the corresponding USEPA MCL.

To gain insight into transport processes affecting contaminants in the zone of contribution to the SSW, the study examined spatial patterns in VOC detections in groundwater samples from across the study area (figs. 19 and 20) for information about the likely individual source(s) of TCE in groundwater produced by the SSW. In addition to being detected in 8 of the 9 existing monitoring wells selected for sampling because of their proximity to the three known sites of solvent contamination within the study area, TCE was detected in groundwater samples from PSW1 and from 4 of the 13 monitoring wells installed for the TANC study (FP3D, FP4S, FP4M, and FP4D). TCE is present at the locations of wells FP4 and (or) FP3 (northwest of the SSW by about 625 $\mathrm{m}$ and $360 \mathrm{~m}$, respectively) at depths from the water table to at least $57 \mathrm{~m}$ below the water table, which includes depths that fall within the screened intervals of both the SSW and PSW1 (fig. 20). Even in the existing monitoring wells located near each of the documented contamination sites (at distances as short as $200 \mathrm{~m}$ away from the most likely origin), TCE was detected in groundwater at depths greater than $30 \mathrm{~m}$, indicating that solvents had migrated to intermediate aquifer depths within relatively short distances. Regulatory agencies investigated the geometry of the solvent plume located northwest of the SSW, leading them to conclude that vertical migration of solvents to observed depths had been enhanced by the pumping of and (or) direct migration down the well bores of private water-supply wells in the vicinity of the contamination source (Landin, 1999; U.S. Environmental Protection Agency, 2001). Similar means of vertical migration also appear to have possibly affected the migration of contaminants at the two other known sites of solvent contamination, given that public-supply wells near the likely origins of contamination at those sites were removed from service as a result of the associated TCE contamination (U.S. Environmental Protection Agency, 2010d; Bart Faris, New Mexico Environment Department, Ground Water Quality Bureau, oral commun., 2006).

The particular mixture of VOCs detected along with TCE in groundwater from FP3D and FP4D implies that the solvents at those locations are associated primarily with the groundwater contamination site located northwest of the SSW. In particular, 1,2-dichlorobenzene, 1,3-dichlorobenzene, and (or) 1,4-dichlorobenzene were detected in samples from the monitoring wells associated with that contamination site (MNW4-D1 and SFMW-46) and in samples from FP3D and FP4D, but not in any other samples (figs. 19 and 20; table 8). Among the approximately 3,500 groundwater samples 


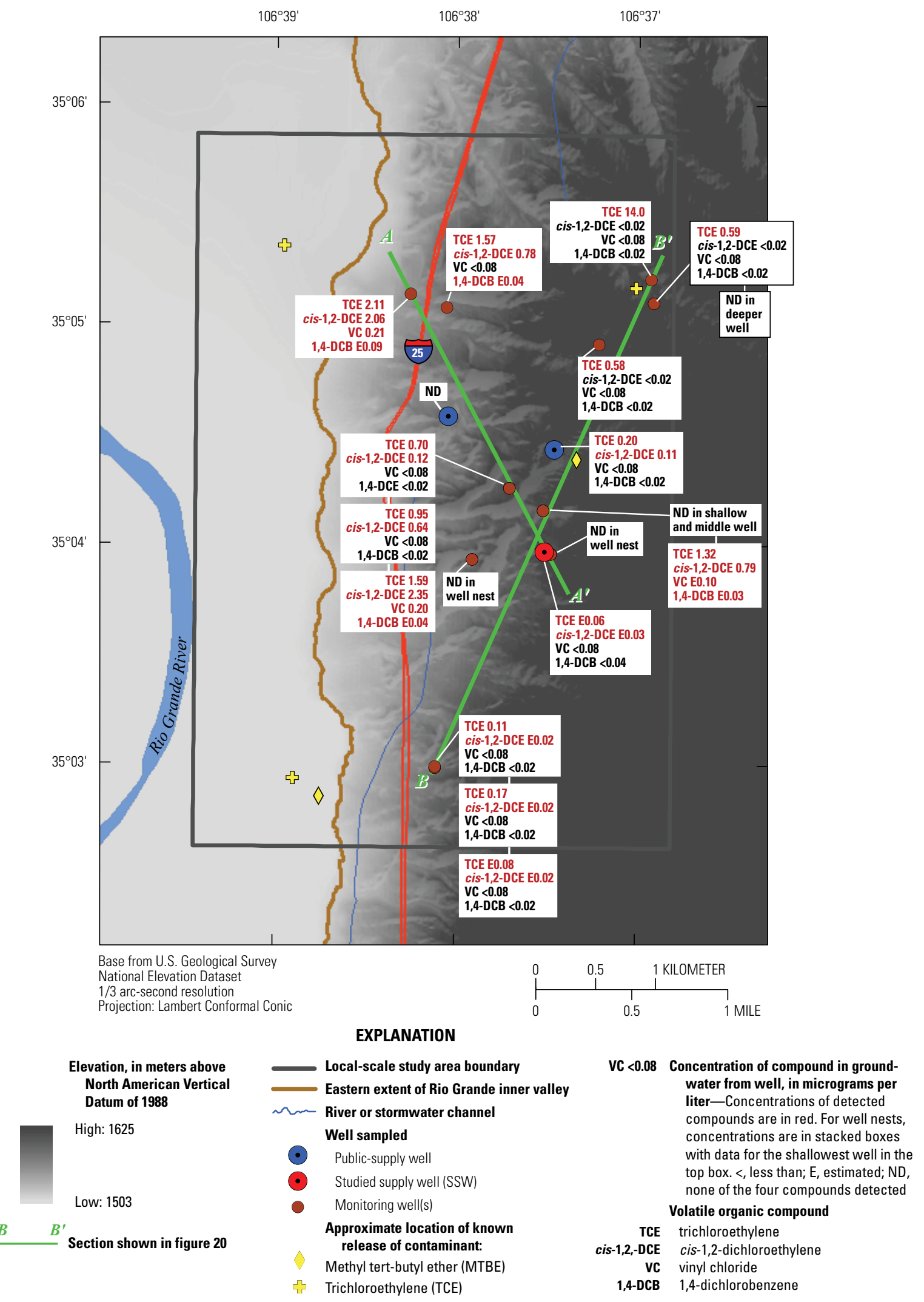

Figure 19. Concentrations of selected volatile organic compounds in groundwater from the local-scale transport of anthropogenic and natural contaminants (TANC) study area in Albuquerque, New Mexico. 


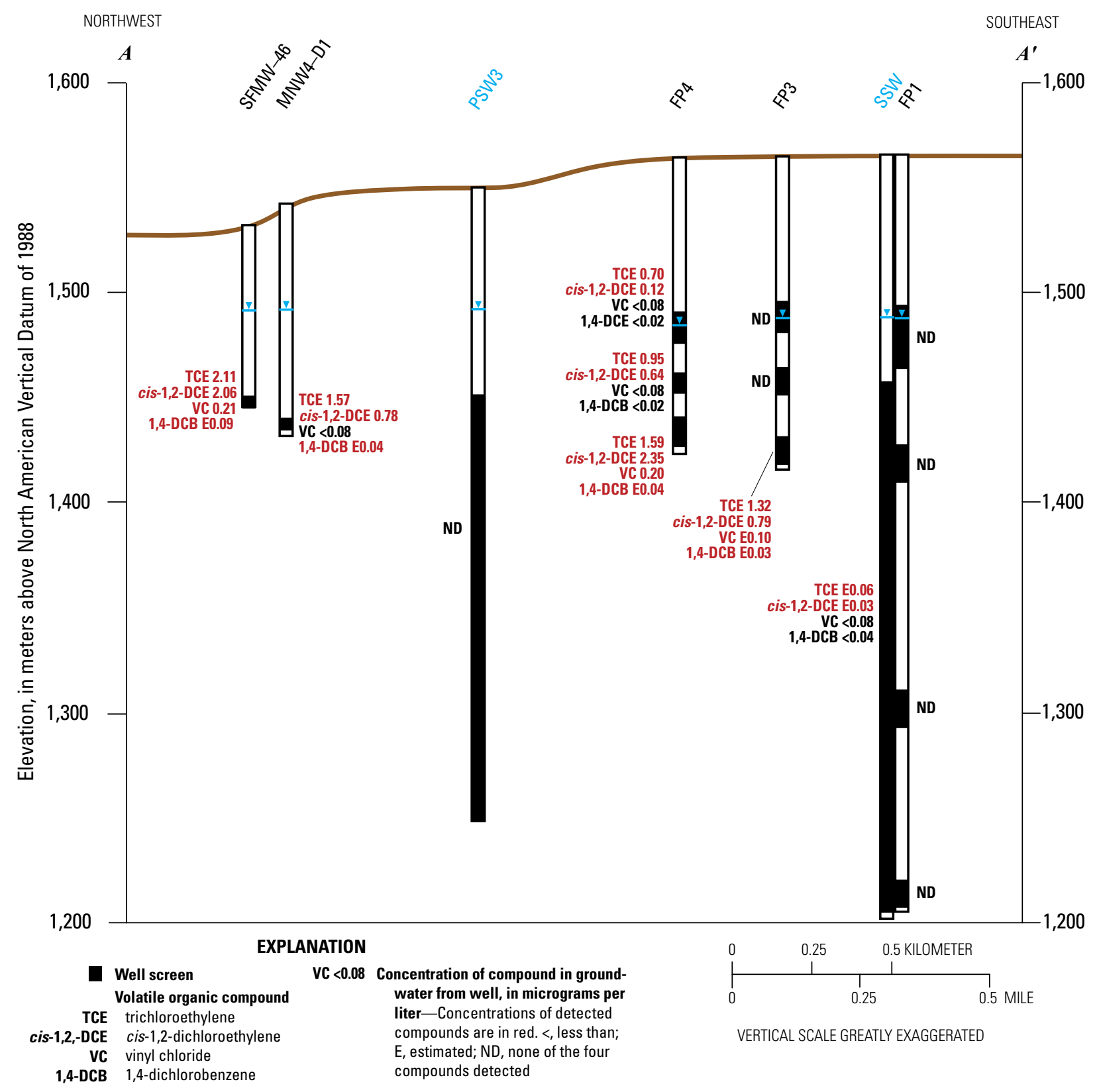

Figure 20. Concentrations of selected volatile organic compounds in groundwater along $A$, a northwest to southeast section and $B$, a southwest to northeast section in the local-scale transport of anthropogenic and natural contaminants (TANC) study area in Albuquerque, New Mexico. Location of sections shown on figure 19. 


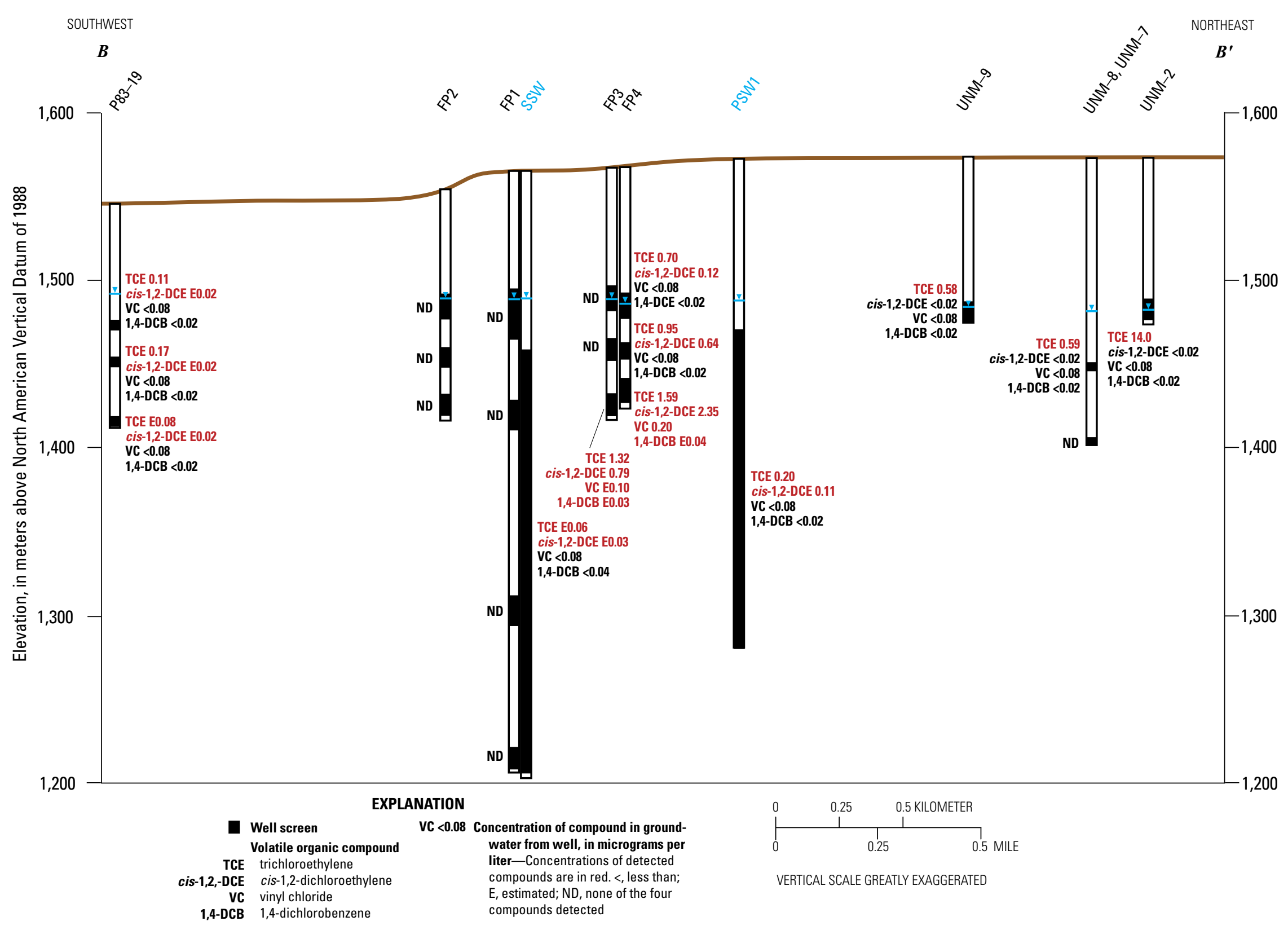

Figure 20. Concentrations of selected volatile organic compounds in groundwater along $A$, a northwest to southeast section and $B$, a southwest to northeast section in the local-scale transport of anthropogenic and natural contaminants (TANC) study area in Albuquerque, New Mexico. Location of sections shown on figure 19.-Continued 
included in the assessment of Zogorski and others (2006), these 3 VOCs were detected at concentrations of $0.2 \mu \mathrm{g} / \mathrm{L}$ or above in fewer than 1 percent of samples; 1,3-dichlorobenzene in particular was not detected in any samples at this level. The relative scarcity of these three VOCs in groundwater across the United States implies that the presence of a second source of these compounds within the small-scale TANC study area is unlikely. Also, advection of groundwater contamination from the site located northwest of the SSW toward the southeast and ultimately to the SSW is consistent with the 100 -year ZOCs simulated by the groundwater-flow model of the regional TANC study area (fig. 2) (Bexfield and others, 2011). These ZOCs account for both the recent west-to-east directions of groundwater flow in the local study area (fig. 3), and the more north-to-south directions of flow that existed previously. Assumption of an effective porosity of 0.20 or lower for the 100-year ZOC (fig. 3) probably best simulates flow through the relatively coarse sedimentary deposit that was identified from the resistivity of logs of multiple wells (fig. 4). Groundwater flow is likely to occur preferentially within this relatively high-conductivity sedimentary deposit, which is oriented in a generally north-south direction, and in the upper part of which FP3D and FP4D are screened.

Spatial patterns in the degradation products of TCE and of PCE in groundwater of the study area are also useful in illustrating the fate and transport of solvents within the zone of contribution to the SSW. Chloroethenes such as TCE and PCE are persistent in oxic groundwater systems (Bradley, 2000), but reductive dechlorination of these compounds to cis-1,2DCE, trans-1,2-DCE, vinyl chloride (VC), and ultimately ethene is facilitated by microorganisms under reducing conditions (Vogel and McCarty, 1985; Bradley, 2000). In particular, reductive dechlorination of $\mathrm{PCE}$ to TCE occurs in all but oxic aquifers; of TCE to cis-1,2-DCE occurs in iron-reducing conditions; and of cis-1,2-DCE to VC occurs in at least sulfatereducing - and more readily in methanogenic - conditions (Bradley, 2000). Reductive dechlorination of TCE and of PCE is often incomplete in groundwater systems, frequently leading to the accumulation of $\mathrm{VC}$ and of cis-1,2-DCE (and perhaps trans-1,2-DCE, which also results from reductive dechlorination of TCE, but is less commonly observed in groundwater) (Bradley, 2000).

Within the local-scale TANC study area, degradation products of TCE were observed in groundwater samples from wells associated with two of the three known sites of groundwater contamination with solvents (figs. 19 and 20; table 8). In particular, cis-1,2-DCE was detected in groundwater samples from all three of the P83-19 wells (associated with the contamination site southwest of the SSW) and from MNW4-D1 and SFMW-46 (associated with the contamination site northwest of the SSW); cis-1,2-DCE also was detected in samples from all three wells in the FP4 nest, from FP3D, from PSW1, and from the SSW. In samples from MNW4-D1, SFMW-46, FP3D, FP4M, FP4D, and from PSW1, trans-1,2DCE and (with the exception of MNW4-D1) VC were also detected. The absence of detections of degradation products of TCE and PCE in samples from wells associated with the contamination site northeast of the SSW (MW2, MW7, MW8, and MW9) is consistent with the classification of samples from these wells as oxic (table 4). Samples from the P83-19 wells were also classified as oxic, but it is likely that these wells have been affected by the pump-and-treat facility operating at the corresponding contamination site, which could result in the apparent inconsistency of TCE degradation products being detected in the presence of oxic conditions. At least one sample from each of wells MNW4-D1, SFMW-46, FP3D, FP4M, and the SSW has been classified as suboxic, anoxic, or mixed; methane (indicating the presence of methanogenic conditions required for degradation of DCE to VC) was detected in samples from MNW4-D1, SFMW-46, and FP3D. Lastly, samples from all wells in the FP4 nest had manganese concentrations above $30 \mu \mathrm{g} / \mathrm{L}$ (table 4). These data indicate that, except for the P83-19 wells and PSW1, all the wells in which degradation products of TCE were detected produce at least a fraction of groundwater under anoxic or suboxic conditions. Because all these wells are screened across at least $6 \mathrm{~m}$ of aquifer, it is plausible that each of them could intersect multiple redox zones. The very long screened interval of PSW1 $(190 \mathrm{~m})$ would seem to indicate that this well could produce a relatively small fraction of anoxic groundwater with substantial enough DCE to allow its detection in the sample from the well, but not substantial enough to affect the overall redox classification of this well as oxic.

As with the dichlorobenzene compounds, the pattern of the degradation products of TCE is consistent with the conclusion that solvents at the FP3 and FP4 locations are associated primarily with the groundwater contamination site located northwest of the SSW. Redox conditions at the contamination site to the northeast do not appear conducive for degrading TCE to DCE or beyond. Also, redox conditions at the contamination site to the southwest do not appear conducive for degrading DCE to VC, a conclusion based on both the TANC dataset and on VC data collected from multiple wells included in Axis Group, Inc. (2007). Based on the proximity of the FP3 and FP4 nests to the SSW and PSW1 (fig. 3), together with the substantial effects of pumping of these public-supply wells on local hydraulic gradients (see water-level fluctuations, figs. $6 \mathrm{C}$ and $6 D$ ), it appears likely that the TCE and DCE detected in groundwater from these supply wells are associated with the same source of TCE that has affected the groundwater sampled from the FP3 and FP4 wells. The absence of detections of dichlorobenzene compounds in the SSW and PSW1 does not contradict this conclusion; on the contrary, data from monitoring wells indicate that these compounds are present in such small concentrations and at such limited depths of the aquifer that they would probably be diluted below detection levels in groundwater produced by SSW and PSW1.

The conclusion that the groundwater contamination site located northwest of the SSW has likely contributed solvents to the water produced by the SSW and PSW1 is further supported by an assessment conducted by the U.S. Environmental Protection Agency (2001), which noted that contamination 
from the site could potentially affect PSW1. The assessment also noted that the same contamination could potentially affect PSW3; however, as discussed in the following "Groundwater Age" section, data from the TANC study indicate that water produced by PSW3 is strongly dominated by inflow from the deep part of the aquifer, which would likely cause any TCE contributed to the well to be diluted below detection by conventional methods. The possibility that TCE associated with the groundwater contamination sites located northeast or southwest of the SSW has also reached the SSW cannot be ruled out, but it appears unlikely based on model-simulated ZOCs (fig. 2) and on regional hydraulic gradients (fig. 3). Another possibility that cannot be ruled out is a contribution of TCE from undocumented contamination sites located broadly northwest of the SSW.

\section{Depth-Dependent Sampling}

Depth-dependent groundwater samples were collected at multiple depths within the SSW to characterize the chemistry of groundwater from different parts of the aquifer that contribute flow to the well while it is pumping. A temporary submersible pump producing about $2,460 \mathrm{~L} / \mathrm{min}$ (not the typical dedicated turbine pump producing $11,660 \mathrm{~L} / \mathrm{min}$ ) was used during sampling. Because the flow profile (fig. 8) indicated that about 61 percent of the flow into the well was from about the upper $60 \mathrm{~m}$ of screens (above about $169 \mathrm{mbls}$ and roughly equivalent to the interval sampled by the intermediate monitoring wells), samples were collected from depths of about 115, 133, 151, 176, and $241 \mathrm{mbls}$ (fig. 21); a sample was also collected from the wellhead. Each sample represents the chemistry of all groundwater entering the screened interval below the depth of sampling, which was assumed to be thoroughly mixed. The upper four samples were collected successively, from top to bottom, in a single day, whereas the lowest depth-dependent sample and the wellhead sample were collected the following day. Although the results of this sampling effort are believed to provide useful information about groundwater chemistry from different depths of the aquifer, the lower pumping rate used during the sampling might have caused flow and chemistry results to differ somewhat from the results that would have been measured during typical operation of the SSW. Also, as described in detail in the following "Temporal Variations in Groundwater Chemistry from the Studied Supply Well" and "Groundwater Age" sections of this report, the chemistry of water produced by the SSW tends to vary between the high-pumping (summer) and low-pumping (winter) seasons. Because depth-dependent sampling was conducted during December 2007, the results probably are more representative of the chemistry of water produced by the SSW during lowpumping seasons.

Well-bore flow measurements indicated that groundwater was alternately entering the SSW across one or more $6.1-\mathrm{m}$ intervals of flow measurement and leaving the well across adjacent interval(s), as evidenced by fluctuations in flow with depth (fig. 21). Therefore, the study could not make reasonably accurate calculations of the chemistry of water entering the well between adjacent groundwater-sampling intervals, such as those that the use of simple mixing equations would typically enable. Nevertheless, general patterns in the chemistry of groundwater entering the well at various aquifer depths could be discerned.

As with the VOC results for groundwater samples collected in early February 2008 from the SSW under typical pumping conditions by using the dedicated turbine pump, the NWQL detected no VOCs in the wellhead sample from the SSW during depth-dependent sampling (table 8). Nor were VOCs detected in any of the five individual depth-dependent samples. Low-level VOC analysis by the USGS CFC laboratory did indicate the likely presence of TCE in samples from $115,133,151 \mathrm{mbls}$ and from the wellhead at concentrations greater than the 325 picograms per liter that could be expected to result from air-water equilibrium (Plummer and others, 2008). The median reported concentrations for individual sample sets from these depths were between about 520 and 570 picograms per liter (table 9 at end of report), more than an order of magnitude below the NWQL LRL. The presence of TCE, even at trace concentrations, in depth-dependent samples from 115, 133, $151 \mathrm{mbls}$ and from the wellhead is consistent with results for age tracers, as discussed in detail in the later "Groundwater Age" section of this report. In particular, all results for ${ }^{3} \mathrm{H}$, for $\mathrm{CFCs}$, and for ${ }^{14} \mathrm{C}$ indicated that the largest fraction of young water was entering the well between 176 and $151 \mathrm{mbls}$, which also was the depth range with the largest overall gain in flow.

The presence of only trace concentrations of TCE in these samples is consistent with well-bore flow measurements, which indicate only a minor contribution to the well of water from aquifer depths (about 135 to $147 \mathrm{mbls}$ ) that correspond with the screened interval of FP3D, the closest location to the SSW at which TCE was detected. Ambient flow that occurs through the well bore while the SSW is not pumping could also have contributed to low TCE concentrations in flow that entered the SSW from depths at which TCE is thought to be present. Flow measurements under ambient conditions indicated that the well bore primarily gains water from the aquifer below about $261 \mathrm{mbls}$ (fig. 8), and that it primarily loses water to the aquifer above about $157 \mathrm{mbls}$, meaning that deep, VOCfree groundwater would have flowed out into the zone where VOCs were present, possibly diluting their concentrations in the aquifer through mixing. Water entering the SSW from that zone would likely have lower concentrations of VOCs for some period of time after pumping resumed.

Patterns in the chemical and isotopic characteristics of the depth-dependent samples generally were consistent with overall patterns observed with depth in groundwater samples from intermediate and deep monitoring wells, which sample the parts of the aquifer where the SSW is screened. In particular, analytes that showed no clear pattern with depth in intermediate and in deep monitoring wells across the study area, such as specific conductance (fig. 10A) and deuterium content (fig. 9), 

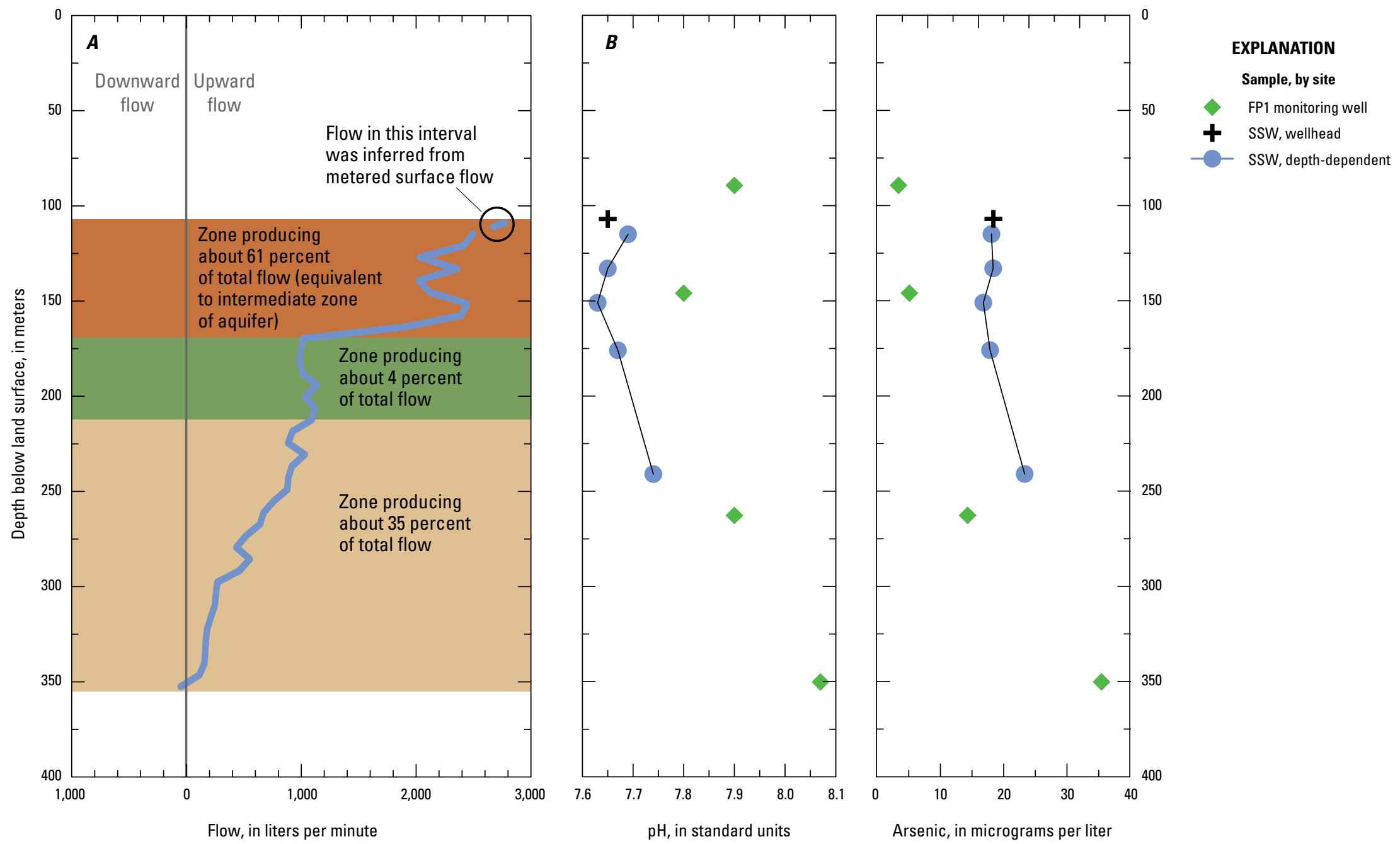

Figure 21. A, vertical distribution of flow in the studied supply well (SSW) and $B$, results for selected constituents in groundwater samples from various depths in the SSW and in adjacent monitoring well nest FP1. 
showed relatively small variability among depth-dependent samples from the SSW (table 3). Analytes that instead showed generally increasing patterns with depth in intermediate and in deep monitoring wells across the study area, such as $\mathrm{pH}$ (fig. 10B) and arsenic (fig. 18A), were highest in the 241-m (deepest) depth-dependent sample and were lower in the samples from $176 \mathrm{~m}$ and shallower depths (fig. 21; table 7). Nitrate concentrations, which were generally lower as a group in intermediate than in deep monitoring wells, probably as a result of denitrification (fig. 15), were also highest in the 241-m sample (table 3). However, analytes having a fairly consistent pattern with depth in monitoring wells often did not show the same consistent pattern with depth in the depthdependent samples, which could reflect a combination of measurement error, incomplete mixing of water in the well bore between sampling depths (possibly partly because water was alternately entering and leaving the well), and (or) chemical disequilibrium resulting from mixing of water in the well bore. Also, patterns in the values of analytes with depth among the depth-dependent samples often did not closely match patterns with depth in FP1 (fig. 21), an outcome that could reflect the three-dimensional convergence of multiple paths of groundwater flow at the SSW.

\section{Temporal Variations in Groundwater Chemistry from the Studied Supply Well}

Groundwater samples collected from the SSW over a 4-year period, during one regional-scale TANC samplecollection effort in 2005 (Eberts and others, 2011) and five local-scale TANC sample-collection efforts in 2007-9 (table 1), show substantial temporal variability in chemistry. By using the dedicated turbine pump, single sample sets were collected from the well in June 2007 and November 2008, 8 sample sets were collected during about 10 hours in February 2008, and 6 sample sets were collected during about 64 hours in May 2009. A single wellhead sample was also collected by using a temporary submersible pump during the depthdependent sampling effort of December 2007 (tables 1 and 2). Because flow measurements made during the depth-dependent sampling indicated the presence of ambient well-bore flow that might affect the chemistry of groundwater from the SSW for some time after pumping resumed, the February 2008 sampling effort was intended to search for associated changes in groundwater chemistry as pumping time increased. Because the NWQL did not detect TCE in the December 2007, February 2008, or November 2008 samples, the May 2009 sampling was designed to determine whether TCE was still reaching the SSW at detectable concentrations and, if so, after what interval of pumping.

A Piper diagram of the chemical compositions of the various samples collected from SSW (fig. 22) illustrates similarities and differences among the samples. The summer samples (July 2005, June 2007, and May 2009) had similar compositions of anions and of cations, with cations being more than 60 percent calcium plus magnesium, while the winter samples (December 2007, February 2008, and November 2008) had a substantially lower proportion of calcium plus magnesium, along with a somewhat lower proportion of sulfate. Based on the general compositions of groundwater samples from monitoring wells completed at various depths, these differences are consistent with the result that winter samples contain a larger fraction of groundwater from deeper parts of the aquifer. This conclusion is consistent with the detection of VOCs in summer samples, but not in most winter samples, and with generally lower arsenic concentrations in summer samples (typically not exceeding $12 \mu \mathrm{g} / \mathrm{L}$ ) than in winter samples (commonly exceeding $12 \mu \mathrm{g} / \mathrm{L}$ ). This conclusion also is consistent with age-tracer data, which are available for four of the six samplings (not July 2005 or February 2008), and which indicate a smaller fraction of young water and an older overall groundwater age for the winter samples, as discussed in the following "Groundwater Age" section of this report.

The February 2008 samples were collected under conditions believed to allow observation of any substantial changes in groundwater chemistry that might occur with pumping time. The samples were collected after reinstalling the dedicated turbine pump in the SSW (the study had collected the depthdependent samples by using a temporary submersible pump). When sampling began, the SSW had been unused for nearly 2 months prior to sampling, except for a short test to confirm that the turbine pump was working. During that time, the direction and magnitude of hydraulic gradients in the aquifer would be expected to change relative to conditions that typically are present when stresses are regularly being applied to the aquifer through pumping of the SSW. During this idle period, well-bore flow through the SSW under ambient conditions would also be expected to have a greater effect on groundwater chemistry in shallow parts of the aquifer than would be typical with regular pumping. Therefore, changes in groundwater chemistry when pumping of the SSW resumed would seem likely to be greater under these conditions than under typical operating conditions. Although substantial changes were evident in several analytes, including $\mathrm{pH}$ and concentrations of arsenic, calcium, and sulfate, they occurred only among samples collected within the first 2 to 3 hours of well operation (fig. 23). These and other changes in chemistry were consistent overall with a greater fraction of water from deeper parts of the aquifer being present in earlier samples from the well, although age-tracer data were not available to help evaluate the fractions of old and young water. It is not known whether the changes in groundwater chemistry among the early samples represent the reestablishment of hydraulic gradients and flow distributions from different aquifer depths that are typical during pumping of the SSW, whether they represent the effects that well-bore flow under ambient conditions had on overall groundwater chemistry near the well, or whether they perhaps represent some other factor or combination of factors. As with results for most other winter samples, no VOCs were detected by the NWQL in any of the 


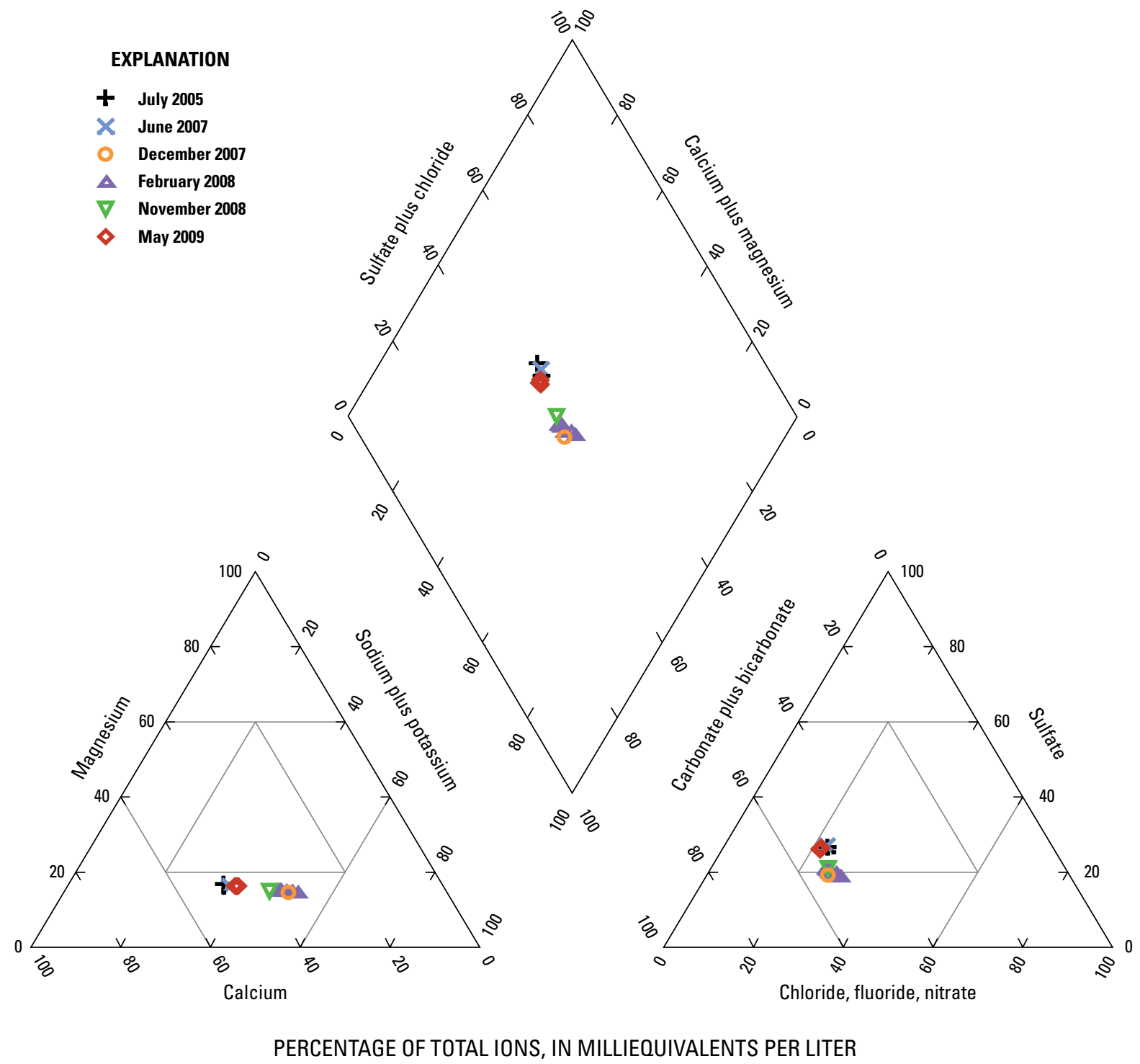

Figure 22. General chemical composition of multiple samples from the studied supply well (SSW) in the local-scale transport of anthropogenic and natural contaminants (TANC) study area in Albuquerque, New Mexico.

February 2008 samples, and the chemical composition of even the later samples included lower proportions of calcium plus magnesium and sulfate (and, therefore, likely higher fractions of water from deeper parts of the aquifer) than were typical for summer samples (fig. 22).

When the May 2009 samples were collected, the SSW had been pumped for at least a few hours on most days during the preceding month, including durations between 3 and 12 hours on each of the final 3 days before sampling began. Laboratory results for all six samples, collected about every 11 to 14 hours between the $3 \mathrm{~d}$ and 64th hour of operation, were quite similar. The relatively small differences observed in results for individual analytes showed no pattern with time (fig. 23). The general chemical composition of all May 2009 samples closely matched that of the other summer samples collected in July 2005 and June 2007 (fig. 22). Results for age tracers in the May 2009 samples were also quite similar to results available for the June 2007 samples. In addition, TCE was detected in all May 2009 samples, and in the July 2005 and June 2007 samples. The NWQL did not report these detections to the NWIS database for four of the six May 2009 samples; however, the laboratory analyst indicated that TCE was probably present in all six samples, even though certain criteria were not met for reporting in all samples (Linda Murtagh, U.S. Geological Survey National Water Quality Laboratory, oral commun., 2009). Also, low-level VOC results from the USGS CFC Laboratory indicated that TCE was present in all samples at concentrations that were at least 


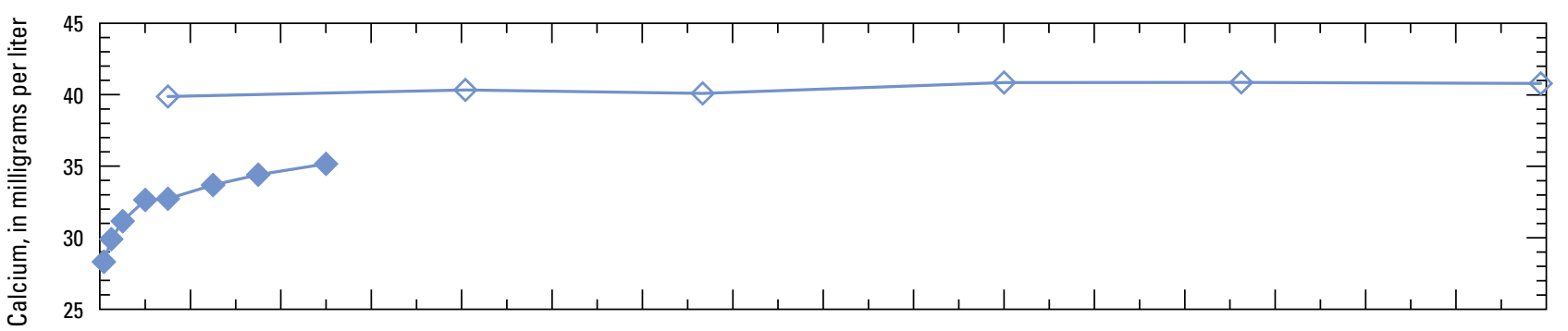

\section{EXPLANATION $\triangle \Delta \square \bullet$ February 2008}
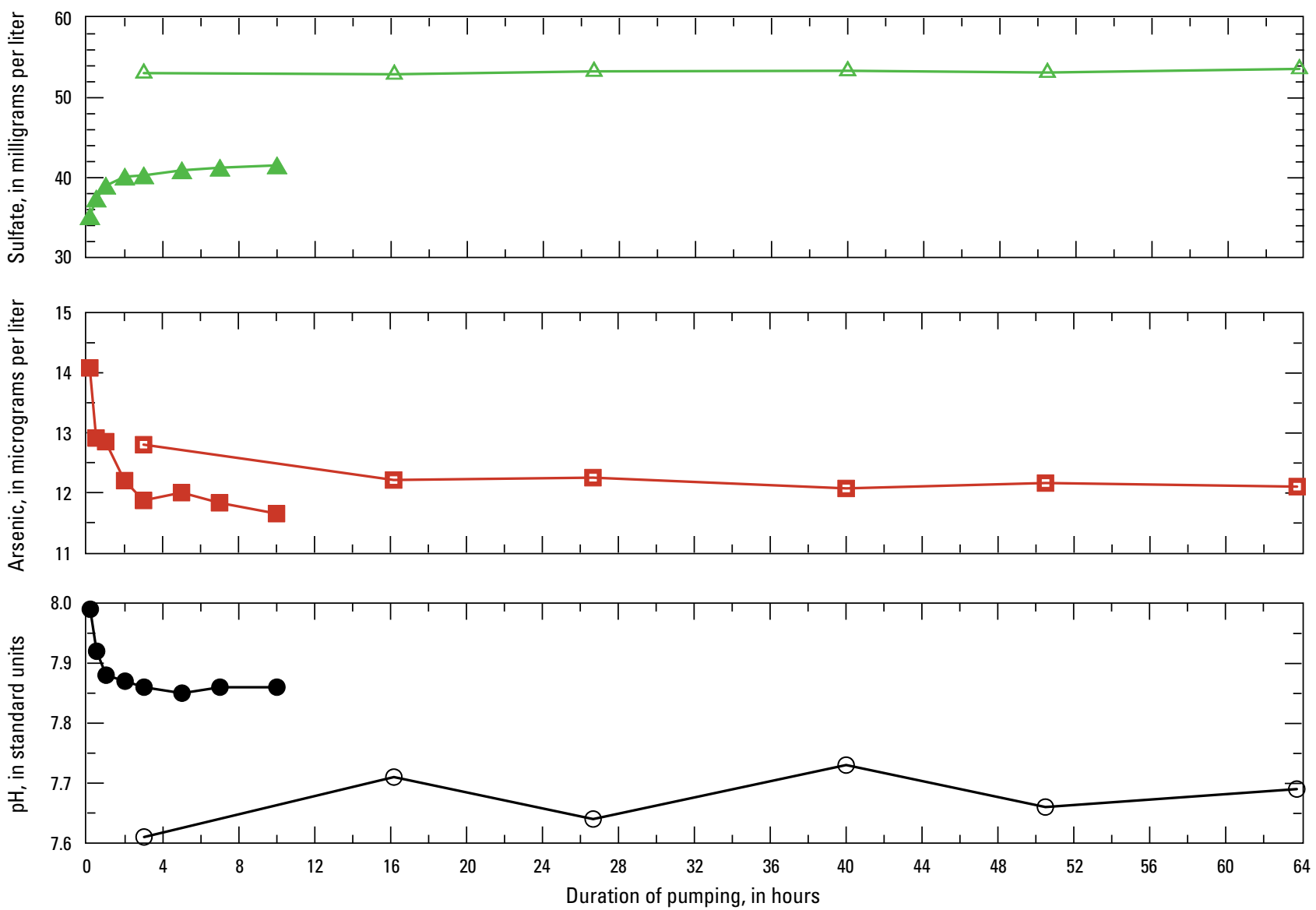

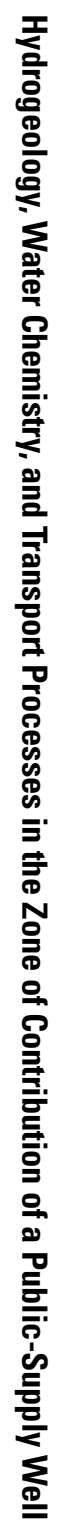

Figure 23. Variation in concentrations of selected constituents in samples from the studied supply well (SSW) with duration of pumping. 
one order of magnitude higher than could be expected from air-water equilibrium. MTBE, which was detected by one of two laboratory schedules in the July 2005 sample, was also detected by the NWQL in all May 2009 samples. Lastly, cis1,2-DCE, which was detected in the June 2005 sample, was detected in the second May 2009 sample, collected about 16 hours after the start of pumping.

Combined with the results from the February 2008 sampling, results from the May 2009 sampling indicate that the length of time since the start of pumping has little effect on the chemistry of groundwater produced by the SSW (even after a long period of inactivity), except perhaps during the first few hours of well operation. Instead, the various samples collected from the SSW during 2005 and 2009 indicate that seasonal factors are likely to be more important to the chemistry of groundwater produced by the well at any particular time. Seasonal patterns in groundwater withdrawals by publicsupply wells within the study area result in temporal variability in both the direction and the magnitude of local horizontal and vertical hydraulic gradients, which could account for the seasonal differences in groundwater chemistry from the SSW. Given the hydrogeology of the study area, and particularly the age characteristics of groundwater reaching the SSW, seasonal patterns in aquifer recharge are not likely to be a factor in the seasonal differences in groundwater chemistry.

\section{Groundwater Age}

Estimates of the age of groundwater are useful in refining our knowledge of a groundwater-flow system, particularly with respect to recharge sources, mixing fractions, chemical and biological reactions occurring along a groundwater-flow path, and overall susceptibility to contamination. Groundwater age is the time elapsed since a parcel of water recharged the groundwater system and became isolated from the atmosphere and is determined by using environmental tracers that include dissolved gases and isotopes. Tritium $\left({ }^{3} \mathrm{H}\right)$, tritium/helium-3 $\left({ }^{3} \mathrm{H} /{ }^{3} \mathrm{He}\right)$, and chlorofluorocarbons (CFCs) are the age-dating tracers that this study collected to investigate the young (post-1950) fraction of recharge; collection of carbon-14 $\left({ }^{14} \mathrm{C}\right)$ allowed investigation of the old (pre-1950) fraction of recharge. To directly support interpretation of these tracers, the study collected data for selected dissolved gases and for carbon-13 $\left({ }^{13} \mathrm{C}\right)$. This discussion of groundwater age in the local-scale TANC study area builds on the investigation of groundwater ages across the MRGB by Plummer and others (2004a). Particular emphasis is placed on understanding the contributions of young and old groundwater recharge as they relate to natural and anthropogenic contaminants that have been detected in groundwater from the SSW and from nearby public-supply and monitoring wells.

Groundwater withdrawn from a well is typically made up of molecules that recharged the aquifer at different times and that therefore have different ages. The distribution of ages that comprises a sample can be narrow and span only a year, or it can be broad, spanning thousands of years. For samples in which age distributions are narrow, it may be appropriate to report a piston-flow age, which assumes that the tracer traveled from the recharge area to the well without the effects of any hydrodynamic dispersion or mixing (Jurgens and others, in press). Previous research showed that groundwater in the MRGB is predominantly old (ages generally greater than 5,000 years), but that groundwater in some areas also contains a small portion of young water that was recharged since the 1950s (Plummer and others, 2004). Groundwater in the local-scale TANC study area would thus be expected to have very broad distributions of age, such that piston-flow ages do not provide a true indication of groundwater age. The use of lumped parameter models (LPMs) is therefore required to more fully characterize the age distribution of a groundwater sample and to determine a mean age that takes into account all of the individual age fractions comprising that sample.

LPMs are mathematical models of tracer transport based on simplified aquifer geometry and flow configurations that account for the effects of dispersion and (or) mixing within the well bore (Maloszewski and Zuber, 1982). The mean ages of groundwater samples from the local-scale TANC study area in Albuquerque were estimated by fitting observed tracer concentrations to idealized tracer concentrations obtained from LPMs. Determination of observed tracer concentrations that are appropriate for analysis with LPMs requires knowledge of the conditions under which recharge occurred, and of various processes within the aquifer that can affect tracer concentrations. Recharge temperature, entrained air, and excess nitrogen gas are important to the determination of appropriate tracer concentrations and are discussed in the following section. Concentrations of the individual tracers of groundwater age are subsequently discussed, followed by presentation of the groundwater ages determined by the use of LPMs.

\section{Recharge Temperature, Entrained Air, and Excess Nitrogen Gas}

Recharge temperature, entrained air (commonly referred to as "excess air"), and excess nitrogen gas were determined for 38 groundwater samples by using data for dissolved argon (Ar) and nitrogen gas $\left(\mathrm{N}_{2}\right)$. At wells where samples for ${ }^{3} \mathrm{H} /{ }^{\beta} \mathrm{He}$ dating were collected, neon $(\mathrm{Ne})$ was also used in calculating the recharge temperature, entrained air, and excess $\mathrm{N}_{2}$ gas. Recharge temperature is the temperature of the water when it first entered the groundwater system, which normally occurs at the water table. Entrained air is the quantity of air trapped during recharge because of fluctuations in the elevation of the water table. The calculation of recharge temperature relies on the temperature and salinity dependence of the Henry's Law solubility of each gas at an assumed elevation (and associated barometric pressure) of recharge. Plummer and others (2004a) found that an elevation of 5,000 feet (1,524 meters) was an appropriate estimate of recharge elevation for groundwater in the study area. Salinity values needed for calculating 
the solubility of oxygen in water were estimated by using an approximate relation between specific conductance and salinity (Pickering, 1981).

In groundwater in which denitrification is thought to have occurred, the conversion of nitrate to $\mathrm{N}_{2}$ gas can lead to an accumulation of $\mathrm{N}_{2}$ gas that is in excess of the calculated solubility equilibrium with the true recharge temperature. When only $\mathrm{Ar}$ and $\mathrm{N}_{2}$ are used to determine recharge temperature, the calculated recharge temperature is often erroneously high for wells where denitrification has occurred. To determine the extent of denitrification in wells throughout the study area and to correct for its effects, the amount of excess $\mathrm{N}_{2}$ gas was first determined for wells with measured Ne concentrations. For these samples, recharge temperature, entrained air, and excess $\mathrm{N}_{2}$ gas were determined by using $\mathrm{Ar}, \mathrm{Ne}$, and $\mathrm{N}_{2}$ with the unfractionated air model of excess air and methods described in Aeschbach-Hertig and others (1999) and Aeschbach-Hertig and others (2000). A linear regression of excess $\mathrm{N}_{2}$ gas and $\delta^{15} \mathrm{~N}-\mathrm{N}_{2}$ for wells with $\mathrm{Ar}, \mathrm{N}_{2}$, and $\mathrm{Ne}$ data (fig. 24) was then used to estimate the amount of excess $\mathrm{N}_{2}$ gas for groundwater samples from the SSW (2007 sample), FP2D, FP3D (2007 sample), FP4S, MW7, and PSW1; for these samples, only $\mathrm{Ar}$ and $\mathrm{N}_{2}$ data were available and their $\delta^{15} \mathrm{~N}-\mathrm{NO}_{3}$ and $\delta^{18} \mathrm{O}-\mathrm{NO}_{3}$ values were consistent with denitrification. Excess nitrogen gas was set to zero for wells that did not have values of $\delta^{15} \mathrm{~N}-\mathrm{NO}_{3}$ and of $\delta^{18} \mathrm{O}-\mathrm{NO}_{3}$ that were consistent with denitrification.

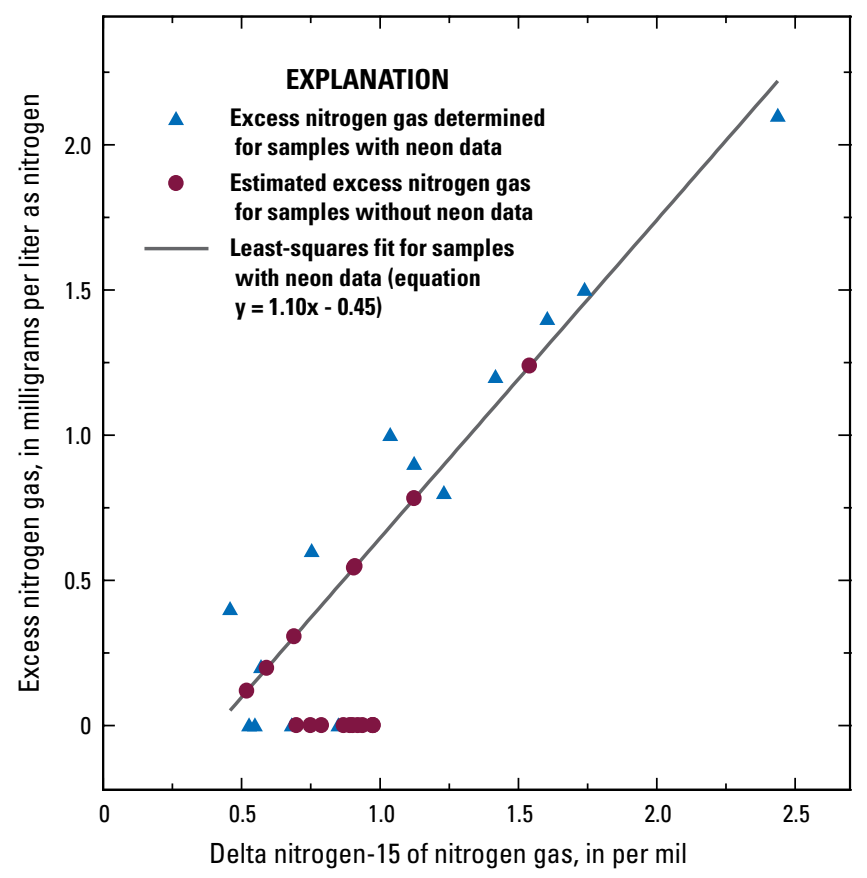

Figure 24. Relation between excess nitrogen gas and delta nitrogen-15 of nitrogen gas for groundwater from the local-scale transport of anthropogenic and natural contaminants (TANC) study area in Albuquerque, New Mexico.
Recharge temperatures in this study ranged from 6.0 to $19.2^{\circ} \mathrm{C}$, and entrained air ranged from 0.2 to 4.5 cubic centimeters at standard temperature and pressure STP per kilogram of water (cc at STP/kg of $\mathrm{H}_{2} \mathrm{O}$ ) (table 10 at end of report). The median recharge temperature was $13.5^{\circ} \mathrm{C}$ and the median entrained air was $1.4 \mathrm{cc}$ at STP $/ \mathrm{kg}$ of water. This median recharge temperature is very close to the mean annual air temperature of $13.7^{\circ} \mathrm{C}$ (Western Regional Climate Center, 2010a). All but one sample had a recharge temperature above $11.0^{\circ} \mathrm{C}$. The sample with the lowest recharge temperature $\left(6.0^{\circ} \mathrm{C}\right)$ is not considered to be representative of groundwater in the study area because the well (FP2S) likely receives a substantial fraction of recharge water from a nearby stormwater conveyance channel during precipitation events. Excess $\mathrm{N}_{2}$ gas ranged from 0 to $2.1 \mathrm{mg} / \mathrm{L}$ as $\mathrm{N}$ (table 10), and its median value was $0.23 \mathrm{mg} / \mathrm{L}$ as $\mathrm{N}$. Recharge temperature and excess $\mathrm{N}_{2}$ were not estimated for the P83-19 wells because dissolvedgas results for these wells likely were affected by a pump-andtreat facility nearby.

Recharge temperatures generally were higher and more variable in the shallow and intermediate parts of the aquifer than in the deep part (fig. 25). The median recharge

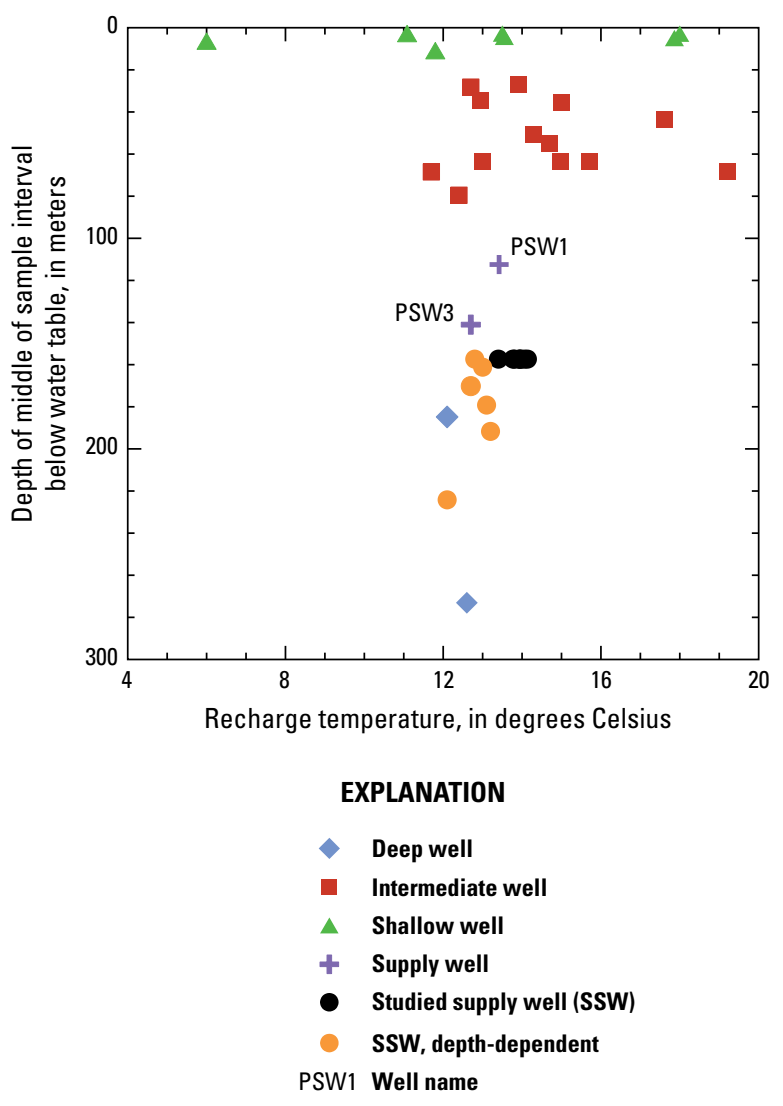

Figure 25. Recharge temperature with depth below the water table in groundwater from the local-scale transport of anthropogenic and natural contaminants (TANC) study area in Albuquerque, New Mexico. 
temperatures for groundwater sampled in the shallow and intermediate parts of the aquifer were 13.5 and $14.3^{\circ} \mathrm{C}$, respectively, whereas the median recharge temperature for groundwater samples from two deep wells were lower at $12.4^{\circ} \mathrm{C}$. Plummer and others (2004a) found that recharge from the Rio Grande likely varied in response to climatic changes during at least the past 20,000 years. It is likely that the source of warmer recharge water to the groundwater system is more recent infiltration of evaporated water through the unsaturated zone. This water would enter the shallow groundwater system and likely be drawn downward into intermediate parts of the aquifer as a result of groundwater pumping from the intermediate portion of the aquifer. However, not all shallow and intermediate wells produced groundwater with higher temperatures. Recharge temperatures in some shallow and intermediate wells more closely resembled those in deep groundwater, indicating that some parts of the groundwater system may not be substantially affected by warmer, more recent recharge water.

Recharge temperatures for groundwater samples from supply wells represent the combined recharge temperature of the different parts of the aquifer tapped by that particular supply well. The SSW had a median recharge temperature of $13.9^{\circ} \mathrm{C}$ for nine samples collected at the wellhead, whereas the recharge temperatures for PSW1 and PSW3 were 13.4 and $12.7^{\circ} \mathrm{C}$, respectively. All three supply wells have screen lengths greater than or equal to 190 meters (625 feet), and they capture groundwater from the intermediate and deep parts of the aquifer. The higher recharge temperatures for SSW and PSW1 indicate that these wells capture a greater proportion of intermediate groundwater with higher recharge temperatures, whereas PSW3 may capture a larger proportion of deep groundwater having lower recharge temperatures (fig. 25).

Depth-dependent samples collected from the SSW indicate that water with the highest recharge temperature entered the well screen between 151 and 241 mbls (table 10). The recharge temperatures for samples collected at 151 and 176 mbls were 13.1 and $13.2^{\circ} \mathrm{C}$, respectively. The higher recharge temperatures at this depth interval relative to other depths indicate that the well is capturing intermediate depth groundwater that has been affected by evaporated recharge water that originally infiltrated to the groundwater system through the unsaturated zone. Lower recharge temperatures above and below this depth (133 and $241 \mathrm{mbls}$ ) indicate that the water entering the well at the associated depth intervals is native (primarily old) groundwater that has not been affected by evaporated recharge water. The higher recharge temperature calculated for the shallowest depth-dependent sample (collected at $115 \mathrm{mbls}$ ) also indicates that the well may capture some shallow groundwater that has been affected by infiltrating evaporated recharge water.

Like chemical characteristics previously discussed in the "Temporal Variations in Groundwater Chemistry from the Studied Supply Well" section, recharge temperatures are also affected by seasonal changes in hydrologic conditions that result from seasonal pumping stresses. Groundwater withdrawals are greatest during summer months, when water demand is high, and create prolonged periods of downward vertical gradients, allowing shallow groundwater having higher recharge temperatures to migrate to somewhat greater depths of the aquifer. Consequently, the median recharge temperature for five summer samples (from FP1MS, FP3S, FP3D, and the SSW, where the average of five time-dependent samples collected in May 2009 is counted as one of two summer samples from the SSW) was about $1^{\circ} \mathrm{C}$ higher than the median recharge temperature for five winter samples collected from the same wells (table 10). This result indicates that shallow groundwater with higher recharge temperatures comprises a larger component of intermediate groundwater during the summer than during the winter. Restoration of the natural upward vertical gradients during the winter, when groundwater withdrawals are smaller, causes deeper groundwater with lower recharge temperatures to move upward to somewhat shallower depths of the aquifer.

\section{Concentrations of Tracers of Groundwater Age}

The current section focuses on determining concentrations for ${ }^{3} \mathrm{H}$, for tritiogenic helium-3 $\left({ }^{3} \mathrm{He}_{\text {tri }}\right)$, for individual CFCs (CFC-11, CFC-12, and CFC-113), and for ${ }^{14} \mathrm{C}$; concentrations of these tracers were subsequently used in model calculations. For reference, table 10 reports piston-flow ages for each tracer as "apparent" ages, even though they do not provide a true indication of groundwater age.

\section{Tritium}

Tritium is a radioactive isotope of hydrogen with a half-life of 12.3 years (Lucas and Untwerger, 2000), and is produced naturally from the bombardment of nitrogen by cosmic radiation in the upper atmosphere (Clark and Fritz, 1997). Because ${ }^{3} \mathrm{H}$ is an isotope of hydrogen, it can bond with oxygen and other hydrogen atoms to form molecules of water in the atmosphere. Most ${ }^{3} \mathrm{H}$ in groundwater therefore comes from precipitation-derived recharge to an aquifer. Tritium concentrations in precipitation increased substantially during the 1950s and 1960s from aboveground testing of nuclear weapons, which produced ${ }^{3} \mathrm{H}$ concentrations in excess of 3,000 tritium units (TU) in precipitation near the peak of such testing during 1963 (Michel, 1989). Consequently, ${ }^{3} \mathrm{H}$ is often a useful indicator of groundwater that was recharged since the 1950s, or of samples containing a fraction of post-1950s precipitation. However, because of ${ }^{3} \mathrm{H}$ decay, concentrations measured in a groundwater sample can be compared only to the ${ }^{3} \mathrm{H}$ concentrations in precipitation minus the amount of ${ }^{3} \mathrm{H}$ lost to decay since the time of first precipitation.

In this study, the activity of ${ }^{3} \mathrm{H}$ was measured in 41 groundwater samples. Tritium concentrations ranged from 0 (statistically not detectable) to $7.8 \mathrm{TU}$. The median ${ }^{3} \mathrm{H}$ concentration was $1.46 \mathrm{TU}$ (table 10). 
Groundwater recharged before the detonation of nuclear weapons testing in the early 1950 s would have a concentration of ${ }^{3} \mathrm{H}$ of about $0.3 \mathrm{TU}$ at most in year 2008 , based on ${ }^{3} \mathrm{H}$ concentrations in precipitation at that time and calculations of subsequent decay. Only 10 samples had concentrations lower than $0.3 \mathrm{TU}$, indicating that most groundwater in the study area has some component of young recharge.

Concentrations of ${ }^{3} \mathrm{H}$ were higher and more variable in shallow and intermediate groundwater than in deep groundwater (fig. 26). The highest ${ }^{3} \mathrm{H}$ concentrations were from wells screened in the intermediate part of the aquifer, although concentrations were significantly lower than would be expected for groundwater recharged around the atmospheric ${ }^{3} \mathrm{H}$ peak in 1963. Two groundwater samples from the deep part of the aquifer had the lowest ${ }^{3} \mathrm{H}$ concentrations of all the samples ( 0 and $0.02 \mathrm{TU}$ ), indicating that deep groundwater has not been affected by young recharge. In addition, ${ }^{3} \mathrm{H}$ concentrations less than $0.3 \mathrm{TU}$ were detected in samples from some wells screened in shallow and in intermediate parts of the aquifer, indicating that not all shallow and intermediate groundwater has been affected by young recharge.
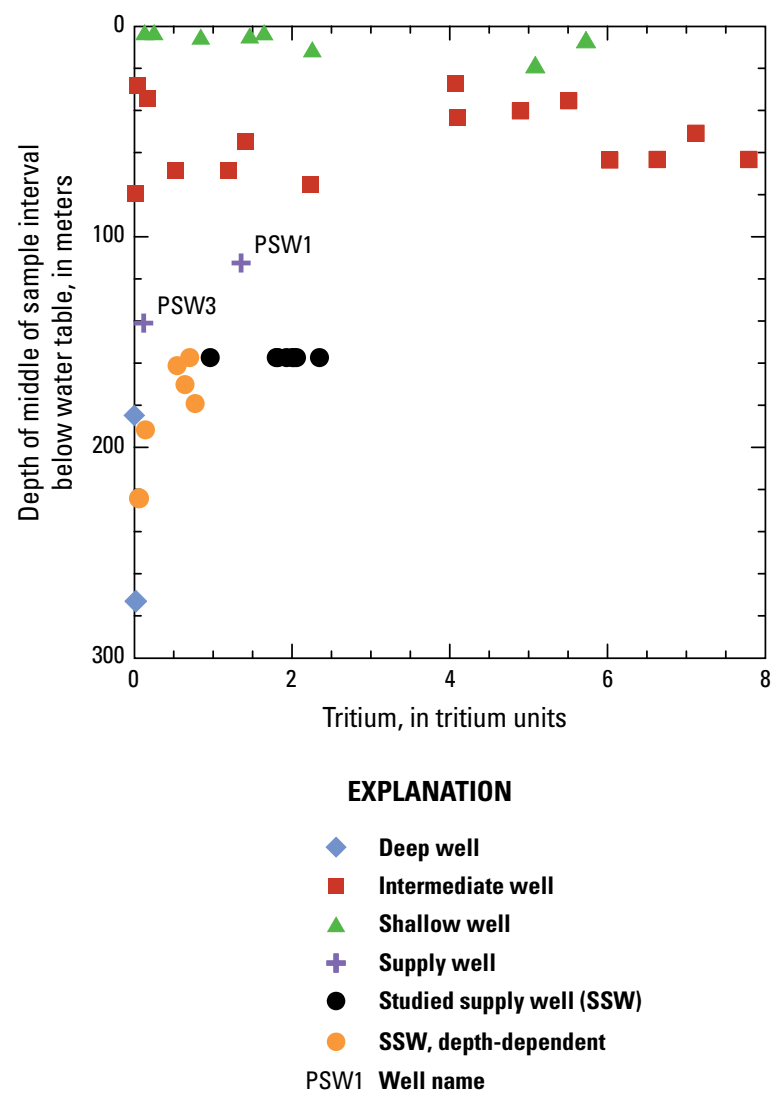

Figure 26. Tritium with depth below the water table in groundwater from the local-scale transport of anthropogenic and natural contaminants (TANC) study area in Albuquerque, New Mexico.
Tritium concentrations varied among supply wells. PSW3 had the lowest ${ }^{3} \mathrm{H}$ concentration of the supply wells at $0.12 \mathrm{TU}$, indicating that this well mainly captures groundwater from the deep portion of the aquifer, which is predominantly free of young water. In contrast, PSW 1 and SSW had ${ }^{3} \mathrm{H}$ concentrations of 1.35 and $1.49 \mathrm{TU}$, respectively, where the value for the SSW is an average of the values from four samples at the wellhead, in June 2007, December 2007, November 2008, and May 2009. It should be noted that for this calculation and all subsequent calculations that include results of the timedependent sampling of the SSW in May 2009, the average of the results for the six individual samples collected at that time is counted as one sample. The ${ }^{3} \mathrm{H}$ concentrations for PSW1 and the SSW indicate that they both capture intermediate and deep groundwater that has some component of young water. These findings are consistent with the results from the analysis of recharge temperature, which found higher recharge temperatures for groundwater from the SSW and PSW1 when compared with that for PSW3.

Tritium concentrations for the depth-dependent samples from the SSW indicate that young groundwater is entering the well at depths between 151 and 241 mbls. The sample collected at $151 \mathrm{mbls}$ had the highest ${ }^{3} \mathrm{H}$ concentration $(0.77 \mathrm{TU})$ of all the depth-dependent samples, which indicates that most of the young groundwater is entering the well at depths between 151 and $176 \mathrm{mbls}$; a smaller fraction of young groundwater is also entering the well at depths between 176 and 241 mbls. Lower ${ }^{3} \mathrm{H}$ concentrations were observed in two samples collected above $151 \mathrm{mbls}$, indicating that intermediate groundwater entering the well above $151 \mathrm{mbls}$ had a smaller component of young recharge or none at all. The lowest ${ }^{3} \mathrm{H}$ concentration of the depth-dependent samples $(0.06$ $\mathrm{TU})$ was from the deepest sample $(241 \mathrm{mbls})$ and is consistent with other samples collected from the deep part of the aquifer, which had ${ }^{3} \mathrm{H}$ concentrations below post-1950s levels that had decayed to the date of sampling.

Tritium concentrations in groundwater of the study area are also apparently affected by seasonal changes in hydrologic conditions resulting from seasonal pumping stresses. Tritium concentrations were about $1 \mathrm{TU}$ higher for the five summer samples collected from FP1MS, FP3S, FP3D, and the SSW than for the winter samples from those same five wells. As with the results for recharge temperatures, these results indicate that seasonal pumping stresses promote the movement of young groundwater from the shallow part of the aquifer to deeper parts of the aquifer during summer months. ${ }^{3} \mathrm{H}$ concentrations in the SSW were 2.3 and $1.9 \mathrm{TU}$ during the summer, and 0.70 and $0.96 \mathrm{TU}$ during the winter (fig. 27). Consequently, the vulnerability of the SSW and other supply wells in the area to natural and anthropogenic contaminants may vary with time of year.

\section{Tritiogenic Helium-3}

Tritium decays to the stable isotope helium-3 $\left({ }^{3} \mathrm{He}_{\mathrm{tri}}\right)$, the subscript "tri" indicating that the ${ }^{3} \mathrm{He}$ is tritiogenic in origin. 


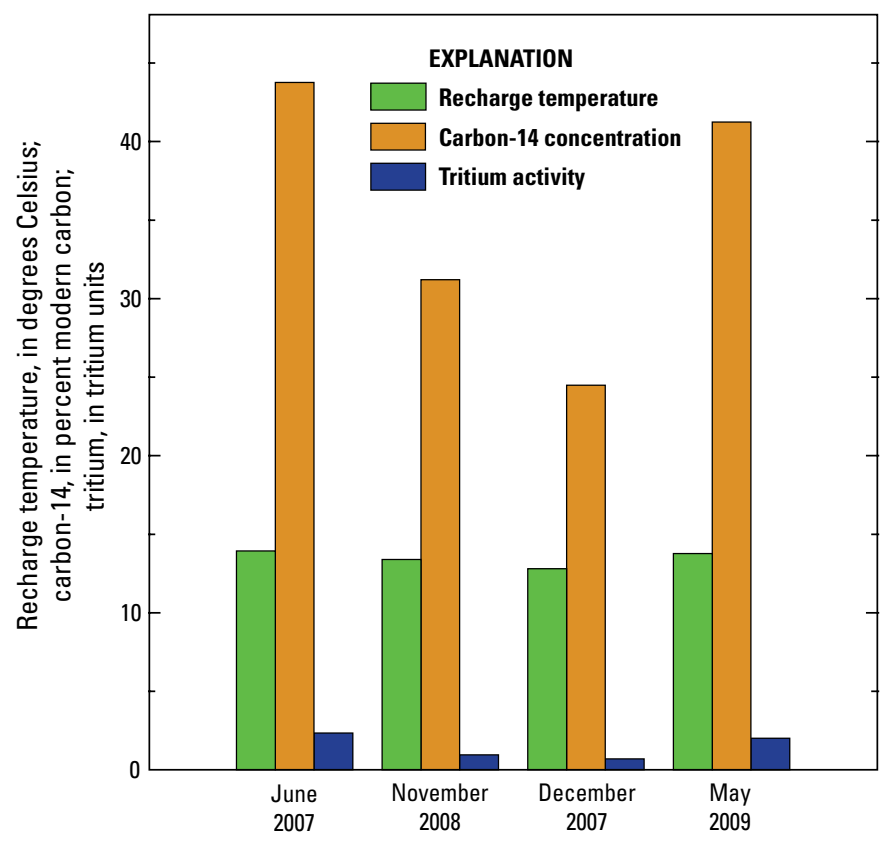

Figure 27. Recharge temperature, carbon-14 concentration, and tritium activity in samples collected from the studied supply well (SSW) during the month and year indicated. The December 2007 sample is the depth-dependent sample collected at the wellhead. For May 2009, the graph shows the average value calculated from five time-dependent samples.

The total amount of helium-3 $\left({ }^{3} \mathrm{He}_{\text {tot }}\right)$ in a sample is calculated from the measured amount of helium (essentially all helium-4 $\left.\left[{ }^{4} \mathrm{He}\right]\right)$, both in cubic centimeters at standard temperature and pressure per gram of water ( $\mathrm{cc} \mathrm{STP} / \mathrm{g}$ of $\left.\mathrm{H}_{2} \mathrm{O}\right)$, and the measured helium-3/helium-4 isotope ratio $\left({ }^{3} \mathrm{He} /{ }^{4} \mathrm{He}\right)$ :

$$
{ }^{3} \mathrm{He}_{\text {tot }}={ }^{4} \mathrm{He} \mathrm{x}{ }^{3} \mathrm{He} /{ }^{4} \mathrm{He} .
$$

In order to date groundwater by using the ${ }^{3} \mathrm{H} /{ }^{3} \mathrm{He}$ method, it is necessary to determine the amount of ${ }^{3} \mathrm{He}_{\text {tri }}$ in the sample. Groundwater samples typically contain ${ }^{3} \mathrm{He}$ from multiple sources: air (from solubility equilibrium with the atmosphere $\left[{ }^{3} \mathrm{He}_{\text {sol }}\right]$ and entrained air $\left.\left[{ }^{3} \mathrm{He}_{\text {air }}\right]\right)$; nucliogenic ${ }^{3} \mathrm{He}$ from in-place production in the aquifer sediment; crustal (probably also nucliogenic in origin) ${ }^{3} \mathrm{He}$; mantle ${ }^{3} \mathrm{He}$; and ${ }^{3} \mathrm{He}_{\text {tri }}$. Combining nucliogenic, crustal, and mantle ${ }^{3} \mathrm{He}$ into one lithogenic term, called "terrigenic ${ }^{3} \mathrm{He}^{\text {" }}\left({ }^{3} \mathrm{He}_{\text {terr }}\right),{ }^{3} \mathrm{He}$ tot can be defined as follows, where all terms are in units of $\operatorname{cc~STP} / g$ of $\mathrm{H}_{2} \mathrm{O}$ :

$$
{ }^{3} \mathrm{He}_{\text {tot }}={ }^{3} \mathrm{He}_{\text {sol }}+{ }^{3} \mathrm{He}_{\text {air }}+{ }^{3} \mathrm{He}_{\text {terr }}+{ }^{3} \mathrm{He}_{\text {tri }} \text {. }
$$

Tritiogenic ${ }^{3} \mathrm{He}$ can be calculated from helium mass balance equations for ${ }^{3} \mathrm{He}$ and ${ }^{4} \mathrm{He}$ by using the measured helium and neon concentrations, the ${ }^{3} \mathrm{He} /{ }^{4} \mathrm{He}$ of a groundwater sample, and the assumed ${ }^{3} \mathrm{He} /{ }^{4} \mathrm{He}$ ratio of terrigenic helium (Schlosser and others, 1989; Solomon and Cook, 2000):

$$
\begin{gathered}
{ }^{3} \mathrm{He}_{\text {tri }}={ }^{4} \mathrm{He}_{\text {tot }} \times \mathrm{R}_{\mathrm{s}}-{ }^{4} \mathrm{He}_{\text {tot }} \times \mathrm{R}_{\mathrm{a}}-{ }^{4} \mathrm{He}_{\text {terr }} \times \mathrm{R}_{\mathrm{a}}+ \\
{ }^{4} \mathrm{He}_{\text {sol }} \times \mathrm{R}_{\mathrm{a}} \times(1-\alpha)-{ }^{4} \mathrm{He}_{\text {terr }} \times \mathrm{R}_{\text {terr }}
\end{gathered}
$$

where

${ }^{4} \mathrm{He}_{\text {tot }}$ is the total amount of helium-4 in units of cc STP/g of $\mathrm{H}_{2} \mathrm{O}$,

$\mathrm{R}_{\mathrm{s}}$ is the measured ${ }^{3} \mathrm{He} /{ }^{4} \mathrm{He}$ ratio of the sample,

${ }^{4} \mathrm{He}_{\text {terr }}$ is the terrigenic helium-4 in units of cc STP/g of $\mathrm{H}_{2} \mathrm{O}$,

$\mathrm{R}_{\mathrm{a}}$ is the ${ }^{3} \mathrm{He} /{ }^{4} \mathrm{He}$ ratio of air,

${ }^{4} \mathrm{He}_{\text {sol }}$ is the helium-4 from solubility equilibrium with the atmosphere in units of $\mathrm{cc} \mathrm{STP} / \mathrm{g}$ of $\mathrm{H}_{2} \mathrm{O}$,

$\alpha$ is the ${ }^{3} \mathrm{He} /{ }^{4} \mathrm{He}$ isotope fractionation between air and water (about 0.983 in this study), and

$\mathrm{R}_{\text {terr }}$ is the assumed ${ }^{3} \mathrm{He} /{ }^{4} \mathrm{He}$ ratio of terrigenic helium.

Although determining helium concentrations from solubility equilibrium with the atmosphere $\left(\mathrm{He}_{\mathrm{sol}}\right)$ and with entrained air $\left(\mathrm{He}_{\text {air }}\right)$ is straightforward, complications can arise if terrigenic helium $\left(\mathrm{He}_{\text {terr }}\right)$ is a significant source of helium to groundwater in the study area. Terrigenic helium is composed of helium generated from the decay of uranium and thorium in subsurface sediments or from the introduction of mantle helium into the groundwater system either by mineral weathering of volcanic sediments or from migration of mantle fluid along faults. Wherever such external sources of helium are present, accurate calculation of the ${ }^{3} \mathrm{He}_{\text {tri }}$ concentration in a sample requires that the ${ }^{3} \mathrm{He} /{ }^{4} \mathrm{He}$ of the $\mathrm{He}_{\text {terr }}$ be known to a sufficient level of precision. The ${ }^{3} \mathrm{He}_{\text {tri }}$ concentration may not be determinable, therefore, when large amounts of mantle helium are present in groundwater,

To evaluate sources of $\mathrm{He}_{\text {terr }}$ in groundwater in the study area, the amount and percentage of $\mathrm{He}_{\text {terr }}$ was calculated for each of 15 samples that were analyzed for ${ }^{3} \mathrm{He} /{ }^{4} \mathrm{He}$, helium, and neon (table 10). The amount of terrigenic helium $\left(\mathrm{He}_{\text {ter }}\right)$ was calculated by subtracting the amount of $\mathrm{He}_{\text {sol }}$ and $\mathrm{He}_{\text {air }}$ from the measured total dissolved helium $\left(\mathrm{He}_{\text {tot }}\right)$ in each sample. The amount of $\mathrm{He}_{\text {terr }}$ is expressed as a percent of the total dissolved helium (table 10). Recharge temperatures and neon concentrations were used to determine the concentration of $\mathrm{He}_{\text {sol }}$ and $\mathrm{He}_{\text {air }}$ (Solomon and Cook, 2000).

Twenty-one samples were submitted for analysis of ${ }^{3} \mathrm{He} /{ }^{4} \mathrm{He}$, helium, and neon, but gas loss during sampling or leaks in the copper tubes prevented the analysis of six of these samples. Samples submitted for analysis were from monitoring wells screened in the shallow or intermediate parts of the aquifer because this groundwater was most likely to contain measurable amounts of ${ }^{3} \mathrm{He}_{\text {tri. }}$. No public-supply well in this study was analyzed for ${ }^{3} \mathrm{He} /{ }^{4} \mathrm{He}$, helium, and neon because prescreening for helium indicated that the samples contained too much terrigenic helium to permit an accurate determination of ${ }^{3} \mathrm{He}_{\text {tri: }}$.

The ${ }^{3} \mathrm{He}_{\text {terr }}$ concentrations comprised more than 30 percent of the total helium in 5 of the 15 samples thus analyzed (from FP1MS [2007 and 2008 samples], MNW4-D1, SFMW-46, and MW7). ${ }^{3} \mathrm{He}_{\text {terr }}$ concentrations comprised less than 10 percent of the total helium in the other 10 samples. 
In order to calculate accurate ${ }^{3} \mathrm{He}_{\text {tri }}$ concentrations for samples with high $\mathrm{He}_{\text {terr }}$, the ${ }^{3} \mathrm{He} /{ }^{4} \mathrm{He}$ of the $\mathrm{He}_{\text {terr }}$ was determined by linear regression of the percentage of terrigenic helium against the $\delta^{3} \mathrm{He}\left(\delta^{3} \mathrm{He}=\left[\mathrm{R}_{\text {meas }} / \mathrm{R}_{\text {air }}-1\right] \times 100\right.$, where $\mathrm{R}_{\text {meas }}$ is the measured ${ }^{3} \mathrm{He} /{ }^{4} \mathrm{He}$ ratio, and $\mathrm{R}_{\text {air }}$ is the ${ }^{3} \mathrm{He} /{ }^{4} \mathrm{He}$ ratio for air) for samples having measured ${ }^{3} \mathrm{H}$ values of less than $1.2 \mathrm{TU}$. From this analysis, the ${ }^{3} \mathrm{He} /{ }^{4} \mathrm{He}$ of $\mathrm{He}_{\text {terr }}$ was found to be $1.0 \times 10^{-6}$, which is identical to the ${ }^{3} \mathrm{He} /{ }^{4} \mathrm{He}$ ratio found by Plummer and Sanford (in press). This value is about two orders of magnitude higher than the ${ }^{3} \mathrm{He} /{ }^{4} \mathrm{He}$ of radiogenic sources (2.0 $\times 10^{-8}$ from decay of uranium and thorium), which indicates that a component of mantle helium is present in groundwater in the study area. The source of mantle helium cannot be known but is likely from the weathering of volcanic rocks present in the aquifer sediments, and (or) is the result of upward flux of mantle helium from depth within the Rio Grande Rift. Unfortunately, it is not possible to determine the ${ }^{3} \mathrm{He} /{ }^{4} \mathrm{He}$ ratio of terrigenic $\mathrm{He}$ with sufficient precision to calculate a ${ }^{3} \mathrm{H} /{ }^{3} \mathrm{He}$ age for several of the samples.

Tritiogenic helium-3 could not be calculated for all 15 samples, usually because the amount of $\mathrm{He}_{\text {terr }}$ was high and (or) the ${ }^{3} \mathrm{He} /{ }^{4} \mathrm{He}$ ratio of terrigenic $\mathrm{He}$ could not be determined with sufficient precision. In this study, these samples also have ${ }^{3} \mathrm{H}$ concentrations indicative of old, pre-1950s recharge water, or are mixtures with old water. The ${ }^{3} \mathrm{He}_{\mathrm{tri}}$ values for these samples are accordingly labeled as " $<1$ " in table 10 to indicate that the ${ }^{3} \mathrm{He}_{\text {tri }}$ is so small it could not be calculated; also, the apparent age is labeled as " $>50$ " in table 10 to indicate that the groundwater is pre-1950s recharge.

In 10 samples, concentrations of ${ }^{3} \mathrm{He}_{\text {tri }}$ could be determined as ranging from about 0.1 to $26.5 \mathrm{TU}$ (table 10). The median ${ }^{3} \mathrm{He}_{\text {tri }}$ in groundwater was $8.4 \mathrm{TU}$. The highest concentrations of ${ }^{3 \mathrm{Hi}} \mathrm{He}_{\text {tri }}$ were found in intermediate groundwater that also generally contained the highest ${ }^{3} \mathrm{H}$ concentrations. Shallow groundwater had the lowest ${ }^{3} \mathrm{He}_{\text {tri }}$ concentrations, indicating that the ${ }^{3} \mathrm{H}$ has not been in the groundwater long enough for ${ }^{3} \mathrm{He}$ to accumulate or that some ${ }^{3} \mathrm{He}_{\text {tri }}$ is being lost to the unsaturated zone above the groundwater system. Either one of these processes could be responsible for the low ${ }^{3} \mathrm{He}_{\text {tri }}$ concentration $(0.1 \mathrm{TU})$ observed for the shallow groundwater sample from MW2. Tritiogenic helium-3 loss is evaluated more fully in the following "Interpreted Groundwater Age" section of this report.

\section{Chlorofluorocarbons}

Chlorofluorocarbons (CFCs) are volatile synthetic compounds that can be used to identify and date groundwater recharged after 1945. Concentrations of CFCs in the atmosphere have closely followed the production rates and industrial use of the individual CFCs since that time (Plummer and Busenberg, 2006). CFCs can be used to date groundwater by calculating the equilibrium concentration (as a dry air mixing ratio) of each CFC in air based on its measured CFC concentration in groundwater, and then relating the mixing ratio with the air curve for that CFC. Chlorofluorocarbon equilibrium concentrations follow Henry's Law; they depend on the temperature, pressure (a function of recharge elevation), and salinity (dissolved-solute content) of water at the time of recharge. This study calculated equilibrium CFC concentrations in the atmosphere by using the recharge temperatures, pressure, and salinity discussed in the previous "Recharge Temperature, Entrained Air, and Excess Nitrogen Gas" section. In some cases, calculated equilibrium CFC concentrations may exceed modern air-water concentrations by more than 10 percent, which indicates that the sample is contaminated. The study rejected and did not report concentrations of CFCs in cases where contamination was suspected or where anaerobic conditions in the groundwater had likely degraded the measured concentration.

In this study, samples for CFC analysis were collected at every well and CFCs were detected in all samples, including in samples from deep groundwater where CFCs were not expected. In total, 41 samples were analyzed for CFC-11, CFC-12, and CFC-113. The continued presence of drilling fluid in the aquifer immediately surrounding the monitoring wells that the USGS installed is the likely explanation for the presence of CFCs in samples from the deep wells, and it may also have affected concentrations of CFCs in samples from other depths. Plummer and others (2004a) noted this same effect for the newly installed monitoring wells they sampled. Because the study area is an urban landscape, it is also possible that other sources of CFCs, which historically have been used as refrigerants and for a variety of industrial applications, may have contaminated the groundwater. Three samples (one collected from FP4S and two from FP3S, during 2007 and 2008) had contamination of all three CFCs that were analyzed. Groundwater could not be dated for these three samples by using CFCs. Overall, CFC-12 contamination, or CFC-11 contamination or degradation, affected 59 percent (24 of 41) samples. In addition, 18 out of 25 wells (72 percent) had at least 1 sample with evidence of CFC contamination and (or) degradation. Concentrations of CFC-12 or CFC-11 were not reported for samples that were contaminated or degraded (table 10). These results indicate that CFC-113 was the most reliable CFC for dating groundwater. Apparent CFC ages reported in table 10 were calculated from the average of noncontaminated, nondegraded samples.

CFC concentrations generally were highest in intermediate and in shallow groundwater and were lowest in deep groundwater (fig. 28). Four shallow groundwater samples had CFC-113 concentrations above 35 parts per trillion by volume (pptv), whereas 13 intermediate samples had concentrations ranging from less than 0.2 to $72 \mathrm{pptv}$. The highest CFC-113 concentration was from MW8. This sample had low concentrations of ${ }^{3} \mathrm{H}(0.2 \mathrm{TU})$ and of ${ }^{14} \mathrm{C}(51.4$ percent modern carbon) for intermediate groundwater, which indicates that the CFC-113 may be partially contaminated. The detection of CFCs in deep monitoring wells, in deep depth-dependent samples from the SSW, and in PSW3, where ${ }^{3} \mathrm{H}$ values were less than $0.15 \mathrm{TU}$ and ${ }^{14} \mathrm{C}$ values were less 15 percent modern carbon, raises the concern of whether CFCs are good tracers of 


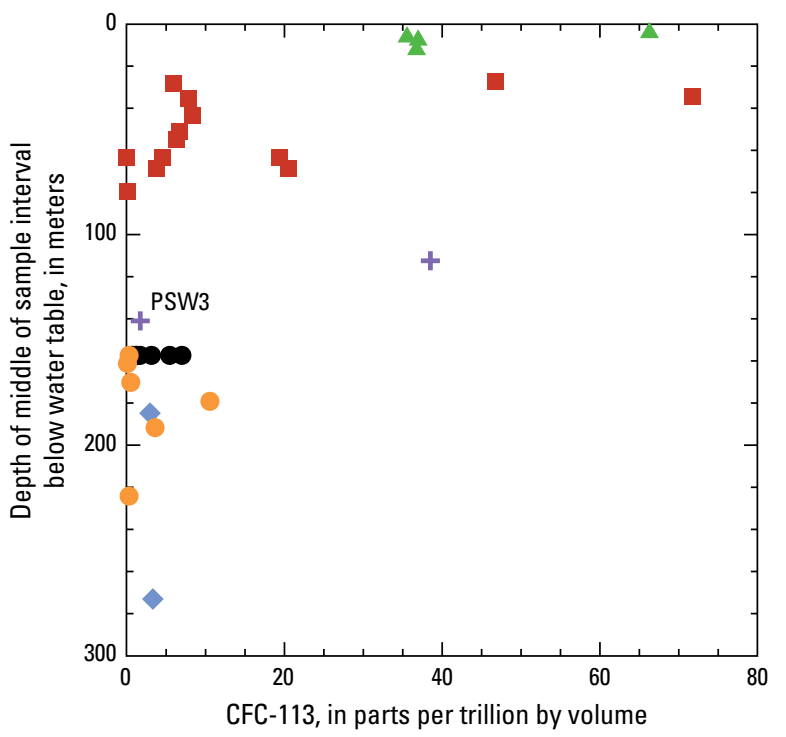

EXPLANATION

\begin{aligned} \hline & Deep well \\ \hline & Intermediate well \\ $+\quad &$ Shallow well \\ $+\quad &$ Supply well \\ & Studied supply well (SSW) \\ PSW3 & Well name \end{aligned}

Figure 28. Chlorofluorocarbon-113 (CFC-113) with depth below the water table in groundwater from the local-scale transport of anthropogenic and natural contaminants (TANC) study in Albuquerque, New Mexico.

groundwater age in the study area because of their substantial potential for contamination. This uncertainty limits the use of CFCs in the interpreting of groundwater age to samples having CFC interpreted ages that correspond closely with those resulting from mixtures of ${ }^{3} \mathrm{H},{ }^{3} \mathrm{He}$, and ${ }^{14} \mathrm{C}$. However, the general relation between CFCs and depth below the water table is similar to patterns observed from ${ }^{3} \mathrm{H}$ and ${ }^{14} \mathrm{C}$, particularly in that the CFCs also show the presence of young groundwater in the shallow and intermediate portions of the aquifer.

\section{Carbon-14}

Because of its long half-life, ${ }^{14} \mathrm{C}$ can be used to estimate groundwater ages ranging from about 1,000 to about 30,000 years before present (BP) (Clarke and Fritz, 1997). Primary uncertainties in ${ }^{14} \mathrm{C}$ dating stem from (1) determining the initial ${ }^{14} \mathrm{C}$ content of dissolved inorganic carbon (DIC) in recharge water, and (2) determining the sources of carbon to the groundwater system that alter the initial ${ }^{14} \mathrm{C}$ concentration. Plummer and others (2004a) found that the initial ${ }^{14} \mathrm{C}$ of DIC over large parts of the MRGB was almost always about 100 percent modern carbon (pmC); even DIC from the Rio Grande appeared consistent with this assumption. Carbon sources were evaluated by using the geochemical inverse modeling programs PHREEQC, version 2.17.1 (Parkhurst and Appelo, 1999), and NetpathXL, version 1.2 (Parkhurst and Charlton, 2008; Plummer and others, 1994). PHREEQC and NetpathXL use equations of chemical mass balance, electron balance, and isotope mass balance to define all possible net geochemical reactions between sources of recharge and the composition of the final water. The mixtures defined in the inverse models and mass transfers of carbon from the phases often result in corrections to the initial ${ }^{14} \mathrm{C}$ concentration $\left(\mathrm{A}_{\mathrm{o}}\right)$ or to measured ${ }^{14} \mathrm{C}$ concentration. These corrections are normally a reduction or dilution of the initial ${ }^{14} \mathrm{C}$ content, or, conversely, an increase in the measured ${ }^{14} \mathrm{C}$ concentration. Because of these adjustments, ${ }^{14} \mathrm{C}$ ages corrected for geochemical reactions are almost always younger than ages reported without consideration of geochemical mass transfers.

Carbon-14 was collected at every well and reported as concentrations in percent modern (table 10). By radiocarbon convention (Stuiver and Pollach, 1977), these laboratory values were normalized for carbon-13 fractionation to a standard $\delta^{13} \mathrm{C}$ of -25 per mil (VPDB). In order to calculate ${ }^{14} \mathrm{C}$ ages, the study converted measured ${ }^{14} \mathrm{C}$ content to $\mathrm{pmC}$ values that were denormalized for carbon-13 fractionation (Stuiver and Polach, 1977; Mook and Van der Plicht, 1999). Carbon-14 concentrations were converted to nonnormalized values by using the $\delta^{13} \mathrm{C}$ of the sample and were then converted to pmC by using the calculation described in Stuiver and Polach (1977) and Plummer and others (2004a). The correction typically results in age differences of less than 500 years between normalized and denormalized ages. Still, it is appropriate to use the denormalized values (Stuiver and Pollach, 1977; Mook and Van der Plicht, 1999).

\section{Inverse Geochemical Modeling}

By using PHREEQC and NetpathXL, the study corrected ${ }^{14} \mathrm{C}$ values for carbon transfers from reservoirs within the aquifer sediments and from mixing of recharge water. Inverse models were first identified by using PHREEQC so that uncertainty in the assigned carbon isotope values of geochemical phases could be included in the models. NetpathXL was then used to calculate the corrected initial ${ }^{14} \mathrm{C}$ concentration of the models generated from PHREEQC.

Sources of recharge to the groundwater system considered in the inverse geochemical models were the Rio Grande and upward leakage of deep saline groundwater. A third source of groundwater was included in models of several monitoring wells and of the SSW (table 11 at end of report) in order to simulate the contribution of young, contaminated groundwater believed to have reached these wells from the solvent plume located to the northwest of the SSW (see the previous "Volatile Organic Compounds" section). This water is from the well SFMW-15, located near the source of the plume (Landin, 1999). It is likely that groundwater from SFMW-15 is a mixture of evaporated recharge (either infiltrating through the unsaturated zone and (or) seeping from the 
Rio Grande) and the solvent plume. Plummer and others (2004a) identified the Rio Grande and the upward leakage of deep saline groundwater as sources of recharge for groundwater in this area.

The primary carbon phases considered in the inverse modeling were carbon dioxide gas $\left(\mathrm{CO}_{2(\mathrm{~g})}\right)$, organic matter $\left(\mathrm{CH}_{2} \mathrm{O}\right)$, and calcite $\left(\mathrm{CaCO}_{3}\right)$. Calcite was allowed to dissolve into or precipitate out of solution, whereas $\mathrm{CO}_{2(\mathrm{~g})}$ and $\mathrm{CH}_{2} \mathrm{O}$ were allowed only to dissolve into solution. The isotopic composition assigned to $\delta^{13} \mathrm{C}$ for calcite was $-3( \pm 1)$, for $\mathrm{pCO}_{2(\mathrm{~g})}$ was $-15( \pm 10)$, and for $\mathrm{CH}_{2} \mathrm{O}$ was $-20( \pm 5)$ per mil. The value assigned to carbon- 14 for calcite was 0 , for $\mathrm{pCO}_{2(\mathrm{~g})}$ was 100 , and for $\mathrm{CH}_{2} \mathrm{O}$ was $0 \mathrm{pmC}$. These values are consistent with measured values or with values used in the inverse models reported in Plummer and others (2004a). The mineral phases included in the inverse models (table 12 at end of report) were the same as or similar to those used in Plummer and others (2004a). The ${ }^{14} \mathrm{C}$ values of calcite and $\mathrm{CH}_{2} \mathrm{O}$ were assigned to equal zero so that geochemical corrections caused by dissolution or oxidation of these phases would give the largest correction to the initial ${ }^{14} \mathrm{C}$ content of recharge. The geochemical reactions involving these phases would then lead to the youngest possible ages. In contrast, ${ }^{14} \mathrm{C}$ ages calculated from the measured (uncorrected) concentrations would give the oldest possible ages. In actuality, calcite and organic matter in the aquifer may have ${ }^{14} \mathrm{C}$ values greater than 0 ; however, it is likely that organic matter deposited at the time of burial is probably carbon dead $\left({ }^{14} \mathrm{C}\right.$ concentration close to $\left.0 \mathrm{pmC}\right)$ or nearly so $\left({ }^{14} \mathrm{C}\right.$ concentration less than $\left.10 \mathrm{pmC}\right)$.

Although many inverse models were generated with PHREEQC and NetpathXL, only one inverse model was chosen to best represent the set of geochemical reactions that explain the chemistry of groundwater for an individual sample from the well (table 12). Inverse models were evaluated partly on the basis of how well the modeled $\delta^{13} \mathrm{C}$ (with Rayleigh fractionation) matched the observed $\delta^{13} \mathrm{C}$ value. Only models that were within 0.5 per mil of the observed $\delta^{13} \mathrm{C}$ value were considered acceptable.

\section{Modeling Results}

Oxidation of organic matter, calcite precipitation, plagioclase dissolution, gypsum precipitation, and cation exchange processes were the major reactions responsible for the chemistry of groundwater in the study area, according to results of the inverse modeling (table 12). Clay mineral formation and biotite, halite, and $\mathrm{CO}_{2(\mathrm{~g})}$ dissolution were minor reactions or occurred in only a small number of wells. Gibbsite was included to balance aluminum; it was a minor reaction that occurred mainly as a result of uncertainty in the mass transfer of precipitating clay mineral cements.

The primary reaction affecting the reductions of initial ${ }^{14} \mathrm{C}$ content in groundwater in the study area was the oxidation of ${ }^{14} \mathrm{C}$-dead organic carbon $\left(\mathrm{CH}_{2} \mathrm{O}\right)$. The inverse models indicate that corrected initial ${ }^{14} \mathrm{C}$ content of recharge was on average about $10 \mathrm{pmC}$ lower than an assumed initial concentration of $100 \mathrm{pmC}$ (table 12). The corrected initial ${ }^{14} \mathrm{C}$ content ranged from 86.0 to $98.6 \mathrm{pmC}$. The dissolution of organic matter is required in order to account for the change in redox state of the initial water to the final water. Because the initial water, primarily that from the Rio Grande, has a dissolved-oxygen concentration of $8 \mathrm{mg} / \mathrm{L}$, and most groundwater in the study area has a concentration of about $1 \mathrm{mg} / \mathrm{L}$ or less, a mass transfer of about 0.23 millimoles (mmols) of organic matter was required in order to reduce the dissolved oxygen content. Because the reduction in ${ }^{14} \mathrm{C}$ content from the oxidation of organic matter assumes that the organic matter has ${ }^{14} \mathrm{C}$ concentration of zero, using this value results in the largest possible correction to the initial ${ }^{14} \mathrm{C}$ content and therefore the youngest possible ${ }^{14} \mathrm{C}$ age. The oldest possible ${ }^{14} \mathrm{C}$ age is determined from the measured (uncorrected) ${ }^{14} \mathrm{C}$ concentration (table 10).

Inverse modeling indicates that calcite precipitation occurs in most of the wells (33 out of 37 samples). These findings are consistent with the analysis of carbon from core samples, which showed large amounts of inorganic carbon minerals, presumably calcite cements (app. 1, table 1-2). Calcite precipitation ranged from 0 to $1.61 \mathrm{mmols}$ per $\mathrm{kg}$ water, the median being $0.46 \mathrm{mmols}$ per $\mathrm{kg}$ water. Shallow wells typically had the highest mole transfers of calcite, mainly because of evapotranspiration. Evaporation factors calculated by PHREEQC for the shallow wells ranged from 1.1 to 3.0, with a median value of 1.4. Shallow wells with the largest evaporation factors were also accompanied by large amounts of halite and gypsum dissolution, which could reflect mobilization of stored salts in the unsaturated zone. The shallow evaporated wells also tended to have the highest geochemical mass transfers among all inverse models.

Wells that were thought to have been affected by the solvent plume located northwest of the SSW (SFMW-46, MNW4-D1, FP3D, FP4D, FP4M, PSW1, and the SSW) had fractions of SFMW-15 water that ranged from 3.4 to 40.1 percent. The fraction of SFMW-15 water in the models of SSW samples collected at the wellhead varied from as much as 15.1 percent in June 2007 to as little as 4.7 percent in December 2007. For the SSW, the fractions of SFMW-15 were higher in the two summer samples than in the winter samples. This pattern is similar to patterns observed for ${ }^{3} \mathrm{H}$ and for recharge temperatures, which showed larger contributions of young, warmer groundwater recharge during the summer than during the winter. This pattern indicates that the plume water represented by SFMW- 15 could also be a source of young groundwater to the SSW.

Monitoring wells (as opposed to supply wells) had the highest fractions of SFMW-15, ranging from 11.3 to 40.1 percent. All of the monitoring wells with fractions of SFMW15 had lighter than normal $\delta^{13} \mathrm{C}$ compositions (fig. 29), which likely reflects the signature of the young, plume-affected groundwater. The inverse models for these wells tended to have lighter $\delta^{13} \mathrm{C}_{\text {of }} \mathrm{CH}_{2} \mathrm{O}$ (-25 per mil) and more enriched values of $\delta^{13} \mathrm{C}$ of calcite than wells that were not influenced by the solvent plume. Lighter $\delta^{13} \mathrm{C}$ of $\mathrm{CH}_{2} \mathrm{O}$ could reflect 


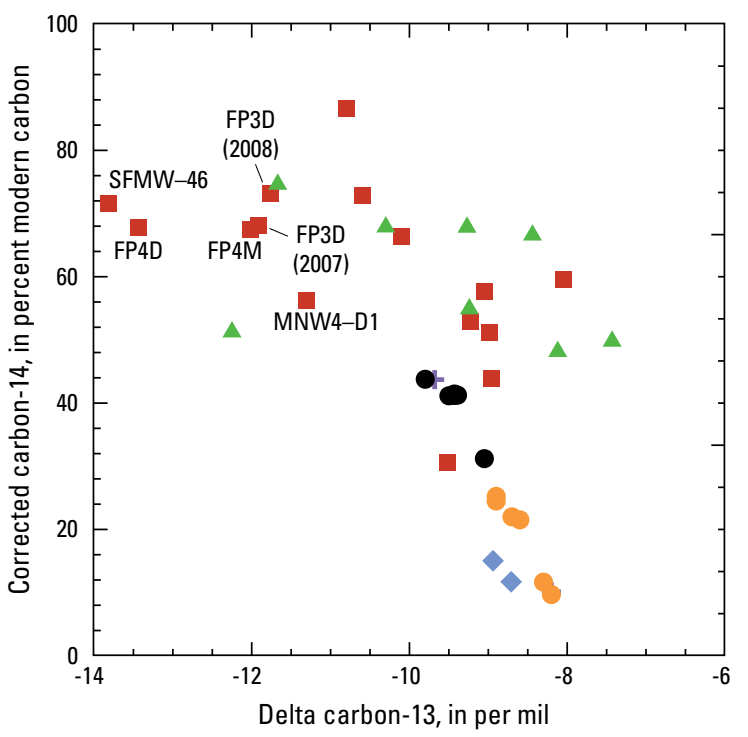

EXPLANATION

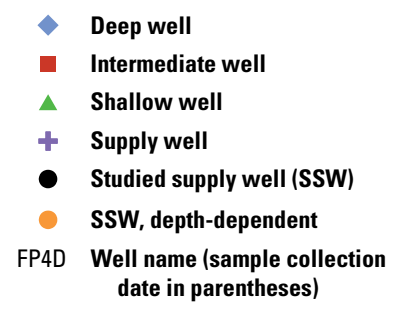

Figure 29. Relation of carbon-14 concentration with delta carbon-13 in groundwater from the local-scale transport of anthropogenic and natural contaminants (TANC) study area in Albuquerque, New Mexico.

the influence of $\mathrm{C}_{3}$ plants, which have lighter $\delta^{13} \mathrm{C}$ compositions, on recent recharge, as suggested by Plummer and others (2004a), or the influence of the $\delta^{13} \mathrm{C}$ composition of $\mathrm{CH}_{2} \mathrm{O}$ associated with the contamination plume.

Gypsum precipitation was modeled to occur in 19 of the 36 groundwater samples, 9 of which were from the SSW. The inverse model results of Plummer and others (2004a) also predicted gypsum precipitation for the Central Zone (representing areas recharged by seepage from the Rio Grande). However, gypsum precipitation in groundwater in this study area is not likely to occur, according to saturation indices calculated by using PHREEQC. The inverse models predict gypsum precipitation because concentrations of calcium and sulfate in the Rio Grande water, which is used as the primary source of recharge for inverse modeling (table 11), were above the concentrations of calcium and sulfate measured in half of the groundwater samples for this study. Therefore, inverse models for those wells could be found only if gypsum precipitated out of solution. For several wells, removing calcium and sulfate from solution through gypsum precipitation led the model to compensate for the loss of calcium by exchanging sodium in solution for calcium. In contrast, geochemical data from this study are consistent with previous studies of groundwater in the MRGB by Anderholm (1988) and Plummer and others (2004a), which indicate that calcium in solution is likely to exchange for sodium on the surfaces of clay minerals.

Because geochemical data indicate that the modeled gypsum precipitation is not likely to occur, the composition of the Rio Grande may have changed through time in that previous recharge from the Rio Grande had lower calcium and sulfate concentrations and (or) was more dilute than it is today. Plummer and others (2004a) also suggested that precipitation chemistry, which should affect Rio Grande chemistry, has probably fluctuated between the time that much of the groundwater in the MRGB recharged (several thousand years ago) and modern times, when sulfur emissions could have caused increases in sulfate in particular. Other anthropogenic activities, including agriculture, likely have affected the modern composition of the Rio Grande, including its concentrations of sulfate and calcium (Passell and others, 2004). Therefore, the modern composition of the Rio Grande may provide only an approximation of the actual composition of recharge to the modeled wells.

\section{Corrected ${ }^{14} \mathrm{C}$}

Carbon-14 adjustments resulting from considering the geochemical reactions can be applied to the initial ${ }^{14} \mathrm{C}$ content of DIC in water or to the measured (final) ${ }^{14} \mathrm{C}$ content of DIC for an assumed initial ${ }^{14} \mathrm{C}$ concentration. NetpathXL and NETPATH apply the correction to the initial ${ }^{14} \mathrm{C}$ concentration. For this study, measured ${ }^{14} \mathrm{C}$ values were also corrected and are reported alongside the adjusted ${ }^{14} \mathrm{C}$ initial concentration reported by NetpathXL (table 12). Correcting the measured ${ }^{14} \mathrm{C}$ values allows for a direct comparison with groundwater flow and transport modeling results that use $100 \mathrm{pmC}$ as the initial ${ }^{14} \mathrm{C}$ value in recharge to estimate the concentration of ${ }^{14} \mathrm{C}$ in wells. Measured ${ }^{14} \mathrm{C}$ values were corrected to an initial ${ }^{14} \mathrm{C}$ concentration of $100 \mathrm{pmC}$ by using the following equation (all variables in $\mathrm{pmC}$ ):

$$
{ }^{14} C_{\text {corrected ffinal }}={ }^{14} C_{\text {measured }}+\left(\frac{{ }^{14} C_{\text {meassured }}}{{ }^{14} C_{\text {corrected initial }}}\right)\left(100-{ }^{14} C_{\text {correceled initial }}\right) .
$$

Corrections to measured ${ }^{14} \mathrm{C}$ (subsequently referred to simply as ${ }^{14} \mathrm{C}$ ) decrease with increasing depth below the water table to the midpoint of each well screen (Spearman's rho = -0.76 , $p$-value $<0.001$ ), indicating that the oldest groundwater is in the deep part of the aquifer, whereas the intermediate and shallow parts of the aquifer generally have the youngest groundwater (fig. 30). The lowest ${ }^{14} \mathrm{C}$ concentrations were from the two deep wells, from the depth-dependent samples collected from the SSW at depths of 241 and $176 \mathrm{mbls}$, and from PSW3. The concentration of ${ }^{14} \mathrm{C}$ from these samples ranged from 10 to $15 \mathrm{pmC}$. The highest concentrations of ${ }^{14} \mathrm{C}$ were from shallow and intermediate wells. The ${ }^{14} \mathrm{C}$ 


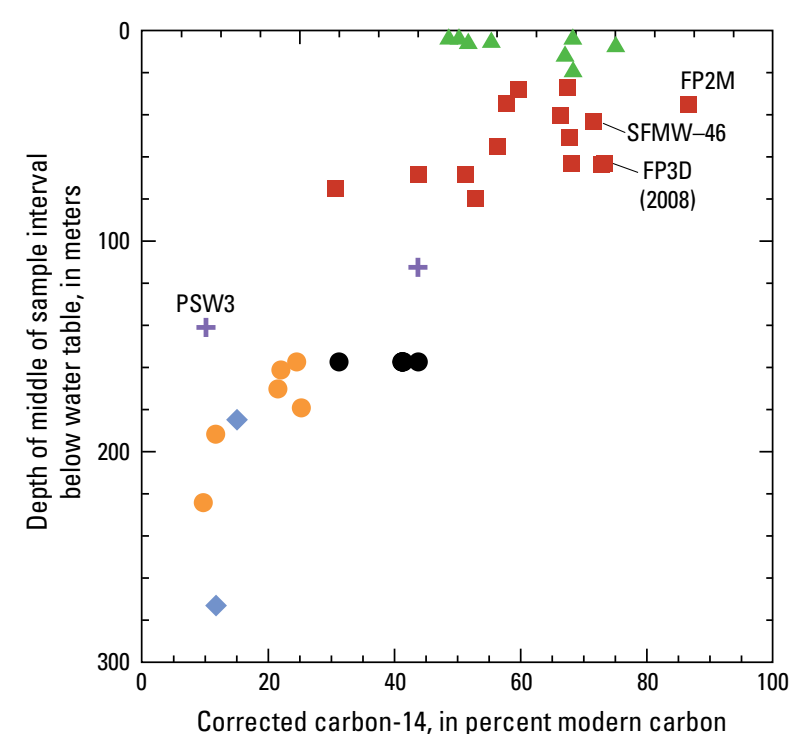

EXPLANATION

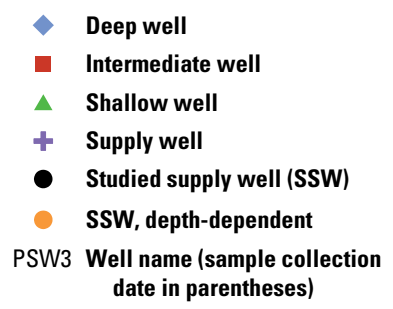

Figure 30. Carbon-14 content with depth below the water table in groundwater from the local-scale transport of anthropogenic and natural contaminants (TANC) study area in Albuquerque, New Mexico.

concentration of shallow groundwater ranged from about 49 to $75 \mathrm{pmC}$ and had a median of $62 \mathrm{pmC}$. The ${ }^{14} \mathrm{C}$ content of intermediate groundwater ranged from about 31 to $87 \mathrm{pmC}$ and had a median of $66 \mathrm{pmC}$. The deepest intermediate groundwater tended to have the lowest ${ }^{14} \mathrm{C}$ concentration, although some intermediate wells had higher ${ }^{14} \mathrm{C}$ concentrations than would be expected for their depths. These wells are likely to contain a significant fraction of young, elevated ${ }^{14} \mathrm{C}$ groundwater derived from the testing of nuclear weapons ("bomb-derived" ${ }^{14} \mathrm{C}$ ).

Carbon-14 concentrations from some monitoring well nests indicate that preferential pathways allow younger groundwater to migrate to greater depths of the aquifer and to underlie older groundwater. The concentration of ${ }^{14} \mathrm{C}$ in well nests FP3 and FP4, the middle and (or) lower completions of which have evidence of influence from the solvent plume to the northwest of the SSW, shows an apparent age inversion where younger groundwater (indicated by the highest ${ }^{14} \mathrm{C}$ concentrations) is found in the intermediate depth wells and older groundwater in the shallow wells (table 10). SFMW-46 also has one of the higher ${ }^{14} \mathrm{C}$ contents among intermediate wells, which would appear to be consistent with the conclusion by Landin (1999) and the U.S. Environmental Protection Agency (2001) that the vertical migration of solvents from shallow to intermediate depths of the aquifer near the plume to the northwest of the SSW had been enhanced by the pumping of and (or) direct migration down well bores. The highest ${ }^{14} \mathrm{C}$ concentration measured in this study, $87 \mathrm{pmC}$, was from FP2M, which is screened at intermediate depths and likely receives recharge from a nearby stormwater conveyance channel.

Concentrations of ${ }^{14} \mathrm{C}$ from the SSW showed seasonal patterns similar to those for ${ }^{3} \mathrm{H}$ and for recharge temperature (fig. 27). The concentrations of ${ }^{14} \mathrm{C}$ were $44 \mathrm{pmC}$ in June 2007 and $41 \mathrm{pmC}$ in May 2009 (the average of six time series samples), whereas the concentrations of ${ }^{14} \mathrm{C}$ were $24 \mathrm{pmC}$ in December 2007 (sample from the wellhead during depthdependent sampling) and $31 \mathrm{pmC}$ in November 2008. Prolonged periods of pumping during the summer appear to cause young groundwater to move from shallow to intermediate depths of the aquifer. In contrast, when water demand is low during the winter, restoration of the natural flow system causes older, deep groundwater to migrate to somewhat shallower depths of the aquifer.

Depth-dependent samples showed that groundwater entering the SSW at or below 176 mbls is predominantly old, deep groundwater that is relatively free of young recharge Above this depth, intermediate groundwater enters the well as a mixture of native intermediate groundwater and of young recharge, which is thought to originate primarily near the solvent plume to the northwest of the SSW. The fraction of young groundwater in the mixture is dependent on hydrologic conditions, which tend to follow seasonal water demands. Inverse modeling indicates that the fraction of young groundwater at the well, if solely derived from the solvent plume, could be as high as 15 percent during the summer and as low as 5 percent during the winter. The lower of the two winter fractions (that is, 5 percent young water in December 2007) was obtained from inverse modeling of the depth-dependent sample collected at the wellhead. Because the temporary submersible pump used for depthdependent sampling caused lower hydraulic stress than does the dedicated turbine pump normally used to operate the well, the depth-dependent samples were likely to be biased towards older, deep groundwater, which naturally flows upwards.

\section{Radiocarbon and Calibrated ${ }^{14} \mathrm{C}$ Calendar Ages}

Conventional radiocarbon ages, in years BP relative to 1950 were calculated as

$$
t_{\text {Radiocarbon }}=\frac{5,568}{\ln (2)} \ln \left(\frac{100}{{ }^{14} \mathrm{C}_{\text {corrected final }}}\right)-\frac{y-1950}{1.029},
$$


where ' 5,568 ' is the "Libby half-life" of ${ }^{14} \mathrm{C}$, y is the year of measurement, ' 1.029 ' is the ratio of the modern and the Libby decay constants $\left(\frac{\lambda_{5,730}}{\lambda_{5,568}}\right)$, and ' 100 ' is the assumed initial ${ }^{14} \mathrm{C}$ concentration of recharge (Plummer and others, 2004a). Calibrated ${ }^{14} \mathrm{C}$ piston-flow ages (table 10 ) were determined from the radiocarbon ages by using the program CALIB (Stuiver and Reimer, 1993) and the 2009 international calibration curve, IntCal09 (Reimer and others, 2009). Because of paleoatmospheric fluctuations in ${ }^{14} \mathrm{C}$ levels, the radiocarbon age (along with the measurement error) can correspond to multiple calendar ages. Therefore, radiocarbon ages typically have a range of calendar ages. The reported ${ }^{14} \mathrm{C}$ piston-flow age is the age at the median probability (assuming that the age range is normally distributed about the radiocarbon age) of the distribution of the range of ages given in parentheses to the right of the piston-flow age (Stuiver and Reimer, 1993). Calibrated ${ }^{14} \mathrm{C}$ ages ranged from 1,010 to over 22,300 years (table 10).

Because most groundwater sampled in the study area contains ${ }^{3} \mathrm{H}$ concentrations above $0.3 \mathrm{TU}$, the ${ }^{14} \mathrm{C}$ measured in groundwater has been affected by bomb-derived ${ }^{14} \mathrm{C}$. The calibrated ${ }^{14} \mathrm{C}$ piston-flow ages listed in table 10 for groundwater samples that have ${ }^{3} \mathrm{H}$ concentrations above $0.3 \mathrm{TU}$ are associated with substantial uncertainty because the age determination does not account for mixing between groundwater having bomb-derived ${ }^{14} \mathrm{C}$ and groundwater that evolved naturally. Therefore, the actual ages for these samples are greater than the reported piston-flow ages, which should not be used. More appropriate ages are discussed in the following section.

For 10 samples, ${ }^{3} \mathrm{H}$ concentrations were less than $0.3 \mathrm{TU}$, and their calibrated ${ }^{14} \mathrm{C}$ piston-flow ages ranged from 4,630 to greater than 22,300 years. Half of the samples were from the deep part of the aquifer (from deep monitoring wells or from supply wells); these samples indicate that the age of old, deep groundwater is greater than 18,000 years. Two samples were from one shallow well, FP3S, the ${ }^{14} \mathrm{C}$ ages from which suggest that groundwater in the shallow part of the aquifer that is unaffected by young recharge is likely to be as much as 6,000 to 6,500 years old. Three other samples with low ${ }^{3} \mathrm{H}$ concentrations were from wells completed in the intermediate part of the aquifer: FP3M, MW7, and MW8. The ${ }^{14} \mathrm{C}$ ages from these samples indicate that groundwater in the intermediate part of the aquifer that is essentially unaffected by young recharge is between 4,630 and 5,820 years old. However, other intermediate wells having ${ }^{3} \mathrm{H}$ greater than $0.3 \mathrm{TU}$ have older ${ }^{14} \mathrm{C}$ ages (likely exceeding 7,000 years), which indicates that the true age of intermediate groundwater might be older or is variable. It is possible that a substantial fraction of the intermediate groundwater at FP3M, MW7, and MW8 could have originated as shallow groundwater that was free of young recharge and moved downward at those depths in response to pumping of public-supply wells.

\section{Interpreted Groundwater Ages}

For analysis of the mean ages of groundwater samples from the local-scale TANC study area in Albuquerque, the interactive program TracerLPM (Jurgens and others, in press) was used to minimize the error between tracer concentrations modeled using LPMs and observed tracer concentrations, thereby providing the best possible estimate of groundwater age. Because low-level CFC contamination was suspected for most groundwater samples, ${ }^{3} \mathrm{H},{ }^{3} \mathrm{He}_{\text {tri }}$, and ${ }^{14} \mathrm{C}$ were the primary tracers used to interpret the age of groundwater in the study area. The corrected (rather than uncorrected) final ${ }^{14} \mathrm{C}$ concentrations were used in the modeling analysis.

Groundwater ages in this study were estimated by modeling tracer concentrations using either a single dispersion model or a binary mixing model comprising two dispersion models: a dispersion model for the young fraction and a dispersion model for the old fraction. The dispersion model used in this report is an analytical solution to the one-dimensional advection-dispersion equation that has been implemented in TracerLPM (Kreft and Zuber, 1978; Maloszewski and Zuber, 1982; Jurgens and others, in press). The model has two parameters: mean age and the dispersion parameter. The dispersion parameter, $\left(\frac{D}{v x}\right)$, where $D$ is the dispersion coefficient, $v$ is the advective groundwater velocity, and $x$ is a characteristic flow length, is the inverse of the Peclet number (used to define the relative importance of advection to dispersion). For most models used in this report, the dispersion parameter was set to 0.01 . This value of the dispersion parameter has the effect of simulating behavior of tracer concentrations that is fairly similar to behavior under piston flow. Increasing the parameter causes more dispersive mixing, or broader distributions of ages or of tracer concentrations in the model.

Samples were modeled differently based on the measured ${ }^{3} \mathrm{H}$ concentration. Groundwater with a ${ }^{3} \mathrm{H}$ concentration below $0.3 \mathrm{TU}$ was assumed to be native groundwater that is primarily unaffected by young recharge (fig. 31 ), whereas groundwater with a ${ }^{3} \mathrm{H}$ concentration above $0.3 \mathrm{TU}$ has some component of young recharge. Native groundwater was modeled by using the single dispersion model, whereas all other samples were modeled by using the binary mixing model. The age of the native groundwater was used as the basis for estimating the age of the old fraction in the binary mixing models. The binary mixing model simulates the mixture of old groundwater that is free of ${ }^{3} \mathrm{H}$, and young groundwater that contains ${ }^{3} \mathrm{H}$ and ${ }^{14} \mathrm{C}$ derived from the testing of nuclear weapons (fig. 31 ). Because long traveltimes through the unsaturated zone can affect ${ }^{3} \mathrm{H}$ and ${ }^{3} \mathrm{He}_{\text {tri }}$, traveltimes through the unsaturated zone were evaluated for samples with ${ }^{3} \mathrm{H}$ greater than $0.3 \mathrm{TU}$. Traveltime through the unsaturated zone was ignored for native groundwater because native groundwater is thought to have originated primarily as seepage along the Rio Grande, where the thickness of the unsaturated zone was not substantial 


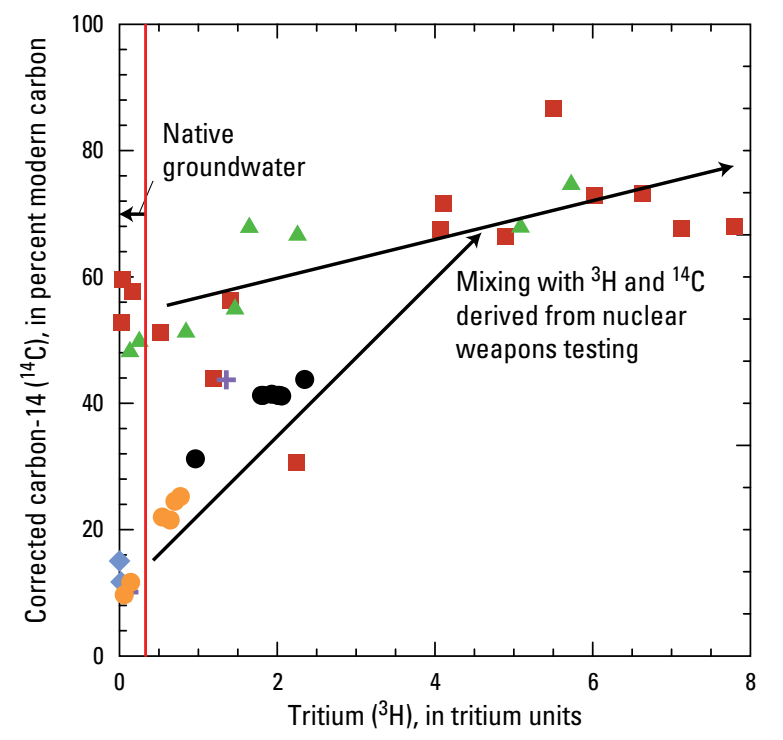

EXPLANATION

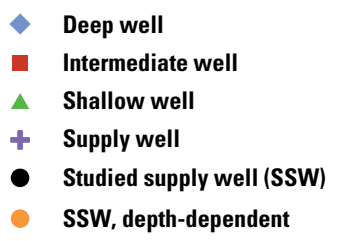

Figure 31. Relation between carbon- $14\left({ }^{14} \mathrm{C}\right)$ and tritium $\left({ }^{3} \mathrm{H}\right)$ in groundwater from the local-scale transport of anthropogenic and natural contaminants (TANC) study area in Albuquerque, New Mexico. The red vertical line distinguishes native groundwater that is primarily unaffected by young recharge from old groundwater that has been affected by young recharge.

and (or) the decay of ${ }^{14} \mathrm{C}$ through the unsaturated zone was negligible.

The SSW was modeled by using the binary mixing model; however, the well is screened across the intermediate and deep parts of the aquifer and therefore captures old groundwater having a much broader range of ages than do wells screened only in the intermediate or deep parts of the aquifer. To simulate the broader distribution of ages, the dispersion parameter of the old fraction was increased from 0.01 to 0.1 . This model for the old fraction was also used for PSW1, which is screened similarly.

\section{Tritium, CFC-113, and Carbon-14 Input History}

Tritium concentrations in precipitation during 1953 through 2002 for Albuquerque, N. Mex., were assigned by updating a dataset of Michel (1989) and averaging the data into half-year increments (fig. 32). Tritium concentrations were extrapolated for the period after 2002. Tritium concentrations in precipitation before aboveground nuclear weapons testing were assumed to be about $4 \mathrm{TU}$. Use of this ${ }^{3} \mathrm{H}$ input

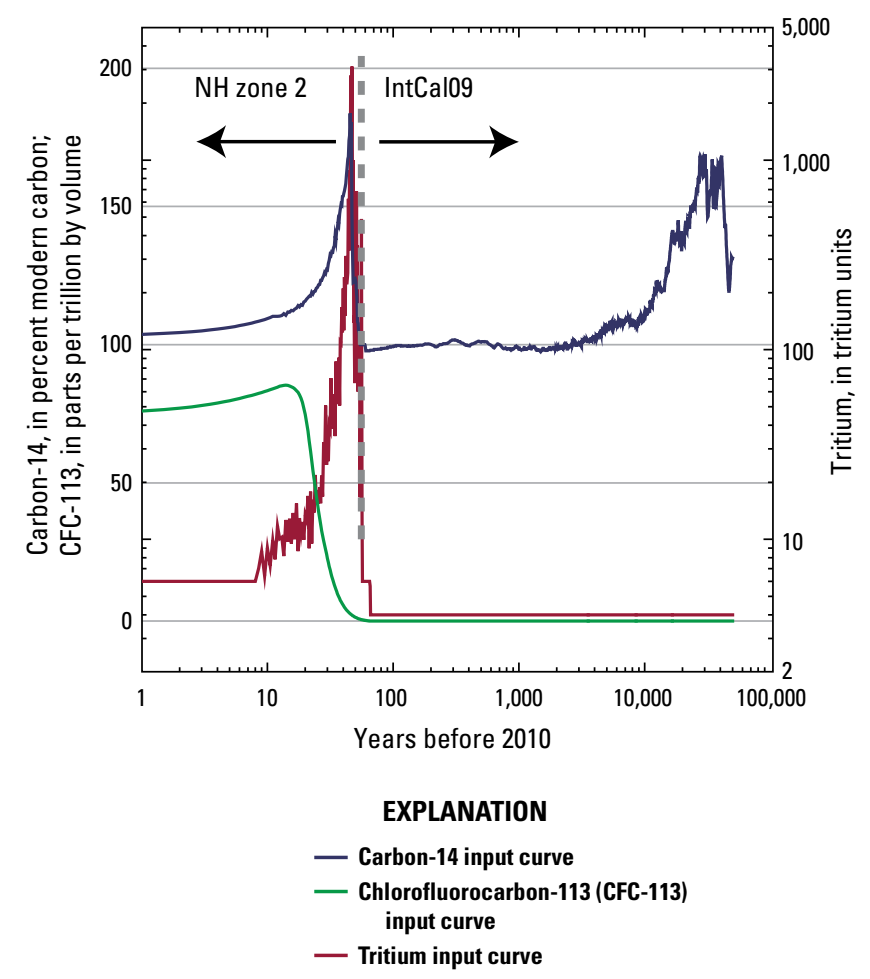

Figure 32. Input curves of carbon-14, chlorofluorocarbon-113 (CFC-113), and tritium used to interpret ages of groundwater from the local-scale transport of anthropogenic and natural contaminants (TANC) study area in Albuquerque, New Mexico. Carbon-14 concentration less than 58 years of age is from tropospheric carbon-14 data for the northern hemisphere zone 2, NH zone 2 (Hua and Barbetti, 2004). Carbon-14 concentrations greater than 58 years of age are from the 2009 international calibration curve, IntCal09 (Reimer and others, 2009). The CFC113 data are from the U.S. Geological Survey Chlorofluorocarbon Laboratory (2009), and the tritium data are from Michel (1989).

curve (as well as the ${ }^{14} \mathrm{C}$ input curve) assumes that ${ }^{3} \mathrm{H}$ (or ${ }^{14} \mathrm{C}$ ) in groundwater was entirely derived from precipitation, which may not be the case if the dominant source of ${ }^{3} \mathrm{H}$ was from seepage from the Rio Grande. In that case, a ${ }^{3} \mathrm{H}$ input curve representative of seepage from the Rio Grande would need to be constructed using LPMs and ${ }^{3} \mathrm{H}$ observations from the Rio Grande. However, the ${ }^{3} \mathrm{H}$ observations available for the Rio Grande for 1996-98 (Plummer and others, 2004a) were compared to the record of ${ }^{3} \mathrm{H}$ concentrations in precipitation, and this comparison indicated that dilution of the ${ }^{3} \mathrm{H}$ was minimal. Also, it is not clear whether the source of ${ }^{3} \mathrm{H}$ in groundwater is from the Rio Grande and (or) from ${ }^{3} \mathrm{H}$ stored in the unsaturated zone that is mobilized by urban recharge water. Consequently, the ${ }^{3} \mathrm{H}$ concentrations for precipitation were used. The Northern Hemisphere atmospheric mixing ratios of CFC-113 were obtained from the U.S. Geological Survey Chlorofluorocarbon Laboratory (2009).

The co-occurrence of ${ }^{3} \mathrm{H}$ greater than $0.3 \mathrm{TU}$ and of ${ }^{14} \mathrm{C}$ much less than $100 \mathrm{pmC}$ indicates that the ${ }^{14} \mathrm{C}$ concentration 
in groundwater in the study area represents a mixture of old groundwater (having ${ }^{14} \mathrm{C}$ resulting from the decay of natural fluctuations in paleoatmospheric ${ }^{14} \mathrm{C}$ levels since the late Pleistocene) and young groundwater (with ${ }^{14} \mathrm{C}$ concentrations resulting from the decay of variations in atmospheric ${ }^{14} \mathrm{C}$ since the early 1950 s from the release of ${ }^{14} \mathrm{C}$ from aboveground nuclear weapons testing). In order to develop an adequate model of tracer concentrations for binary mixtures of old ${ }^{14} \mathrm{C}$ and bomb-derived ${ }^{14} \mathrm{C}$, a curve of ${ }^{14} \mathrm{C}$ input was developed by combining the 2009 international calibration curve, IntCal09 (Reimer and others, 2009) with tropospheric ${ }^{14} \mathrm{C}$ data for the northern hemisphere (zone 2; Hua and Barbetti, 2004). For the periods $1950-55$ and $2000-10$, the tropospheric ${ }^{14} \mathrm{C}$ data were extrapolated (fig. 32). Use of this curve allows piston-flow ages determined with lumped parameter models to correspond to the piston-flow ages for the range determined in the ${ }^{14} \mathrm{C}$ section of this report. However, the piston-flow model was not used to interpret ages of groundwater in the study area, for reasons set forth in the previous section.

\section{Unsaturated Zone Traveltime}

Because of the thick unsaturated zone in the study area, the concentration of radioactive tracers reaching the water table may be lower than that when the tracer first entered the unsaturated zone. Tritium and its daughter product, ${ }^{3} \mathrm{He}_{\text {tri' }}$, can be substantially affected by traveltime delays of more than a year through the unsaturated zone because the decay of ${ }^{3} \mathrm{H}$ leads to the loss of ${ }^{3} \mathrm{He}_{\text {tri }}$ to the atmosphere (Schlosser and others, 1989; Solomon and Cook, 2000). As a result, ${ }^{3} \mathrm{He}_{\mathrm{tri}}$ concentrations in groundwater are lower than would be expected if traveltime through the unsaturated zone were less than a year. The effects of traveltime delay on ${ }^{3} \mathrm{He}_{\text {tri }}$ observed in groundwater can also occur because of a lack of confinement of ${ }^{3} \mathrm{He}$ in groundwater (Schlosser and others, 1989; Solomon and Cook, 2000). In such cases, the decay of ${ }^{3} \mathrm{H}$ at the water table can lead to the loss of ${ }^{3} \mathrm{He}_{\text {tri }}$ across the water table. If water movement at the water table is dominated by lateral flow rather than downward flow, then substantial ${ }^{3} \mathrm{He}_{\text {tri }}$ loss can occur. Unfortunately, traveltime delays and confinement issues in the unsaturated zone are difficult to distinguish from one another. However, the thickness of the unsaturated zone in the study area (commonly exceeding $30 \mathrm{~m}$ ) indicates that the traveltime through the unsaturated zone is perhaps the more important process.

TracerLPM was used to simulate the effects of delays in piston-flow traveltime through the unsaturated zone. Samples from six monitoring wells (FP2M, SFMW-46, MNW4-D1, FP3D, FP4D, and FP4M) with ${ }^{3} \mathrm{He}_{\text {tri }}$ concentrations above 5 TU (table 10) were used to evaluate traveltime through the unsaturated zone by using ${ }^{14} \mathrm{C},{ }^{3} \mathrm{H}$, and ${ }^{3} \mathrm{He}_{\text {tri }}$ concentrations. In order to match all three tracer concentrations from the wells, unsaturated zone traveltime had to be greater than zero (fig. 33). The modeling analyses for these wells indicate that traveltime through the unsaturated zone was typically about 15 or 16 years (table 13 at end of report). The sample from
SFMW-46 indicates that the unsaturated zone traveltime was about 8 years. This well is closest to the solvent plume to the northwest of the SSW, where depth to groundwater is smaller, and so shorter traveltimes through the unsaturated zone would be expected. Except for FP2M, all wells with ${ }^{3} \mathrm{He}$ concentrations above $5 \mathrm{TU}$ produce groundwater that is thought to have been affected by the same plume.

Four monitoring wells (FP1S, FP2S, FP4S, and MW2) had quantifiable ${ }^{3} \mathrm{He}_{\text {tri }}$ concentrations less than $5 \mathrm{TU}$, but the concentration from MW2 was too small ( $0.1 \mathrm{TU})$ to be useful for determining its associated unsaturated zone traveltime. When ${ }^{3} \mathrm{He}_{\text {tri }}$ was included in the modeling analysis for wells FP1S and FP4S, the unsaturated traveltimes were 20 years, somewhat longer than the traveltime indicated by the wells with higher ${ }^{3} \mathrm{He}_{\text {tri }}$ concentrations. Tritium and ${ }^{3} \mathrm{He}_{\text {tri }}$ concentrations from FP2S, which is thought to contain a fraction of recharge from a nearby stormwater channel, could not be satisfactorily modeled in TracerLPM. The ${ }^{3} \mathrm{He}_{\text {tri }}$ concentration from this well is low in comparison with its measured ${ }^{3} \mathrm{H}$, suggesting a loss of ${ }^{3} \mathrm{He}_{\text {tri }}$ either as a result of a long traveltime through the unsaturated zone or lack of confinement of ${ }^{3} \mathrm{He}_{\text {tri }}$. An unsaturated zone traveltime of 15 years was assumed for this well.

From this analysis, unsaturated zone traveltimes in the study area appear to vary from about 8 to 20 years, with data from most of the monitoring wells indicating a traveltime delay of around 15 years in the unsaturated zone. Based on this analysis, an unsaturated zone traveltime delay of 15 or 16 years was assumed for all wells that had ${ }^{3} \mathrm{H}$ concentrations above $0.3 \mathrm{TU}$ and did not have measurable amounts of ${ }^{3} \mathrm{He}_{\text {tri }}$ or had no ${ }^{3} \mathrm{He}_{\text {tri }}$ data. It should be noted that the estimated traveltimes through the unsaturated zone may also reflect the time that elapsed between water falling on the watershed as precipitation and seeping from the Rio Grande to the aquifer, if that is the source of ${ }^{3} \mathrm{H}$ or ${ }^{14} \mathrm{C}$ to the groundwater system. Therefore, the unsaturated zone traveltimes reported here could also be interpreted as the cumulative traveltime from the watershed to the unsaturated zone as seepage, plus the traveltime through the unsaturated zone. However, it is expected that traveltime from the watershed to the unsaturated zone is up to only a few years, and that the majority of the reported traveltime is therefore spent in the unsaturated zone.

\section{Age of Native Groundwater}

Native groundwater in the study area is defined as groundwater having ${ }^{3} \mathrm{H}$ concentrations less than $0.3 \mathrm{TU}$. This concentration corresponds to the maximum piston-flow concentration of ${ }^{3} \mathrm{H}$ in groundwater sampled in 2008 that had recharged just before the aboveground nuclear bomb testing increased in 1952. Groundwater that meets this criterion is thought to be predominantly native groundwater that has not been affected by the entry of young recharge into the groundwater system. Young recharge could affect some wells with ${ }^{3} \mathrm{H}$ concentrations less than $0.3 \mathrm{TU}$, as evidenced by small concentrations of VOCs in MW8 and FP3S (table 8), but the 


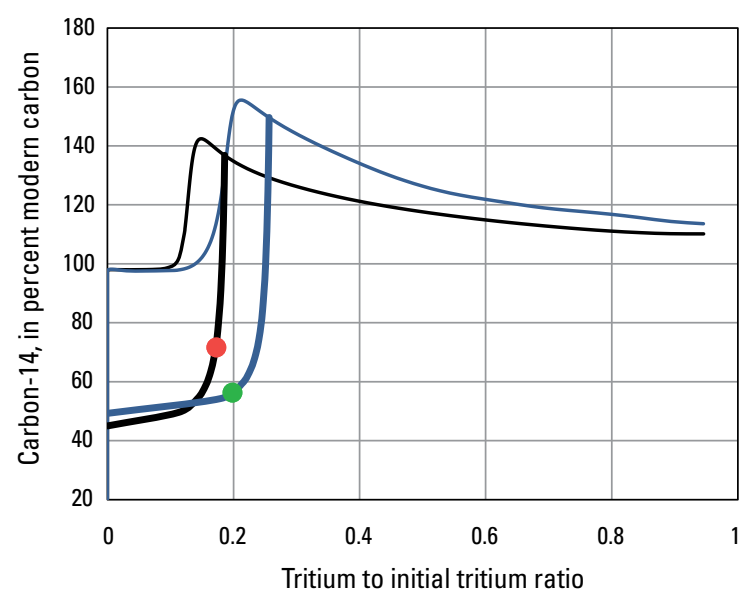

\section{EXPLANATION}

acer output from the dispersion model for a range of ages using an unsaturated-zone traveltime of 15 years

Tracer output from the binary mixing model of two dispersion models (for the young and old groundwater components), where the young component has a mean age of 22 years and the old

component has a mean groundwater age of about 6,500 years

Groundwater sample from MNW4-D1
Tracer output from the dispersion model for a range of ages using an unsaturated-zone traveltime of 8 years

Tracer output from the binary mixing model of two dispersion models (for the young and old groundwater components), where the young component has a mean age of 24 years and the old component has a mean groundwater age of about 7,300 years

- Groundwater sample from SFMW-46
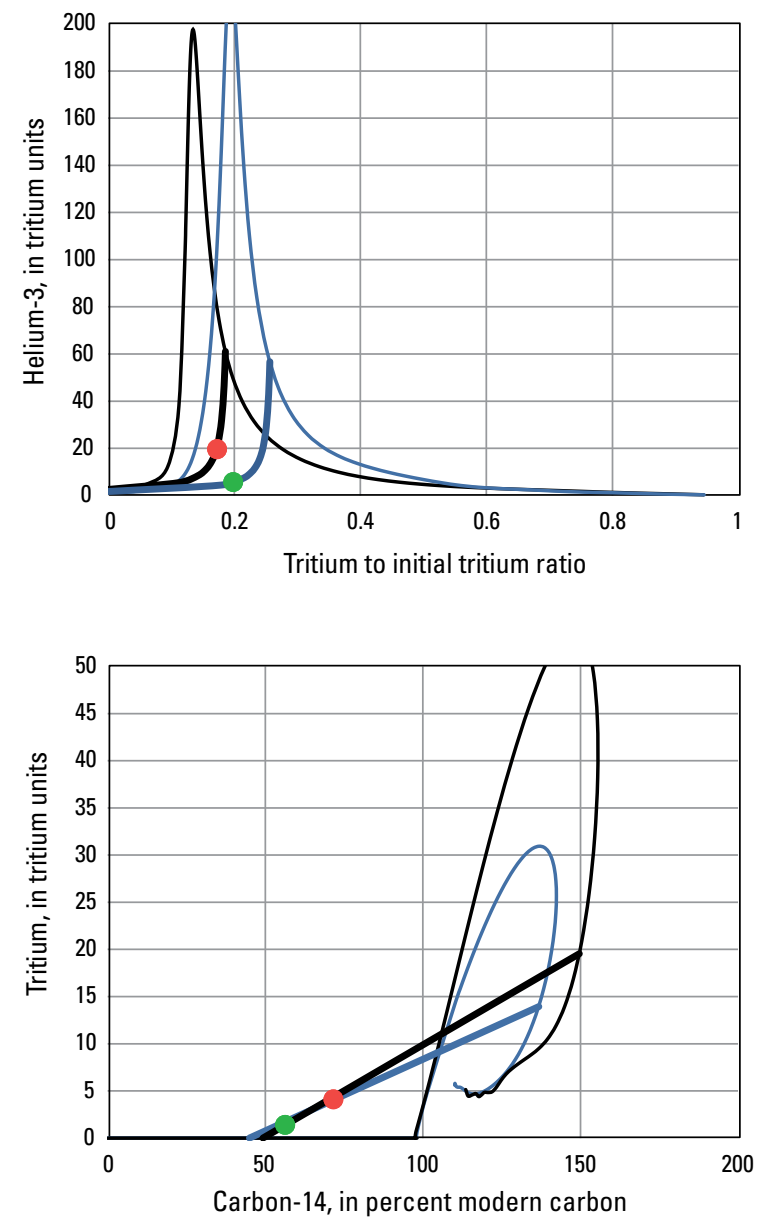

Figure 33. Selected tracer output for dispersion models and binary mixing models, and measured tracers for groundwater from wells MNW4-D1 and SFMW-46 in the local-scale transport of anthropogenic and natural contaminants (TANC) study area in Albuquerque, New Mexico. Details of the models are provided in table 13. 
fraction of young groundwater in such wells is likely to be very small. The presence of small fractions of young groundwater that were unaccounted for during modeling would mean that the age of the native, old groundwater for a sample is actually older than the interpreted age presented in table 13. Ten samples (9 wells) had ${ }^{3} \mathrm{H}$ concentrations less than $0.3 \mathrm{TU}$; tables 10 and 13 classify them as "old".

The age of native, deep groundwater as determined from two deep wells, FP1MD and FP1D, was about 19,000 to 21,000 years (table 13). Other samples that represent primarily deep groundwater are two depth-dependent samples collected from the SSW at depths of 176 and 241 mbls (ages of about 21,000 and 23,000 years, respectively) and the sample from well PSW3 (age exceeding 22,000 years). Combined, results from these five samples indicate that the age of old, deep groundwater is, on average, greater than 21,000 years. Interpreted ages from three wells (FP3M, MW7, and MW8) indicate that the age of native groundwater at intermediate depths is between about 4,700 and 5,900 years. The age of native groundwater at shallow depths was determined for one well, FP3S, which had two samples. The interpreted age of the shallow groundwater from this well was on average about 6,500 years. The ages determined from the dispersion model (table 13) are in good agreement with the ages determined from the piston-flow assumption (table 10), although the dispersion model ages are slightly older.

\section{Age of Mixed Groundwater}

The total mean age (including unsaturated zone traveltime) of groundwater from wells with an age classification of "mixed" (tables 10 and 13) was interpreted by using binary mixing models; table 13 lists the mean age of groundwater for each well. The interpreted total mean age of mixed shallow groundwater ranged from about 5,000 to 7,600 years, with a median age of about 5,600 years. The median fraction of young groundwater in shallow wells was about 26 percent, with the fractions ranging from 13.7 to 36.1 percent. The fraction of young groundwater was generally larger for shallow wells than for deeper wells. The median age of the young fraction was about 10 years, and the ages of the young fraction ranged from about 5 to 22 years. The age of the young fraction was generally younger than that for mixed groundwater at intermediate depths. Ages of the old fraction for mixed shallow groundwater ranged from about 7,000 to 9,900 years.

The interpreted total mean age of mixed intermediate groundwater ranged from about 4,300 to 16,000 years, with a median age of about 5,600 years. The median fraction of young groundwater was 19 percent, and the fraction ranged from 1.5 to 45.7 percent. FP2M had the largest fraction of young groundwater in all the wells analyzed; however, the amount of young groundwater in intermediate wells overall was smaller than that in shallow wells. The median age of the young fraction in intermediate wells was about 22 years, and the age ranged from about 16 to 26 years. Ages of the old fraction for mixed intermediate groundwater ranged from about 6,100 to 18,000 years.

The interpreted total mean age of groundwater from PSW1 was about 11,000 years. The fraction of young groundwater produced by this supply well was about 11 percent, and the age of the young fraction was about 20 years.

For samples collected from the SSW at the wellhead, the mean ages of young and old groundwater in the binary mixing models were determined primarily from modeling of ${ }^{14} \mathrm{C}$ and ${ }^{3} \mathrm{H}$ (fig. 34; table 13). These samples plotted along binary mixing lines comprising old groundwater having a mean age
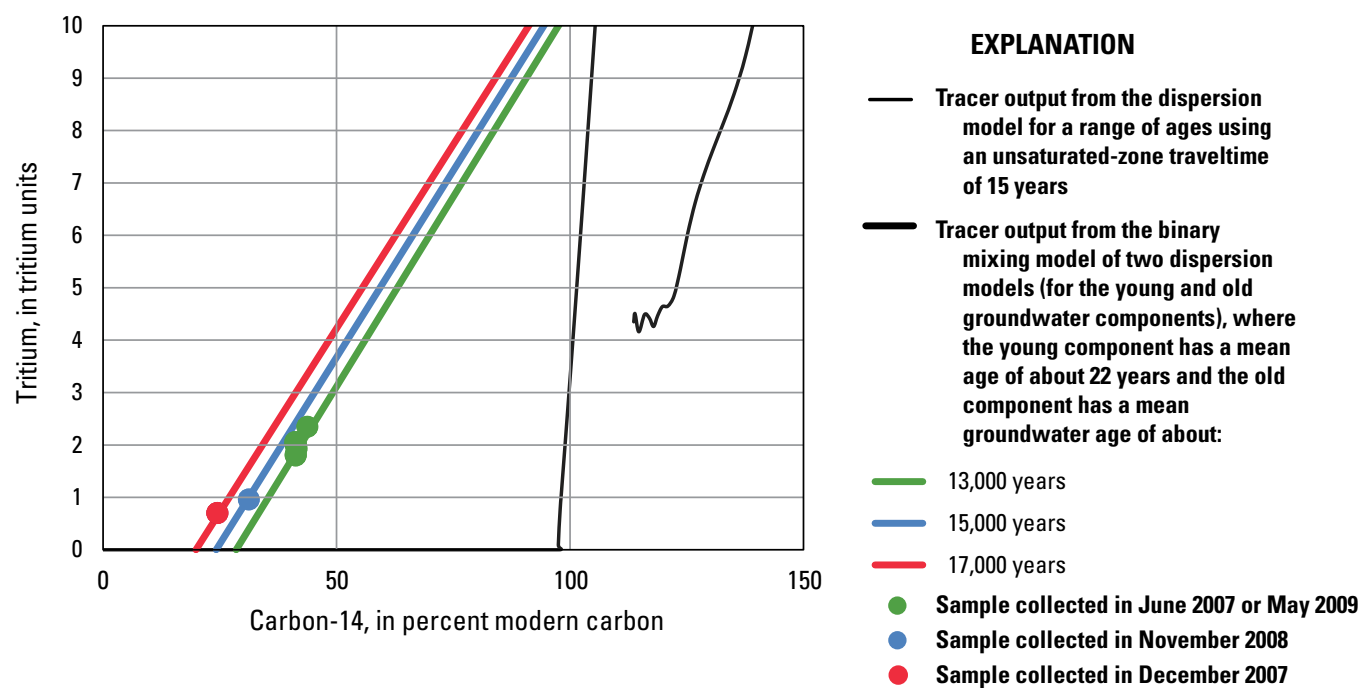

Figure 34. Tritium and carbon-14 output concentrations for three binary mixing models and tracer concentrations measured from the studied supply well (SSW) at different times. Details of the models are provided in table 13. 
of about $13,000,15,000$, and 17,000 years and young water having a mean age of about 22 years.

The total mean age of SSW samples ranged from about 11,000 years to 17,000 years, with a median of about 13,000 years (table 13). The age of groundwater produced by the SSW varies depending on hydrologic stresses caused by seasonal pumping in response to water demand. The mean age of groundwater is younger in the summer than in the winter because changes in groundwater flow allow greater amounts of younger water to reach the SSW. The fraction of young groundwater in summer samples was 10.9 percent in June 2007 and 11.2 percent in May 2009 (average of five samples), with an age of about 21 to 22 years; the old groundwater fraction in these samples had an age of about 12,000 to 13,000 years. In contrast, the fraction of young groundwater in winter samples was 3.2 percent in December 2007 (wellhead sample) and 5.9 percent in November 2008, with an age of about 20 to 21 years; the old groundwater fraction in these samples had an age of about 15,000 to 17,000 years. The submersible pump that was used during sample collection in December 2007 was less powerful than the dedicated turbine pump that is normally used in the SSW. Consequently, this sample likely had a larger fraction of deep, old groundwater than is generally present under normal operation, and the higher estimate of 5.9 percent is probably more representative of actual winter conditions.

The summer and winter fractions of young groundwater are similar to fractions of SFMW-15 water estimated by using NetpathXL (tables 12 and 13). The fractions estimated from age tracers indicate that the proportion of young groundwater is slightly higher than would be estimated from the NetpathXL results, assuming that SFMW-15 represented the only source of young water. Young groundwater reaching the well from other sources that the inverse geochemical modeling did not take into account may account for this difference.

It should be noted that the exact source(s) of young groundwater in the study area are uncertain. Recharge that contains tritium and ${ }^{14} \mathrm{C}$ derived from nuclear weapons testing may originate from the Rio Grande, from precipitation, from water leaking from distribution and (or) sewer lines, from infiltrating urban irrigation water, or from some combination of these or other sources. In addition, recharge from leaky water-supply distribution lines could be a source of old groundwater - that is, water having ${ }^{14} \mathrm{C}$ less than $100 \mathrm{pmC}$ - to the groundwater system; the interpreted ages of groundwater from some wells could therefore be somewhat older than the actual ages. Several documented sources of contamination in the study area contribute VOCs and may also be (or be associated with) sources of ${ }^{3} \mathrm{H}$ and ${ }^{14} \mathrm{C}$ to selected wells. In particular, there are solvent plumes to the northwest, northeast, and southwest of the SSW, and monitoring wells near those plumes were targeted for sampling. Young groundwater originating near the solvent plume to the northwest was thought to be the primary source of VOCs, and therefore of young groundwater, in seven wells (SFMW-46, MNW4-D1, FP3D, PSW1, FP4M, FP4D, and the SSW), partly because of specific VOCs detected in those wells. However, young groundwater and solvents in affected wells may not be derived from the same source(s), but instead may be a mixture of young and contaminated water that co-occur in groundwater reaching those wells. Regardless of these uncertainties about the precise source(s) of young recharge and its associated age tracers, conclusions about the general ranges of age for old and for young fractions of recharge to the sampled wells are not expected to change substantially.

\section{Age Distribution for the Studied Supply Well}

The cumulative age distribution for groundwater from the SSW was calculated for the June 2007 and November 2008 samples (fig. 35). As determined from the interpreted ages, the mean age and the age distribution for the SSW depend on hydrologic stresses caused by seasonal water demands. Therefore, the vulnerability of the SSW to contaminants also

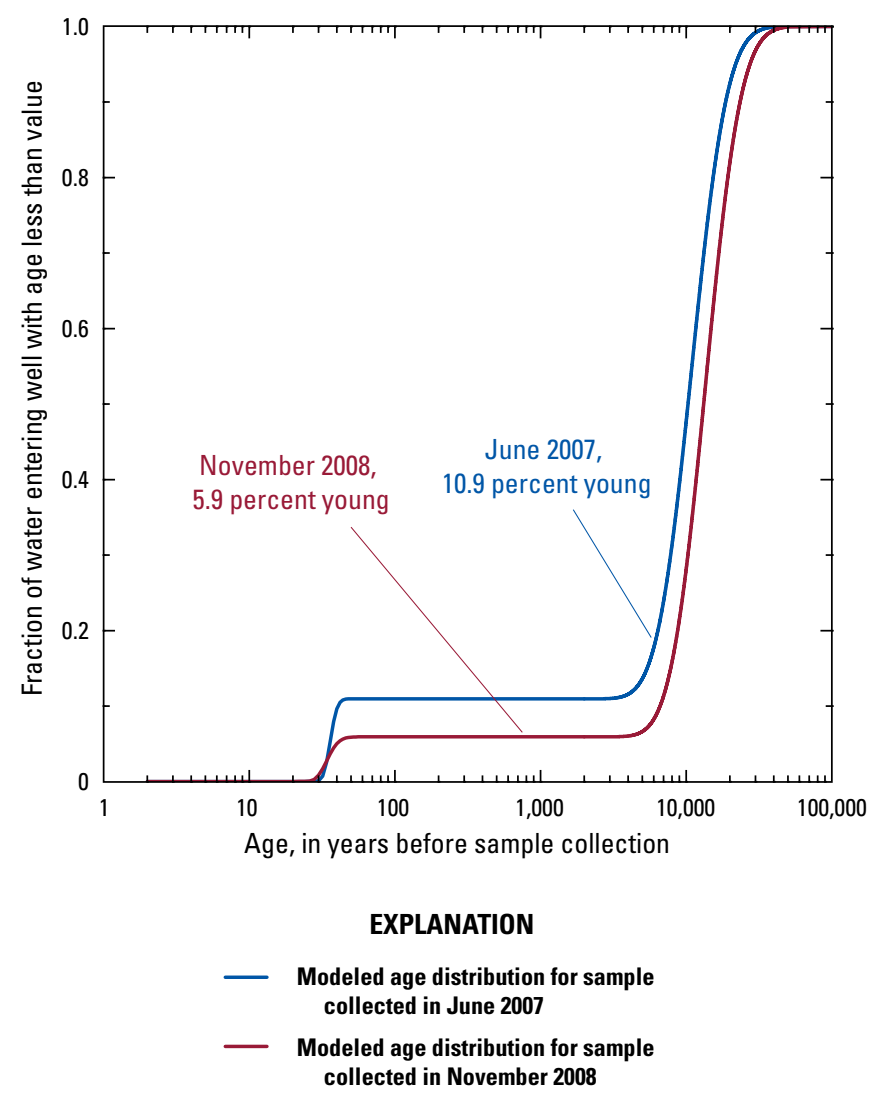

Figure 35. Seasonal variability of the distribution of ages for two groundwater samples from the studied supply well (SSW) in the local-scale transport of anthropogenic and natural contaminants (TANC) study area in Albuquerque, New Mexico. The age distributions were determined from lumped parameter modeling of tracer concentrations. Details of the models are provided in table 13. 
varies during the year. During the summer, the SSW is likely more vulnerable to anthropogenic contaminants such as VOCs or nitrate. During the winter, the SSW is likely more vulnerable to high arsenic concentrations because of larger contributions of old groundwater, which past studies have shown to be associated with higher arsenic concentrations (Bexfield and Plummer, 2003).

The results of the analysis of age tracers and interpreted ages for the SSW have implications that extend to other public-supply wells in and near the local-scale TANC study area that are likely affected by the same seasonal stresses and variability in water quality. PSW1, for example, is completed in a similar manner to the SSW; its water chemistry likely also varies seasonally. These findings are important because understanding the reasons for changes in the quality of groundwater from public-supply wells can lead to the development and testing of strategies to mitigate seasonal contamination. For example, the finding by Jurgens and others (2008) that the well bore of a public-supply well in Modesto, California was acting as a preferential pathway of vertical migration of contaminants from shallower to deeper parts of the aquifer when the well was not pumping led to changes in the operation of the well to reduce its vulnerability.

\section{Processes Affecting Transport of Anthropogenic and Natural Contaminants to the Public-Supply Well}

Previous sections of this report have described the hydrogeologic data obtained through drilling and (or) sampling of monitoring wells and public-supply wells throughout the local-scale TANC study area in Albuquerque and the implications for sources of water and solutes to the groundwater system, for the movement of water and solutes through the system, and for the effects of operation of the studied supply well on solute transport and fate within the system. This section focuses on these major concepts as they relate to the quality of groundwater produced by the SSW and, as is likely, by other public-supply wells within the study area.

\section{Sources of Water and Solutes}

Most groundwater produced by the SSW and other public-supply wells within the study area recharged the aquifer thousands of years ago, prior to the influence of human activities on water quality. Age-tracer data for groundwater samples from three public-supply wells indicate that the fraction of old (pre-1950) groundwater ranges from about 89 to 100 percent, with the fraction for the SSW estimated at about 89 to 97 percent. Old groundwater is present even at shallow depths of the aquifer, and therefore it enters the supply wells across their entire screened intervals, which start between about 17 and 39 $\mathrm{m}$ below the water table (table 1 ). The $\delta \mathrm{D}$ and $\delta^{18} \mathrm{O}$ compositions of old groundwater from monitoring wells and from supply wells are consistent with a source of water associated with seepage from the Rio Grande. Because of its age, this groundwater contains no anthropogenic contaminants and will dilute concentrations of such contaminants from other sources. However, concentrations of some natural contaminants, particularly arsenic, can reach levels of concern in old groundwater of the study area under certain conditions. Concentrations of arsenic exceeding $5 \mu \mathrm{g} / \mathrm{L}$ generally are present in groundwater from deep parts of the aquifer, where $\mathrm{pH}$ is substantially above 7 , and sufficient arsenic is available for desorption from iron oxides present on aquifer sediments. Concentrations of arsenic commonly exceed the USEPA MCL of $10 \mu \mathrm{g} / \mathrm{L}$ in water from 2 of the 3 sampled public-supply wells, including the SSW, because of the relatively large fractions of old, deep groundwater that these wells produce. Based on flow measurements made during the depth-dependent sampling effort, about 40 percent of the groundwater entering the SSW probably came from depths at which monitoring wells indicate that concentrations of arsenic exceed $10 \mu \mathrm{g} / \mathrm{L}$. Although substantial quantities of uranium are also present in deep aquifer sediments, geochemical conditions do not appear to be conducive to its desorption.

Relatively small fractions of young (post-1950) water that has been influenced by human activities are reaching public-supply wells within the study area. Age-tracer data for groundwater samples from three public-supply wells indicate that the fraction of young groundwater ranges to as much as 11 percent, with the fraction for the SSW estimated as generally ranging from about 3 to 11 percent (table 13). Young groundwater is common, though not ubiquitous, in monitoring wells from the water table to depths as great as $75 \mathrm{~m}$ below the water table, and therefore it likely enters the supply wells across parts of about the upper 37 to $58 \mathrm{~m}$ of their screened intervals. Data collected for young age tracers and for low-level VOCs during depth-dependent sampling of the SSW indicate that young water enters the well across at least the upper $44 \mathrm{~m}$ of screen. The $\delta \mathrm{D}$ and $\delta^{18} \mathrm{O}$ compositions of groundwater from monitoring wells with relatively large fractions of young water tend to be heavier than the typical range of these stable isotopes for recharge from the Rio Grande, indicating that some fraction of the water has probably been evaporated. This conclusion is supported by the relatively large concentrations of dissolved solids and nitrate in several of the shallow monitoring wells; however, these concentrations could also indicate that the origin of young recharge is high in these constituents, and (or) that young recharge is flushing accumulated solutes out of the unsaturated zone. The exact source and mechanism of young recharge is not clear and might vary across the study area, but it appears likely to be associated largely with human activities because high rates of evapotranspiration relative to precipitation are believed to result in negligible quantities of natural areal recharge. The common detection of chloroform in shallow monitoring wells 
with relatively large fractions of young water indicates that input of the young recharge that mixes with the older, regional recharge present at shallow depths is fairly widespread and that it results at least partly from infiltration of chlorinated municipal-supply water.

In addition to VOCs such as chloroform that are associated with nonpoint sources, other VOCs (particularly solvents and a gasoline oxygenate) that are associated with point sources of contamination are commonly present in monitoring wells that produce a fraction of young water. Even though public-supply wells in the area produce primarily old groundwater, the fractions of young, contaminated groundwater reaching 2 of the 3 sampled public-supply wells (including the $\mathrm{SSW}$ ) are large enough to result in detections of chloroform; cis-1,2-DCE; trans-1,2,-DCE; MTBE; PCE; and (or) TCE. Fortunately, VOC concentrations in these supply wells are far below corresponding USEPA MCLs, at least partly because of dilution by large fractions of old, VOC-free groundwater.

\section{Movement of Water and Solutes to Supply Wells}

\section{Effects of Groundwater Development}

Extensive groundwater development, centered primarily in the eastern part of Albuquerque, has altered dominant directions of groundwater flow through the local-scale TANC study area from their formerly northeast-to-southwest flow under predevelopment conditions to their present west-to-east flow under modern conditions. Modern patterns of groundwater flow allow transport of water and solutes from the inner valley of the Rio Grande, where the intrinsic susceptibility of groundwater to contamination from human activities at the land surface is relatively high, toward the supply wells sampled within the study area. Groundwater development has also steepened horizontal gradients, resulting in faster transport of water and solutes through the aquifer toward pumping centers. In addition, pumping of public-supply wells has enhanced vertical movement of shallow groundwater (commonly including a fraction of young groundwater affected by human activities) to intermediate depths of the aquifer, where public-supply wells are generally screened. Specifically, continuous water-level data indicate that vertical gradients in at least the upper $75 \mathrm{~m}$ of the aquifer reverse locally from upward to downward during pumping (fig. 6). In areas where vertical gradients have been documented to be downward even in the absence of substantial nearby pumping, such as near the known site of groundwater contamination located in the northwestern part of the study area (Landin, 1999), pumping tends to increase the magnitude of those downward gradients.

Flow measurements recorded in the SSW during the depth-dependent sampling effort indicate that the presence of long-screened public-supply wells alters the movement of water and solutes through the aquifer even when those public-supply wells are not pumping. In long-screened wells throughout the region, water and solutes will tend to enter the well bore through screened sections of the aquifer where hydraulic head is the highest, and then will leave the well bore through screened sections of the aquifer where hydraulic head is lowest. In the case of the SSW, the well bore primarily gains water from the aquifer below about $261 \mathrm{mbls}$ and primarily loses water to the aquifer above about $157 \mathrm{mbls}$. This flow results in movement of old groundwater containing high arsenic concentrations from deeper parts of the aquifer to shallower parts of the aquifer, likely affecting the chemistry of water produced by the SSW for some period of time after pumping resumes. Investigation of the solvent plume associated with the contamination site located northwest of the SSW led to the conclusion that vertical migration of solvents had been enhanced at least partly by direct migration down the well bore(s) of private water-supply wells in the vicinity of the contamination source (Landin, 1999; U.S. Environmental Protection Agency, 2001), affecting the chemistry of groundwater at aquifer depths that are within the screened intervals of public-supply wells (including the SSW) located downgradient. Solvents detected in the intermediate monitoring wells FP3D and FP4D and in the SSW and PSW1 likely originated at this groundwater contamination site, and preferential vertical flow allowed them to be detected at these depths.

The presence of young age tracers and VOCs in groundwater from monitoring wells that are screened as much as $75 \mathrm{~m}$ below the water table is evidence of the role of watersupply wells, the pumping of which and (or) well-bore flow through which can cause preferential downward migration of young groundwater. Age tracers did not show a clear pattern of increasing age of groundwater with depth in shallow and in intermediate depths of the aquifer. Instead, groundwater from wells screened at approximately the same depth below the water table generally had a relatively wide range of estimated ages. Also, younger groundwater was found at greater depths than older groundwater, sometimes within the same well nest. These age patterns imply nonuniform mixing of young, shallow groundwater down to fairly substantial depths, which would be most likely to occur in the vicinity of deep supply wells. The presence of young water containing VOCs beneath water containing no young fraction and no VOCs, such as in the FP3 wells, could imply preferential vertical flow that effectively allows certain aquifer depths to be bypassed. This type of preferential flow could occur if flow were through well bores of abandoned or seasonally used wells, as Landon and others (2008) documented in the High Plains aquifer near York, Nebraska. However, a pattern similar to that observed in the FP3 wells might also occur downgradient from a pumping well if directions and velocities of groundwater flow differed among sedimentary deposits at various aquifer depths. Whether enhancement of downward gradients by pumping or by direct movement of water through well bores is the primary mechanism of vertical mixing within the study area, the end result is the presence across broad areas of young, potentially contaminated water at greater depths than would be expected in the absence of deep supply wells, 
including at depths within the screened intervals of publicsupply wells.

\section{Effects of Geochemical Conditions and Attenuation Reactions}

Measurements of redox-sensitive parameters indicate that groundwater throughout the local-scale TANC study area is primarily oxic, with only localized areas of suboxic or anoxic conditions. However, despite the common presence of some dissolved oxygen in groundwater and the general paucity of organic carbon in aquifer sediments, groundwater samples from multiple wells, particularly intermediate monitoring wells, show evidence of denitrification as based on results for excess nitrogen gas, $\delta^{15} \mathrm{~N}-\mathrm{NO}_{3}, \delta^{18} \mathrm{O}-\mathrm{NO}_{3}$, and $\delta^{15} \mathrm{~N}-\mathrm{N}_{2}$. For groundwater samples in which denitrification appears to have occurred, estimated reaction progress ranges from 0.03 to 0.99 , indicating that denitrification could substantially reduce nitrate concentrations in some parts of the aquifer. However, most wells where denitrification has probably progressed most extensively are associated with known or suspected sites of anthropogenic input of organic carbon, which microbial respiration requires; denitrification might not progress substantially in parts of the aquifer without such anthropogenic input of organic carbon. Although concentrations of nitrate did not exceed the USEPA MCL of $10 \mathrm{mg} / \mathrm{L}$ in water from any of the study wells, concentrations ranged between about 3.4 and $5.9 \mathrm{mg} / \mathrm{L}$ in most shallow (water-table) wells, indicating that natural attenuation through denitrification could be beneficial in helping to keep concentrations in water in deeper parts of the aquifer (and in public-supply wells) substantially below the drinking-water standard. Data for excess nitrogen gas and nitrogen isotopes indicate that denitrification has affected concentrations of nitrate in groundwater reaching PSW1 and the SSW. If shallow groundwater with relatively high concentrations of nitrate were to migrate to intermediate depths of the aquifer without being affected by denitrification, either because of fast migration down a well bore or because of a lack of organic carbon along the flow path, concentrations of nitrate in groundwater from public-supply wells could rise above the maximum supply-well concentration of $0.76 \mathrm{mg} / \mathrm{L}$ observed during this study.

The primarily oxic conditions of groundwater within the study area have allowed TCE to persist in the aquifer for several kilometers from known contaminant sources and to be transported to 2 of the 3 sampled public-supply wells at high enough concentrations to lead to its detection in those wells. TCE detected in the SSW is believed to be associated with the known site of groundwater contamination located about $3.4 \mathrm{~km}$ to the northwest. PCE and TCE associated with 2 of 3 known contamination sites appears to be degrading through reductive dechlorination in parts of the aquifer where conditions have become reducing, likely as a result of introducing additional organic carbon associated with the source of VOCs to groundwater. The degradation products cis-1,2-DCE, trans1,2-DCE, and VC have all been detected along with TCE and (or) PCE in several monitoring wells, and cis-1,2-DCE has been detected along with TCE and (or) PCE in two publicsupply wells. Therefore, although reductive dechlorination of PCE and TCE has occurred, reaction progress has not been sufficient to attenuate these compounds to a level that prevents their detection in public-supply wells located substantial distances away from sources. However, preferential vertical flow resulting from pumping by or well-bore flow through supply wells, along with preferential lateral flow through particularly conductive sedimentary deposits, appears to have accelerated transport of the these VOCs to public-supply wells, reducing the time available for attenuation between the source and the public-supply well. Despite being relatively recalcitrant under reducing conditions and more biodegradable under oxic conditions (Kauffman and Chapelle, 2010), MTBE also was detected in the SSW and PSW1, possibly because of short flow paths between the source and the wells and (or) insufficient organic carbon along those flow paths to support microbial activity.

\section{Effects of Operation of the Studied Supply Well on Transport of Water and Solutes}

Along with the effects of regional groundwater development on transport of water and solutes through the groundwater system of the local-scale TANC study area, the chemistry of water produced by the SSW appears to be affected by operation of the SSW itself and (or) the operation of nearby publicsupply wells. The chemistry of water produced by the SSW varies seasonally and can show relatively minor variations with pumping duration. The variations observed in chemistry for up to the first few hours of pumping after a period during which the well has been idle likely are associated with upward flow observed through the well bore under ambient conditions. This well-bore flow results in movement of old groundwater containing high arsenic concentrations from deeper parts of the aquifer to shallower parts of the aquifer, where it is stored until pumping resumes. When pumping first resumes, water produced by the SSW has generally higher concentrations of arsenic and other indicators of water from deeper parts of the aquifer than it has after several hours of pumping, a consequence consistent with removal of deep water from shallower parts of the aquifer where it has been stored as a result of wellbore flow. The exact role that well-bore flow plays in variability observed in the chemistry of water from the SSW between the summer (when the well typically operates more frequently and for longer periods) and winter (when the well typically operates less frequently and for shorter periods, allowing for more ambient well-bore flow) is not clear. However, the observation of substantial decreases in markers of deep water over just a few hours after pumping resumes might imply that the effects of well-bore flow on the chemistry of water from the SSW are sustainable for shorter periods than the effects of similar (though downward) well-bore flow in a public-supply well that Jurgens and others (2008) studied in the San Joaquin Valley of California. 
Seasonal variation in the chemistry of water produced by the SSW appears likely to be associated with the seasonal effects of pumping by the SSW and by nearby public-supply wells on local hydraulic gradients. Among other characteristics, water samples collected from the SSW during the summer pumping season have larger fractions of young water, younger overall ages, higher recharge temperatures, more common detections of VOCs, and smaller concentrations of arsenic than do samples collected during the winter pumping season. These characteristics imply that the SSW produces larger fractions of water from shallower parts of the aquifer during the summer than during the winter. Water-level data from the FP well nests (particularly from FP1) indicate that vertical hydraulic gradients between the shallow and intermediate parts of the aquifer commonly reverse from upward to downward when the SSW is pumping and (or) has been pumping frequently. Younger, shallower water would therefore be expected to migrate to greater depths within parts of the aquifer intersected by the well screen of the SSW during the summer, when the SSW and (or) nearby public-supply wells are being pumped for longer periods of time and more frequently. Further study would be needed to determine whether seasonal variation in the chemistry of water from a supply well commonly reflects the effects of seasonal pumping at a regional scale, as well as at a local scale.

\section{Summary and Conclusions}

In 2001, the National Water-Quality Assessment Program of the U.S. Geological Survey began a series of groundwater studies designed to increase understanding of the factors that affect transport of anthropogenic and natural contaminants (TANC) to public-supply wells. During 2007 through 2009, a local-scale TANC study investigated the hydrogeology, water chemistry, and factors affecting the transport of contaminants in the zone of contribution of a public-supply well in Albuquerque, New Mexico. The studied supply well (SSW) is fairly typical of the relatively deep, high-capacity wells operated by municipalities in the area. The $24-\mathrm{km}^{2}$ study area surrounding the well consists of primarily urban land within the Middle Rio Grande Basin, a deep alluvial basin in central New Mexico that has hydrogeologic properties, land-use characteristics, and water-quality issues that are common among southwestern alluvial basins.

The aquifer is composed primarily of unconsolidated to moderately consolidated fluvial deposits of Pliocene age. Conditions generally are unconfined, but are semiconfined at depth. Prior to human development, groundwater within the study area flowed from northeast to southwest. Under modern conditions, urban recharge sources add to the primary source of recharge, which is seepage from the Rio Grande. Daily to seasonal patterns in groundwater withdrawals for public supply cause temporal variability in the direction and magnitude of local hydraulic gradients, but the primary direction of groundwater flow within the study area is west to east.
Groundwater samples were collected from 22 monitoring wells and 3 public-supply wells. Analysis of groundwater samples included field measurements, major and trace elements, arsenic speciation, nutrients, dissolved organic carbon, volatile organic compounds (VOCs), dissolved gases, stable isotopes, and tracers of young and old water. During installation of nests of monitoring wells, core samples were collected for analysis of the chemical, mineralogical, and physical properties of the sedimentary deposits. Depth-dependent flow and chemistry data were collected from the SSW to improve understanding of the depths where water and contaminants enter the well.

Data from seven shallow wells screened across or near the water table indicate the common presence of young recharge associated with urban land and water use. Relatively heavy $\delta \mathrm{D}$ values and relatively large concentrations of chloride in groundwater from shallow wells are consistent with shallow groundwater in the area typically including a fraction that evaporated prior to recharge and (or) flushed accumulated solutes out of the unsaturated zone during recharge. Calculated recharge temperatures from shallow wells were quite variable, which may indicate spatial differences in the quantity of young (generally warmer) recharge contributed to the water table. Although concentrations of nitrate were above $1 \mathrm{mg} / \mathrm{L}$ in all shallow (water-table) wells, neither nitrogen isotopes nor chloride/bromide ratios indicate a substantial component of recharge from wastewater sources. However, the presence of VOCs in water from all shallow wells screened across the water table indicates that shallow groundwater in the study area commonly is affected by human activities in the primarily urban setting. Most shallow wells had tritium concentrations indicating the presence of young (post-1950s) recharge. For these wells, young ages and fractions ranged from about 5 to 22 years and about 14 to 36 percent, respectively. Ages of the old water fraction among all shallow wells (including the well without a fraction of young water) ranged from about 6,500 to 9,900 years.

Data from 13 intermediate wells, which have a screened interval with a midpoint between about 27.1 and $79.6 \mathrm{~m}$ below the water level in the well, indicate that substantial fractions of young recharge are present at this range of aquifer depths in some locations. Groundwater samples from five intermediate wells had relatively light $\delta \mathrm{D}$ values that indicate relatively large fractions of old recharge, sourced primarily from the Rio Grande, and small fractions of young recharge. However, most intermediate wells had somewhat heavier $\delta \mathrm{D}$ values that indicate mixing between shallow and deeper groundwater. Variations in observed chloride/bromide ratios and calculated recharge temperatures for intermediate wells are also consistent with greater mixing between shallow and deeper groundwater in some areas than others. Nitrate concentrations and nitrogen isotopes indicate that denitrification is occurring at intermediate aquifer depths, and that denitrification reaction progress typically is greatest for wells that include a fraction of groundwater associated with particular recharge sources or known sites of contamination that contribute dissolved organic carbon to the aquifer. Arsenic concentrations 
for intermediate wells generally were less than $5 \mu \mathrm{g} / \mathrm{L}$. One or more VOCs were detected in nine intermediate wells. Several of these wells are located near known sites of solvent contamination that were targeted for sampling because of detections of trichloroethylene (TCE) and cis-1,2-dichloroethylene (cis-1,2-DCE) in the SSW, and several of these wells may have become contaminated at least partly because of enhanced vertical migration associated with the pumping of and (or) direct migration down deep well bores. Of the five intermediate wells with relatively light $\delta \mathrm{D}$ values, three did not have VOC detections; also, three had tritium results consistent with essentially no fraction of young recharge and estimated groundwater ages between about 4,700 and 5,900 years. Among other intermediate wells, young ages and fractions ranged from about 16 to 26 years and about 1.5 to 46 percent, respectively. Ages of the old water fraction ranged from about 6,100 to 18,000 years.

Data from two deep monitoring wells, which have a screened interval with a midpoint located about $185 \mathrm{~m}$ or more below the water level in the well, indicate that no young recharge is present in deep groundwater. The relatively light $\delta \mathrm{D}$ values and relatively low recharge temperatures for these wells are consistent with old recharge sourced from the Rio Grande. Nitrogen isotopes from the deep wells are consistent with minimal denitrification, likely because little organic carbon was encountered along flow paths to the wells and original concentrations of nitrate were relatively low. Concentrations of arsenic (present primarily as arsenate) in both wells exceeded the Maximum Contaminant Level of $10 \mu \mathrm{g} / \mathrm{L}$; waterquality and solid-phase data from deep parts of the aquifer are consistent with $\mathrm{pH}$-dependent desorption of arsenic from ferric oxyhydroxides in aquifer sediments. No VOCs were detected in deep wells, and tritium and CFC results were consistent with essentially no fraction of young recharge. Groundwater ages for the deep wells were about 19,000 to 21,000 years.

Data from two supply wells (not including the SSW), which have screen lengths exceeding $190 \mathrm{~m}$, demonstrate that substantial fractions of young recharge reach some supply wells within the study area, but not others. For one of these supply wells, PSW3, chemical and isotopic results were consistent with the lack of a substantial fraction of young recharge, and with a large contribution of deep groundwater. The interpreted age for this well, which had no VOC detections, was more than 22,000 years. Several VOCs were detected in the other supply well, PSW1, at concentrations less than one-tenth of the corresponding drinking-water standards, and tritium and $\mathrm{CFC}$ results indicated the presence of a substantial fraction of young recharge. The young fraction was about 11 percent, with an age of about 20 years, and the old fraction had an age of about 12,000 years.

Data available for multiple samples from the SSW, which is screened across intermediate and deep parts of the aquifer, indicate that the fraction of young recharge reaching the well varies seasonally. During the summer season, when supply-well pumping tends to be greatest, TCE generally was detected in water from the SSW (along with other VOCs, all at concentrations less than one-hundredth the corresponding drinking-water standards), and arsenic concentrations generally did not exceed $12 \mu \mathrm{g} / \mathrm{L}$. During the winter season, VOCs generally were not detected and arsenic concentrations commonly exceeded $12 \mu \mathrm{g} / \mathrm{L}$. Well-bore flow data collected from the pumping SSW during the winter season indicated that about 61 percent of the total flow from the SSW entered the well from the intermediate part of the aquifer, whereas the remaining 39 percent entered the well from the deep part of the aquifer. Compared to the summer season, samples collected during the winter season had lower recharge temperatures, smaller tritium concentrations, and smaller carbon-14 concentrations, indicating a larger contribution of deep groundwater and a smaller contribution of young recharge; however, the data showed that a fraction of young recharge was present in every well-head sample from the SSW. For winter samples, the young fraction was about 3 to 6 percent, with an age of about 20 to 21 years, and the old fraction had an age of about 15,000 to 17,000 years. For summer samples, the young fraction was about 11 percent, with an age of about 21 to 22 years, and the old fraction had an age of about 12,000 to 13,000 years. Seasonal variability in the chemistry of groundwater produced by the SSW is likely associated with the effects of seasonal pumping patterns on the direction and magnitude of local horizontal and vertical hydraulic gradients and (or) with flow observed to occur through the well bore when the SSW is not pumping.

Hydrologic and chemical data from the study area indicate that young recharge is reaching the aquifer across broad areas and is migrating from shallow to intermediate depths of the aquifer largely as a result of mixing that is associated with groundwater development. Consequently, groundwater that has potentially been affected by anthropogenic activities in the urban study area is present at depths that are within the screened intervals of public-supply wells, resulting in detections of VOCs and implying greater vulnerability to anthropogenic contamination than might be assumed based on the dominantly old (thousands of years) age of groundwater. However, the large fractions of old groundwater produced by the public-supply wells substantially dilute anthropogenic contaminants. Based on data from the SSW, vulnerability of public-supply wells in the area to natural contaminants (primarily arsenic in deep parts of the aquifer) and anthropogenic contaminants changes with time, including with seasonal changes in pumping stresses that alter the fractions of young and old water being contributed to the wells.

\section{Acknowledgments}

The authors of this study gratefully acknowledge the generous assistance of many people affiliated with the Albuquerque Bernalillo County Water Utility Authority (ABCWUA), the University of New Mexico (UNM), the Central New Mexico Community College (CNM), and the New Mexico Environment Department (NMED). In particular, John Stomp 
and Barbara Gastian were instrumental in the ABCWUA's participation in this study, particularly with respect to granting access to their supply wells for sampling, including allowing the alteration of pumping schedules and even the disassembly of pumping equipment in the studied supply well for depthdependent sampling. Barbara Gastian also shared her extensive knowledge about factors affecting groundwater quality in the ABCWUA's wells and the surrounding aquifer. Harold Greear (retired), Jane DeRose-Bamman, and Daniel Garcia of the ABCWUA coordinated with the USGS field teams to ensure that samples could be collected under the desired conditions. The knowledge of Victor Powell of Alpha Southwest Inc. was essential to completion of data collection during depth-dependent sampling, as was the assistance of Evan Bennett of Bennett Sample Pumps, Inc.

The assistance of Vernon Hershberger of UNM was critical to obtaining permission and coordinating logistics for the drilling of monitoring wells at several locations on UNM property; the efforts of Thomas Neale of UNM also were important to the drilling effort. Along with Bart Faris of the NMED, Vernon Hershberger shared data and knowledge related to investigations of groundwater quality in the UNM area, in addition to assisting with the collection of water samples from monitoring wells. Luis Campos of CNM generously assisted with permissions and logistics for the drilling of monitoring wells on CNM property. The contributions of Sabino Rivera of the NMED in allowing and assisting with sampling of monitoring wells also are greatly appreciated. Oscar Lackey of General Electric Aviation kindly assisted with permissions for the sampling of monitoring wells.

Assistance with analysis and interpretation of data related to the hydrogeology and solid-phase chemistry of the study area also is greatly appreciated. Sean Connell of the New Mexico Bureau of Geology and Mineral Resources shared his extensive knowledge of the hydrogeology of the area and provided input on data collected as part of this study. Gary Weissmann of UNM contributed information on approaches to modeling of aquifer heterogeneity, which was conducted by Nick Engdahl while attending UNM and working for the USGS. Nicole Thomas of the USGS performed detailed descriptions of borehole cuttings. Laboratory analysis of core samples and insight into the results was provided by Ken Stollenwerk, Kathryn Conko, Dan Webster, and Rick Healy of the USGS.

Other colleagues at the USGS also provided assistance that was essential to the completion of this study. Dale Rankin, Sarah Falk, Anne Tillery, Eric Scherff, and Casey Seaman all spent long days in the field to ensure the proper completion of monitoring wells and (or) collection of data from monitoring wells and supply wells. The knowledge and assistance of Greg Stanton, Mike Nyman, and Allen Christensen were critical to data collection during depth-dependent sampling. The technical expertise of Niel Plummer and J.K. Böhlke of the USGS was critical to interpretation of groundwater ages, and their assistance is greatly appreciated. Finally, the authors are indebted to other members of the local and national TANC teams for their technical assistance and advice regarding data collection and interpretation.

\section{References Cited}

Aeschbach-Hertig, W., Peeters, F., Beyerle, U., and Kipfer, R., 1999, Interpretation of dissolved atmospheric noble gases in natural waters: Water Resources Research, v. 35, no. 9, p. $2,779-2,792$.

Aeschbach-Hertig, W., Peeters, F., Beyerle, U., and Kipfer, R., 2000, Paleotemperature reconstruction from noble gases in groundwater taking into account equilibration with entrapped air: Nature, v. 405, no. 6790: 1,040-1,044.

Albuquerque Bernalillo County Water Utility Authority, 2007, Water resources management strategy, October 2007, accessed September 2011 at http://www.abcwua.org/pdfs/ WRMS_Update_101207.pdf.

Albuquerque Bernalillo County Water Utility Authority, 2010, San Juan-Chama drinking water project, accessed June 2010 at http://www.abcwua.org/content/view/31/24/.

American Public Health Association, 1995, UV-absorbing organic constituents (19th ed.): Standard Methods for the Examination of Water and Wastewater, p. 5-60 to 5-62.

Anderholm, S.K., 1988, Groundwater geochemistry of the Albuquerque-Belen Basin, Central New Mexico: U.S. Geological Survey Water-Resources Investigations Report 86-4094, $110 \mathrm{p}$.

Anderholm, S.K., 1997, Water-quality assessment of the Rio Grande valley, Colorado, New Mexico, and Texas-Shallow groundwater quality and land use in the Albuquerque area, central New Mexico, 1993: U.S. Geological Survey Water-Resources Investigations Report 97-4067, 73 p.

Anderholm, S.K., 2001, Mountain-front recharge along the east side of the Albuquerque Basin, Central New Mexico (revised): U.S. Geological Survey Water-Resources Investigations Report 00-4010, 36 p.

Aravena, Ramon, and Robertson, W.D., 1998, Use of multiple isotope tracers to evaluate denitrification in ground waterStudy of nitrate from a large-flux septic system plume: Ground Water, v. 36, no. 6, p. 975-982.

ASTM International, 1998, Standard test method for radon in drinking water: ASTM D5072-98, 3 p.

Axis Group, Inc., 2007, 2006-2007 annual report and semiannual quality assurance report, deep zone groundwater remediation system, former Air Force Plant 83/General Electric operable unit, South Valley Superfund site, Albuquerque, New Mexico: Albuquerque, Axis Group, Inc., prepared for General Electric Aviation, Albuquerque, New Mexico, August 15, 2007, variously paged. 
Bartolino, J.R., and Cole, J.C., 2002, Groundwater resources of the Middle Rio Grande Basin, New Mexico: U.S. Geological Survey Circular 1222, 132 p.

Bartolino, J.R., and Niswonger, R.G., 1999, Numerical simulation of vertical ground-water flux of the Rio Grande from ground-water temperature profiles, central New Mexico: U.S. Geological Survey Water-Resources Investigations Report 99-4212, 34 p.

Bexfield, L.M., 2010, Conceptual understanding and groundwater quality of the basin-fill aquifer in the Middle Rio Grande Basin, New Mexico, in Thiros, S.A., Bexfield, L.M., Anning, D.W., Green, J.M., and McKinney, T.S., Conceptual understanding and groundwater quality of selected basin-fill aquifers in the Southwestern United States: U.S. Geological Survey Professional Paper 1781, p. 189-218.

Bexfield, L.M., and Anderholm, S.K., 2000, Predevelopment water-level map of the Santa Fe Group aquifer system in the Middle Rio Grande Basin between Cochiti Lake and San Acacia, New Mexico: U.S. Geological Survey WaterResources Investigations Report 00-4249, 1 sheet.

Bexfield, L.M., and Anderholm, S.K., 2002a, Estimated waterlevel declines in the Santa Fe Group aquifer system in the Albuquerque area, central New Mexico, predevelopment to 2002: U.S. Geological Survey Water-Resources Investigations Report 02-4233, 1 sheet.

Bexfield, L.M., and Anderholm, S.K., 2002b, Spatial patterns and temporal variability in water quality from City of Albuquerque drinking-water supply wells and piezometer nests, with implications for the groundwater flow system: U.S. Geological Survey Water-Resources Investigations Report 01-4244, $101 \mathrm{p}$.

Bexfield, L.M., Heywood, C.E., Rattray, G.W., Kauffman, L.J., and Vogler, E.T., 2011, Hydrogeologic setting and groundwater flow simulation of the Middle Rio Grande Basin regional study area, New Mexico, section 2 of Eberts, S.M., ed., Hydrologic settings and groundwater-flow simulations for regional investigations of the transport of anthropogenic and natural contaminants to public-supply wells - investigations begun in 2004: U.S. Geological Survey Professional Paper 1737-B, p. 2-1 to 2-61.

Bexfield, L.M., Lindberg, W.E., and Anderholm, S.K., 1999, Summary of water-quality data from City of Albuquerque drinking-water supply wells, 1988-97: U.S. Geological Survey Open-File Report 99-195, 138 p.

Bexfield, L.M., and Plummer, L.N., 2003, Chapter 11-Occurrence of arsenic in ground water of the Middle Rio Grande Basin, central New Mexico, in Welch, A.H., and Stollenwerk, K.G., eds., Arsenic in ground water-Geochemistry and occurrence: Boston, Kluwer Academic Publishers, p. 295-327.
Bjorklund, L.J., and Maxwell, B.W., 1961, Availability of ground water in the Albuquerque area, Bernalillo and Sandoval Counties, New Mexico: New Mexico State Engineer Technical Report 21, 117 p.

Böttcher, J., Strebel, O., Voerkelius, Susanne, and Schmidt, H.-L., 1990, Using isotope fractionation of nitrate-nitrogen and nitrate-oxygen for evaluation of microbial denitrification in a sandy aquifer: Journal of Hydrology, v. 114, p. 413-424.

Bradley, P.M., 2000, Microbial degradation of chloroethenes in groundwater systems: Hydrogeology Journal, v. 8, no. 1, p. 104-111.

Brinton, S.R., and O'Connor, G.A., 2003, Sorption of molybdenum in soils field-equilibrated with biosolids: Communications in Soil Science and Plant Analysis, v. 34, no. 9-10, p. 1,331-1,346.

Brenton, R.W., and Arnett, T.L., 1993, Methods of analysis by the U.S. Geological Survey National Water Quality Laboratory-Determination of dissolved organic carbon by UVpromoted persulfate oxidation and infrared spectrometry: U.S. Geological Survey Open-File Report 92-480, 12 p.

Bullister, J.L., 1984, Atmospheric chlorofluoromethanes as tracers of ocean circulation and mixing - Studies in the Greenland and Norwegian seas: La Jolla, University of California San Diego, Ph.D. dissertation, 172 p.

Bullister, J.L., and Weiss, R.F., 1988, Determination of $\mathrm{CFC}_{3} \mathrm{~F}$ and $\mathrm{CCl}_{2} \mathrm{~F}_{2}$ in seawater and air: Deep Sea Research, v. 35, p. $839-854$.

Busenberg, E., and Plummer, L.N., 1992, Use of chlorofluorocarbons $\left(\mathrm{CFC}_{3} \mathrm{~F}\right.$ and $\left.\mathrm{CCl}_{2} \mathrm{~F}_{2}\right)$ as hydrologic tracers and age-dating tools - The alluvium and terrace system of central Oklahoma: Water Resources Research, v. 28, no. 9, p. 2,257-2,283.

CH2M Hill, 1991, Identification of potential problem areas (subtask 4a memorandum): Albuquerque, Water quality program (arsenic) of the Water Resources Management Project, prepared for the City of Albuquerque, 2 pls., variously paged.

Chapelle, F.H., McMahon, P.B., Dubrovsky, N.M., Fujii, R.F., Oaksford, E.T., and Vroblesky, D.A., 1995, Deducing the distribution of terminal electron-accepting processes in hydrologically diverse groundwater systems: Water Resources Research, v. 31, no. 2, p. 359-371.

Childress, C.J.O, Foreman, W.T., Conner, B.F., and Maloney, T.J., 1999, New reporting procedures based on longterm method detection levels and some considerations for interpretations of water-quality data provided by the U.S. Geological Survey National Water Quality Laboratory: U.S. Geological Survey Open-File Report 99-193, 19 p. Available at http://water.usgs.gov/owq/OFR_99-193/index.html. 
City of Albuquerque, 2003, San Juan-Chama Diversion Project, accessed August 2003 at http://www.cabq.gov/ waterresources/sjc.html.

Clark, I.D., and Fritz, P., 1997, Environmental isotopes in hydrogeology: Boca Raton, Fla., Lewis Publishers, 328 p.

Clark, W.B., Jenkins, W.J., and Top, Z., 1976, Determination of tritium by mass spectrometric measurement of ${ }^{3} \mathrm{He}$ : International Journal of Applied Radiation and Isotopes, v. 27, p. 515-522.

Connell, S.D., 2006, Preliminary geologic map of the Albuquerque-Rio Rancho metropolitan area and vicinity, Bernalillo and Sandoval Counties, New Mexico: New Mexico Bureau of Geology and Mineral Resources OpenFile Report 496, 2 plates.

Connell, S.D., 2008, Refinements to the stratigraphic nomenclature of the Santa Fe Group, northwestern Albuquerque Basin, New Mexico: New Mexico Geology, v. 30, no. 1, p. 14-35.

Connell, S. D., Koning, D. J., and Cather, S. M., 1999, Revisions to the stratigraphic nomenclature of the Santa Fe Group, northwestern Albuquerque Basin, New Mexico, in Pazzaglia, F.J., and Lucas, S.G., eds., Albuquerque geology: New Mexico Geological Society, Guidebook 50, p. 337-353.

Connor, B.F., Rose, D.L., Noriega, M.C., Murtagh, L.K., and Abney, S.R., 1998, Methods of analysis by the U.S. Geological Survey National Water Quality Laboratory-Determination of 86 volatile organic compounds in water by gas chromatography/mass spectrometry, including detections less than reporting limits: U.S. Geological Survey OpenFile Report 97-829, 78 p.

Drimmie, R.J., Heemskerk, A.R., and Aravena, R.O., 1994, Dissolved Inorganic Carbon (DIC), Technical Procedure 5.0, Rev. 02, Environmental Isotope Laboratory: Waterloo, Ontario, Department of Earth Sciences, University of Waterloo, 7 p.

Eberts, S.M., ed., 2011, Hydrogeologic settings and groundwater-flow simulations for regional investigations of the transport of anthropogenic and natural contaminants to public-supply wells - investigations begun in 2004: U.S. Geological Survey Professional Paper 1737-B [variously paged].

Eberts, S.M., Erwin, M.L, and Hamilton, P.A., 2005, Assessing the vulnerability of public-supply wells to contamination from urban, agricultural, and natural sources: U.S. Geological Survey Fact Sheet 2005-3022, 4 p.

Eberts, S.M., Kauffman, L.J., Bexfield, L.M., and Lindgren, R.J., 2011, Overview of chapter B: Additional regional studies of the transport of anthropogenic and natural contaminants to public-supply wells, section 1 of Eberts, S.M., ed., Hydrologic settings and groundwater-flow simulations for regional investigations of the transport of anthropogenic and natural contaminants to public-supply wells - investigations begun in 2004: U.S. Geological Survey Professional Paper 1737-B, p. 1-1 to 1-6.

Fishman, M.J., ed., 1993, Methods of analysis by the U.S. Geological Survey National Water Quality LaboratoryDetermination of inorganic and organic constituents in water and fluvial sediments: U.S. Geological Survey OpenFile Report 93-125, 217 p.

Fishman, M.J., and Friedman, L.C., 1989, Methods for determination of inorganic substances in water and fluvial sediments: U.S. Geological Survey Techniques of WaterResources Investigations, book 5, chap. A1, 545 p.

Fukada, Teppei, Hiscock, K.M., Dennis, P.F., and Grischek, Thomas, 2003, A dual isotope approach to identify denitrification in groundwater at a river-bank infiltration site: Water Research, v. 37, p. 3,070-3,078.

Garbarino, J.R., 1999, Methods of analysis by the U.S. Geological Survey National Water Quality LaboratoryDetermination of dissolved arsenic, boron, lithium, selenium, strontium, thallium, and vanadium using inductively coupled plasma-mass spectrometry: U.S. Geological Survey Open-File Report 99-093, 31 p.

Garbarino, J.R., Bednar, A.J., and Burkhardt, M.R., 2002, Methods of analysis by the U.S. Geological Survey National Water Quality Laboratory-Arsenic speciation in naturalwater samples using laboratory and field methods: U.S. Geological Survey Water-Resources Investigations Report 02-4144, $40 \mathrm{p}$.

Garbarino, J.R., Kanagy, L.K., and Cree, M.E., 2006, Determination of elements in natural-water, biota, sediment, and soil samples using collision/reaction cell inductively coupled plasma-mass spectrometry: U.S. Geological Survey Techniques and Methods, book 5, sec. B, chap. 1, 88 p.

GNS Stable Isotope Laboratory, 2010, Stable isotopes, carbon, ${ }^{13} \mathrm{C} /{ }^{12} \mathrm{C}$, accessed September 2010 at http://www.gns.cri.nz/ nic/stableisotopes/carbon.html.

Goldberg, Sabine, Forster, H.S., and Godfrey, C.L., 1996, Molybdenum adsorption on oxides, clay minerals, and soils: Soil Science Society of America Journal, v. 60, no. 2, p. $425-432$.

Grauch, V.J.S., Gillespie, C.L., and Keller, G.R., 1999, Discussion of new gravity maps for the Albuquerque Basin area, in Pazzaglia, F.J., and Lucas, S.G., eds., Albuquerque Geology, New Mexico Geological Society Fiftieth Annual Field Conference, September 22-25, 1999: Socorro, New Mexico Geological Society, p. 119-124.

Harding Lawson Associates, 2000, Five-year review report of remedial actions, Plant 83/General Electric operable unit, South Valley Superfund site, Albuquerque, New Mexico: Denver, Harding Lawson Associates, prepared for General 
Electric Aircraft Engines, September 15, 2000, variously paged.

Hawley, J.W., and Haase, C.S., 1992, Hydrogeologic framework of the northern Albuquerque Basin: Socorro, New Mexico Bureau of Mines and Mineral Resources Open-File Report 387, variously paged.

Hawley, J.W., and Haase, C.S., and Lozinsky, R.P., 1995, An underground view of the Albuquerque Basin, in OrtegaKlett, C.T., ed., The water future of Albuquerque and the Middle Rio Grande Basin: Proceedings of the 39th Annual New Mexico Water Conference, November 3-4, 1994, New Mexico Water Resources Research Institute WRRI Report No. 290, p. 37-55.

Helsel, D.R., and Hirsch, R.M., 1995, Statistical methods in water resources: Amsterdam, Netherlands, Elsevier Science, $529 \mathrm{p}$.

Hem, J.D., 1985, Study and interpretation of the chemical characteristics of natural water: U.S. Geological Survey Water-Supply Paper 2254, 264 p.

Hester, D.J., 2006, Analyzing Albuquerque's landscape evolution in the 20th and 21st centuries, in Acevedo, W., Taylor, J.L, Hester, D.J., Mladinich, C.S., and Glavac, S., eds., Rates, trends, causes, and consequences of urban land-use change in the United States: U.S. Geological Survey Circular 1726, p. 113-128.

Hua, Q., and Barbetti, M., 2004, Review of tropospheric bomb ${ }^{14} \mathrm{C}$ data for carbon cycle modeling and age calibration purposes: Radiocarbon, v. 46, p. 1,273-1,298.

Jurgens, B.C., Böhlke, J.K., and Eberts, S.M., in press, TracerLPM (version 1) -An Excel ${ }^{\circledR}$ workbook for interpreting groundwater age distributions from environmental tracer data: U.S. Geological Survey Techniques and Methods Report 4-F3.

Jurgens, B.C., Burow, K.R., Dalgish, B.A., and Shelton, J.L., 2008, Hydrogeology, water chemistry, and factors affecting the transport of contaminants in the zone of contribution of a public-supply well in Modesto, eastern San Joaquin Valley, California: U.S. Geological Survey Scientific Investigations Report 2008-5156, 78 p.

Jurgens, B.C., McMahon, P.B., Chapelle, F.H., and Eberts, S.M., 2009, An Excel ${ }^{\mathbb{B}}$ workbook for identifying redox processes in ground water: U.S. Geological Survey Open-File Report 2009-1004, 8 p. Available at http://pubs.usgs.gov/ of/2009/1004/.

Kauffman, L.J., and Chapelle, F.H., 2010, Relative vulnerability of public supply wells to VOC contamination in hydrologically distinct regional aquifers: Ground Water Monitoring and Remediation, v. 30, no. 4, p. 54-63.
Kendall, Carol, and Aravena, Ramon, 2000, Nitrate isotopes in groundwater systems, in Cook, P.G., and Herczeg, A.L., eds., Environmental tracers in subsurface hydrology: Boston, Kluwer Academic Publishers, p. 261-297.

Kernodle, J.M., McAda, D.P., and Thorn, C.R., 1995, Simulation of groundwater flow in the Albuquerque Basin, central New Mexico, 1901-1994, with projections to 2020: U.S. Geological Survey Water-Resources Investigations Report 94-4251, $114 \mathrm{p}$.

Keys, W.S., 1990, Borehole geophysics applied to groundwater investigations: U.S. Geological Survey Techniques of Water-Resources Investigation book 2, chap. E2, 150 p.

Kinkel, B., 1995, Estimates of consumptive use requirements for irrigated agriculture and riparian vegetation, v. I: Bureau of Reclamation Albuquerque Area Office, Middle Rio Grande Water Assessment Supporting Document No. 6, $31 \mathrm{p}$.

Klots, C.E., and Benson, B.B., 1963, Isotope effect in the solution of oxygen and nitrogen in distilled water: Journal of Chemical Physics, v. 38, p. 890-892.

Koester, C.J., Beller, H.R., and Halden, R.U., 2000, Analysis of perchlorate in groundwater by electrospray ionization mass spectrometry/mass spectrometry: Environmental Science and Technology, v. 34, no. 9, p. 1,862-1,864.

Koterba, M.T., Wilde, F.D., and Lapham, W.W., 1995, Ground-water data-collection protocols and procedures for the National Water-Quality Assessment Program-Collection and documentation of water-quality samples and related data: U.S. Geological Survey Open-File Report 95-399, $113 \mathrm{p}$.

Kreft, A., and Zuber, A., 1978, On the physical meaning of the dispersion equation and its solution for different initial and boundary conditions: Chemical Engineering Science, v. 33, p. $1,471-1,480$.

Landin, B.K., 1999, Background investigation report, Fruit Avenue plume, Albuquerque, New Mexico, CERCLIS no. NMD986668911: New Mexico Environment Department, Groundwater Quality Bureau, Superfund Oversight Section, v. I of III, prepared for the U.S. Environmental Protection Agency, Region 6, variously paged.

Landon, M.K., Clark, B.R., McMahon, P.B., McGuire, V.L., and Turco, M.J., 2008, Hydrogeology, chemical characteristics, and transport processes in the zone of contribution of a public-supply well in York, Nebraska: U.S. Geological Survey Scientific Investigations Report 2008-5050, 149 p.

Langmuir, Donald, 1997, Aqueous environmental geochemistry: New Jersey, Prentice-Hall, Inc., 600 p. 
Logan, L.M., 1990, Geochemistry of the Albuquerque municipal area, Albuquerque, New Mexico: Socorro, New Mexico Institute of Mining and Technology, Independent study, $234 \mathrm{p}$.

Lucas, L.L., and Unterweger, M.P., 2000, Comprehensive review and critical evaluation of the half-life of tritium: Journal of Research of the National Institute of Standards and Technology, v. 105, no. 4, p. 541-549.

Maloszewski, P., and Zuber A., 1982, Determining the turnover time of groundwater systems with the aid of environmental tracers. 1. Models and their applicability: Journal of Hydrology, v. 57, p. 207-231.

Maupin, M.A., and Barber, N.L., 2005, Estimated withdrawals from principal aquifers in the United States, 2000: U.S. Geological Survey Circular 1279, 46 p. Available at http:// pubs.usgs.gov/circ/2005/1279/pdf/circ1279.pdf.

McAda, D.P., and Barroll, Peggy, 2002, Simulation of groundwater flow in the Middle Rio Grande Basin between Cochiti and San Acacia, New Mexico: U.S. Geological Survey Water-Resources Investigations Report 02-4200, 81 p.

McCurdy, D.E., Garbarino, J.R., and Mullin, A.H., 2008, Interpreting and reporting radiological water-quality data: U.S. Geological Survey Techniques and Methods, book 5, chap. B6, 33 p.

McMahon, P.B., Böhlke, J.K., and Christenson, S.C., 2004, Geochemistry, radiocarbon ages, and paleorecharge conditions along a transect in the central High Plains aquifer, southwestern Kansas, USA: Applied Geochemistry, v. 19, no. 11 , p. $1,655-1,686$.

McMahon, P.B., Böhlke, J.K., Kauffman, L.J., Kipp, K.L, Landon, M.K., Crandall, C.A, Burow, K.R., and Brown, C.J., 2008, Source and transport controls on the movement of nitrate to public supply wells in selected principal aquifers of the United States: Water Resources Research, v. 44, W04401, doi:10.1029/2007WR006252.

McMahon, P.B., and Chapelle, F.H., 2008, Redox processes and water quality of selected principal aquifer systems: Ground Water, v. 46, no. 2, p. 259-271.

McQuillan, D.M., Jasper, M.J., and Swanson, B.H., 1989, Ground-water contamination by septic-tank use-A field study in the Albuquerque South Valley-West Mesa region, Bernalillo County, New Mexico: New Mexico Environment Department Open-File Report EID/GWB-89/2, 37 p.

McQuillan, D.M., and Keller, N.S., 1988, Ground-water contamination in New Mexico-1927-1986, in Proceedings of the 32nd Annual New Mexico Water Conference, November 5-6, 1987, Albuquerque, N. Mex., New Mexico Water Resources Research Institute Report No. 229, p. 12-33.
Mengis, M., Schiff, S.L., Harris, M., English, M.C., Aravena, R., Elgood, R.J., and MacLean, A., 1999, Multiple geochemical and isotopic approaches for assessing ground water $\mathrm{NO}_{3}^{-}$elimination in a riparian zone: Ground Water, v. 37 , no. 3 , p. $448-457$.

Michel, R.L., 1989, Tritium deposition in the continental United States, 1953-83: U.S. Geological Survey WaterResources Investigations Report 89-4072, 46 p.

Microseeps, Inc., 2010, Microseeps, Inc., accessed September 2010 at http://www.fedvendor.com/brochureFile/2004\%20 Handout.PDF.

Mook, W.G., and van der Plicht, J., 1999, Reporting ${ }^{14} \mathrm{C}$ activities and concentrations: Radiocarbon, v. 41, no. 3, p. $227-239$

National Ocean Sciences Accelerator Mass Spectrometry Facility, 2010, General statement of ${ }^{14} \mathrm{C}$ procedures at the National Ocean Sciences AMS Facility, accessed September 2010 at http://www.nosams.whoi.edu/images/amsgenst.pdf.

Östlund, H.G., 1987, Tritum: GEOSECS Atlantic, Pacific, and Indian Ocean Expeditions, v. 7, p. 7-10.

Parkhurst, D.L., and Appelo, C.A.J., 1999, User's guide to PHREEQC (version 2)-A computer program for speciation, batch-reaction, one-dimensional transport, and inverse geochemical calculations: U.S. Geological Survey WaterResources Investigations Report 99-4259, 310 p.

Parkhurst, D.L., and Charlton, S.R., 2008, NetpathXL-An Excel $^{@}$ interface to the program NETPATH: U.S. Geological Survey Techniques and Methods 6-A26, 11 p.

Paschke, S.S., 2007, ed., Hydrogeologic settings and groundwater flow simulations for regional studies of the transport of anthropogenic and natural contaminants to public-supply wells - Studies begun in 2001: U.S. Geological Survey Professional Paper 1737-A, 244 p.

Paschke, S.S., Kauffman, L.J., Eberts, S.M., and Hinkle, S.R., 2007, Overview of regional studies of the transport of anthropogenic and natural contaminants to public-supply wells, in Paschke, S.S., ed., Hydrogeologic settings and ground-water flow simulations for regional studies of the transport of anthropogenic and natural contaminants to public-supply wells - Studies begun in 2001: U.S. Geological Survey Professional Paper 1737-A, p. 1-1 to 1-17.

Passell, H.D., Dahm, C.N., and Bedrick, E.J., 2004, Hydrological and geochemical trends and patterns in the upper Rio Grande, 1975 to 1999: Journal of the American Water Resources Association, v. 40, no. 1, p. 111-127.

Patton, C.J., and Kryskalla, J.R., 2003, Methods of analysis by the U.S. Geological Survey National Water Quality Laboratory_Evaluation of alkaline persulfate digestion as an alternative to Kjeldahl digestion for determination of total and dissolved nitrogen and phosphorus in water: 
U.S. Geological Survey Water-Resources Investigations Report 2003-4174, 33 p.

Pickering, R.J., 1981, Water quality-New tables of dissolved oxygen saturation values: U.S. Geological Survey, Quality of Water Branch Technical Memorandum No. 81.11, accessed January 19, 2010, at http://water.usgs.gov/admin/ memo/QW/qw81.11.html.

Plummer, L.N., Bexfield, L.M., Anderholm, S.K., Sanford, W.E., and Busenberg, Eurybiades, 2004a, Geochemical characterization of groundwater flow in the Santa Fe Group aquifer system, Middle Rio Grande Basin, New Mexico: U.S. Geological Survey Water-Resources Investigations Report 03-4131,395 p.

Plummer, L.N., Bexfield, L.M., Anderholm, S.K., Sanford, W.E., and Busenberg, Eurybiades, 2004b, Hydrochemical tracers in the Middle Rio Grande Basin, USA-1. Conceptualization of groundwater flow: Hydrogeology Journal, v. 12 , no. 4 , p. 359-388.

Plummer, L.N., Sanford, W.E., Bexfield, L.M., Anderholm, S.K., and Busenberg, Eurybiades, 2004c, Using chemical data and aquifer simulation to characterize recharge and groundwater flow in the Middle Rio Grande Basin, New Mexico, in Hogan, J.F., Phillips, F.M., and Scanlon, B.R., eds., Groundwater recharge in a desert environment-The Southwestern United States, Water Science and Applications Series, v. 9: Washington, D.C., American Geophysical Union, p. 185-216.

Plummer, N.L., and Busenberg, E., 2006, Chlorofluorocarbons in aquatic environments, in Use of chlorofluorocarbons in hydrology - A guidebook, Vienna, International Atomic Energy Agency, 277 p.

Plummer, L.N., Busenberg, Eurybiades, Eberts, S.M., Bexfield, L.M., Brown, C.J., Fahlquist, L.S., Katz, B.G., and Landon, M.K., 2008, Low-level detections of halogenated volatile organic compounds in ground water-Use in vulnerability assessments: Journal of Hydrologic Engineering, v. 13 , no. 11, p. 1,049-1,068.

Plummer, L.N., Prestemon, E.C., and Parkhurst, D.L., 1994, An interactive code (NETPATH) for modeling NET geochemical reactions along a flow PATH, version 2.0: U.S. Geological Survey Water-Resources Investigations Report 94-4169, 130 p., accessed June 7, 2010, at http://pubs. er.usgs.gov/usgspubs/wri/wri944169.

Plummer, L.N., and Sanford, W.E., in press, Case study-Middle Rio Grande Basin, New Mexico, USA, in Dating old groundwater-A guidebook: Vienna, International Atomic Energy Agency.

Plummer, L.N., Sanford, W.E., Bexfield, L.M., Anderholm, S.K., and Busenberg, Eurybiades, 2004c, Using chemical data and aquifer simulation to characterize recharge and groundwater flow in the Middle Rio Grande Basin, New Mexico, in Hogan, J.F., Phillips, F.M., and Scanlon, B.R., eds., Groundwater recharge in a desert environment-The Southwestern United States, Water Science and Applications Series, v. 9: Washington, D.C., American Geophysical Union, p. 185-216.

Rafter Radiocarbon Laboratory, 2010, Measuring radiocarbon, accessed September 2010 at http://www.rafterradiocarbon. co.nz/measure.htm.

Reimer, P.J., Baillie, M.G.L., Bard, E., Bayliss, A., Beck, J.W., Blackwell, P.G., Bronk Ramsey, C., Buck, C.E., Burr, G.S., Edwards, R.L., Friedrich, M., Grootes, P.M., Guilderson, T.P., Hajdas, I., Heaton, T.J., Hogg, A.G., Hughen, K.A., Kaiser, K.F., Kromer, B., McCormac, F.G., Manning, S.W., Reimer, R.W., Richards, D.A., Southon, J.R., Talamo, S., Turney, C.S.M., van der Plicht, J., and Weyhenmeyer, C.E., 2009, IntCal09 and Marine09 radiocarbon age calibration curves, $0-50,000$ years cal BP: Radiocarbon, v. 51 , no. 4 , p. $1,111-1,150$.

Révész, K., and Casciotti, K., 2007, Determination of the $\delta\left({ }^{15} \mathrm{~N} /{ }^{14} \mathrm{~N}\right)$ and $\delta\left({ }^{18} \mathrm{O} /{ }^{16} \mathrm{O}\right)$ of nitrate in water-RSIL lab code 2900, in Révész, K., and Coplen, T.B., eds., Methods of the Reston Stable Isotope Laboratory: U.S. Geological Survey Techniques and Methods, book 10, sec. C, chap. 17, 24 p.

Révész, K., and Coplen, T.B., 2008a, Determination of the $\delta\left({ }^{2} \mathrm{H} /{ }^{1} \mathrm{H}\right)$ of water-RSIL lab code 1574 , in Révész, K., and Coplen, T.B., eds., Methods of the Reston Stable Isotope Laboratory: U.S. Geological Survey Techniques and Methods, book 10, chap. C1, 27 p.

Révész, K., and Coplen, T.B., 2008b, Determination of the $\delta\left({ }^{18} \mathrm{O} /{ }^{16} \mathrm{O}\right)$ of water-RSIL lab code 489 , in Révész, K., and Coplen, T.B., eds., Methods of the Reston Stable Isotope Laboratory: U.S. Geological Survey Techniques and Methods, book 10, chap. C2, $28 \mathrm{p}$.

Robertson, F.N., 1991, Geochemistry of ground water in alluvial basins of Arizona and adjacent parts of Nevada, New Mexico, and California: U.S. Geological Survey Professional Paper 1406-C, 90 p.

Rozanski, K., Araguás-Araguás, L., and Gonfiantini, R., 1993, Isotopic patterns in modern global precipitation, in Smart, P.K., Lohmann, K.C., McKenzie, J., and Savin, S., eds., Climate change in continental isotopic records: Washington, D.C., American Geophysical Union, Geophysical Monograph 78, p. 1-36.

Sanford, W.E., Plummer, L.N., McAda, D.P., Bexfield, L.M., and Anderholm, S.K., 2004a, Use of environmental tracers to estimate parameters for a predevelopment ground-waterflow model of the Middle Rio Grande Basin, New Mexico: U.S. Geological Survey Water-Resources Investigations Report 03-4286. 
Sanford, W.E., Plummer, L.N., McAda, D.P., Bexfield, L.M., and Anderholm, S.K., 2004b, Hydrochemical tracers in the Middle Rio Grande Basin, USA-2. Calibration of a groundwater-flow model: Hydrogeology Journal, v. 12, no. 4 , p. $389-407$.

Schlosser, P., Stute, M., Sonntag, C., and Munnich, K.O., 1989, Tritiogenic ${ }^{3} \mathrm{He}$ in shallow groundwater: Earth and Planetary Science Letters, v. 94, p. 245-256.

Shapiro, S.D., Busenberg, E., Plummer, L.N., and Focazio, M.J., 2003, Data from archived chromatograms on halogenated volatile organic compounds in untreated ground water used for drinking water in the United States, 1997-2000: U.S. Geological Survey Open-File Report 03-352, 31 p.

Sigman, D.M., Granger, Julie, DiFiore, P.J., Lehmann, M.M., Ho, Ruby, Cane, Greg, and van Geen, Alexander, 2005 , Couple nitrogen and oxygen isotope measurements of nitrate along the eastern North Pacific margin: Global Biogeochemical Cycles, v. 19, GB4022, doi:10.1029/2005GB002458.

Solomon, D.K., and Cook, P.G., 2000, ${ }^{3} \mathrm{H}$ and ${ }^{3} \mathrm{He}$, in Cook, P.G., and Herczeg, A.L., eds., Environmental tracers in subsurface hydrology: Boston, Kluwer Academic Publishers, p. 397-424.

Stanton, M.R., Sanzolone, R.F., Sutley, S.J., Grimes, D.J., and Meier, A.M., 2001a, Mineralogical and geochemical constraints on $\mathrm{Fe}$ and As residence and mobility in the Albuquerque Basin-Examples from basin sediments and volcanic rocks, in Cole, J.C., ed., U.S. Geological Survey Middle Rio Grande Basin Study_-Proceedings of the Fourth Annual Workshop, Albuquerque, New Mexico, February 15-16, 2000: U.S. Geological Survey Open-File Report 00-488, p. 45-46.

Stanton, M.R., Sanzolone, R.F., Sutley, S.J., Grimes, D.J., Meier, A.M., and Lamothe, P.J., 2001b, Abundance, residence, and mobility of arsenic in Santa Fe Group sediments, Albuquerque Basin, New Mexico: Geological Society of America, 2001 Abstracts with Programs, Rocky Mountain and South-Central Sections, v. 33, p. A-2.

Stollenwerk, K.G., 2003, Geochemical processes controlling transport of arsenic in groundwater-A review of adsorption, chap. 3 of Welch, A.H., and Stollenwerk, K.G., eds., Arsenic in ground water-Geochemistry and occurrence: Boston, Kluwer Academic Publishers, p. 295-327.

Stuiver, M., and Pollach, H.A., 1977, Discussion-Reporting of ${ }^{14} \mathrm{C}$ data: Radiocarbon, v. 19 , no. 3, p. 353-363.

Stuiver M., and Reimer, P.J., 1993, Extended ${ }^{14} \mathrm{C}$ data base and revised CALIB $3.0{ }^{14} \mathrm{C}$ age calibration program: Radiocarbon, v. 35, no. 1, p. 215-230.

Summers, W.K., 1992, Albuquerque's water table-Winter 1988-89: New Mexico Geology, v. 14, no. 1, p. 8.
Thiros, S.A., Bexfield, L.M., Anning, D.W., and Huntington, J.M., eds., 2010, Conceptual understanding and groundwater quality of selected basin-fill aquifers in the Southwestern United States: U.S. Geological Survey Professional Paper $1781,288 \mathrm{p}$.

Thorn, C.R., McAda, D.P., and Kernodle, J.M., 1993, Geohydrologic framework and hydrologic conditions in the Albuquerque Basin, central New Mexico: U.S. Geological Survey Water-Resources Investigations Report 93-4149, $106 \mathrm{p}$.

U.S. Census Bureau, 2001, Ranking tables in metropolitan areas-Population in 2000 and population change from 1990 to 2000 (PHC-T-3), accessed October 2006 at http:// www.census.gov/population/www/cen2000/phc-t3.html.

U.S. Census Bureau, 2006, GCT-PH1. Population, housing units, area, and density - 2000 for New Mexico, accessed October 2006 at http://factfinder.census.gov/servlet/ GCTTable?_bm=y\&-context $=$ gct\&-ds_name $=$ DEC_2000 SF1_U\&-mt_name $=$ DEC_2000_SF1_U_GCTPH1_ST7\&CONTEXT $=$ gct\&-tree_id $=4001 \&$-geo_id $=04000$ US35\&format $=$ ST-7|ST-7S\&-_lang=en.

U.S. Environmental Protection Agency, 1980, Prescribed procedures for measurement of radioactivity in drinking water: U.S. Environmental Protection Agency EPA-600-4-80-032.

U.S. Environmental Protection Agency, 2001, Record of decision, Fruit Avenue Plume site, Albuquerque, New Mexico, CERCLIS no. NMD986668911: U.S. Environmental Protection Agency, Region 6, Superfund Division, variously paged.

U.S. Environmental Protection Agency, 2010a, Drinking water contaminants, accessed August 2010 at http://www.epa.gov/ safewater/contaminants/index.html.

U.S. Environmental Protection Agency, 2010b, Fruit Avenue Plume (Bernalillo County), New Mexico, EPA ID no. NMD986668911, accessed July 2010 at http://www.epa. gov/earth1r6/6sf/pdffiles/0604068.pdf.

U.S. Environmental Protection Agency, 2010c, Record of Decision System, South Valley, Abstract, accessed July 2010 at http://cfpub.epa.gov/superrods/index. $\mathrm{cfm}$ ? fuseaction $=$ data.rodinfo $\& \mathrm{id}=0600881 \& \operatorname{mrod}=0600881$ 1988ROD043.

U.S. Environmental Protection Agency, 2010d, South Valley (Bernalillo County), Albuquerque, New Mexico, EPA ID no. NMD980745558, accessed April 2010 at http://www. epa.gov/region6/6sf/pdffiles/0600881.pdf.

U.S. Geological Survey, variously dated, National field manual for the collection of water-quality data: U.S. Geological Survey Techniques of Water-Resources Investigations, 
book 9, chaps. A1-A9. Available at http://water.usgs.gov/ owq/FieldManual/.

U.S. Geological Survey, 2003, Multi-Resolution Land Characteristics Consortium, National Land Cover Database (NLCD 2001), accessed May 17, 2010 at http://www.mrlc. gov/.

U.S. Geological Survey, 2010, The Reston Chlorofluorocarbon Laboratory, analytical procedures for dissolved gas, accessed September 2010 at http://water.usgs.gov/lab/ dissolved-gas/lab/analytical_procedures/.

U.S. Geological Survey Chlorofluorocarbon Laboratory, 2009, Air curve, accessed April 2011 at http://water.usgs.gov/lab/ software/air_curve/.

U.S. Geological Survey, Water Resources, 2010, National Water Information System, USGS surface water annual statistics for New Mexico, 1974-2009: U.S. Geological Survey database, accessed October 28, 2010, at http://waterdata.usgs.gov/nm/nwis/annual/?referred module $=$ sw\&site_no $=08330000 \&$ por_08330000_3 $=55890$ $3,00060,3,1942,2009 \&$ start_dt $=1974 \&$ end_dt $=2009 \& y e a r$ type $=$ W\& format $=$ html_table\&date_format $=$ YYYY-MMDD\&rdb_compression=file\&submitted_form=parameter selection_list.

Vogel, T.M., and McCarty, P.L., 1985, Biotransformation of tetrachloroethylene to trichloroethylene, dichloroethylene, vinyl chloride, and carbon dioxide under methanogenic conditions: Applied Environmental Microbiology, v. 49, no. 5, p. $1,080-1,083$.

Wagner, R.J., Boulger, R.W., Jr., Oblinger, C.J., and Smith, B.A., 2006, Guidelines and standard procedures for continuous water-quality monitors-Station operation, record computation, and data reporting: U.S. Geological Survey Techniques and Methods 1-D3, $96 \mathrm{p}$.

Wershaw, R.L., Fishman, M.J., Grabbe, R.R., and Lowe, L.E., eds., 1987, Methods for the determination of organic substances in water and fluvial sediments: U.S. Geological Survey Techniques of Water-Resources Investigations, book 5, chap. A3, 80 p.

Western Regional Climate Center, 2010a, Period of record general climate summary-Precipitation, Albuquerque WSFO Airport, New Mexico, accessed November 2010 at http://www.wrcc.dri.edu/cgi-bin/cliMAIN.pl?nm0234.

Western Regional Climate Center, 2010b, Period of record general climate summary-Temperature, Albuquerque WSFO Airport, New Mexico, accessed November 2010 at http://www.wrcc.dri.edu/cgi-bin/cliMAIN.pl?nm0234.

Wilson, B.C., Lucero, A.A., Romero, J.T., and Romero, P.J., 2003, Water use by categories in New Mexico counties and river basins, and irrigated acreage in 2000: New Mexico State Engineer Office Technical Report 51, 164 p.

Wright, M.T., and Belitz, Kenneth, 2010, Factors controlling the regional distribution of vanadium in groundwater: Ground Water, v. 48, p. 515-525, doi: 10.1111/j.1745-6584.2009.00666.x.

Yapp, C.J., 1985, D/H variations of meteoric waters in Albuquerque, New Mexico, U.S.A.: Journal of Hydrology, v. 76, p. $63-84$.

Zogorski, J.S., Carter, J.M., Ivahnenko, T., Lapham, W.W., Moran, M.J., Rowe, B.L., Squillace, P.J., and Toccalino, P.L., 2006, Volatile organic compounds in the Nation's ground water and drinking-water supply wells: U.S. Geological Survey Circular 1292, 101 p. 
Table 1. Well completion information, sampling dates, and the suites of analytes sampled for wells installed and (or) sampled for the local-scale transport of anthropogenic and natural contaminants (TANC) study near Albuquerque, New Mexico, 2007-9.

[Approximate well locations are shown on figure 1. Altitude is referenced to the North American Vertical Datum of 1988. All depths are in meters below land surface unless otherwise specified. Shallow (water table), well grouped into the shallow category that is screened across the water table; SSW, studied supply well; stainless, stainless steel; PVC, polyvinyl chloride; nd, no data; USGS, U.S. Geological Survey; NMED, New Mexico Environment Department; PSSMM, Proactive SS Mega-Monsoon]

\begin{tabular}{lccccccc}
\hline $\begin{array}{c}\text { Well } \\
\text { name }\end{array}$ & $\begin{array}{c}\text { Well } \\
\text { category }\end{array}$ & $\begin{array}{c}\text { Altitude of } \\
\text { land surface } \\
\text { (meters) }\end{array}$ & Well depth & $\begin{array}{c}\text { Depth to top } \\
\text { of screen }\end{array}$ & $\begin{array}{c}\text { Depth to } \\
\text { bottom of } \\
\text { screen }\end{array}$ & $\begin{array}{c}\text { Screen } \\
\text { length } \\
\text { (meters) }\end{array}$ & $\begin{array}{c}\text { Screen } \\
\text { material }\end{array}$ \\
\hline SSW & Supply & 1,565 & 363 & 107 & 359 & 252
\end{tabular}

\begin{tabular}{|c|c|c|c|c|c|c|c|}
\hline PSW1 & Supply & 1,572 & 293 & 102 & 293 & 190 & steel \\
\hline PSW3 & Supply & 1,551 & 306 & 97.5 & 302 & 205 & steel \\
\hline FP1D & Deep & 1,565 & 359 & 344 & 356 & 12.2 & stainless \\
\hline FP1MD & Deep & 1,565 & 275 & 254 & 272 & 18.3 & stainless \\
\hline FP1MS & Intermediate & 1,565 & 158 & 137 & 155 & 18.3 & stainless \\
\hline FP1S & Shallow (water table) & 1,565 & 103 & 69.8 & 100 & 30.5 & stainless \\
\hline FP2D & Intermediate & 1,555 & 139 & 123 & 136 & 12.2 & stainless \\
\hline FP2M & Intermediate & 1,555 & 110 & 95.1 & 107 & 12.2 & stainless \\
\hline FP2S & Shallow (water table) & 1,555 & 82.3 & 64.0 & 79.2 & 15.2 & stainless \\
\hline FP3D & Intermediate & 1,566 & 151 & 136 & 148 & 12.2 & stainless \\
\hline FP3M & Intermediate & 1,566 & 117 & 102 & 114 & 12.2 & stainless \\
\hline FP3S & Shallow (water table) & 1,566 & 88.4 & 70.1 & 85.3 & 15.2 & stainless \\
\hline FP4D & Intermediate & 1,565 & 141 & 123 & 138 & 15.2 & stainless \\
\hline FP4M & Intermediate & 1,565 & 116 & 104 & 113 & 9.1 & stainless \\
\hline FP4S & Shallow (water table) & 1,565 & 93.0 & 74.7 & 89.9 & 15.2 & stainless \\
\hline MW2 & Shallow (water table) & 1,570 & 96.3 & 81.1 & 93.3 & 12.2 & nd \\
\hline MW7 & Intermediate & 1,573 & 172 & 166 & 172 & 6.1 & nd \\
\hline MW8 & Intermediate & 1,573 & 128 & 122 & 128 & 6.1 & nd \\
\hline MW9 & Shallow (water table) & 1,575 & 101 & 88.4 & 101 & 12.2 & nd \\
\hline SFMW-46 & Intermediate & 1,532 & 86.6 & 80.5 & 86.6 & 6.1 & nd \\
\hline MNW4-D1 & Intermediate & 1,544 & 112 & 103 & 109 & 6.1 & nd \\
\hline P83-19U & Shallow & 1,545 & 77.7 & 70.1 & 76.2 & 6.1 & nd \\
\hline P83-19M & Intermediate & 1,545 & 99.1 & 91.4 & 97.5 & 6.1 & nd \\
\hline P83-19LR & Intermediate & 1,545 & 134 & 126 & 133 & 6.1 & nd \\
\hline
\end{tabular}


Table 1. Well completion information, sampling dates, and the suites of analytes sampled for wells installed and (or) sampled for the local-scale transport of anthropogenic and natural contaminants (TANC) study near Albuquerque, New Mexico, 2007-9.-Continued

[Approximate well locations are shown on figure 1. Altitude is referenced to the North American Vertical Datum of 1988. All depths are in meters below land surface unless otherwise specified. Shallow (water table), well grouped into the shallow category that is screened across the water table; SSW, studied supply well; stainless, stainless steel; PVC, polyvinyl chloride; nd, no data; USGS, U.S. Geological Survey; NMED, New Mexico Environment Department; PSSMM, Proactive SS Mega-Monsoon]

\begin{tabular}{|c|c|c|c|c|c|c|c|}
\hline $\begin{array}{l}\text { Well } \\
\text { name }\end{array}$ & $\begin{array}{l}\text { Casing } \\
\text { mate- } \\
\text { rial }\end{array}$ & $\begin{array}{l}\text { Depth } \\
\text { to } \\
\text { water }\end{array}$ & $\begin{array}{l}\text { Water- } \\
\text { level } \\
\text { date }\end{array}$ & $\begin{array}{c}\text { Depth of midpoint } \\
\text { of saturated screen } \\
\text { below water level } \\
\text { (meters) }\end{array}$ & Sample date & Sample pump & $\begin{array}{c}\text { Suite of analytes } \\
\text { sampled } \\
\text { (number from } \\
\text { table 2) }\end{array}$ \\
\hline \multirow[t]{4}{*}{ SSW } & steel & 75.8 & $3 / 23 / 2007$ & 157 & June 2007 & Dedicated turbine & 1 \\
\hline & & & & & December $2007^{1}$ & $\begin{array}{l}\text { USGS Bennett } 2 \text { and (or) } \\
\text { temporary submersible }\end{array}$ & 1 \\
\hline & & & & & November 2008 & Dedicated turbine & 2 \\
\hline & & & & & May 2009 & Dedicated turbine & 4 \\
\hline PSW1 & steel & 85.1 & $2 / 26 / 2001$ & 112 & November 2008 & Dedicated turbine & 1 \\
\hline PSW3 & steel & 59.0 & $11 / 3 / 2008$ & 141 & November 2008 & Dedicated turbine & 1 \\
\hline FP1MS & & & & & November 2008 & USGS Bennett 2 & 2 \\
\hline FP1S & PVC & 78.5 & $5 / 25 / 2007$ & 10.9 & June 2007 & USGS Bennett 1 & 1 \\
\hline FP2D & PVC & 66.0 & $5 / 25 / 2007$ & 63.5 & June 2007 & USGS Bennett 1 & 1 \\
\hline FP2M & PVC & 65.8 & $5 / 25 / 2007$ & 35.4 & June 2007 & USGS Bennett 1 & 1 \\
\hline FP2S & PVC & 66.5 & $5 / 25 / 2007$ & 6.4 & June 2007 & USGS Bennett 1 & 1 \\
\hline \multirow[t]{2}{*}{ FP3D } & PVC & 78.7 & $5 / 23 / 2007$ & 63.3 & June 2007 & USGS Bennett 1 & 1 \\
\hline & & & & & November 2008 & USGS Bennett 2 & 2 \\
\hline FP3M & PVC & 80.0 & $5 / 25 / 2007$ & 28.2 & June 2007 & USGS Bennett 1 & 1 \\
\hline MW2 & steel & 87.6 & $12 / 19 / 07$ & 2.8 & December 2007 & NMED Bennett & 1 \\
\hline MW7 & PVC & 89.6 & $12 / 18 / 07$ & 79.5 & December 2007 & NMED Bennett & 1 \\
\hline MW8 & PVC & 90.5 & $12 / 18 / 07$ & 34.5 & December 2007 & NMED Bennett & 1 \\
\hline MW9 & PVC & 90.8 & $01 / 21 / 08$ & 4.9 & January 2008 & USGS Bennett 2 & 1 \\
\hline SFMW-46 & PVC & 40.1 & $02 / 18 / 07$ & 43.4 & January 2008 & USGS Grundfos & 1 \\
\hline MNW4-D1 & PVC & 50.9 & $02 / 20 / 08$ & 54.9 & February 2008 & NMED PSSMM & 1 \\
\hline P83-19U & nd & 54.9 & $1 / 29 / 2008$ & 18.3 & January 2008 & USGS Grundfos & 1 \\
\hline P83-19M & nd & 54.3 & $1 / 31 / 2008$ & 40.2 & January 2008 & USGS Grundfos & 1 \\
\hline P83-19LR & nd & 54.4 & $1 / 30 / 2008$ & 75.2 & January 2008 & USGS Grundfos & 1 \\
\hline
\end{tabular}

${ }^{1}$ Depth-dependent sampling event (the supply well was pumped with a temporary submersible pump rather than the dedicated turbine pump typically present in the well). 
Table 2. Methods of analysis for water samples and suites of analytes sampled from wells for the local-scale transport of anthropogenic and natural contaminants (TANC) study near Albuquerque, New Mexico, 2007-9.

[For analyte groups for which more than one analyzing laboratory and analytical code are listed, the laboratory changed during the course of the local-scale TANC study. DO, dissolved oxygen; SC, specific conductance; USGS, U.S. Geological Survey; Sch, analytical schedule number; LC, laboratory code; na, not applicable. USGS laboratories: NWQL, National Water Quality Laboratory, Denver, Colorado; RSIL, Reston Stable Isotope Laboratory, Reston, Virginia; Böhlke, J.K. Böhlke, Reston, Virginia; CFC, Chlorofluorocarbon Laboratory, Reston, Virginia. Additional laboratories: Waterloo, University of Waterloo, Environmental Isotope Laboratory, Waterloo, Ontario, Canada; Rafter, Rafter Radiocarbon Laboratory, Lower Hutt, New Zealand; GNS, GNS Stable Isotope Laboratory, Lower Hutt, New Zealand; NOSAMS, National Ocean Sciences Accelerator Mass Spectrometry Facility, Woods Hole Oceanographic Institution, Woods Hole, Massachusetts; Miami, University of Miami, Tritium Laboratory, Miami, Florida; Eberline, Eberline Services, Richmond, California; Lamont-Doherty, Lamont-Doherty Earth Observatory of Columbia University, Noble Gas Laboratory, Palisades, New York; TXTech, Texas Tech University, Department of Civil Engineering, Lubbock, Texas; Microseeps, Microseeps, Inc., Pittsburgh, Pennsylvania]

\begin{tabular}{|c|c|c|c|c|c|c|}
\hline \multirow{2}{*}{$\begin{array}{l}\text { Analyte } \\
\text { group }\end{array}$} & \multirow{2}{*}{$\begin{array}{c}\text { Filtered (dissolved } \\
\text { concentration) or unfiltered } \\
\text { (whole-water concentration) }\end{array}$} & \multirow{2}{*}{$\begin{array}{l}\text { Analytical } \\
\text { code }\end{array}$} & \multicolumn{4}{|c|}{ Suite of analytes sampled } \\
\hline & & & 1 & 2 & 3 & 4 \\
\hline $\begin{array}{l}\text { Water-quality field measurements (temperature, } \\
\text { SC, pH, DO, alkalinity, hydrogen sulfide }{ }^{1} \text { ) }\end{array}$ & Unfiltered except for alkalinity & na & $\mathrm{X}$ & $\mathrm{X}$ & $\mathrm{X}$ & $\mathrm{X}$ \\
\hline Major elements & Filtered & Sch 2750 & $\mathrm{X}$ & $\mathrm{X}$ & $\mathrm{X}$ & $\mathrm{X}$ \\
\hline Trace elements & Filtered & Sch 2710 & $\mathrm{X}$ & $\mathrm{X}$ & $\mathrm{X}$ & $\mathrm{X}$ \\
\hline Low-level perchlorate & Filtered & na & $\mathrm{X}$ & & & \\
\hline Iodide & Filtered & LC 1202 & $\mathrm{X}$ & & & \\
\hline Nutrients & Filtered & Sch 2755 & $\mathrm{X}$ & & & \\
\hline Ultraviolet absorbance & Filtered & LC 2614,2615 & $\mathrm{X}$ & & & \\
\hline Radium isotopes & Filtered & Sch 1262 & $\mathrm{X}$ & & & \\
\hline Oxygen and hydrogen isotopes of water & Unfiltered & Sch 1142 & $\mathrm{X}$ & & & \\
\hline Nitrogen and oxygen isotopes of nitrate & Filtered & na & $\mathrm{X}$ & & & \\
\hline Nitrogen isotopes of nitrogen gas & Unfiltered & na & $\mathrm{X}$ & & & \\
\hline \multirow[t]{3}{*}{ Carbon isotopes } & Filtered & Sch 1000 & $\mathrm{X}$ & $\mathrm{X}$ & & $\mathrm{X}$ \\
\hline & & Sch 1054 & & & & \\
\hline & & Sch 2255 & & & & \\
\hline \multirow[t]{3}{*}{ Carbon-14 } & Filtered & Sch 1000 & $\mathrm{X}$ & $\mathrm{X}$ & & $\mathrm{X}$ \\
\hline & & Sch 1054 & & & & \\
\hline & & Sch 2255 & & & & \\
\hline Low-level volatile organic compounds & Unfiltered & na & $\mathrm{X}$ & $\mathrm{X}$ & & $\mathrm{X}$ \\
\hline Hydrogen gas ${ }^{1}$ & Unfiltered & na & $\mathrm{X}$ & $\mathrm{X}$ & & \\
\hline
\end{tabular}


Table 2. Methods of analysis for water samples and suites of analytes sampled from wells for the local-scale transport of anthropogenic and natural contaminants (TANC) study near Albuquerque, New Mexico, 2007-9.-Continued

[For analyte groups for which more than one analyzing laboratory and analytical code are listed, the laboratory changed during the course of the local-scale TANC study. DO, dissolved oxygen; SC, specific conductance; USGS, U.S. Geological Survey; Sch, analytical schedule number; LC, laboratory code; na, not applicable. USGS laboratories: NWQL, National Water Quality Laboratory, Denver, Colorado; RSIL, Reston Stable Isotope Laboratory, Reston, Virginia; Böhlke, J.K. Böhlke, Reston, Virginia; CFC, Chlorofluorocarbon Laboratory, Reston, Virginia. Additional laboratories: Waterloo, University of Waterloo, Environmental Isotope Laboratory, Waterloo, Ontario, Canada; Rafter, Rafter Radiocarbon Laboratory, Lower Hutt, New Zealand; GNS, GNS Stable Isotope Laboratory, Lower Hutt, New Zealand; NOSAMS, National Ocean Sciences Accelerator Mass Spectrometry Facility, Woods Hole Oceanographic Institution, Woods Hole, Massachusetts; Miami, University of Miami, Tritium Laboratory, Miami, Florida; Eberline, Eberline Services, Richmond, California; Lamont-Doherty, Lamont-Doherty Earth Observatory of Columbia University, Noble Gas Laboratory, Palisades, New York; TXTech, Texas Tech University, Department of Civil Engineering, Lubbock, Texas; Microseeps, Microseeps, Inc., Pittsburgh, Pennsylvania]

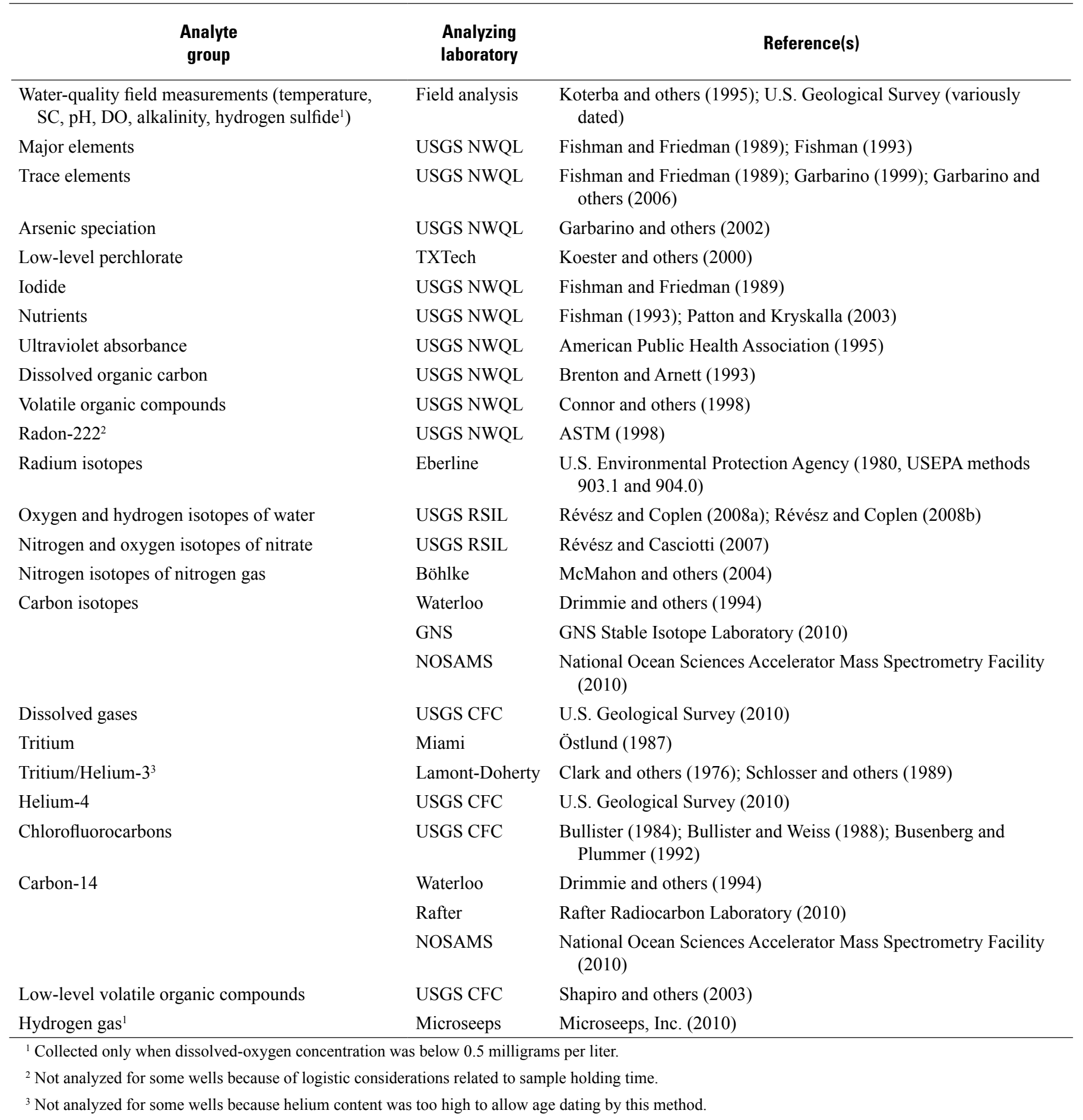


Table 3. Values of selected field measurements, inorganic constituents, and isotopes for groundwater samples collected for the localscale transport of anthropogenic and natural contaminants (TANC) study in Albuquerque, New Mexico, $2007-9$.

[Stable isotope ratios are reported in the standard delta notation $(\delta)$, the ratio of a heavier isotope to the more common lighter isotope of that element, relative to a standard reference material. USGS, U.S. Geological Survey; $\mathrm{mg} / \mathrm{L}$, milligrams per liter; E, estimated value; std, standard; $\mu \mathrm{S} / \mathrm{cm}$, microsiemens per centimeter; na, not applicable; nc, not collected; - , not detected; $\mathrm{CaCO}_{3}$, calcium carbonate; $\mathrm{N}$, nitrogen; ${ }^{\circ} \mathrm{C}$, degrees Celsius; $\delta \mathrm{D}$, delta deuterium stable isotopic ratio; $\delta^{18} \mathrm{O}$, delta oxygen-18 stable isotopic ratio; $\mathrm{pCO} 2(\mathrm{~g})$, partial pressure of carbon dioxide gas; SSW, studied public-supply well; DD, depth-dependent sample, depth of collection in meters below land surface; $\mathrm{WH}$, wellhead]

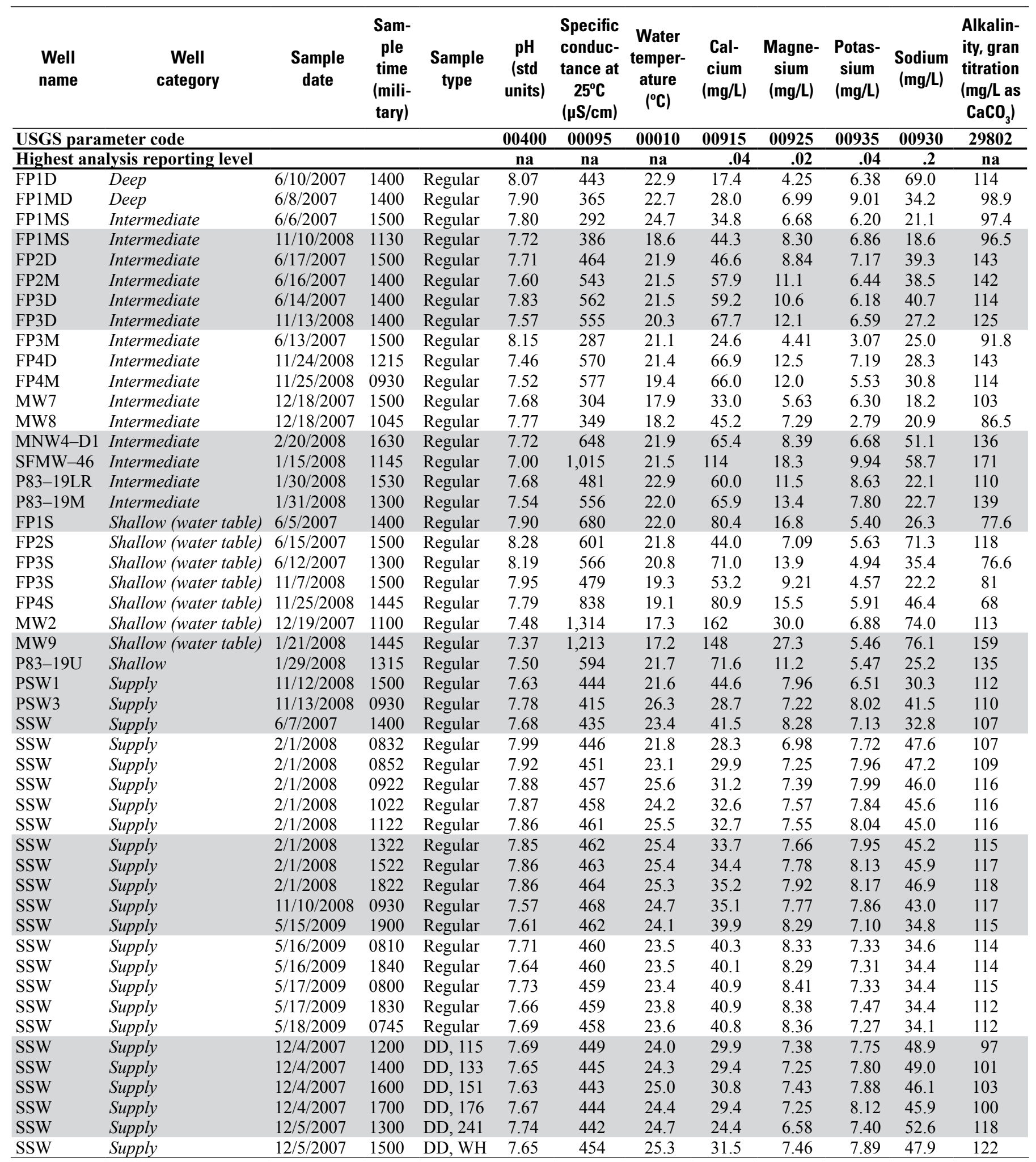


Table 3. Values of selected field measurements, inorganic constituents, and isotopes for groundwater samples collected for the localscale transport of anthropogenic and natural contaminants (TANC) study in Albuquerque, New Mexico, 2007-9.-Continued

[Stable isotope ratios are reported in the standard delta notation $(\delta)$, the ratio of a heavier isotope to the more common lighter isotope of that element, relative to a standard reference material. USGS, U.S. Geological Survey; mg/L, milligrams per liter; E, estimated value; std, standard; $\mu \mathrm{S} / \mathrm{cm}$, microsiemens per centimeter; na, not applicable; nc, not collected; - , not detected; $\mathrm{CaCO}_{3}$, calcium carbonate; $\mathrm{N}$, nitrogen; ${ }^{\circ} \mathrm{C}$, degrees Celsius; $\delta \mathrm{D}$, delta deuterium stable isotopic ratio; $\delta^{18} \mathrm{O}$, delta oxygen-18 stable isotopic ratio; $\mathrm{pCO}_{2}(\mathrm{~g})$, partial pressure of carbon dioxide gas; SSW, studied public-supply well; DD, depth-dependent sample, depth of collection in meters below land surface; $\mathrm{WH}$, wellhead]

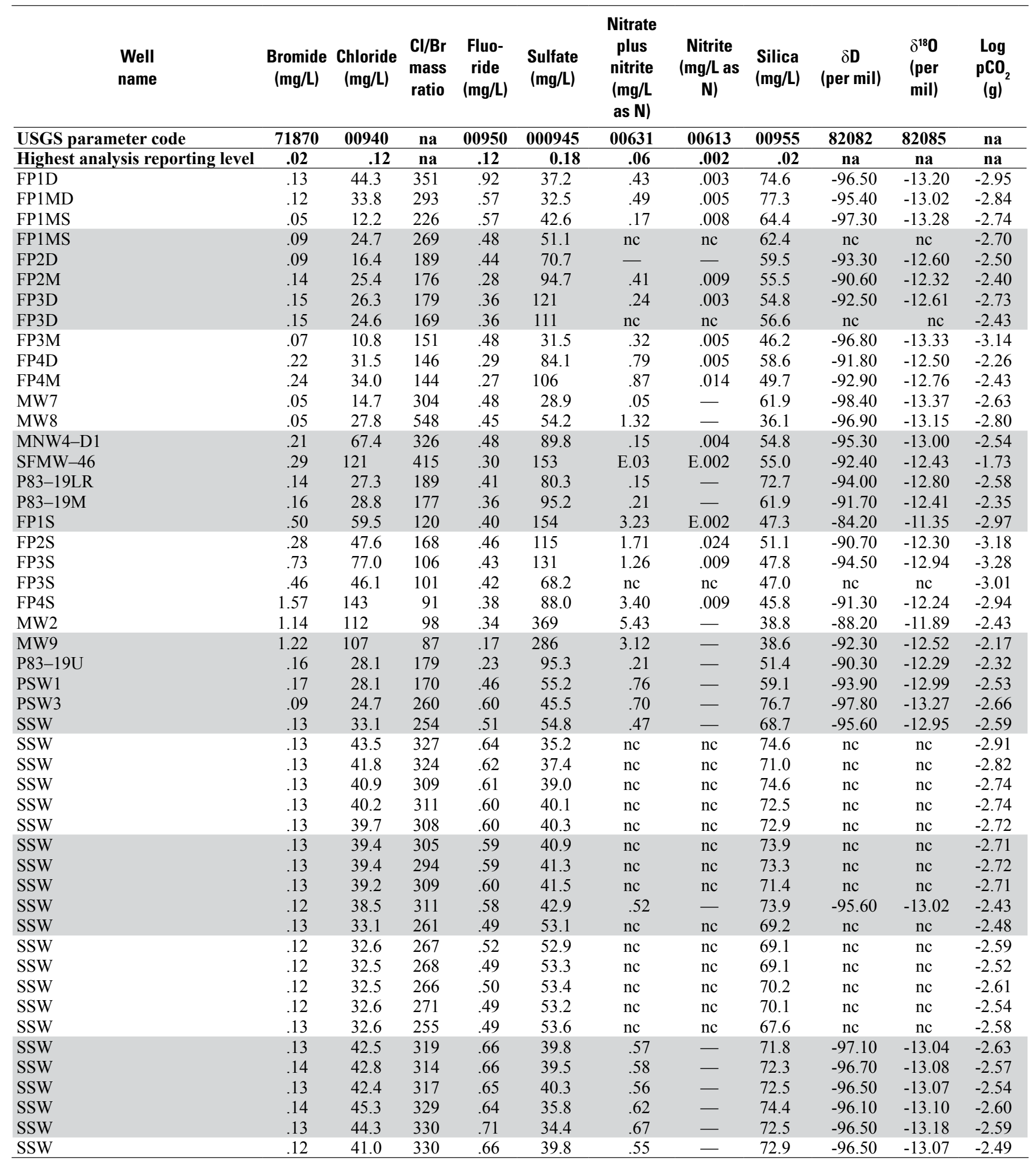


Table 4. Framework for classifying groundwater samples with respect to reduction/oxidation (redox) conditions (modified from McMahon and Chapelle, 2008).

$\left[\mathrm{O}_{2}\right.$, oxygen; $\mathrm{NO}_{3}^{-}$, nitrate; $\mathrm{N}$, nitrogen; Mn, manganese; $\mathrm{Fe}$, iron; $\mathrm{SO}_{4}{ }^{2-}$, sulfate; $\mathrm{mg} / \mathrm{L}$, milligrams per liter; $\geq$, greater than or equal to; $<$, less than; - , not applicable]

\begin{tabular}{|c|c|c|c|c|c|c|}
\hline \multirow[t]{2}{*}{ Redox process } & \multicolumn{5}{|c|}{$\begin{array}{l}\text { Water-quality criteria } \\
\text { (mg/L) }\end{array}$} & \multirow[t]{2}{*}{ Comments } \\
\hline & $\mathbf{O}_{2}$ & $\mathrm{NO}_{3}^{-}$as $\mathrm{N}$ & $\mathbf{M n}^{2+}$ & $\mathrm{Fe}^{2+}$ & $\mathrm{SO}_{4}^{2-}$ & \\
\hline \multicolumn{7}{|l|}{ Oxic } \\
\hline $\mathrm{O}_{2}$ reduction & $\geq 0.5$ & - & $<0.05$ & $<0.1$ & - & - \\
\hline \multicolumn{7}{|l|}{ Suboxic } \\
\hline - & $<.5$ & $<0.5$ & $<.05$ & $<.1$ & - & $\begin{array}{l}\text { Further definition of } \\
\text { redox processes is } \\
\text { not possible }\end{array}$ \\
\hline \multicolumn{7}{|l|}{ Anoxic } \\
\hline $\mathrm{NO}_{3}^{-}$reduction & $<.5$ & $\geq .5$ & $<.05$ & $<.1$ & - & - \\
\hline $\mathrm{Mn}(\mathrm{IV})$ reduction & $<.5$ & $<.5$ & $\geq .05$ & $<.1$ & - & - \\
\hline $\mathrm{Fe}(\mathrm{III}) / \mathrm{SO}_{4}^{2-}$ reduction & $<.5$ & $<.5$ & - & $\geq .1$ & $\geq 0.5$ & - \\
\hline Methanogenesis & $<.5$ & $<.5$ & - & $\geq .1$ & $<.5$ & - \\
\hline \multicolumn{7}{|l|}{ Mixed } \\
\hline - & - & - & - & - & - & $\begin{array}{l}\text { Criteria for more than } \\
\text { one redox process } \\
\text { are met }\end{array}$ \\
\hline
\end{tabular}


Table 5. Values of selected field measurements and concentrations of constituents used to classify reduction/oxidation (redox) conditions in groundwater samples collected for the local-scale transport of anthropogenic and natural contaminants (TANC) study in Albuquerque, New Mexico, 2007-9.

[USGS, U.S. Geological Survey; mg/L, milligrams per liter; E, estimated value; V, censored value possibly affected by contamination during sample collection; $\mathrm{M}$, present but not quantified; $\mu \mathrm{g} / \mathrm{L}$, micrograms per liter; na, not applicable; nc, not collected; - , not detected; N, nitrogen; redox classification, reduction/oxidation classification according to the framework shown in table 6; SSW, studied public-supply well; DD, depth-dependent sample, depth of collection in meters below land surface; $\mathrm{WH}$, wellhead; $\mathrm{O}_{2}$ reduction, oxygen reduction; $\mathrm{NO}_{3}^{-}$, nitrate; $\mathrm{Mn}$ reduction, manganese(IV) reduction; $\mathrm{CH}_{4}$ gen, methane generation]

\begin{tabular}{|c|c|c|c|c|c|c|c|c|}
\hline $\begin{array}{l}\text { Well } \\
\text { name }\end{array}$ & $\begin{array}{c}\text { Well } \\
\text { category }\end{array}$ & $\begin{array}{c}\text { Sample } \\
\text { date }\end{array}$ & $\begin{array}{c}\text { Sample } \\
\text { time } \\
\text { (military) }\end{array}$ & $\begin{array}{c}\text { Sample } \\
\text { type }\end{array}$ & $\begin{array}{c}\text { Dissolved } \\
\text { oxygen } \\
\text { (mg/L) }\end{array}$ & $\begin{array}{c}\text { Nitrate plus } \\
\text { nitrite } \\
\text { (mg/L as N) }\end{array}$ & $\begin{array}{c}\text { Manga-nese } \\
(\mu \mathrm{g} / \mathrm{L})\end{array}$ & $\begin{array}{c}\text { Iron } \\
\text { ( } \mu \mathrm{g} / \mathrm{L})\end{array}$ \\
\hline \multicolumn{5}{|c|}{ USGS Parameter Code } & 00300 & 00631 & 01056 & 01046 \\
\hline FP1D & Deep & $6 / 10 / 2007$ & 1400 & Regular & .66 & .43 & 6.9 & - \\
\hline FP1MD & Deep & $6 / 8 / 2007$ & 1400 & Regular & .80 & .49 & 12.3 & - \\
\hline FP1MS & Intermediate & $6 / 6 / 2007$ & 1500 & Regular & .44 & .17 & 36.0 & E4 \\
\hline FP2M & Intermediate & $6 / 16 / 2007$ & 1400 & Regular & .14 & .41 & 55.5 & 14 \\
\hline FP3D & Intermediate & $6 / 14 / 2007$ & 1400 & Regular & .26 & .24 & 17.5 & E3 \\
\hline FP3D & Intermediate & $11 / 13 / 2008$ & 1400 & Regular & .65 & $\mathrm{nc}$ & 41.5 & 7 \\
\hline FP3M & Intermediate & $6 / 13 / 2007$ & 1500 & Regular & .50 & .32 & 4.6 & - \\
\hline FP4D & Intermediate & $11 / 24 / 2008$ & 1215 & Regular & .60 & .79 & 32.9 & - \\
\hline SFMW-46 & Intermediate & $1 / 15 / 2008$ & 1145 & Regular & .72 & E.03 & 9.1 & E6 \\
\hline P83-19LR & Intermediate & $1 / 30 / 2008$ & 1530 & Regular & 1.77 & .15 & V.4 & - \\
\hline P83-19M & Intermediate & $1 / 31 / 2008$ & 1300 & Regular & 4.56 & .21 & - & - \\
\hline FP1S & Shallow (water table) & $6 / 5 / 2007$ & 1400 & Regular & 8.21 & 3.23 & 2.1 & - \\
\hline FP2S & Shallow (water table) & $6 / 15 / 2007$ & 1500 & Regular & 6.48 & 1.71 & 165 & - \\
\hline FP3S & Shallow (water table) & $6 / 12 / 2007$ & 1300 & Regular & 4.65 & 1.26 & 38.9 & - \\
\hline FP3S & Shallow (water table) & $11 / 7 / 2008$ & 1500 & Regular & 3.11 & $\mathrm{nc}$ & 3.2 & E3 \\
\hline FP4S & Shallow (water table) & $11 / 25 / 2008$ & 1445 & Regular & 6.03 & 3.40 & 34.4 & E4 \\
\hline MW2 & Shallow (water table) & $12 / 19 / 2007$ & 1100 & Regular & 6.68 & 5.43 & V.6 & E5 \\
\hline MW9 & Shallow (water table) & $1 / 21 / 2008$ & 1445 & Regular & 6.41 & 3.12 & V.4 & - \\
\hline P83-19U & Shallow & $1 / 29 / 2008$ & 1315 & Regular & 4.84 & .21 & V.3 & - \\
\hline PSW1 & Supply & $11 / 12 / 2008$ & 1500 & Regular & .73 & .76 & - & - \\
\hline SSW & Supply & $2 / 1 / 2008$ & 1522 & Regular & .75 & nc & V.4 & 9 \\
\hline SSW & Supply & $2 / 1 / 2008$ & 1822 & Regular & .72 & $\mathrm{nc}$ & V.3 & 9 \\
\hline SSW & Supply & $11 / 10 / 2008$ & 0930 & Regular & .75 & .52 & V.2 & - \\
\hline SSW & Supply & $5 / 15 / 2009$ & 1900 & Regular & 1.01 & $\mathrm{nc}$ & - & - \\
\hline SSW & Supply & $5 / 16 / 2009$ & 0810 & Regular & .80 & $\mathrm{nc}$ & - & - \\
\hline SSW & Supply & $5 / 16 / 2009$ & 1840 & Regular & .49 & $\mathrm{nc}$ & - & - \\
\hline SSW & Supply & $5 / 17 / 2009$ & 0800 & Regular & .52 & $\mathrm{nc}$ & - & - \\
\hline SSW & Supply & $5 / 17 / 2009$ & 1830 & Regular & .62 & $\mathrm{nc}$ & - & - \\
\hline SSW & Supply & $5 / 18 / 2009$ & 0745 & Regular & .51 & $\mathrm{nc}$ & - & - \\
\hline SSW & Supply & $12 / 4 / 2007$ & 1200 & $\mathrm{DD}, 115$ & $\mathrm{nc}$ & .57 & V.4 & - \\
\hline SSW & Supply & $12 / 4 / 2007$ & 1400 & $\mathrm{DD}, 133$ & $\mathrm{nc}$ & .58 & VE. 2 & - \\
\hline SSW & Supply & $12 / 4 / 2007$ & 1600 & $\mathrm{DD}, 151$ & nc & .56 & VE. 2 & - \\
\hline SSW & Supply & $12 / 4 / 2007$ & 1700 & $\mathrm{DD}, 176$ & 1.08 & .62 & VE. 2 & - \\
\hline SSW & Supply & $12 / 5 / 2007$ & 1300 & $\mathrm{DD}, 241$ & .94 & .67 & VE. 2 & - \\
\hline SSW & Supply & $12 / 5 / 2007$ & 1500 & $\mathrm{DD}, \mathrm{WH}$ & .74 & .55 & V.4 & 18 \\
\hline
\end{tabular}


Table 5. Values of selected field measurements and concentrations of constituents used to classify reduction/oxidation (redox) conditions in groundwater samples collected for the local-scale transport of anthropogenic and natural contaminants (TANC) study in Albuquerque, New Mexico, 2007-9.-Continued

[USGS, U.S. Geological Survey; mg/L, milligrams per liter; E, estimated value; V, censored value possibly affected by contamination during sample collection; $\mathrm{M}$, present but not quantified; $\mu \mathrm{g} / \mathrm{L}$, micrograms per liter; na, not applicable; nc, not collected; - , not detected; N, nitrogen; redox classification, reduction/oxidation classification according to the framework shown in table 6; SSW, studied public-supply well; DD, depth-dependent sample, depth of collection in meters below land surface; $\mathrm{WH}$, wellhead; $\mathrm{O}_{2}$ reduction, oxygen reduction; $\mathrm{NO}_{3}^{-}$, nitrate; $\mathrm{Mn}$ reduction, manganese(IV) reduction; $\mathrm{CH}_{4}$ gen, methane generation]

\begin{tabular}{|c|c|c|c|c|c|c|}
\hline $\begin{array}{c}\text { Well } \\
\text { name }\end{array}$ & $\begin{array}{c}\text { Sulfate } \\
\text { (mg/L) }\end{array}$ & $\begin{array}{l}\text { Hydrogen } \\
\text { sulfide, pres- } \\
\text { ence of odor }\end{array}$ & $\begin{array}{c}\text { Sulfide, } \\
\text { field } \\
\text { (mg/L) }\end{array}$ & $\begin{array}{c}\text { Methane } \\
\text { gas } \\
\text { (mg/L) }\end{array}$ & $\begin{array}{c}\text { Redox } \\
\text { classifi- } \\
\text { cation }\end{array}$ & Redox classification notes \\
\hline USGS Parameter Code & 000945 & 71875 & 99119 & 76994 & & \\
\hline FP1D & 37.2 & - & .002 & - & Oxic & $\mathrm{O}_{2}$ reduction \\
\hline FP1MD & 32.5 & - & $\mathrm{nc}$ & - & Oxic & $\mathrm{O}_{2}^{2}$ reduction \\
\hline FP1MS & 42.6 & - & $\mathrm{nc}$ & - & Suboxic & \\
\hline FP2M & 94.7 & - & .006 & - & Anoxic & Mn reduction \\
\hline FP3D & 121 & - & .001 & .0011 & Mixed & Suboxic; $\mathrm{CH}_{4}$ gen \\
\hline FP3D & 111 & M & $\mathrm{nc}$ & .1815 & Mixed & $\mathrm{O}_{2}>0.5 \mathrm{mg} / \mathrm{L} ; \mathrm{CH}_{4}$ gen \\
\hline FP3M & 31.5 & - & $\mathrm{nc}$ & - & Oxic & $\mathrm{O}_{2}$ reduction \\
\hline FP4D & 84.1 & - & $\mathrm{nc}$ & - & Oxic & $\mathrm{O}_{2}^{2}$ reduction \\
\hline SFMW-46 & 153 & - & - & .0240 & Mixed & $\mathrm{O}_{2}$ reduction; $\mathrm{CH}_{4}$ gen \\
\hline P83-19LR & 80.3 & - & $\mathrm{nc}$ & - & Oxic & $\mathrm{O}_{2}^{2}$ reduction \\
\hline P83-19M & 95.2 & - & $\mathrm{nc}$ & - & Oxic & $\mathrm{O}_{2}^{2}$ reduction \\
\hline FP1S & 154 & - & $\mathrm{nc}$ & - & Oxic & $\mathrm{O}_{2}^{2}$ reduction \\
\hline FP2S & 115 & M & .088 & - & Mixed & $\mathrm{O}_{2}^{2}$ reduction; $\mathrm{Mn}$ reduction \\
\hline FP3S & 131 & - & $\mathrm{nc}$ & - & Oxic & $\mathrm{O}_{2}^{2}$ reduction \\
\hline FP3S & 68.2 & - & $\mathrm{nc}$ & - & Unknown & $\mathrm{O}_{2}^{2}>0.5 \mathrm{mg} / \mathrm{L}$ \\
\hline FP4S & 88.0 & - & $\mathrm{nc}$ & - & Oxic & $\mathrm{O}_{2}^{2}$ reduction \\
\hline MW2 & 369 & - & nc & - & Oxic & $\mathrm{O}_{2}^{2}$ reduction \\
\hline MW9 & 286 & - & $\mathrm{nc}$ & - & Oxic & $\mathrm{O}_{2}$ reduction \\
\hline P83-19U & 95.3 & - & $\mathrm{nc}$ & - & Oxic & $\mathrm{O} 2$ reduction \\
\hline PSW1 & 55.2 & - & $\mathrm{nc}$ & - & Oxic & $\mathrm{O} 2$ reduction \\
\hline SSW & 41.3 & - & $\mathrm{nc}$ & $\mathrm{nc}$ & Unknown & $\mathrm{O}_{2}^{2}>0.5 \mathrm{mg} / \mathrm{L}$ \\
\hline SSW & 41.5 & - & $\mathrm{nc}$ & $\mathrm{nc}$ & Unknown & $\mathrm{O}_{2}^{2}>0.5 \mathrm{mg} / \mathrm{L}$ \\
\hline SSW & 42.9 & - & $\mathrm{nc}$ & - & Oxic & $\mathrm{O}_{2}$ reduction \\
\hline SSW & 53.1 & - & $\mathrm{nc}$ & - & Unknown & $\mathrm{O}_{2}>0.5 \mathrm{mg} / \mathrm{L}$ \\
\hline SSW & 52.9 & - & $\mathrm{nc}$ & - & Unknown & $\mathrm{O}_{2}>0.5 \mathrm{mg} / \mathrm{L}$ \\
\hline SSW & 53.3 & - & nc & - & Unknown & $\mathrm{O}_{2}^{2}<0.5 \mathrm{mg} / \mathrm{L}$ \\
\hline SSW & 53.4 & - & $\mathrm{nc}$ & - & Unknown & $\mathrm{O}_{2}^{2}>0.5 \mathrm{mg} / \mathrm{L}$ \\
\hline SSW & 53.2 & - & $\mathrm{nc}$ & - & Unknown & $\mathrm{O}_{2}^{2}>0.5 \mathrm{mg} / \mathrm{L}$ \\
\hline SSW & 53.6 & - & nc & - & Unknown & $\mathrm{O}_{2}^{2}>0.5 \mathrm{mg} / \mathrm{L}$ \\
\hline SSW & 39.8 & - & $\mathrm{nc}$ & - & Unknown & $\mathrm{NO}_{3}^{-}>0.5 \mathrm{mg} / \mathrm{L}$ \\
\hline SSW & 39.5 & - & $\mathrm{nc}$ & - & Unknown & $\mathrm{NO}_{3}^{-}>0.5 \mathrm{mg} / \mathrm{L}$ \\
\hline SSW & 40.3 & - & $\mathrm{nc}$ & - & Unknown & $\mathrm{NO}_{3}^{-}>0.5 \mathrm{mg} / \mathrm{L}$ \\
\hline SSW & 35.8 & - & .008 & - & Oxic & $\mathrm{O}$, reduction \\
\hline SSW & 34.4 & - & .001 & - & Oxic & $\mathrm{O}_{2}^{2}$ reduction \\
\hline SSW & 39.8 & - & .003 & - & Oxic & $\mathrm{O}_{2}^{2}$ reduction \\
\hline
\end{tabular}


Table 6. Results for selected constituents, isotopes, and calculations related to the investigation of denitrification in groundwater samples collected for the local-scale transport of anthropogenic and natural contaminants (TANC) study in Albuquerque, New Mexico, 2007-9.

[Stable isotope ratios are reported in the standard delta notation $(\delta)$, the ratio of a heavier isotope to the more common lighter isotope of that element, relative to a standard reference material. USGS, U.S. Geological Survey; mg/L, milligrams per liter; per mil, per thousand; E, estimated value; na, not applicable; nc, not collected; - , not detected; not calculated, data needed for estimation were unavailable; no denitrif, no denitirification indicated and so no value estimated; N, nitrogen; $\delta^{15} \mathrm{~N}$, delta nitrogen-15 stable isotopic ratio; SSW, studied public-supply well; DD, depth-dependent sample,depth of collection in meters below land surface; $\mathrm{WH}$, wellhead]

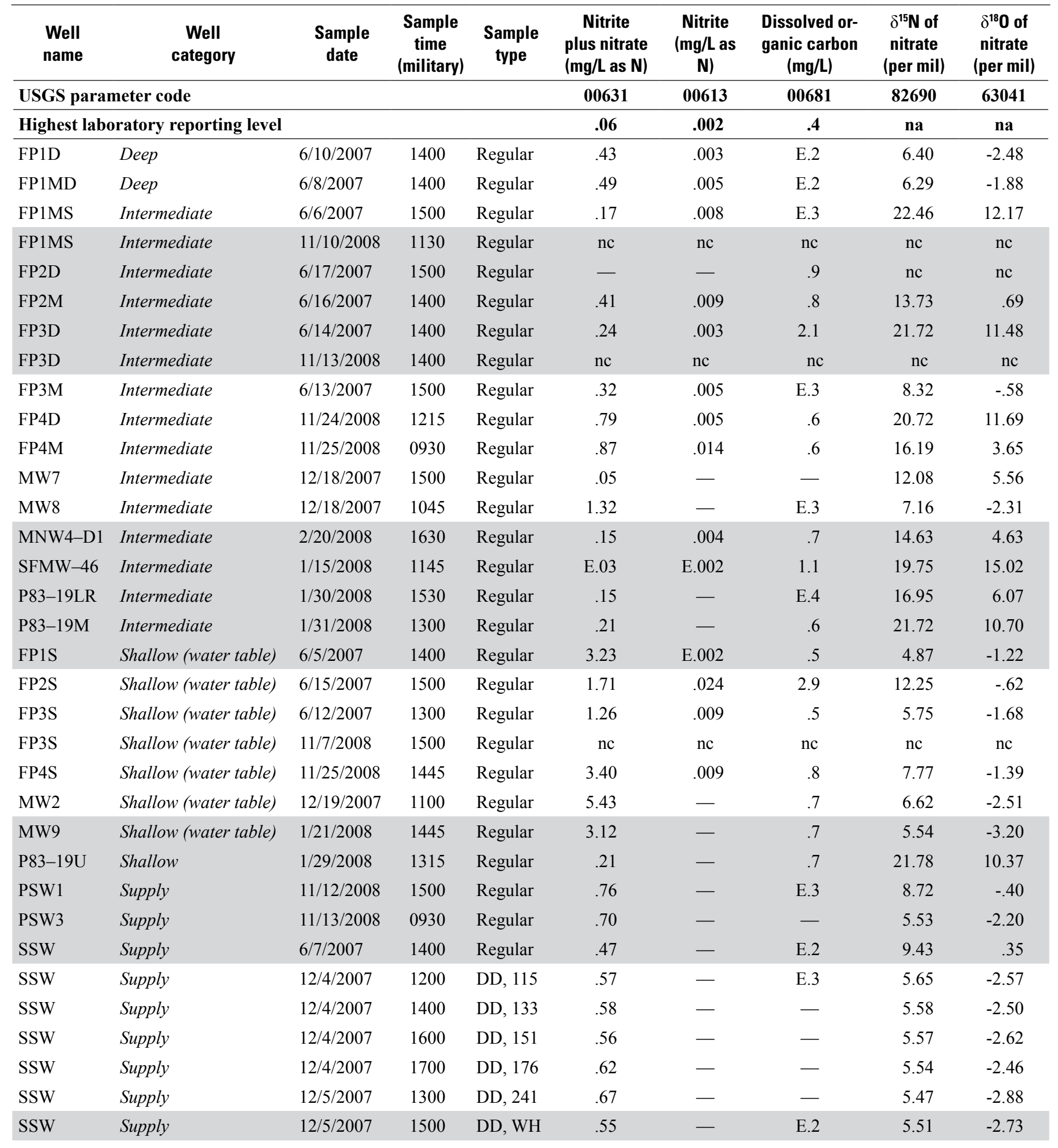




\section{Hydrogeology, Water Chemistry, and Transport Processes in the Zone of Contribution of a Public-Supply Well}

Table 6. Results for selected constituents, isotopes, and calculations related to the investigation of denitrification in groundwater samples collected for the local-scale transport of anthropogenic and natural contaminants (TANC) study in Albuquerque, New Mexico, 2007-9.-Continued

[Stable isotope ratios are reported in the standard delta notation $(\delta)$, the ratio of a heavier isotope to the more common lighter isotope of that element, relative to a standard reference material. USGS, U.S. Geological Survey; mg/L, milligrams per liter; per mil, per thousand; E, estimated value; na, not applicable; nc, not collected; - , not detected; not calculated, data needed for estimation were unavailable; no denitrif, no denitirification indicated and so no value estimated; N, nitrogen; $\delta^{15} \mathrm{~N}$, delta nitrogen-15 stable isotopic ratio; SSW, studied public-supply well; DD, depth-dependent sample,depth of collection in meters below land surface; WH, wellhead]

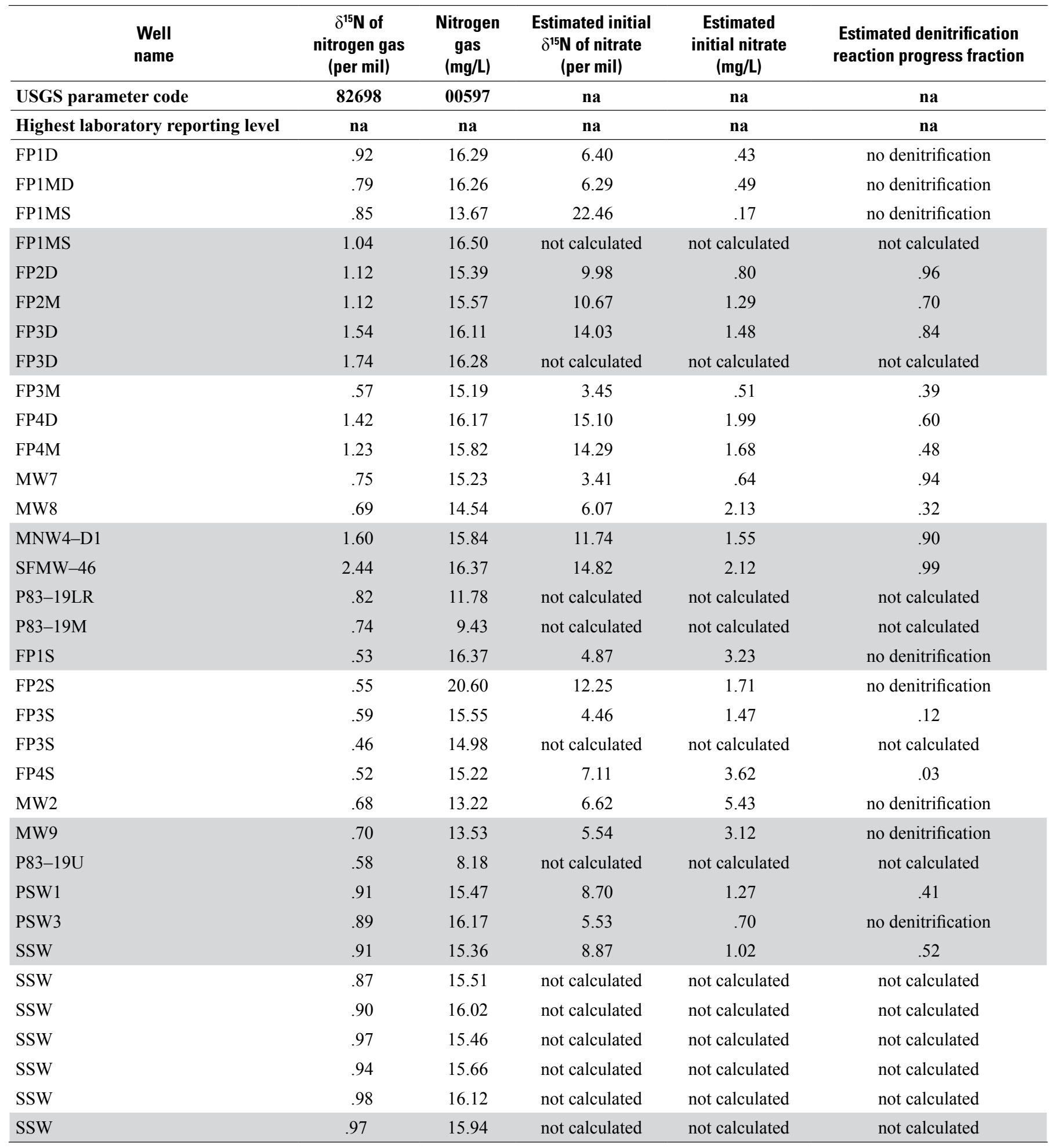


Table 7. Concentrations of selected trace elements in groundwater samples collected for the local-scale transport of anthropogenic and natural contaminants (TANC) study in Albuquerque, New Mexico, 2007-9.

[USGS, U.S. Geological Survey; mg/L, milligrams per liter; E, estimated value; V, censored value possibly affected by contamination during sample collection; std, standard; $\mu \mathrm{g} / \mathrm{L}$, micrograms per liter; na, not applicable; nc, not collected; —, not detected; As, arsenic; SSW, studied public-supply well; DD, depthdependent sample, depth of collection in meters below land surface; WH, wellhead]

\begin{tabular}{|c|c|c|c|c|c|c|c|c|c|}
\hline $\begin{array}{c}\text { Well } \\
\text { name }\end{array}$ & $\begin{array}{c}\text { Well } \\
\text { category }\end{array}$ & $\begin{array}{c}\text { Sample } \\
\text { date }\end{array}$ & $\begin{array}{c}\text { Sample } \\
\text { time } \\
\text { (military) }\end{array}$ & $\begin{array}{c}\text { Sample } \\
\text { type }\end{array}$ & $\begin{array}{c}\text { pH } \\
\text { (std units) }\end{array}$ & $\begin{array}{c}\text { Arsenic } \\
\text { ( } \mu \mathrm{g} / \mathrm{L})\end{array}$ & $\begin{array}{c}\text { Arsenate } \\
\text { ( } \mu \mathrm{g} / \mathrm{L} \text { as As) }\end{array}$ & $\begin{array}{c}\text { Arsenite } \\
\text { ( } \mu \mathrm{g} / \mathrm{L} \text { as As) }\end{array}$ & $\begin{array}{l}\text { Boron } \\
\text { ( } \mu \mathrm{g} / \mathrm{L} \text { ) }\end{array}$ \\
\hline \multicolumn{2}{|c|}{ USGS parameter code } & & & & 00400 & 01000 & 62453 & 62452 & 01020 \\
\hline FP1D & Deep & $6 / 10 / 2007$ & 1400 & Regular & 8.07 & 35 & 37 & - & 201 \\
\hline FP1MD & Deep & $6 / 8 / 2007$ & 1400 & Regular & 7.90 & 14 & 14 & - & 100 \\
\hline FP1MS & Intermediate & $6 / 6 / 2007$ & 1500 & Regular & 7.80 & 5.1 & 5.4 & - & 48 \\
\hline FP2D & Intermediate & $6 / 17 / 2007$ & 1500 & Regular & 7.71 & 4.6 & 2.3 & 2.2 & 85 \\
\hline FP2M & Intermediate & $6 / 16 / 2007$ & 1400 & Regular & 7.60 & 2.6 & 2.7 & - & 80 \\
\hline FP3D & Intermediate & $6 / 14 / 2007$ & 1400 & Regular & 7.83 & 2.9 & 2.8 & - & 60 \\
\hline FP3D & Intermediate & $11 / 13 / 2008$ & 1400 & Regular & 7.57 & 2.9 & nc & nc & 68 \\
\hline FP3M & Intermediate & $6 / 13 / 2007$ & 1500 & Regular & 8.15 & 5.2 & 5.2 & - & 47 \\
\hline FP4D & Intermediate & $11 / 24 / 2008$ & 1215 & Regular & 7.46 & 2.1 & 1.9 & - & 83 \\
\hline SFMW-46 & Intermediate & $1 / 15 / 2008$ & 1145 & Regular & 7.00 & 7.9 & 8.0 & - & 124 \\
\hline P83-19LR & Intermediate & $1 / 30 / 2008$ & 1530 & Regular & 7.68 & 4.4 & 3.9 & - & 68 \\
\hline P83-19M & Intermediate & $1 / 31 / 2008$ & 1300 & Regular & 7.54 & 3.3 & 2.8 & - & 65 \\
\hline FP1S & Shallow (water table) & $6 / 5 / 2007$ & 1400 & Regular & 7.90 & 3.4 & 4.1 & - & 48 \\
\hline FP2S & Shallow (water table) & $6 / 15 / 2007$ & 1500 & Regular & 8.28 & 3.4 & 2.9 & - & 91 \\
\hline FP3S & Shallow (water table) & $6 / 12 / 2007$ & 1300 & Regular & 8.19 & 4.2 & 4.3 & - & 48 \\
\hline FP3S & Shallow (water table) & $11 / 7 / 2008$ & 1500 & Regular & 7.95 & 4.0 & $\mathrm{nc}$ & $\mathrm{nc}$ & 40 \\
\hline FP4S & Shallow (water table) & $11 / 25 / 2008$ & 1445 & Regular & 7.79 & 2.7 & 2.3 & - & 38 \\
\hline MW2 & Shallow (water table) & $12 / 19 / 2007$ & 1100 & Regular & 7.48 & 2.6 & E1.6 & - & 165 \\
\hline MW9 & Shallow (water table) & $1 / 21 / 2008$ & 1445 & Regular & 7.37 & 1.7 & - & - & 153 \\
\hline P83-19U & Shallow & $1 / 29 / 2008$ & 1315 & Regular & 7.50 & 1.8 & E1.3 & - & 73 \\
\hline SSW & Supply & $2 / 1 / 2008$ & 1122 & Regular & 7.86 & 12 & $\mathrm{nc}$ & nc & 99 \\
\hline SSW & Supply & $2 / 1 / 2008$ & 1322 & Regular & 7.85 & 12 & nc & nc & 104 \\
\hline SSW & Supply & $2 / 1 / 2008$ & 1522 & Regular & 7.86 & 12 & $\mathrm{nc}$ & $\mathrm{nc}$ & 120 \\
\hline SSW & Supply & $2 / 1 / 2008$ & 1822 & Regular & 7.86 & 12 & $\mathrm{nc}$ & $\mathrm{nc}$ & 124 \\
\hline SSW & Supply & $11 / 10 / 2008$ & 0930 & Regular & 7.57 & 16 & $\mathrm{nc}$ & $\mathrm{nc}$ & 156 \\
\hline SSW & Supply & $5 / 15 / 2009$ & 1900 & Regular & 7.61 & 13 & $\mathrm{nc}$ & nc & 121 \\
\hline SSW & Supply & $5 / 16 / 2009$ & 0810 & Regular & 7.71 & 12 & $\mathrm{nc}$ & nc & 122 \\
\hline SSW & Supply & $5 / 16 / 2009$ & 1840 & Regular & 7.64 & 12 & $\mathrm{nc}$ & $\mathrm{nc}$ & 121 \\
\hline SSW & Supply & $5 / 17 / 2009$ & 0800 & Regular & 7.73 & 12 & $\mathrm{nc}$ & $\mathrm{nc}$ & 121 \\
\hline SSW & Supply & $5 / 17 / 2009$ & 1830 & Regular & 7.66 & 12 & $\mathrm{nc}$ & $\mathrm{nc}$ & 119 \\
\hline SSW & Supply & $5 / 18 / 2009$ & 0745 & Regular & 7.69 & 12 & nc & nc & 120 \\
\hline SSW & Supply & $12 / 4 / 2007$ & 1200 & $\mathrm{DD}, 115$ & 7.69 & 18 & 17 & - & 171 \\
\hline SSW & Supply & $12 / 4 / 2007$ & 1400 & $\mathrm{DD}, 133$ & 7.65 & 18 & 19 & - & 146 \\
\hline SSW & Supply & $12 / 4 / 2007$ & 1600 & $\mathrm{DD}, 151$ & 7.63 & 17 & 16 & - & 148 \\
\hline SSW & Supply & $12 / 4 / 2007$ & 1700 & $\mathrm{DD}, 176$ & 7.67 & 18 & 17 & - & 161 \\
\hline SSW & Supply & $12 / 5 / 2007$ & 1300 & $\mathrm{DD}, 241$ & 7.74 & 23 & 22 & - & 137 \\
\hline SSW & Supply & $12 / 5 / 2007$ & 1500 & $\mathrm{DD}, \mathrm{WH}$ & 7.65 & 18 & 17 & - & 120 \\
\hline
\end{tabular}


Table 7. Concentrations of selected trace elements in groundwater samples collected for the local-scale transport of anthropogenic and natural contaminants (TANC) study in Albuquerque, New Mexico, 2007-9.-Continued

[USGS, U.S. Geological Survey; mg/L, milligrams per liter; E, estimated value; V, censored value possibly affected by contamination during sample collection; std, standard; $\mu \mathrm{g} / \mathrm{L}$, micrograms per liter; na, not applicable; nc, not collected; —, not detected; As, arsenic; SSW, studied public-supply well; DD, depthdependent sample, depth of collection in meters below land surface; $\mathrm{WH}$, wellhead]

\begin{tabular}{|c|c|c|c|c|c|c|c|c|}
\hline $\begin{array}{l}\text { Well } \\
\text { name }\end{array}$ & $\begin{array}{l}\text { Fluoride } \\
\text { (mg/L) }\end{array}$ & $\begin{array}{l}\text { Iron } \\
(\mu \mathrm{g} / \mathrm{L})\end{array}$ & $\begin{array}{c}\text { Lithium } \\
\text { ( } \mu \mathrm{g} / \mathrm{L})\end{array}$ & $\begin{array}{c}\text { Manga- } \\
\text { nese } \\
\text { ( } \mu \mathrm{g} / \mathrm{L})\end{array}$ & $\begin{array}{l}\text { Molyb- } \\
\text { denum } \\
\text { (pg/L) }\end{array}$ & $\begin{array}{c}\text { Strontium } \\
(\mu \mathrm{g} / \mathrm{L})\end{array}$ & $\begin{array}{l}\text { Vanadium } \\
(\mu \mathrm{g} / \mathrm{L})\end{array}$ & $\begin{array}{c}\text { Uranium } \\
\text { ( } \mu \mathrm{g} / \mathrm{L})\end{array}$ \\
\hline USGS parameter code & 00950 & 01046 & 01130 & 01056 & 01060 & 01080 & 01085 & 22703 \\
\hline FP1D & .92 & - & 129 & 6.9 & 6.5 & 231 & 23.7 & 2.14 \\
\hline FP1MD & .57 & - & 88.3 & 12.3 & 4.4 & 413 & 13.4 & 1.74 \\
\hline FP1MS & .57 & E4 & 17.9 & 36.0 & 2.8 & 360 & 7.5 & 1.48 \\
\hline FP2M & .28 & 14 & 20.7 & 55.5 & 1.7 & 540 & 4.4 & 3.63 \\
\hline FP3D & .36 & E3 & 17.1 & 17.5 & 3.3 & 581 & 5.1 & 2.90 \\
\hline FP3D & .36 & 7 & 19.4 & 41.5 & 1.7 & 625 & 5.2 & 3.41 \\
\hline FP3M & .48 & - & 13.9 & 4.6 & 6.0 & 217 & 8.1 & 1.24 \\
\hline FP4D & .29 & - & 22.2 & 32.9 & 1.2 & 628 & 5.1 & 4.28 \\
\hline SFMW-46 & .30 & E6 & 116 & 9.1 & 1.1 & 1,011 & 4.4 & 21.8 \\
\hline P83-19LR & .41 & - & 13.5 & V.4 & 2.5 & 605 & 6.5 & 4.16 \\
\hline P83-19M & .36 & - & 17.2 & - & 1.7 & 674 & 5.2 & 5.09 \\
\hline FP1S & .40 & - & 19.9 & 2.1 & 3.6 & 663 & 7.4 & 1.58 \\
\hline FP2S & .46 & - & 20.7 & 165 & 5.8 & 417 & 5.9 & 3.67 \\
\hline FP3S & .43 & - & 20.7 & 38.9 & 4.7 & 520 & 8.3 & 1.25 \\
\hline FP3S & .42 & E3 & 16.4 & 3.2 & 3.2 & 421 & 8.3 & 1.59 \\
\hline FP4S & .38 & E4 & 24.5 & 34.4 & 4.7 & 703 & 5.2 & 1.74 \\
\hline MW2 & .34 & E5 & 39.2 & V.6 & 1.6 & 998 & 5.3 & 4.10 \\
\hline MW9 & .17 & - & 28.4 & V.4 & 0.6 & 712 & 3.6 & 7.40 \\
\hline P83-19U & .23 & - & 12.2 & V.3 & 0.8 & 577 & 4.6 & 3.49 \\
\hline SSW & .60 & 11 & 55.1 & V.6 & 4.5 & 344 & 9.8 & 3.99 \\
\hline SSW & .59 & 10 & 58.7 & V.4 & 4.6 & 337 & 10.2 & 4.19 \\
\hline SSW & .59 & 9 & 68.1 & V.4 & 4.5 & 338 & 10.1 & 4.21 \\
\hline SSW & .60 & 9 & 72.5 & V.3 & 4.6 & 326 & 10.0 & 4.25 \\
\hline SSW & .58 & - & 92.8 & V.2 & 4.4 & 423 & 13.5 & 4.49 \\
\hline SSW & .49 & - & 67.7 & - & 3.6 & 483 & 10.5 & 4.20 \\
\hline SSW & .52 & - & 67.0 & - & 3.6 & 473 & 10.5 & 4.10 \\
\hline SSW & .49 & - & 67.7 & - & 3.7 & 482 & 10.8 & 4.15 \\
\hline SSW & .50 & - & 65.6 & - & 3.6 & 471 & 10.4 & 4.08 \\
\hline SSW & .49 & - & 64.5 & - & 3.6 & 478 & 10.4 & 4.09 \\
\hline SSW & .49 & - & 65.1 & - & 3.6 & 473 & 10.4 & 4.06 \\
\hline SSW & .66 & - & 115 & V.4 & 4.7 & 399 & 13.7 & 3.42 \\
\hline SSW & .66 & - & 90.9 & VE. 2 & 4.7 & 418 & 13.6 & 3.42 \\
\hline SSW & .65 & - & 91.0 & VE. 2 & 4.7 & 440 & 13.0 & 3.80 \\
\hline SSW & .64 & - & 102 & VE.2 & 4.9 & 396 & 13.9 & 2.71 \\
\hline SSW & .71 & - & 81.3 & VE. 2 & 5.7 & 322 & 16.1 & 2.52 \\
\hline SSW & .66 & 18 & 71.2 & .4 & 4.9 & 374 & 13.5 & 3.80 \\
\hline
\end{tabular}


Table 8. Summary of results from the U.S. Geological Survey National Water Quality Laboratory (NWQL) for selected volatile organic compounds in groundwater samples collected for the local-scale transport of anthropogenic and natural contaminants (TANC) study in Albuquerque, New Mexico, 2007-9.

[This table includes only those volatile organic compounds that were detected in at least one groundwater sample that did not appear to have been affected by contamination during sample collection. USGS, U.S. Geological Survey; E, estimated value; V, censored value possibly affected by contamination during sample collection; $\mu \mathrm{g} / \mathrm{L}$, micrograms per liter; - , not detected; SSW, studied public-supply well; DD, depth-dependent sample, depth of collection in meters below land surface; $\mathrm{WH}$, wellhead]

\begin{tabular}{|c|c|c|c|c|c|c|c|c|c|c|c|c|}
\hline $\begin{array}{l}\text { Well } \\
\text { name }\end{array}$ & Well category & $\begin{array}{c}\text { Sample } \\
\text { date }\end{array}$ & $\begin{array}{c}\text { Sam- } \\
\text { ple } \\
\text { time } \\
\text { (mili- } \\
\text { tary) }\end{array}$ & $\begin{array}{c}\text { Sample } \\
\text { type }\end{array}$ & $\begin{array}{c}\text { 1,1-Di- } \\
\text { chloro- } \\
\text { ethane } \\
(\mu \mathrm{g} / \mathrm{L})\end{array}$ & $\begin{array}{c}\text { 1,1-Di- } \\
\text { chloro- } \\
\text { eth- } \\
\text { ylene } \\
\text { ( } \mu \mathrm{g} / \mathrm{L})\end{array}$ & $\begin{array}{c}\text { 1,2,4-Tri- } \\
\text { methyl- } \\
\text { benzene } \\
\text { ( } \mu \mathrm{g} / \mathrm{L})\end{array}$ & $\begin{array}{c}\text { 1,2-Di- } \\
\text { chloro- } \\
\text { benzene } \\
(\mu \mathrm{g} / \mathrm{L})\end{array}$ & $\begin{array}{c}\text { 1,2-Di- } \\
\text { chlo- } \\
\text { ro- } \\
\text { ethane } \\
\text { ( } \mu \mathrm{g} / \mathrm{L} \text { ) }\end{array}$ & $\begin{array}{c}\text { 1,3-Di- } \\
\text { chloro- } \\
\text { benzene } \\
(\mu \mathrm{g} / \mathrm{L})\end{array}$ & $\begin{array}{c}\text { 1,4-Di- } \\
\text { chloro- } \\
\text { ben- } \\
\text { zene } \\
\text { ( } \mu \mathrm{g} / \mathrm{L} \text { ) }\end{array}$ & $\begin{array}{c}\text { 4-Iso- } \\
\text { propyl- } \\
\text { toluene } \\
(\mu \mathrm{g} / \mathrm{L})\end{array}$ \\
\hline \multicolumn{5}{|c|}{ USGS Parameter Code } & 34496 & 34501 & 77222 & 34536 & 32103 & 34566 & 34571 & 77356 \\
\hline \multicolumn{5}{|c|}{ Highest Laboratory Reporting Level } & .06 & .02 & .04 & .04 & .1 & .04 & .04 & .08 \\
\hline FP1D & Deep & $6 / 10 / 2007$ & 1400 & Regular & - & - & - & - & - & - & - & - \\
\hline FP1MD & Deep & $6 / 8 / 2007$ & 1400 & Regular & - & - & - & - & - & - & - & - \\
\hline FP1MS & Intermediate & $6 / 6 / 2007$ & 1500 & Regular & - & - & - & - & - & - & - & - \\
\hline FP1MS & Intermediate & $11 / 10 / 2008$ & 1130 & Regular & - & - & - & - & - & - & - & - \\
\hline FP2D & Intermediate & $6 / 17 / 2007$ & 1500 & Regular & - & - & - & - & - & - & - & - \\
\hline FP2M & Intermediate & $6 / 16 / 2007$ & 1400 & Regular & - & - & - & - & - & - & - & E.04 \\
\hline FP3D & Intermediate & $6 / 14 / 2007$ & 1400 & Regular & E.09 & E.04 & - & .22 & 1.09 & E.01 & E.03 & - \\
\hline FP3D & Intermediate & $11 / 13 / 2008$ & 1400 & Regular & E.07 & E.03 & - & .21 & .72 & E.02 & E.03 & - \\
\hline FP3M & Intermediate & $6 / 13 / 2007$ & 1500 & Regular & - & - & - & - & - & - & - & - \\
\hline FP4D & Intermediate & $11 / 24 / 2008$ & 1215 & Regular & .12 & E.05 & - & .22 & .73 & - & E.04 & - \\
\hline FP4M & Intermediate & $11 / 25 / 2008$ & 0930 & Regular & E.05 & - & - & - & .22 & - & - & - \\
\hline MW7 & Intermediate & $12 / 18 / 2007$ & 1500 & Regular & - & - & - & - & - & - & - & - \\
\hline MW8 & Intermediate & $12 / 18 / 2007$ & 1045 & Regular & - & - & E.05 & - & - & - & - & - \\
\hline MNW4-D1 & Intermediate & $2 / 20 / 2008$ & 1630 & Regular & - & E.03 & - & - & - & E.05 & E.04 & - \\
\hline SFMW-46 & Intermediate & $1 / 15 / 2008$ & 1145 & Regular & - & E.05 & - & E.05 & .20 & E.09 & E.09 & - \\
\hline P83-19LR & Intermediate & $1 / 30 / 2008$ & 1530 & Regular & .15 & E.03 & - & - & E.07 & - & - & - \\
\hline P83-19M & Intermediate & $1 / 31 / 2008$ & 1300 & Regular & .24 & E. 05 & - & - & - & - & - & - \\
\hline FP1S & Shallow (water table) & $6 / 5 / 2007$ & 1400 & Regular & - & - & - & - & - & - & - & - \\
\hline FP2S & Shallow (water table) & $6 / 15 / 2007$ & 1500 & Regular & - & - & - & - & - & - & - & E.05 \\
\hline FP3S & Shallow (water table) & $6 / 12 / 2007$ & 1300 & Regular & - & - & - & - & - & - & - & - \\
\hline FP3S & Shallow (water table) & $11 / 7 / 2008$ & 1500 & Regular & - & - & - & - & - & - & - & - \\
\hline FP4S & Shallow (water table) & $11 / 25 / 2008$ & 1445 & Regular & - & - & - & - & E.09 & - & - & - \\
\hline MW2 & Shallow (water table) & $12 / 19 / 2007$ & 1100 & Regular & - & - & E.04 & - & - & - & - & - \\
\hline MW9 & Shallow (water table) & $1 / 21 / 2008$ & 1445 & Regular & - & - & L.07 & - & - & - & - & - \\
\hline P83-19U & Shallow & $1 / 29 / 2008$ & 1315 & Regular & .18 & E.03 & - & - & .10 & - & - & - \\
\hline PSW1 & Supply & $11 / 12 / 2008$ & 1500 & Regular & - & - & - & - & - & - & - & - \\
\hline PSW3 & Supply & $11 / 13 / 2008$ & 0930 & Regular & - & - & - & - & - & - & - & - \\
\hline SSW & Supply & $6 / 7 / 2007$ & 1400 & Regular & - & - & - & - & - & - & - & - \\
\hline SSW & Supply & $2 / 1 / 2008$ & 0832 & Regular & - & - & - & - & - & - & - & - \\
\hline SSW & Supply & $2 / 1 / 2008$ & 0852 & Regular & - & - & - & - & - & - & - & - \\
\hline SSW & Supply & $2 / 1 / 2008$ & 0922 & Regular & - & - & - & - & - & - & - & - \\
\hline SSW & Supply & $2 / 1 / 2008$ & 1022 & Regular & - & - & - & - & - & - & - & - \\
\hline SSW & Supply & $2 / 1 / 2008$ & 1122 & Regular & - & - & - & - & - & - & - & - \\
\hline SSW & Supply & $2 / 1 / 2008$ & 1322 & Regular & - & - & - & - & - & - & - & - \\
\hline SSW & Supply & $2 / 1 / 2008$ & 1522 & Regular & - & - & - & - & - & - & - & - \\
\hline SSW & Supply & $2 / 1 / 2008$ & 1822 & Regular & - & - & - & - & - & - & - & - \\
\hline SSW & Supply & $11 / 10 / 2008$ & 0930 & Regular & - & - & - & - & - & - & - & - \\
\hline SSW & Supply & $5 / 15 / 2009$ & 1900 & Regular & - & - & - & - & - & - & - & - \\
\hline SSW & Supply & $5 / 16 / 2009$ & 0810 & Regular & - & - & - & - & - & - & - & - \\
\hline SSW & Supply & $5 / 16 / 2009$ & 1840 & Regular & - & - & - & - & - & - & - & - \\
\hline SSW & Supply & $5 / 17 / 2009$ & 0800 & Regular & - & - & - & - & - & - & - & - \\
\hline SSW & Supply & $5 / 17 / 2009$ & 1830 & Regular & - & - & - & - & - & - & - & - \\
\hline SSW & Supply & $5 / 18 / 2009$ & 0745 & Regular & - & - & - & - & - & - & - & - \\
\hline SSW & Supply & $12 / 4 / 2007$ & 1200 & $\mathrm{DD}, 115$ & - & - & - & - & - & - & - & - \\
\hline SSW & Supply & $12 / 4 / 2007$ & 1400 & $\mathrm{DD}, 133$ & - & - & - & - & - & - & - & - \\
\hline SSW & Supply & $12 / 4 / 2007$ & 1600 & $\mathrm{DD}, 151$ & - & - & - & - & - & - & - & - \\
\hline SSW & Supply & $12 / 4 / 2007$ & 1700 & $\mathrm{DD}, 176$ & - & - & - & - & - & - & - & - \\
\hline SSW & Supply & $12 / 5 / 2007$ & 1300 & $\mathrm{DD}, 241$ & - & - & - & - & - & - & - & - \\
\hline SSW & Supply & $12 / 5 / 2007$ & 1500 & DD, WH & - & - & - & - & - & - & - & - \\
\hline
\end{tabular}


Table 8. Summary of results from the U.S. Geological Survey National Water Quality Laboratory (NWQL) for selected volatile organic compounds in groundwater samples collected for the local-scale transport of anthropogenic and natural contaminants (TANC) study in Albuquerque, New Mexico, 2007-9.-Continued

[This table includes only those volatile organic compounds that were detected in at least one groundwater sample that did not appear to have been affected by contamination during sample collection. USGS, U.S. Geological Survey; E, estimated value; V, censored value possibly affected by contamination during sample collection; $\mu \mathrm{g} / \mathrm{L}$, micrograms per liter; - , not detected; SSW, studied public-supply well; DD, depth-dependent sample, depth of collection in meters below land surface; WH, wellhead]

\begin{tabular}{|c|c|c|c|c|c|c|c|c|c|c|c|c|}
\hline $\begin{array}{l}\text { Well } \\
\text { name }\end{array}$ & $\begin{array}{c}\text { Bromodi- } \\
\text { chloro- } \\
\text { methane, } \\
\text { (CHBrCl2) } \\
(\mu \mathrm{g} / \mathrm{L})\end{array}$ & $\begin{array}{c}\text { Car- } \\
\text { bon } \\
\text { disul- } \\
\text { fide } \\
(\mu \mathrm{g} / \mathrm{L})\end{array}$ & $\begin{array}{c}\text { cis- } \\
\text { 1,2-Di- } \\
\text { chloro- } \\
\text { eth- } \\
\text { ylene } \\
\text { ( } \mu \mathrm{g} / \mathrm{L} \text { ) }\end{array}$ & $\begin{array}{c}\text { Dibro- } \\
\text { mo- } \\
\text { chloro- } \\
\text { meth- } \\
\text { ane } \\
(\mu \mathrm{g} / \mathrm{L})\end{array}$ & $\begin{array}{c}\text { Di- } \\
\text { chloro- } \\
\text { meth- } \\
\text { ane } \\
(\mu \mathrm{g} / \mathrm{L})\end{array}$ & $\begin{array}{c}\text { Methyl } \\
\text { tert- } \\
\text { butyl } \\
\text { ether } \\
\text { (MTBE) } \\
\text { ( } \mu \mathrm{g} / \mathrm{L})\end{array}$ & $\begin{array}{c}\text { Tetra- } \\
\text { chloro- } \\
\text { eth- } \\
\text { ylene } \\
\text { ( } \mu \mathrm{g} / \mathrm{L})\end{array}$ & $\begin{array}{c}\text { Tetra- } \\
\text { chloro- } \\
\text { meth- } \\
\text { ane } \\
(\mu \mathrm{g} / \mathrm{L})\end{array}$ & $\begin{array}{c}\text { trans- } \\
\text { 1,2-Di- } \\
\text { chloro- } \\
\text { eth- } \\
\text { ylene } \\
\text { ( } \mu \mathrm{g} / \mathrm{L})\end{array}$ & $\begin{array}{l}\text { Trichlo- } \\
\text { roeth- } \\
\text { ylene } \\
\text { ( } \mu \mathrm{g} / \mathrm{L})\end{array}$ & $\begin{array}{c}\text { Tri- } \\
\text { chloro- } \\
\text { methane } \\
\text { (chlo- } \\
\text { roform) } \\
\text { ( } \mu \mathrm{g} / \mathrm{L})\end{array}$ & $\begin{array}{c}\text { Vinyl } \\
\text { chlo- } \\
\text { ride } \\
(\mu \mathrm{g} / \mathrm{L})\end{array}$ \\
\hline USGS Parameter Code & 32101 & 77041 & 77093 & 32105 & 34423 & 78032 & 34475 & 32102 & 34546 & 39180 & 32106 & 39175 \\
\hline Highest Laboratory Reporting Level & .04 & .06 & .02 & .12 & .04 & .1 & .04 & .08 & .02 & .02 & .04 & .08 \\
\hline FP1MS & - & - & - & - & - & - & - & - & - & - & - & - \\
\hline FP1MS & - & - & - & - & - & - & - & - & - & - & - & - \\
\hline FP2D & - & - & - & - & - & - & - & - & - & - & V.06 & - \\
\hline FP2M & - & - & - & - & - & - & - & - & - & - & V.07 & - \\
\hline FP3D & - & - & .79 & - & - & - & - & - & E.03 & 1.32 & .34 & E. 10 \\
\hline FP3D & - & - & .61 & - & V.03 & - & - & - & E.02 & .79 & V.02 & E.07 \\
\hline MW8 & - & - & - & - & - & - & E.04 & - & - & .59 & VE.04 & - \\
\hline MNW4-D1 & - & - & .78 & - & - & - & .17 & - & .15 & 1.57 & - & - \\
\hline SFMW-46 & - & - & 2.06 & - & - & - & - & - & .45 & 2.11 & - & .21 \\
\hline P83-19LR & - & - & E.02 & - & - & .14 & - & - & - & E.08 & - & - \\
\hline P83-19M & - & - & E.02 & - & - & .11 & E.05 & - & - & .17 & - & - \\
\hline FP1S & .11 & - & - & - & - & - & - & .23 & - & - & .17 & - \\
\hline FP2S & - & E.06 & - & - & .11 & - & - & - & - & - & .73 & - \\
\hline FP3S & - & - & - & - & - & - & .15 & - & - & - & V.09 & - \\
\hline FP3S & - & - & - & - & - & - & .12 & - & - & - & V.02 & - \\
\hline FP4S & V.06 & - & .12 & - & - & - & .44 & - & - & .70 & V.19 & - \\
\hline MW2 & - & - & - & - & E.07 & - & .11 & E.06 & - & 14.03 & 2.11 & - \\
\hline MW9 & .76 & - & - & E.07 & E.06 & - & .52 & E.03 & - & .58 & .70 & - \\
\hline P83-19U & - & - & E.02 & - & - & .11 & E.02 & - & - & .11 & - & - \\
\hline SSW & - & - & - & - & - & - & - & - & - & - & - & - \\
\hline SSW & - & - & - & - & - & - & - & - & - & - & - & - \\
\hline SSW & - & - & - & - & - & - & - & - & - & - & - & - \\
\hline SSW & - & - & - & - & - & E.07 & - & - & - & - & - & - \\
\hline SSW & - & - & - & - & - & E.07 & - & - & - & -1 & - & - \\
\hline SSW & - & - & E.01 & - & - & E.07 & - & - & - & E.02 & - & - \\
\hline SSW & - & - & - & - & - & E.07 & - & - & - & $-^{1}$ & - & - \\
\hline SSW & - & - & - & - & - & E.07 & - & - & - & $-^{1}$ & - & - \\
\hline SSW & - & - & - & - & - & E.07 & - & - & - & E.02 & - & - \\
\hline SSW & - & - & - & - & - & E.07 & - & - & - & $-^{1}$ & - & - \\
\hline SSW & - & - & - & - & - & - & - & - & - & - & - & - \\
\hline SSW & - & - & - & - & - & - & - & - & - & - & - & - \\
\hline SSW & - & - & - & - & - & - & - & - & - & - & - & - \\
\hline SSW & - & - & - & - & - & - & - & - & - & - & - & - \\
\hline SSW & - & - & - & - & - & - & - & - & - & - & - & - \\
\hline SSW & - & - & - & - & - & - & - & - & - & - & - & - \\
\hline
\end{tabular}

${ }^{1}$ In oral communications, the laboratory analyst indicated that trichloroethylene was probably present in this groundwater sample at an estimated concentration of $0.02 \mu \mathrm{g} / \mathrm{L}$ but that certain criteria had not been met for reporting the presence of the compound to the National Water Information Systems database. 
Table 9. Results of low-level analysis at the U.S. Geological Survey Chlorofluorocarbon Laboratory for trichloroethylene (TCE) in groundwater from depth-dependent public-supply well samples, local-scale transport of anthropogenic and natural contaminants (TANC) study area, Albuquerque, New Mexico.

[This table lists the median concentration of trichloroethylene reported by the laboratory for two or three replicate samples. pg/L, picograms per liter; SSW, studied public-supply well; DD, depth-dependent sample, depth of collection in meters below land surface; $\mathrm{WH}$, wellhead]

\begin{tabular}{llcccc}
\hline $\begin{array}{c}\text { Well } \\
\text { name }\end{array}$ & $\begin{array}{c}\text { Well } \\
\text { category }\end{array}$ & $\begin{array}{c}\text { Sample } \\
\text { date }\end{array}$ & $\begin{array}{c}\text { Sample } \\
\text { time } \\
\text { (military) }\end{array}$ & $\begin{array}{c}\text { Sample } \\
\text { type }\end{array}$ & $\begin{array}{c}\text { Tri- } \\
\text { chloro- } \\
\text { ethylene } \\
\text { (pg/L) }\end{array}$ \\
\hline SSW & Supply & $12 / 4 / 2007$ & 1200 & DD, 115 & 567 \\
SSW & Supply & $12 / 4 / 2007$ & 1400 & DD, 133 & 520 \\
SSW & Supply & $12 / 4 / 2007$ & 1600 & DD, 151 & 533 \\
SSW & Supply & $12 / 4 / 2007$ & 1700 & DD, 176 & 38 \\
SSW & Supply & $12 / 5 / 2007$ & 1300 & DD, 241 & 86 \\
SSW & Supply & $12 / 5 / 2007$ & 1500 & DD, WH & 703 \\
\hline
\end{tabular}


Table 10. Results for recharge temperature, entrained air, excess nitrogen gas, tritium/helium-3 dating, chlorofluorocarbon dating, carbon-14 dating, and age classification for groundwater samples collected for the local-scale transport of anthropogenic and natural contaminants (TANC) study area in Albuquerque, New Mexico, 2007-9.

[Stable isotope ratios are reported in the standard delta notation $(\delta)$, the ratio of a heavier isotope to the more common lighter isotope of that element, relative to a standard reference material. Values shown with a strikethrough were determined to be unacceptable for use in interpreting recharge temperatures and groundwater ages. nc, not collected; na, not applicable; nd, not determined; $\mathrm{H}_{2} \mathrm{O}$, water; g, gram; kg, kilogram; cc, cubic centimeters; STP, standard temperature and pressure; ${ }^{\circ} \mathrm{C}$, degrees celsius; $\mathrm{mg} / \mathrm{L}$, milligrams per liter; $\mathrm{TU}$, tritium units; $\mathrm{CFC}-11$, trichlorofluoromethane $\left(\mathrm{CFCl}_{3}\right)$; $\mathrm{CFC}-12$, dichlorodifluoromethane $\left(\mathrm{CF}_{2} \mathrm{Cl}_{2}\right)$; $\mathrm{CFC}-113$, trichlorotrifluoromethane $\left(\mathrm{C}_{2} \mathrm{~F}_{3} \mathrm{Cl}_{3}\right) ; \mathrm{pg} / \mathrm{kg}$ picogram per kilogram; pptv, parts per trillion by volume; +/-, plus or minus; per mil, per thousand; VPDB, Vienna Pee Dee Belemnite standard; BP, before present; $\delta^{15} \mathrm{~N}$, delta nitrogen- $15 ;{ }^{3} \mathrm{He}$, helium-3; ${ }^{4} \mathrm{He}$, helium-4; ${ }^{3} \mathrm{He} \mathrm{tri}_{\text {, }}$ tritiogenic helium-3; $\delta^{13} \mathrm{C}$, carbon-13; ${ }^{14} \mathrm{C}$, carbon-14; DD, depth-dependent sample, depth of collection in meters below land surface; WH, wellhead; contam., contaminated; <, less than; $>$, greater than]

Recharge temperature, entrained air, and excess nitrogen gas

\begin{tabular}{|c|c|c|c|c|c|c|c|c|c|c|}
\hline $\begin{array}{l}\text { Well } \\
\text { name }\end{array}$ & $\begin{array}{c}\text { Well } \\
\text { category }\end{array}$ & $\begin{array}{c}\text { Sample } \\
\text { date }\end{array}$ & $\begin{array}{l}\text { Sample } \\
\text { time } \\
\text { (mili- } \\
\text { tary) }\end{array}$ & $\begin{array}{c}\text { Sample } \\
\text { type }\end{array}$ & $\begin{array}{c}\text { Salinity } \\
\text { (per } \\
\text { mil) }\end{array}$ & $\begin{array}{c}\text { Recharge } \\
\text { temper- } \\
\text { ature } \\
\left({ }^{\circ} \mathrm{C}\right)\end{array}$ & $\begin{array}{c}\text { Entrained } \\
\text { air } \\
\text { (cc STP/ } \\
\text { kg of } \mathrm{H}_{2} \mathrm{O} \text { ) }\end{array}$ & $\begin{array}{c}\text { Excess } \\
\text { nitrogen } \\
\text { gas } \\
\text { (mg/L) }\end{array}$ & $\begin{array}{c}\text { Gases } \\
\text { used in } \\
\text { recharge } \\
\text { temperature } \\
\text { analysis }\end{array}$ & $\begin{array}{c}\delta^{15} \mathrm{~N} \text { of } \\
\text { nitrogen } \\
\text { gas } \\
\text { (per mil) }\end{array}$ \\
\hline
\end{tabular}

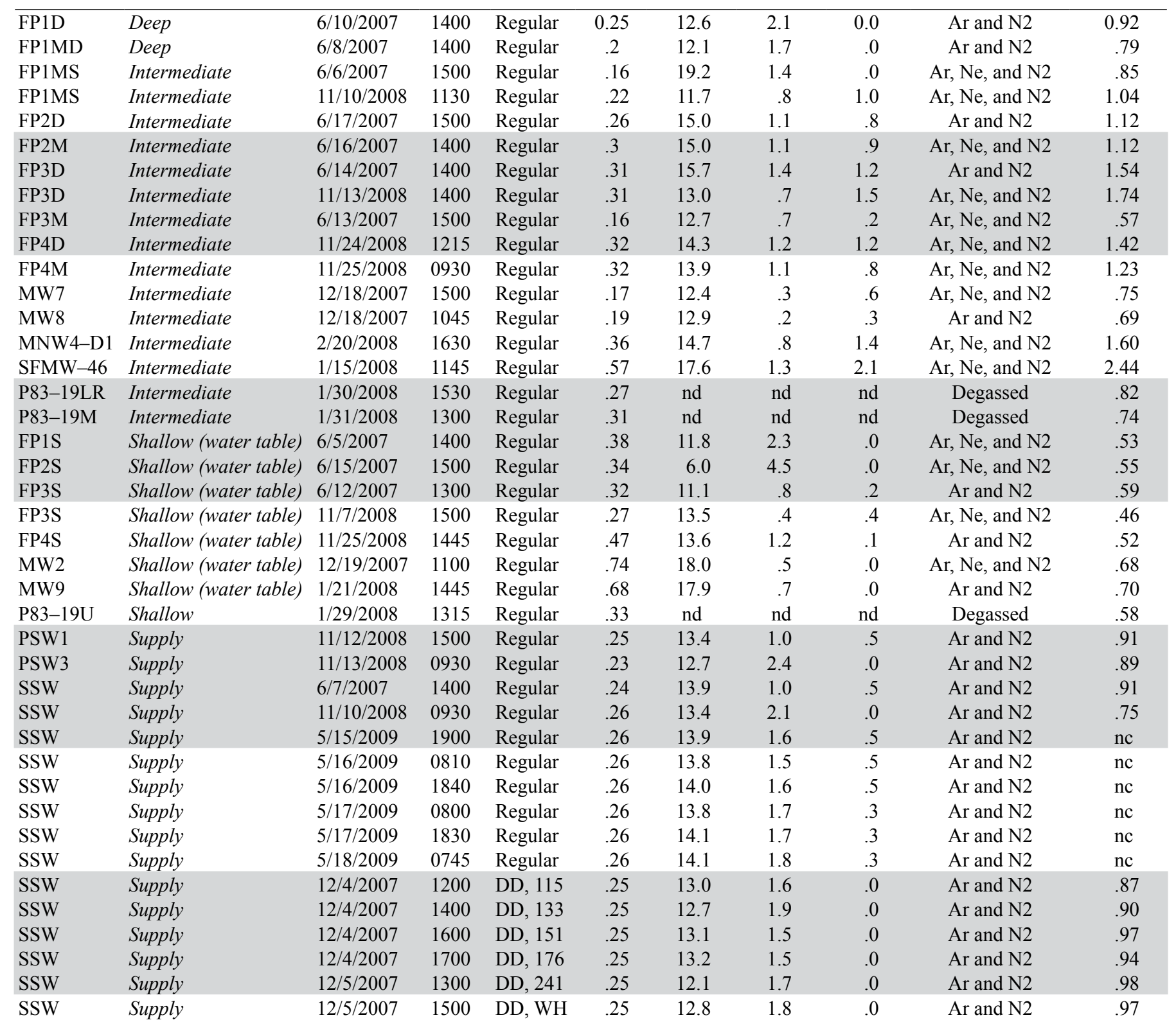


Table 10. Results for recharge temperature, entrained air, excess nitrogen gas, tritium/helium-3 dating, chlorofluorocarbon dating, carbon-14 dating, and age classification for groundwater samples collected for the local-scale transport of anthropogenic and natural contaminants (TANC) study area in Albuquerque, New Mexico, 2007-9. - Continued

[Stable isotope ratios are reported in the standard delta notation $(\delta)$, the ratio of a heavier isotope to the more common lighter isotope of that element, relative to a standard reference material. Values shown with a strikethrough were determined to be unacceptable for use in interpreting recharge temperatures and groundwater ages. nc, not collected; na, not applicable; nd, not determined; $\mathrm{H}_{2} \mathrm{O}$, water; g, gram; kg, kilogram; cc, cubic centimeters; STP, standard temperature and pressure; ${ }^{\circ} \mathrm{C}$, degrees celsius; $\mathrm{mg} / \mathrm{L}$, milligrams per liter; $\mathrm{TU}$, tritium units; $\mathrm{CFC}-11$, trichlorofluoromethane $\left(\mathrm{CFCl}_{3}\right)$; $\mathrm{CFC}-12$, dichlorodifluoromethane $\left(\mathrm{CF}_{2} \mathrm{Cl}_{2}\right)$; CFC-113, trichlorotrifluoromethane $\left(\mathrm{C}_{2} \mathrm{~F}_{3} \mathrm{Cl}_{3}\right)$; pg/kg picogram per kilogram; pptv, parts per trillion by volume; +/-, plus or minus; per mil, per thousand; VPDB, Vienna Pee Dee Belemnite standard; BP, before present; $\delta^{15} \mathrm{~N}$, delta nitrogen-15; ${ }^{3} \mathrm{He}$, helium-3; ${ }^{4} \mathrm{He}$, helium-4; ${ }^{3} \mathrm{He}$ tri tritiogenic helium-3; $\delta^{13} \mathrm{C}$, carbon-13; ${ }^{14} \mathrm{C}$, carbon-14; DD, depth-dependent sample, depth of collection in meters below land surface; WH, wellhead; contam., contaminated; <, less than; $>$, greater than]

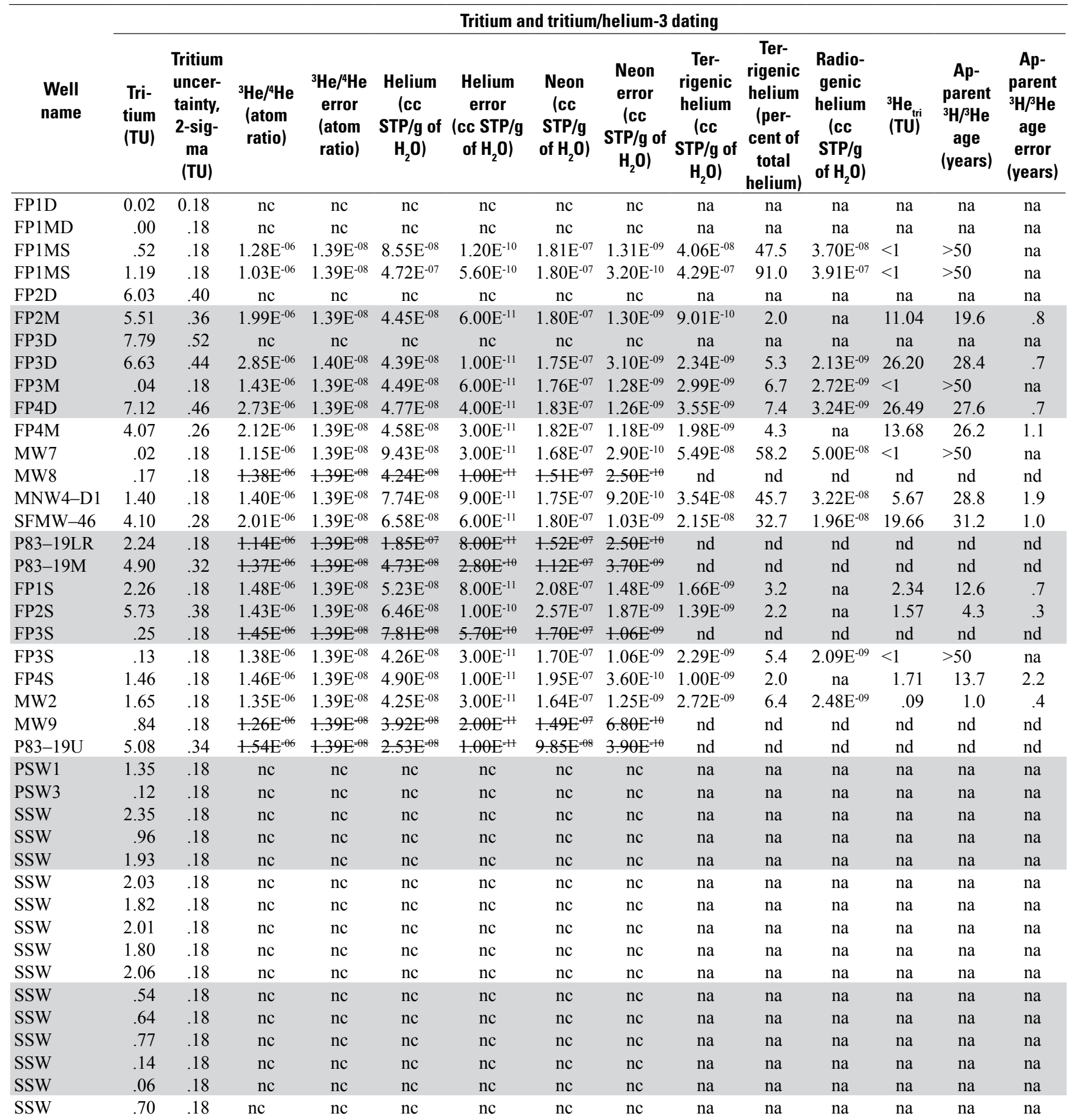


Table 10. Results for recharge temperature, entrained air, excess nitrogen gas, tritium/helium-3 dating, chlorofluorocarbon dating, carbon-14 dating, and age classification for groundwater samples collected for the local-scale transport of anthropogenic and natural contaminants (TANC) study area in Albuquerque, New Mexico, 2007-9.-Continued

[Stable isotope ratios are reported in the standard delta notation $(\delta)$, the ratio of a heavier isotope to the more common lighter isotope of that element, relative to a standard reference material. Values shown with a strikethrough were determined to be unacceptable for use in interpreting recharge temperatures and groundwater ages. nc, not collected; na, not applicable; nd, not determined; $\mathrm{H}_{2} \mathrm{O}$, water; g, gram; kg, kilogram; cc, cubic centimeters; STP, standard temperature and pressure; ${ }^{\circ} \mathrm{C}$, degrees celsius; $\mathrm{mg} / \mathrm{L}$, milligrams per liter; TU, tritium units; $\mathrm{CFC}-11$, trichlorofluoromethane $\left(\mathrm{CFCl}_{3}\right)$; $\mathrm{CFC}-12$, dichlorodifluoromethane $\left(\mathrm{CF}_{2} \mathrm{Cl}_{2}\right)$; $\mathrm{CFC}-113$, trichlorotrifluoromethane $\left(\mathrm{C}_{2} \mathrm{~F}_{3} \mathrm{Cl}_{3}\right) ; \mathrm{pg} / \mathrm{kg}$ picogram per kilogram; pptv, parts per trillion by volume; +/-, plus or minus; per mil, per thousand; VPDB, Vienna Pee Dee Belemnite standard; BP, before present; $\delta^{15} \mathrm{~N}$, delta nitrogen- $15 ;{ }^{3} \mathrm{He}$, helium-3; ${ }^{4} \mathrm{He}$, helium- $4 ;{ }^{3} \mathrm{He}$ tri tritiogenic helium-3; $\delta^{13} \mathrm{C}$, carbon-13; ${ }^{14} \mathrm{C}$, carbon-14; DD, depth-dependent sample, depth of collection in meters below land surface; WH, wellhead; contam., contaminated; <, less than; $>$, greater than]

\begin{tabular}{|c|c|c|c|c|c|c|c|c|c|}
\hline \multirow[b]{2}{*}{$\begin{array}{l}\text { Well } \\
\text { name }\end{array}$} & \multicolumn{9}{|c|}{ Chlorofluorocarbon dating } \\
\hline & $\begin{array}{l}\text { CFC-11 } \\
\text { (pg/kg) }\end{array}$ & $\begin{array}{l}\text { CFC-12 } \\
\text { (pg/kg) }\end{array}$ & $\begin{array}{l}\text { CFC-113 } \\
(\mathrm{pg} / \mathrm{kg})\end{array}$ & $\begin{array}{l}\text { Calculated } \\
\text { atmospheric } \\
\text { mixing ratio } \\
\text { of CFC-11 } \\
\text { (pptv) }\end{array}$ & $\begin{array}{l}\text { Calculated } \\
\text { atmospheric } \\
\text { mixing ratio } \\
\text { of CFC-12 } \\
\text { (pptv) }\end{array}$ & $\begin{array}{l}\text { Calculated } \\
\text { atmospheric } \\
\text { mixing ratio } \\
\text { of CFC-113 } \\
\text { (pptv) }\end{array}$ & $\begin{array}{l}\text { Estimated } \\
\text { apparent } \\
\text { CFC age } \\
\text { (years) }\end{array}$ & $\begin{array}{l}\text { Age sensitivity to } \\
\text { recharge temperature } \\
\text { errors of } 2^{\circ} \mathrm{C},+/- \\
\text { (years) }\end{array}$ & $\begin{array}{l}\text { Age sensitivity } \\
\text { to recharge } \\
\text { elevation at } \\
6,500 \text { feet, +/- } \\
\text { (years) }\end{array}$ \\
\hline FP1D & 6.0 & 12.8 & 2.9 & 2.9 & 26.2 & 3.3 & 48.3 & 0.7 & 0.3 \\
\hline FP1MS & Degraded & 57.0 & 3.4 & nd & 113.2 & 3.8 & 42.4 & .5 & .3 \\
\hline FP2D & 20.4 & 29.0 & .0 & 11.2 & 67.0 & .0 & 48.1 & .5 & .2 \\
\hline FP2M & 67.6 & Contam. & 5.9 & 37.0 & nd & 7.8 & 38.1 & .7 & .4 \\
\hline FP3D & Degraded & Contam. & 14.1 & nd & nd & 19.4 & 29.0 & 1.0 & .5 \\
\hline FP3D & Degraded & 75.5 & 3.8 & nd & 159.8 & 4.5 & 39.5 & .8 & .5 \\
\hline FP3M & 47.3 & 3.9 & 5.1 & 23.0 & 8.2 & 5.9 & 45.9 & .7 & .3 \\
\hline MW8 & Contam. & Contam. & 60.3 & nd & nd & 71.7 & 19.7 & 2.0 & .8 \\
\hline MNW4-D1 & Degraded & Contam. & 4.8 & nd & nd & 6.3 & 38.1 & 1.0 & .5 \\
\hline SFMW-46 & Degraded & Contam. & 5.5 & nd & nd & 8.4 & 36.5 & 1.0 & .5 \\
\hline P83-19LR & 200.6 & Contam. & Contam. & 101.6 & nd & nd & 34.4 & 1.0 & .5 \\
\hline P83-19M & 365.7 & Contam. & Contam. & 185.3 & nd & nd & 26.3 & 2.2 & 1.3 \\
\hline FP1S & 560.9 & 268.8 & 33.7 & 259.4 & 528.7 & 36.8 & 17.5 & 2.1 & 1.4 \\
\hline FP2S & 350.4 & Contam. & 49.0 & 116.1 & nd & 37.0 & 28.2 & 1.1 & .4 \\
\hline FP3S & Contam. & Contam. & Contam. & nd & nd & nd & Modern & na & na \\
\hline FP3S & Contam. & Contam. & Contam. & nd & nd & nd & Modern & na & na \\
\hline FP4S & Contam. & Contam. & Contam. & nd & nd & nd & Modern & na & na \\
\hline MW2 & Contam. & Contam. & 42.1 & nd & nd & 66.3 & 20.2 & 1.5 & .5 \\
\hline SSW & 388.9 & 54.8 & 1.4 & 201.7 & 119.9 & 1.7 & 38.1 & .8 & .5 \\
\hline SSW & 360.3 & 65.2 & 5.7 & 185.3 & 141.5 & 7.0 & 35.0 & .8 & .5 \\
\hline SSW & 247.9 & 57.5 & 2.5 & 129.7 & 126.6 & 3.1 & 39.0 & .8 & .3 \\
\hline SSW & 256.2 & 56.9 & 1.0 & 133.4 & 124.7 & 1.2 & 40.9 & .8 & .3 \\
\hline SSW & Contam. & 7.5 & .1 & nd & 15.8 & .1 & 54.4 & .5 & .3 \\
\hline SSW & Contam. & 8.8 & .4 & nd & 18.0 & .5 & 52.9 & .4 & .2 \\
\hline SSW & Contam. & 41.0 & 8.9 & nd & 86.3 & 10.5 & 43.2 & .8 & .4 \\
\hline SSW & 15.6 & 13.4 & 3.0 & 7.8 & 28.3 & 3.6 & 50.3 & .6 & .3 \\
\hline SSW & 8.5 & .0 & .3 & 4.0 & .0 & .3 & 58.5 & .1 & .0 \\
\hline SSW & Contam. & 3.7 & .3 & nd & 7.6 & .3 & 56.4 & .3 & .1 \\
\hline
\end{tabular}


Table 10. Results for recharge temperature, entrained air, excess nitrogen gas, tritium/helium-3 dating, chlorofluorocarbon dating, carbon-14 dating, and age classification for groundwater samples collected for the local-scale transport of anthropogenic and natural contaminants (TANC) study area in Albuquerque, New Mexico, 2007-9.-Continued

[Stable isotope ratios are reported in the standard delta notation $(\delta)$, the ratio of a heavier isotope to the more common lighter isotope of that element, relative to a standard reference material. Values shown with a strikethrough were determined to be unacceptable for use in interpreting recharge temperatures and groundwater ages. nc, not collected; na, not applicable; nd, not determined; $\mathrm{H}_{2} \mathrm{O}$, water; g, gram; kg, kilogram; cc, cubic centimeters; STP, standard temperature and pressure; ${ }^{\circ} \mathrm{C}$, degrees celsius; $\mathrm{mg} / \mathrm{L}$, milligrams per liter; TU, tritium units; $\mathrm{CFC}-11$, trichlorofluoromethane $\left(\mathrm{CFCl}_{3}\right)$; $\mathrm{CFC}-12$, dichlorodifluoromethane $\left(\mathrm{CF}_{2} \mathrm{Cl}_{2}\right)$; CFC-113, trichlorotrifluoromethane $\left(\mathrm{C}_{2} \mathrm{~F}_{3} \mathrm{Cl}_{3}\right)$; pg/kg picogram per kilogram; pptv, parts per trillion by volume; +/-, plus or minus; per mil, per thousand; VPDB, Vienna Pee Dee Belemnite standard; BP, before present; $\delta^{15} \mathrm{~N}$, delta nitrogen-15; ${ }^{3} \mathrm{He}$, helium-3; ${ }^{4} \mathrm{He}$, helium-4; ${ }^{3} \mathrm{He}$ tri , tritiogenic helium-3; $\delta^{13} \mathrm{C}$, carbon-13; ${ }^{14} \mathrm{C}$, carbon-14; DD, depth-dependent sample, depth of collection in meters below land surface; WH, wellhead; contam., contaminated; <, less than; $>$, greater than]

\begin{tabular}{|c|c|c|c|c|c|c|c|c|c|}
\hline \multirow[b]{2}{*}{$\begin{array}{l}\text { Well } \\
\text { name }\end{array}$} & \multicolumn{8}{|c|}{ Carbon-14 dating } & \multirow[b]{2}{*}{$\begin{array}{c}\text { Age } \\
\text { classifi- } \\
\text { cation }\end{array}$} \\
\hline & $\begin{array}{c}\delta^{13} \mathrm{C} \\
\text { (per mil } \\
\text { VPDB) }\end{array}$ & $\begin{array}{l}{ }^{14} \mathrm{C} \\
\text { (percent } \\
\text { modern) }\end{array}$ & $\begin{array}{l}{ }^{14} \mathrm{C} \\
\text { (percent } \\
\text { modern } \\
\text { carbon) }\end{array}$ & $\begin{array}{l}{ }^{14} \text { C error } \\
\text { (percent } \\
\text { modern } \\
\text { carbon) }\end{array}$ & $\begin{array}{l}\text { Corrected } \\
\text { final }{ }^{14} \mathrm{C} \\
\text { (percent } \\
\text { modern carbon) }\end{array}$ & $\begin{array}{c}\text { Conventional } \\
\text { radiocarbon } \\
\text { age } \\
\text { (years BP) }\end{array}$ & $\begin{array}{l}\text { Radiocarbon } \\
\text { age error, } \\
\text { 1-sigma } \\
\text { (years) }\end{array}$ & $\begin{array}{c}\text { Calibrated apparent }{ }^{14} \mathrm{C} \\
\text { piston-flow age }{ }^{1} \text {, with } \\
\text { range in parentheses } \\
\text { (years BP) }\end{array}$ & \\
\hline FP1D & -8.7 & 10.1 & 10.5 & 0.1 & 12 & 17,171 & 108 & $20,380(20,070-21,040)$ & Old \\
\hline FP1MD & -8.9 & 13.0 & 13.4 & .2 & 15 & 15,164 & 102 & $18,290(18,030-18,650)$ & Old \\
\hline FP1MS & -9.0 & 37.8 & 39.1 & .2 & 44 & 6,563 & 34 & $7,460(7,430-7,560)$ & Mixed \\
\hline FP2D & -10.6 & 64.6 & 66.5 & .5 & 73 & 2,488 & 56 & $2,570(2,360-2,730)$ & Mixed \\
\hline FP2M & -10.8 & 77.0 & 79.2 & .6 & 87 & 1,095 & 62 & $1,010(0,920-1,180)$ & Mixed \\
\hline FP3D & -11.9 & 61.5 & 63.2 & .4 & 68 & 3,035 & 52 & $3,250(3,080-3,360)$ & Mixed \\
\hline FP3D & -11.8 & 66.3 & 68.1 & .3 & 73 & 2,448 & 36 & $2,510(2,360-2,700)$ & Mixed \\
\hline FP3M & -8.1 & 50.7 & 52.5 & .4 & 60 & 4,100 & 66 & $4,630(4,440-4,830)$ & Old \\
\hline MNW4-D1 & -11.3 & 49.3 & 50.7 & .2 & 56 & 4,560 & 28 & $5,170(5,060-5,430)$ & Mixed \\
\hline SFMW-46 & -13.8 & 65.4 & 66.9 & .2 & 72 & 2,627 & 23 & $2,750(2,740-2,780)$ & Mixed \\
\hline P83-19LR & -9.5 & 27.4 & 28.3 & .1 & 31 & 9,442 & 35 & $10,670(10,580-10,760)$ & Mixed \\
\hline P83-19M & -10.1 & 55.4 & 57.1 & .2 & 66 & 3,239 & 24 & $3,450(3,390-3,560)$ & Mixed \\
\hline FP1S & -8.4 & 57.3 & 59.2 & .4 & 67 & 3,158 & 53 & $3,380(3,250-3,550)$ & Mixed \\
\hline FP2S & -11.7 & 70.4 & 72.3 & .5 & 75 & 2,248 & 51 & $2,240(2,150-2,350)$ & Mixed \\
\hline FP3S & -7.4 & 45.1 & 46.8 & .4 & 50 & 5,477 & 65 & $6,280(6,030-6,410)$ & Old \\
\hline FP3S & -8.1 & 42.1 & 43.6 & .2 & 49 & 5,740 & 29 & $6,540(6,450-6,630)$ & Old \\
\hline FP4S & -9.2 & 48.8 & 50.4 & .2 & 55 & 4,695 & 33 & $5,400(5,320-5,580)$ & Mixed \\
\hline MW2 & -9.3 & 59.1 & 61.1 & .2 & 68 & 3,011 & 24 & $3,220(3,080-3,330)$ & Mixed \\
\hline MW9 & -12.3 & 49.6 & 50.9 & .2 & 52 & 5,245 & 27 & $5,990(5,920-6,180)$ & Mixed \\
\hline SSW & -9.4 & 36.4 & 37.6 & .2 & 41 & 7,056 & 44 & $7,890(7,790-7,960)$ & Mixed \\
\hline SSW & -9.4 & 36.6 & 37.8 & .2 & 41 & 7,056 & 44 & $7,890(7,790-7,960)$ & Mixed \\
\hline SSW & -9.4 & 36.9 & 38.1 & .2 & 41 & 7,056 & 43 & $7,890(7,790-7,960)$ & Mixed \\
\hline SSW & -9.5 & 36.7 & 37.9 & .2 & 41 & 7,075 & 44 & $7,900(7,800-7,980)$ & Mixed \\
\hline SSW & -8.7 & 18.7 & 19.4 & .1 & 22 & 12,110 & 25 & $13,950(13,810-14,090)$ & Mixed \\
\hline SSW & -8.6 & 18.2 & 18.8 & .1 & 22 & 12,286 & 30 & $14,160(13,980-14,830)$ & Mixed \\
\hline SSW & -8.9 & 21.4 & 22.1 & .1 & 25 & 11,006 & 30 & $12,870(12,700-13,070)$ & Mixed \\
\hline SSW & -8.3 & 10.0 & 10.4 & .1 & 12 & 17,211 & 62 & $20,410(20,160-20,980)$ & Old \\
\hline SSW & -8.2 & 8.4 & 8.7 & .1 & 10 & 18,695 & 83 & $22,310(22,070-22,510)$ & Old \\
\hline SSW & -8.9 & 20.9 & 21.6 & .1 & 24 & 11,244 & 49 & $13,150(12,960-13,290)$ & Mixed \\
\hline
\end{tabular}

${ }^{1}$ Calibrated carbon-14 age is the age at the median probability distribution for 2-sigma error; see text for details. 
Table 11. Sources of recharge considered in inverse geochemical models for the local-scale transport of anthropogenic and natural contaminants (TANC) study area in Albuquerque, New Mexico.

[Stable isotope ratios are reported in the standard delta notation $(\delta)$, the ratio of a heavier isotope to the more common lighter isotope of that element, relative to a standard reference material. ${ }^{\circ} \mathrm{C}$, degrees Celsius; $\mathrm{mg} / \mathrm{L}$, milligrams per liter; $\mathrm{CaCO}_{3}$, calcium carbonate; $\delta^{13} \mathrm{C}$, delta carbon-13; ${ }^{14} \mathrm{C}$, carbon-14; per mil, per thousand; pmC, percent modern carbon; RGA, source water representing the composition of the Rio Grande at Albuquerque; Saline 1, source water representing the composition of deep saline groundwater; SFMW-15, composition of groundwater from well SFMW-15 (Landin, 1999)]

\begin{tabular}{|c|c|c|c|c|c|c|c|c|c|c|c|c|c|c|}
\hline $\begin{array}{c}\text { Source } \\
\text { water }\end{array}$ & $\begin{array}{l}\text { Tem- } \\
\text { pera- } \\
\text { ture } \\
\left({ }^{\circ} \mathrm{C}\right)\end{array}$ & $\begin{array}{c}\text { pH } \\
\text { (stan- } \\
\text { dard } \\
\text { units) }\end{array}$ & $\begin{array}{l}\text { Cal- } \\
\text { cium } \\
(\mathrm{mg} / \mathrm{L})\end{array}$ & $\begin{array}{c}\text { Mag- } \\
\text { nesium } \\
\text { (mg/L) }\end{array}$ & $\begin{array}{l}\text { Sodium } \\
\text { (mg/L) }\end{array}$ & $\begin{array}{c}\text { Potas- } \\
\text { sium } \\
(\mathrm{mg} / \mathrm{L})\end{array}$ & $\begin{array}{l}\text { Chlo- } \\
\text { ride } \\
\text { (mg/L) }\end{array}$ & $\begin{array}{l}\text { Sulfate } \\
\text { (mg/L) }\end{array}$ & $\begin{array}{l}\text { Alkalin- } \\
\text { ity as } \\
\mathrm{CaCO}_{3} \\
\text { (mg/L) }\end{array}$ & $\begin{array}{c}\text { Alumi- } \\
\text { num } \\
\text { (mg/L) }\end{array}$ & $\begin{array}{l}\text { Silica } \\
\text { (mg/L) }\end{array}$ & $\begin{array}{l}\text { Ortho- } \\
\text { phos- } \\
\text { phate } \\
\text { (mg/L) }\end{array}$ & $\begin{array}{l}\delta^{13} \mathrm{C} \\
\text { (per } \\
\mathrm{mil})\end{array}$ & $\begin{array}{c}{ }^{14} \mathrm{C} \\
\text { activity } \\
\text { (pmC) }\end{array}$ \\
\hline Saline $1^{1}$ & 27 & 7 & 185 & 25.7 & 1,530 & 107 & 2,520 & 296.2 & 149 & .001 & 43.4 & .1 & -7.5 & 23 \\
\hline SFMW-15 & 20 & 7.62 & 152 & 24.8 & 112 & 14.2 & 49.6 & 238 & 380 & .001 & 40 & 6 & -14 & 100 \\
\hline
\end{tabular}

${ }^{1}$ From table 4 of Plummer and others (2004a). 
Table 12. Inverse geochemical modeling results for the local-scale transport of anthropogenic and natural contaminants (TANC) study area in Albuquerque, New Mexico, 2007-9.

[Stable isotope ratios are reported in the standard delta notation $(\delta)$, the ratio of a heavier isotope to the more common lighter isotope of that element, relative to a standard reference material. The chemical composition of recharge sources is shown in table 11. For mass transfers, a positive value represents dissolution of the species indicated, and a negative value represents precipitation. For the exchange species, the cation specified is added to solution when the value is positive and is removed from solution when the value is negative. An evaporation factor greater than 1.0 indicates that a sample has been evaporated. per mil, per thousand; mmols, millimoles; $\delta^{13} \mathrm{C}$, carbon- $13 ; \mathrm{CH}_{2} \mathrm{O}$, organic matter; $\mathrm{CO}_{2}(\mathrm{~g})$, carbon dioxide gas; ${ }^{14} \mathrm{C}$, carbon-14; pmC, percent modern carbon; $\mathrm{RGA}$, source water representing the composition of the Rio Grande at Albuquerque; Saline 1, source water representing the composition of deep saline groundwater; SFMW-15, composition of groundwater from well SFMW-15 (Landin, 1999); Ca, calcium; Mg, magnesium; Na, sodium; K, potassium; X, an unspecified cation involved in an exchange process; DD, depth-dependent sample, depth of collection in meters below land surface; WH, wellhead]

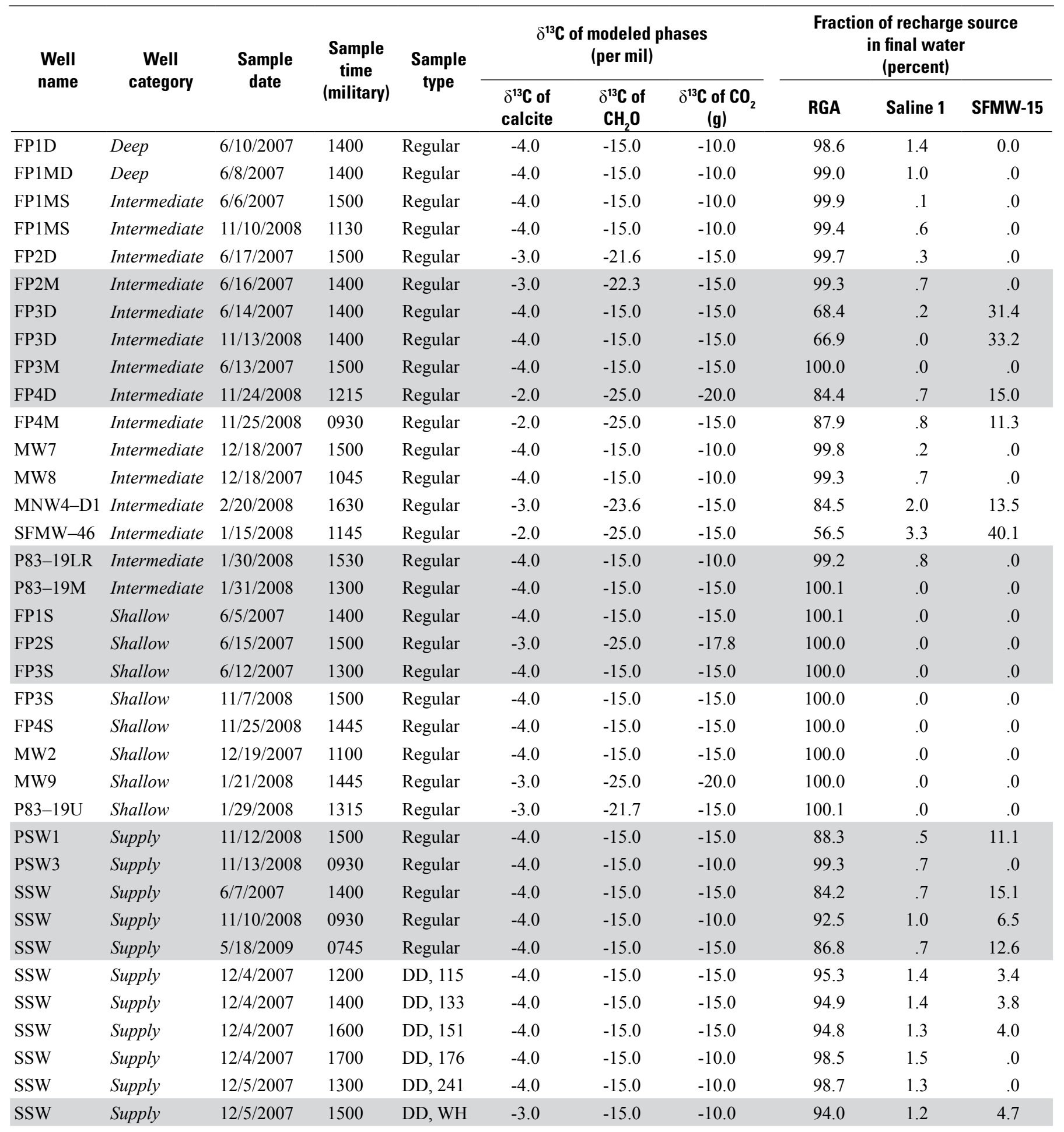


Table 12. Inverse geochemical modeling results for the local-scale transport of anthropogenic and natural contaminants (TANC) study area in Albuquerque, New Mexico, 2007-9. - Continued

[Stable isotope ratios are reported in the standard delta notation $(\delta)$, the ratio of a heavier isotope to the more common lighter isotope of that element, relative to a standard reference material. The chemical composition of recharge sources is shown in table 11. For mass transfers, a positive value represents dissolution of the species indicated, and a negative value represents precipitation. For the exchange species, the cation specified is added to solution when the value is positive and is removed from solution when the value is negative. An evaporation factor greater than 1.0 indicates that a sample has been evaporated. per mil, per thousand; mmols, millimoles; ${ }^{13} \mathrm{C}$, carbon-13; $\mathrm{CH}_{2} \mathrm{O}$, organic matter; $\mathrm{CO}_{2}(\mathrm{~g})$, carbon dioxide gas; ${ }^{14} \mathrm{C}$, carbon-14; pmC, percent modern carbon; RGA, source water representing the composition of the Rio Grande at Albuquerque; Saline 1, source water representing the composition of deep saline groundwater; SFMW-15, composition of groundwater from well SFMW-15 (Landin, 1999); Ca, calcium; Mg, magnesium; Na, sodium; K, potassium; X, an unspecified cation involved in an exchange process; DD, depth-dependent sample, depth of collection in meters below land surface; $\mathrm{WH}$, wellhead]

\begin{tabular}{|c|c|c|c|c|c|c|c|c|c|c|c|c|c|}
\hline \multirow{2}{*}{$\begin{array}{l}\text { Well } \\
\text { name }\end{array}$} & \multicolumn{3}{|c|}{$\begin{array}{c}\text { Carbon mass transfers } \\
\text { (mmols per kilogram } \\
\text { of water) }\end{array}$} & \multicolumn{6}{|c|}{$\begin{array}{c}\text { Mineral mass transfers } \\
\text { (mmols per kilogram of water) }\end{array}$} & \multicolumn{4}{|c|}{$\begin{array}{c}\text { Exchange species } \\
\text { (mmols per kilogram of water) }\end{array}$} \\
\hline & Calcite & $\mathrm{CH}_{2} \mathrm{O}$ & $\begin{array}{l}\mathrm{CO}_{2} \\
(\mathrm{~g})^{2}\end{array}$ & $\begin{array}{l}\text { Plagio- } \\
\text { clase }\end{array}$ & Kaolinite & Biotite & Gibbsite & Gypsum & Halite & $\mathrm{CaX}_{2}$ & $\mathrm{MgX}_{2}$ & $\mathrm{NaX}$ & KX \\
\hline FP1D & -0.35 & 0.23 & 0.44 & 0.75 & -0.52 & 0.00 & 0.00 & -0.25 & 0.00 & -0.22 & -0.10 & 0.59 & 0.05 \\
\hline FP1MD & -.53 & .22 & .35 & .79 & -.54 & .00 & .00 & -.29 & .00 & .26 & .00 & -.65 & .13 \\
\hline FP1MS & -.38 & .24 & .27 & .62 & -.42 & .00 & .00 & -.16 & .00 & .21 & .00 & -.50 & .08 \\
\hline FP1MS & -.40 & .23 & .24 & .59 & -.41 & .00 & .00 & -.06 & .00 & .34 & .07 & -.91 & .08 \\
\hline FP2D & .00 & .25 & .75 & .50 & -.36 & .03 & .00 & .13 & .00 & -.14 & .00 & .22 & .07 \\
\hline FP2M & .00 & .24 & .86 & .39 & -.30 & .06 & .00 & .36 & .00 & .00 & .00 & .00 & .00 \\
\hline FP3D & -1.60 & .22 & .00 & .00 & -.13 & .27 & .00 & .00 & .00 & 1.23 & -.86 & -.46 & -.28 \\
\hline FP3D & -1.61 & .23 & .00 & .00 & -.13 & .26 & .00 & .00 & .00 & 1.42 & -.79 & -.99 & -.26 \\
\hline FP3M & -.23 & .23 & .00 & .35 & -.24 & .00 & .00 & -.28 & .00 & .08 & -.08 & .00 & .00 \\
\hline FP4D & -.40 & .22 & .42 & .42 & -.31 & .05 & .00 & .00 & .00 & .48 & .00 & -.96 & .00 \\
\hline FP4M & -.40 & .22 & .00 & .38 & -.26 & .00 & .00 & .31 & .00 & .26 & .14 & -.80 & .00 \\
\hline MW7 & -.53 & .23 & .49 & .46 & -.35 & .08 & .00 & -.31 & .00 & .56 & -.27 & -.59 & .00 \\
\hline MW8 & -.61 & .21 & .23 & .00 & -.07 & .15 & .00 & .00 & .00 & .77 & -.41 & -.56 & -.17 \\
\hline MNW4-D1 & -.40 & .23 & .00 & .44 & -.30 & .00 & .00 & .00 & .00 & .46 & .00 & -.92 & .00 \\
\hline SFMW-46 & -.76 & .20 & .00 & .36 & -.25 & .00 & .00 & .00 & .00 & 1.14 & .16 & -2.60 & .00 \\
\hline P83-19LR & -.59 & .19 & .83 & .54 & -.43 & .12 & .00 & .26 & .00 & .61 & -.17 & -.88 & .00 \\
\hline P83-19M & -1.21 & .20 & .00 & .00 & -.28 & .20 & .12 & -.29 & .00 & 1.10 & -.67 & -.64 & -.21 \\
\hline FP1S & -1.35 & .14 & .00 & .00 & -.31 & .21 & .17 & .00 & .19 & 1.22 & -.62 & -.95 & -.23 \\
\hline FP2S & -.90 & .09 & .79 & 1.32 & -1.53 & .00 & 1.03 & .39 & .71 & .00 & -.02 & .00 & .04 \\
\hline FP3S & -.67 & .12 & .00 & .18 & -.17 & .08 & .00 & .66 & 1.60 & .72 & .00 & -1.39 & -.04 \\
\hline FP3S & -.82 & .17 & .00 & .00 & -.07 & .14 & .00 & .00 & .61 & .93 & -.38 & -.96 & -.12 \\
\hline FP4S & -1.15 & .13 & .00 & .65 & -.83 & .05 & .47 & .00 & 1.61 & 1.25 & .00 & -2.47 & -.03 \\
\hline MW2 & -1.05 & .16 & .00 & .83 & -1.11 & .00 & .46 & 1.15 & .48 & .34 & .28 & -1.23 & .00 \\
\hline MW9 & .00 & .05 & 1.39 & .00 & -.08 & .17 & .00 & 2.53 & 2.85 & .00 & .36 & -.61 & -.10 \\
\hline P83-19U & -1.20 & .20 & .00 & .00 & -.30 & .19 & .14 & -.27 & .00 & 1.10 & -.69 & -.60 & -.22 \\
\hline PSW1 & -.54 & .22 & .00 & .51 & -.35 & .00 & .00 & -.23 & .00 & .39 & .00 & -.83 & .04 \\
\hline PSW3 & -.30 & .21 & .42 & .65 & -.37 & .00 & -.16 & -.15 & .00 & .00 & .00 & -.11 & .11 \\
\hline SSW & -.87 & .22 & .00 & .56 & -.41 & .04 & .00 & -.35 & .00 & .64 & -.17 & -.94 & .00 \\
\hline SSW & -.15 & .22 & .15 & .32 & .00 & .00 & -.44 & -.29 & .00 & .00 & -.03 & .00 & .07 \\
\hline SSW & -.66 & .22 & .00 & .62 & -.43 & .00 & .00 & -.30 & .00 & .41 & .00 & -.87 & .05 \\
\hline SSW & -.26 & .20 & .00 & .30 & .00 & .00 & -.41 & -.26 & .00 & .00 & -.03 & .00 & .06 \\
\hline SSW & -.27 & .21 & .00 & .31 & .00 & .00 & -.43 & -.28 & .00 & .00 & -.03 & .00 & .06 \\
\hline SSW & -.26 & .22 & .00 & .31 & .00 & .00 & -.43 & -.26 & .00 & .00 & .00 & -.08 & .08 \\
\hline SSW & -.17 & .21 & .17 & .35 & .00 & .00 & -.49 & -.25 & .00 & .00 & .00 & -.09 & .09 \\
\hline SSW & -.27 & .22 & .52 & .69 & -.48 & .00 & .00 & -.29 & .00 & .00 & .00 & -.08 & .08 \\
\hline SSW & .00 & .22 & .28 & .31 & .00 & .00 & -.43 & -.34 & .00 & .00 & -.03 & .00 & .07 \\
\hline
\end{tabular}


Table 12. Inverse geochemical modeling results for the local-scale transport of anthropogenic and natural contaminants (TANC) study area in Albuquerque, New Mexico, 2007-9. - Continued

[Stable isotope ratios are reported in the standard delta notation $(\delta)$, the ratio of a heavier isotope to the more common lighter isotope of that element, relative to a standard reference material. The chemical composition of recharge sources is shown in table 11. For mass transfers, a positive value represents dissolution of the species indicated, and a negative value represents precipitation. For the exchange species, the cation specified is added to solution when the value is positive and is removed from solution when the value is negative. An evaporation factor greater than 1.0 indicates that a sample has been evaporated. per mil, per thousand; mmols, millimoles; $\delta^{13} \mathrm{C}$, carbon- $13 ; \mathrm{CH}_{2} \mathrm{O}$, organic matter; $\mathrm{CO}_{2}(\mathrm{~g})$, carbon dioxide gas; ${ }^{14} \mathrm{C}$, carbon-14; pmC, percent modern carbon; $\mathrm{RGA}$, source water representing the composition of the Rio Grande at Albuquerque; Saline 1, source water representing the composition of deep saline groundwater; SFMW-15, composition of groundwater from well SFMW-15 (Landin, 1999); Ca, calcium; Mg, magnesium; Na, sodium; K, potassium; X, an unspecified cation involved in an exchange process; DD, depth-dependent sample, depth of collection in meters below land surface; WH, wellhead]

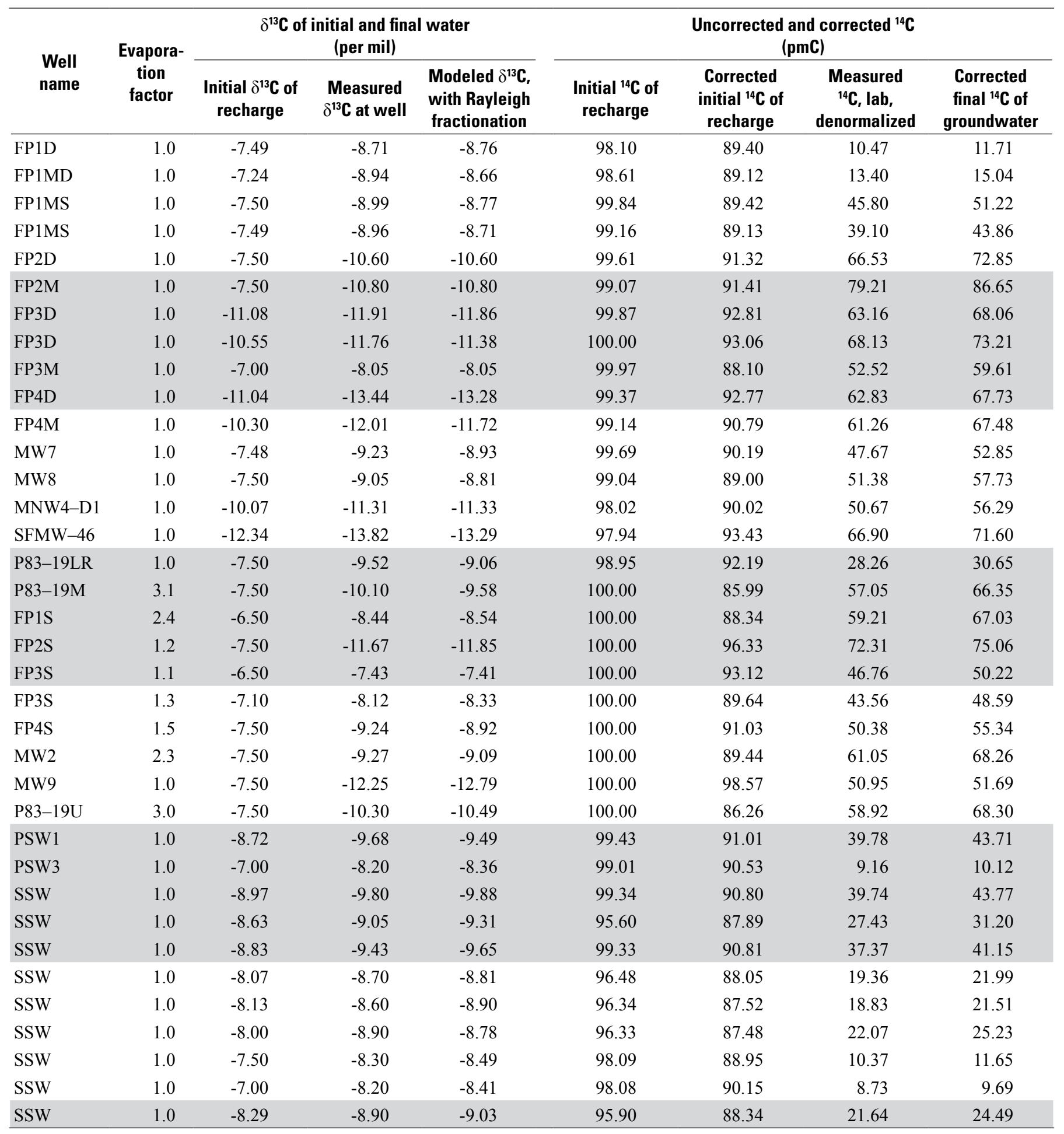


Table 13. Interpreted groundwater ages for the local-scale transport of anthropogenic and natural contaminants (TANC) study area in Albuquerque, New Mexico, 2007-9.

[DM, dispersion model; BMM, binary mixing model; BMM-DM-DM, binary mixing model between a dispersion model of the young fraction and a dispersion model of the old fraction; na, not applicable; UZ, unsaturated zone; GW, groundwater; tt, traveltime; ${ }^{14} \mathrm{C}$, carbon-14; ${ }^{3} \mathrm{H}$, tritium; ${ }^{3} \mathrm{He}$ tri , tritiogenic helium-3; CFC-113, chlorofluorocarbon-113; DD, depth-dependent sample, depth of collection in meters below land surface; WH, wellhead]

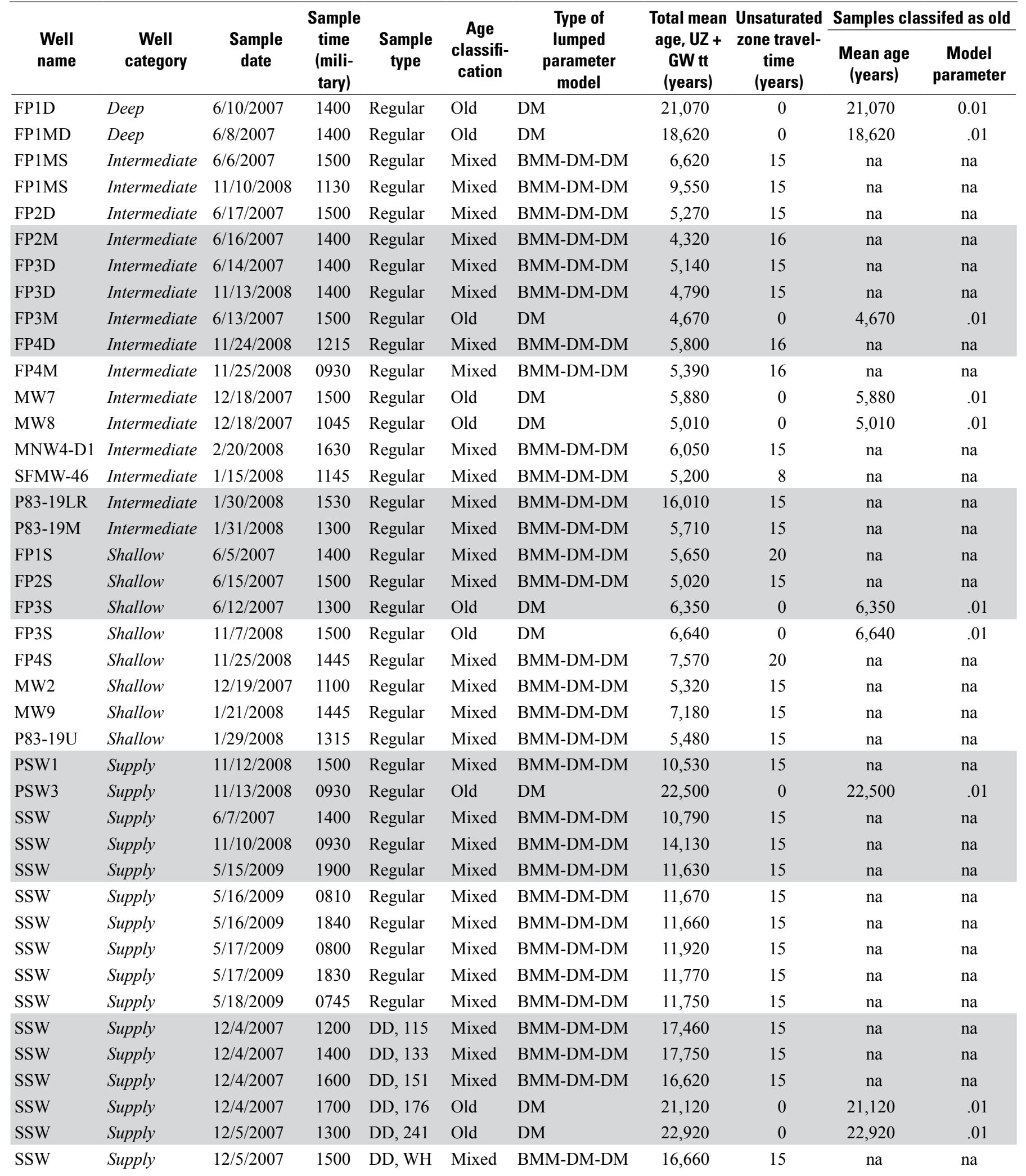


Table 13. Interpreted groundwater ages for the local-scale transport of anthropogenic and natural contaminants (TANC) study area in Albuquerque, New Mexic0, 2007-9.-Continued

[DM, dispersion model; BMM, binary mixing model; BMM-DM-DM, binary mixing model between a dispersion model of the young fraction and a dispersion model of the old fraction; na, not applicable; UZ, unsaturated zone; GW, groundwater; tt, traveltime; ${ }^{14} \mathrm{C}$, carbon-14; ${ }^{3} \mathrm{H}$, tritium; ${ }^{3} \mathrm{He}$ tri, tritiogenic helium-3; CFC-113, chlorofluorocarbon-113; DD, depth-dependent sample, depth of collection in meters below land surface; WH, wellhead]

\begin{tabular}{|c|c|c|c|c|c|c|c|}
\hline \multirow{3}{*}{$\begin{array}{l}\text { Well } \\
\text { name }\end{array}$} & \multicolumn{5}{|c|}{ Samples classified as mixed } & \multirow{3}{*}{$\begin{array}{l}\text { Age tracers } \\
\text { used in } \\
\text { optimization }\end{array}$} & \multirow{3}{*}{$\begin{array}{c}\text { Total relative } \\
\text { error from } \\
\text { optimization } \\
\text { (percent) }\end{array}$} \\
\hline & \multicolumn{3}{|c|}{ Young water in BMM } & \multicolumn{2}{|c|}{ Old water in BMM } & & \\
\hline & $\begin{array}{c}\text { Mean age } \\
\text { (years) }\end{array}$ & $\begin{array}{c}\text { Model } \\
\text { parameter }\end{array}$ & $\begin{array}{c}\text { Fraction } \\
\text { (percent) }\end{array}$ & $\begin{array}{c}\text { Mean age } \\
\text { (years) }\end{array}$ & $\begin{array}{c}\text { Model } \\
\text { parameter }\end{array}$ & & \\
\hline$\overline{\text { FP1D }}$ & na & na & na & na & na & ${ }^{14} \mathrm{C}$ & 0.00 \\
\hline FP1MD & na & na & na & na & na & ${ }^{14} \mathrm{C}$ & .00 \\
\hline FP1MS & 24 & .01 & 1.5 & 6,700 & .1 & ${ }^{3} \mathrm{H},{ }^{14} \mathrm{C}$ & .00 \\
\hline FP1MS & 22 & .01 & 7.0 & 10,250 & .1 & ${ }^{3} \mathrm{H},{ }^{14} \mathrm{C}, \mathrm{CFC}-113$ & .01 \\
\hline FP2D & 22 & .01 & 25.0 & 7,000 & .01 & ${ }^{3} \mathrm{H},{ }^{14} \mathrm{C}$ & .00 \\
\hline FP2M & 16 & .02 & 45.7 & 7,900 & .01 & ${ }^{3} \mathrm{H},{ }^{3} \mathrm{He}_{\text {trii }}{ }^{14} \mathrm{C}$ & .00 \\
\hline FP3D & 26 & .01 & 16.1 & 6,100 & .01 & ${ }^{3} \mathrm{H},{ }^{11} \mathrm{C}$ & .00 \\
\hline FP3D & 25 & .02 & 21.8 & 6,100 & .01 & ${ }^{3} \mathrm{H},{ }^{3} \mathrm{He}_{\mathrm{trir}}{ }^{14} \mathrm{C}$ & .00 \\
\hline FP3M & na & na & na & na & na & ${ }^{14} \mathrm{C}$ & .00 \\
\hline FP4D & 24 & .02 & 21.9 & 7,400 & .01 & ${ }^{3} \mathrm{H},{ }^{3} \mathrm{He}_{\text {trii }}{ }^{14} \mathrm{C}$ & .01 \\
\hline FP4M & 22 & .01 & 18.6 & 6,600 & .01 & ${ }^{3} \mathrm{H},{ }^{3} \mathrm{He}_{\text {tri }}{ }^{14} \mathrm{C}$ & .01 \\
\hline MW7 & na & na & na & na & na & ${ }^{14} \mathrm{C}$ & .00 \\
\hline MW8 & na & na & na & na & na & ${ }^{14} \mathrm{C}$ & .00 \\
\hline MNW4-D1 & 22 & .01 & 7.2 & 6,500 & .01 & ${ }^{3} \mathrm{H},{ }^{3} \mathrm{He}_{\text {tri }}{ }^{14} \mathrm{C}$ & .00 \\
\hline SFMW-46 & 24 & .03 & 29.0 & 7,300 & .01 & ${ }^{3} \mathrm{H},{ }^{3} \mathrm{He}_{\text {trii }}{ }^{14} \mathrm{C}$ & .00 \\
\hline P83-19LR & 21 & .02 & 11.1 & 18,000 & .01 & ${ }^{3} \mathrm{H},{ }^{14} \mathrm{C}$ & .00 \\
\hline P83-19M & 23 & .01 & 18.7 & 7,000 & .01 & ${ }^{3} \mathrm{H},{ }^{14} \mathrm{C}$ & .00 \\
\hline FP1S & 8 & .03 & 27.9 & 7,800 & .01 & ${ }^{3} \mathrm{H},{ }^{3} \mathrm{He}_{\text {trii }}{ }^{14} \mathrm{C}$ & .00 \\
\hline FP2S & 20 & .02 & 28.6 & 7,000 & .01 & ${ }^{3} \mathrm{H},{ }^{14} \mathrm{C}$ & .00 \\
\hline FP3S & na & na & na & na & na & ${ }^{14} \mathrm{C}$ & .00 \\
\hline FP3S & na & na & na & na & na & ${ }^{14} \mathrm{C}$ & .00 \\
\hline FP4S & 7 & .01 & 23.8 & 9,900 & .01 & ${ }^{3} \mathrm{H},{ }^{3} \mathrm{He}_{\mathrm{trir}}{ }^{14} \mathrm{C}$ & .00 \\
\hline MW2 & 5 & .02 & 36.1 & 8,300 & .01 & ${ }^{3} \mathrm{H},{ }^{14} \mathrm{C}$ & .00 \\
\hline MW9 & 11 & .03 & 13.7 & 8,300 & .01 & ${ }^{3} \mathrm{H},{ }^{14} \mathrm{C}$ & .00 \\
\hline P83-19U & 22 & .03 & 21.9 & 7,000 & .01 & ${ }^{3} \mathrm{H},{ }^{14} \mathrm{C}$ & .00 \\
\hline PSW1 & 20 & .01 & 10.9 & 11,800 & .1 & ${ }^{3} \mathrm{H},{ }^{14} \mathrm{C}$ & .00 \\
\hline PSW3 & na & na & na & na & na & ${ }^{14} \mathrm{C}$ & .00 \\
\hline SSW & 21 & .01 & 10.9 & 12,100 & .1 & ${ }^{3} \mathrm{H},{ }^{14} \mathrm{C}, \mathrm{CFC}-113$ & .00 \\
\hline SSW & 20 & .03 & 5.9 & 15,000 & .1 & ${ }^{3} \mathrm{H},{ }^{14} \mathrm{C}$ & .00 \\
\hline SSW & 21 & .02 & 11.3 & 13,100 & .1 & ${ }^{3} \mathrm{H},{ }^{14} \mathrm{C}$ & .00 \\
\hline SSW & 22 & .02 & 11.0 & 13,100 & .1 & ${ }^{3} \mathrm{H},{ }^{14} \mathrm{C}$ & .00 \\
\hline SSW & 21 & .02 & 11.1 & 13,100 & .1 & ${ }^{3} \mathrm{H},{ }^{14} \mathrm{C}$ & .00 \\
\hline SSW & 21 & .02 & 11.8 & 13,500 & .1 & ${ }^{3} \mathrm{H},{ }^{14} \mathrm{C}, \mathrm{CFC}-113$ & .02 \\
\hline SSW & 22 & .01 & 11.0 & 13,200 & .1 & ${ }^{3} \mathrm{H},{ }^{14} \mathrm{C}$ & .00 \\
\hline SSW & 22 & .02 & 11.1 & 13,200 & .1 & ${ }^{3} \mathrm{H},{ }^{14} \mathrm{C}$ & .00 \\
\hline SSW & 23 & .03 & 2.0 & 17,800 & .1 & ${ }^{3} \mathrm{H},{ }^{14} \mathrm{C}$ & .00 \\
\hline SSW & 25 & .03 & 2.0 & 18,100 & .1 & ${ }^{3} \mathrm{H},{ }^{14} \mathrm{C}$ & .00 \\
\hline SSW & 20 & .03 & 4.0 & 17,300 & .1 & ${ }^{3} \mathrm{H},{ }^{14} \mathrm{C}$ & .00 \\
\hline SSW & na & na & na & na & na & ${ }^{14} \mathrm{C}$ & .00 \\
\hline SSW & na & na & na & na & na & ${ }^{14} \mathrm{C}$ & .00 \\
\hline SSW & 21 & .02 & 3.2 & 17,200 & .1 & ${ }^{3} \mathrm{H},{ }^{14} \mathrm{C}$ & .00 \\
\hline
\end{tabular}





\section{Appendixes}




\section{Appendix 1. Mineralogy and Chemistry of Core Samples}

Methods and results of laboratory analysis of core samples are presented in this appendix. Methods of collection of core samples are described in the Drilling, Coring, Geophysical Logging, and Well Installation section of this report.

\section{Mineralogical Analyses}

The mineralogy of core samples was determined in a USGS laboratory by using powder X-ray diffraction (Daniel Webster, U.S. Geological Survey, written commun., 2007). Analysis was conducted on bulk samples and on clay separates, less than 1 micrometer in size. Results are presented in table 1-1, with minerals listed in order of decreasing abundance.

\section{Carbon Content}

Inorganic carbon and total carbon contents of core samples were determined at the NWQL using coulometric/ hydrochloric acid and gasometric techniques, respectively, as described in Wershaw and others (1987) and National Water Quality Laboratory Technical Memorandum 98-08 (issued September 29, 1998). Organic carbon was calculated as the difference between total carbon and inorganic carbon. Results of these analyses are presented in table $1-2$.

\section{Elemental Analysis}

Element abundance in grain coatings and (or) other mineral phases from core samples was evaluated in USGS laboratories using different acids and reagents for extraction, as documented in detail in Landon and others (2008) and described in general here. Analyses were conducted on wet sediments, but moisture contents determined for separate subsamples were used to correct analytical concentrations to dry weight. The sample-to-solution ratio was $5 \pm 1$ gram $(\mathrm{g})$ wet sediment to 15 millimeters $(\mathrm{mL})$ of acid solution for the $6 \mathrm{~N} \mathrm{HCl}$ and 10 percent $\mathrm{HNO}_{3}$ extractions and $4-10 \mathrm{~g}$ wet sediment to $75 \mathrm{~mL}$ of reagent for the $0.5 \mathrm{~N} \mathrm{HCl}-\mathrm{HA}$ extractions. The sediment-acid aliquots were set on a shaker table for 6 hours, then centrifuged, filtered with 0.45 micrometer pore filters, and analyzed for several minor elements. Results for selected elements are presented in table A3. Sulfide phases, particularly acid-volatile sulfides and pyritic sulfur, in sediments were extracted and analyzed as described in Landon and others (2008); results also are presented in table 1-3.

\section{Arsenic Adsorption Experiments}

Batch reactor experiments were used to quantify sorption of arsenate onto sediments from core samples. Experiments were conducted by combining $35 \mathrm{~mL}$ of deionized water with $2 \mathrm{~g}$ of dried sediment in 40-mL polypropylene centrifuge tubes. To obtain the results presented in table $1-3$, the initial arsenate concentration of the solution was 0 micrograms per

Table 1-1. Minerals identified through X-ray diffraction of core samples from boreholes drilled for the local-scale TANC study in Albuquerque, New Mexico.

[mbls, meters below land surface; K-spar, orthoclase feldspar; plagioclase, plagioclase feldspar; (?) indicates that presence of the mineral was not conclusively established]

\begin{tabular}{|c|c|c|c|c|c|}
\hline $\begin{array}{l}\text { Bore- } \\
\text { hole }\end{array}$ & $\begin{array}{l}\text { Depth to top } \\
\text { of sample } \\
\text { interval } \\
\text { (mbls) }\end{array}$ & $\begin{array}{l}\text { Depth to } \\
\text { bottom of } \\
\text { sample } \\
\text { interval } \\
\text { (mbls) }\end{array}$ & $\begin{array}{l}\text { Sub- } \\
\text { sample }\end{array}$ & $\begin{array}{l}\text { Minerals identified in bulk samples, } \\
\text { in order of decreasing abundance }\end{array}$ & $\begin{array}{l}\text { Minerals identified in sample fraction } \\
\text { less than } 1 \text { micrometer in size, in } \\
\text { order of decreasing abundance }\end{array}$ \\
\hline FP1 & 86.4 & 89.4 & na & $\begin{array}{l}\text { quartz, K-spar, plagioclase, calcite, } \\
\text { amphibole, total clay }\end{array}$ & smectite, illite, kaolinite, chlorite trace \\
\hline FP1 & 261.4 & 264.1 & na & quartz, K-spar, plagioclase, mica, calcite & $\begin{array}{l}\text { smectite, illite, kaolinite, chlorite trace, } \\
\text { amphibole trace }\end{array}$ \\
\hline FP1 & 369.5 & 372.2 & A, sandy & $\begin{array}{l}\text { quartz, K-spar, plagioclase, calcite, total } \\
\text { clay, amphibole trace (?) }\end{array}$ & $\begin{array}{l}\text { smectite, illite, kaolinite, amphibole trace, } \\
\text { chlorite trace (?) }\end{array}$ \\
\hline FP1 & 369.5 & 372.2 & B, clayey & $\begin{array}{l}\text { quartz, K-spar, plagioclase, calcite, total } \\
\text { clay }\end{array}$ & $\begin{array}{l}\text { smectite, illite, kaolinite, chlorite } \\
\text { trace (?), amphibole trace (?) }\end{array}$ \\
\hline FP3 & 141.9 & 143.7 & na & $\begin{array}{l}\text { quartz, K-spar, plagioclase, calcite, total } \\
\text { clay }\end{array}$ & $\begin{array}{l}\text { smectite, illite, kaolinite trace, chlorite } \\
\text { trace (?) }\end{array}$ \\
\hline
\end{tabular}


liter $(\mu \mathrm{g} / \mathrm{L})$. Sediment and solution were continuously mixed for 4 days on an end-rotating mixer at 2 revolutions per minute under ambient atmospheric conditions. Solutions were then separated from the sediments by centrifuging at
$15,000 \mathrm{rpm}$ for 15 minutes followed by filtering at $0.2 \mu \mathrm{m}$. Arsenic concentrations in the resulting solutions were determined by inductively coupled plasma-mass spectrometry.

Table 1-2. Results of analysis for carbon and moisture content in core samples from boreholes drilled for the local-scale TANC study in Albuquerque, New Mexico.

[The reporting of a larger inorganic carbon content than total carbon content is the result of error inherent to the laboratory analysis. mbls, meters below land surface; g/kg, grams per kilogram; na, not applicable; nc, not collected; - , not detected; USGS, U.S. Geological Survey]

\begin{tabular}{lccccccc}
\hline Borehole & $\begin{array}{c}\text { Depth to top } \\
\text { of sample } \\
\text { interval } \\
\text { (mbls) }\end{array}$ & $\begin{array}{c}\text { Depth to } \\
\text { bottom of } \\
\text { sample } \\
\text { interval } \\
\text { (mbls) }\end{array}$ & $\begin{array}{c}\text { Sub- } \\
\text { sample }\end{array}$ & $\begin{array}{c}\text { Total } \\
\text { carbon, } \\
\text { inorganic } \\
\text { plus organic } \\
\text { (g/kg) }\end{array}$ & $\begin{array}{c}\text { Inorganic } \\
\text { carbon } \\
(\mathbf{g} / \mathbf{k g})\end{array}$ & $\begin{array}{c}\text { Organic } \\
\text { carbon } \\
\mathbf{( g / k g})\end{array}$ & $\begin{array}{c}\text { Moisture } \\
\text { content } \\
\text { (percent) }\end{array}$ \\
\hline USGS parameter code & & & & $\mathbf{4 9 2 7 2}$ & $\mathbf{4 9 2 7 0}$ & $\mathbf{4 9 2 7 1}$ & $\mathbf{6 2 9 4 9}$ \\
\hline Highest laboratory reporting level & & & & $\mathbf{. 1}$ & $\mathbf{. 2}$ & $\mathbf{. 2}$ & $\mathbf{n a}$ \\
\hline FP1 & 86.4 & 89.4 & na & 4.2 & 4.0 & .23 & 29 \\
FP1 & 156.1 & 159.1 & na & 2.8 & 2.8 & - & 35 \\
FP1 & 261.4 & 264.1 & na & 1.9 & 1.8 & - & 30 \\
FP1 & 369.5 & 372.2 & A, sandy & 2.1 & 2.0 & - & 30 \\
FP1 & 369.5 & 372.2 & B, clayey & nc & nc & nc & - \\
FP3 & 108.9 & 110.4 & na & 2.7 & 2.6 & - & 35 \\
FP3 & 141.9 & 143.7 & na & 5.0 & 5.1 & - & 27 \\
\hline
\end{tabular}

Table 1-3. Results of selected elemental analysis and arsenic sorption experiments on core samples from boreholes drilled for the local-scale TANC study in Albuquerque, New Mexico.

[For samples with replicate analyses, this table lists the median value. mbls, meters below land surface; $\mathrm{mg} / \mathrm{kg}$, milligrams per kilogram; $\mu \mathrm{g} / \mathrm{kg}$, micrograms per kilogram; $\mu \mathrm{g} / \mathrm{g}$; micrograms per gram; $\mathrm{N}$, normal; $\mathrm{HCl}$, hydrochloric acid; \%, percent; $\mathrm{HNO}_{3}$, nitric acid; $\mathrm{HA}$, hydroxylamine; AVS+PS, acid-volatile sulfides plus pyritic sulfur; na, not applicable; USGS, U.S. Geological Survey]

\begin{tabular}{|c|c|c|c|c|c|c|c|c|c|c|c|}
\hline \multirow{2}{*}{ Borehole } & \multirow{2}{*}{$\begin{array}{l}\text { Depth } \\
\text { to top } \\
\text { of } \\
\text { sample } \\
\text { interval } \\
\text { (mbls) }\end{array}$} & \multirow{2}{*}{$\begin{array}{c}\text { Depth } \\
\text { to bot- } \\
\text { tom of } \\
\text { sample } \\
\text { interval } \\
\text { (mbls) }\end{array}$} & \multirow{2}{*}{$\begin{array}{c}\text { Sub- } \\
\text { sample }\end{array}$} & \multicolumn{2}{|c|}{ 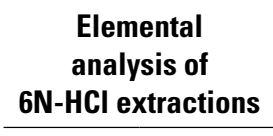 } & \multicolumn{2}{|c|}{$\begin{array}{c}\text { Elemental } \\
\text { analysis of } 10 \% \\
\mathrm{HNO}_{3} \text { extractions }\end{array}$} & \multirow{2}{*}{$\begin{array}{c}\text { Total iron } \\
\text { analysis } \\
\text { of } 0.5 \mathrm{~N}- \\
\mathrm{HCl}-\mathrm{HA} \\
\text { extrac- } \\
\text { tions } \\
\text { (mg/kg) }\end{array}$} & \multirow{2}{*}{$\begin{array}{c}\text { AVS+ } \\
\text { PS } \\
(\mu \mathrm{g} / \mathrm{kg})\end{array}$} & \multirow{2}{*}{$\begin{array}{c}\text { Arsenic } \\
\text { de- } \\
\text { sorbed } \\
\text { from wet } \\
\text { sediment } \\
(\mu \mathrm{g} / \mathrm{g})\end{array}$} & \multirow{2}{*}{$\begin{array}{c}\text { Arsenic } \\
\text { de- } \\
\text { sorbed } \\
\text { from dry } \\
\text { sediment } \\
(\mu \mathrm{g} / \mathrm{g})\end{array}$} \\
\hline & & & & $\begin{array}{l}\text { Iron } \\
(\mathbf{m g} / \mathbf{k g})\end{array}$ & $\begin{array}{c}\text { Manga- } \\
\text { nese } \\
(\mathrm{mg} / \mathrm{kg})\end{array}$ & $\begin{array}{l}\text { Arsenic } \\
(\mathbf{m g} / \mathbf{k g})\end{array}$ & $\begin{array}{l}\text { Uranium } \\
(\mathrm{mg} / \mathrm{kg})\end{array}$ & & & & \\
\hline USGS parameter code & & & & 91712 & 91713 & 91700 & 91703 & 91083 & 91081 & na & na \\
\hline FP1 & 86.4 & 89.4 & na & 451 & 51 & .15 & .10 & 120 & .6 & .019 & .034 \\
\hline FP1 & 156.1 & 159.1 & na & 339 & 83 & .19 & .13 & 136 & 1.0 & .009 & .014 \\
\hline FP1 & 261.4 & 264.1 & na & 270 & 54 & .18 & .13 & 80 & 2.5 & .013 & .014 \\
\hline FP1 & 369.5 & 372.2 & A, sandy & 465 & 75 & .26 & .34 & 150 & .3 & .033 & .032 \\
\hline FP1 & 369.5 & 372.2 & B, clayey & 640 & 68 & .54 & 1.24 & 186 & .5 & .106 & .134 \\
\hline FP3 & 108.9 & 110.4 & na & 462 & 79 & .18 & .18 & 123 & .7 & .018 & .022 \\
\hline FP3 & 141.9 & 143.7 & na & 431 & 133 & .16 & .12 & 132 & .7 & .019 & .014 \\
\hline
\end{tabular}




\section{Appendix 2. Quality-Control Summary for Field Blanks}

This appendix presents a summary table of results for field blanks that were collected for selected analytes to ascertain any evidence of bias resulting from methods of sample collection, processing, transport, or laboratory analysis (table 2-1). Implications of the results for field blanks and other types of quality-control samples are discussed in detail in the Quality Control of Water Samples section of this report.

Table 2-1. Quality-control summary for constituents detected in field blanks and environmental samples collected for the local-scale TANC study in Albuquerque, New Mexico.

[This table lists only constituents that were detected in at least one field blank and at least one environmental sample. The censoring threshold is equal to onehalf of the the laboratory reporting level (LRL) plus the maximum concentration detected in field blank samples. For constituents with changing LRLs during the sampling period, this table lists the highest LRL in effect at the time of constituent detection(s). $\mu \mathrm{g} / \mathrm{L}$, micrograms per liter; $\mathrm{mg} / \mathrm{L}, \mathrm{milligrams}$ per liter; E, estimated; DOC, dissolved organic carbon]

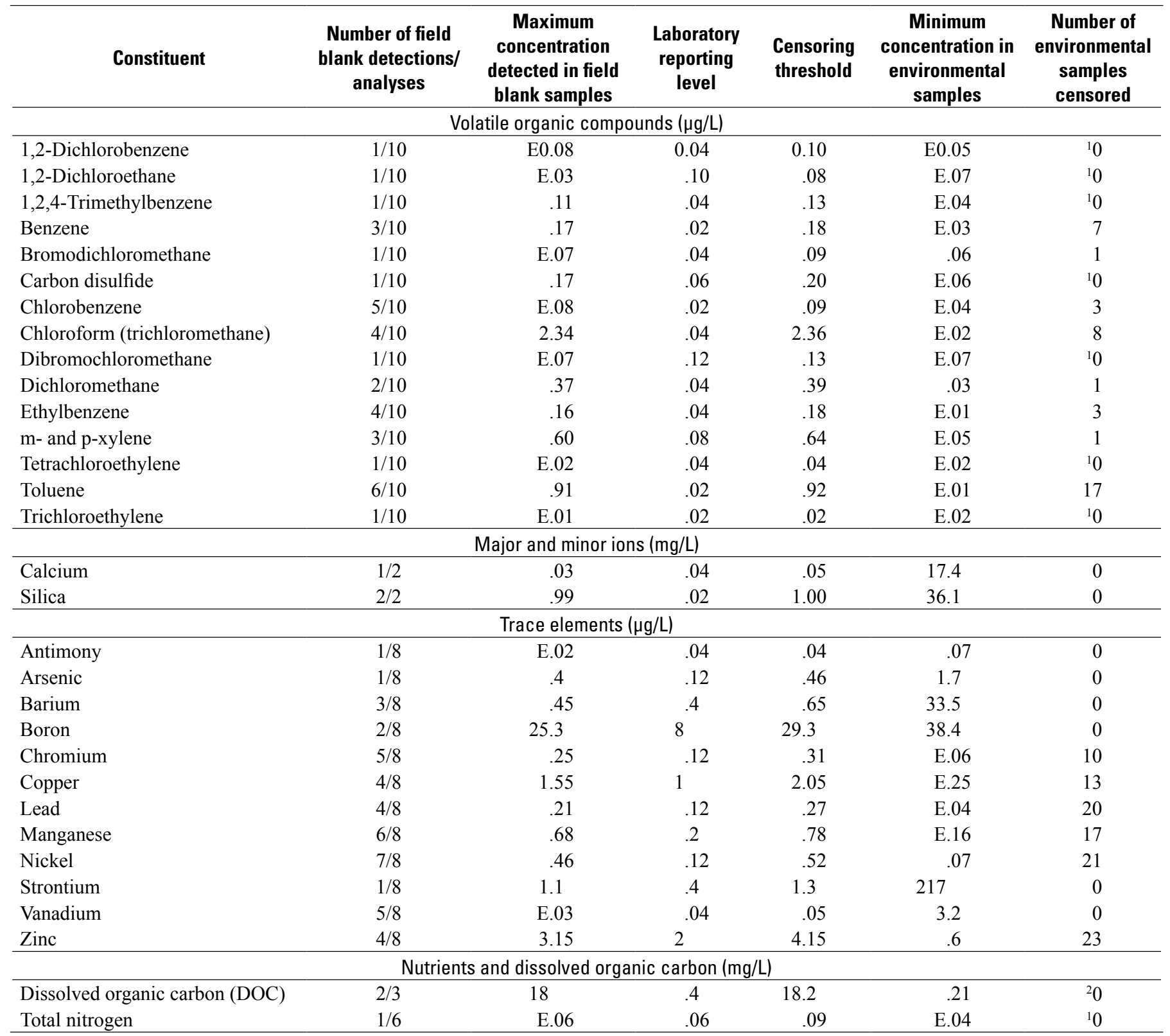

${ }^{1}$ No environmental samples were censored because detections in field blanks occurred during a different sampling period and (or) for different sampling equipment than environmental concentrations below the quality-control threshold.

${ }^{2}$ The detections of DOC in the field blanks were attributed to the use of capsule filters that were later found to be inappropriate for collecting DOC field blanks; this contamination issue is not believed to have affected environmental samples. 
Publishing support provided by Lafayette Publishing Service Center 
